Rhode Island College

Digital Commons @ RIC

\title{
Investigating Predictors of Academic Success in a Foundational Business Mathematics Course
}

Brooke Elise D'Aloisio

Rhode Island College

Follow this and additional works at: https://digitalcommons.ric.edu/etd

Part of the Educational Assessment, Evaluation, and Research Commons, and the Higher Education Commons

\section{Recommended Citation}

D'Aloisio, Brooke Elise, "Investigating Predictors of Academic Success in a Foundational Business Mathematics Course" (2016). Master's Theses, Dissertations, Graduate Research and Major Papers Overview. 138.

https://digitalcommons.ric.edu/etd/138

This Dissertation is brought to you for free and open access by the Master's Theses, Dissertations, Graduate Research and Major Papers at Digital Commons @ RIC. It has been accepted for inclusion in Master's Theses, Dissertations, Graduate Research and Major Papers Overview by an authorized administrator of Digital Commons @ RIC. For more information, please contact digitalcommons@ric.edu. 
INVESTIGATING PREDICTORS OF ACADEMIC SUCCESS IN A FOUNDATIONAL BUSINESS MATHEMATICS COURSE

BY

BROOKE ELISE D’ALOISIO

A DISSERTATION SUBMITTED IN PARTIAL FULFILLMENT OF THE REQUIREMENTS FOR THE DEGREE OF DOCTOR OF PHILOSOPHY

IN

EDUCATION

UNIVERSITY OF RHODE ISLAND

AND

RHODE ISLAND COLLEGE

2016 


\title{
DOCTOR OF PHILOSOPHY DISSERTATION \\ OF
}

BROOKE ELISE D'ALOISIO

\author{
APPROVED: \\ Dissertation Committee: \\ Major Professor Cornelis de Groot \\ Kathy Peno \\ Anne Goodrow \\ Donna Christy \\ Donald Halquist \\ Dean, The Feinstein School of Education - RIC \\ Nasser H. Zawia \\ Dean, The Graduate School - URI
}

UNIVERSITY OF RHODE ISLAND

AND

RHODE ISLAND COLLEGE

2016 


\begin{abstract}
Research reveals that the majority of students are unprepared in making the transition from high school to college mathematics. Many students choose majors outside of STEM and business fields to pursue degrees with less rigorous mathematics requirements. According to recent findings, it is likely that over $25 \%$ of all freshmen will fail their first mathematics course. Few studies examine student success in business mathematics courses, and business is currently the most popular major in the United States. Thus, the purpose of this research was to examine what factors predict success in a foundational business mathematics course (BUS 111) at a large Northeastern university.

Eight independent variables were examined: gender, high school GPA, mathematics SAT score, score on the university's placement exam, student attitudes using the Attitudes Towards Mathematics Inventory (ATMI), anxiety using the Mathematics Anxiety Scale (MAS), number of hours per week spent on mathematics, and number of classes missed. The dependent variable was BUS 111 final average. All students $(n=247)$ enrolled in BUS 111 were invited to participate during the Fall 2015. Upon completion of pre- and post-surveys, multiple regression was used to determine which variables were significant predictors. Statistical findings revealed that placement score, high school GPA, a combination of ATMI/MAS scores, and number of classes missed were the best predictors of BUS 111 average overall $\left(\mathrm{R}^{2}=44.2 \%, p=0.000\right)$. Different models are presented for comparison and examination. Significant correlations found between perceived instructor effectiveness and student attitudes, anxiety, and course grades are also presented. Overall, combinations of non-affective and affective measures serve as the best predictors of success in business mathematics.
\end{abstract}

\title{
ACKNOWLEDGEMENTS
}

First, I would like to thank my family for their patience and love over the last few years. Their unconditional support has helped motivate me to persevere through the hardest of times. 
Thank you also to Kees, my supportive major professor and dear friend, as well as my dedicated committee members (Kathy, Anne, and Donna) for their feedback and ideas throughout this doctoral process. They would not settle for anything less than my absolute best, and I am forever grateful for that. Further, the members of my Ph.D. cohort have helped me consider alternative points of view and observe the world through multiple lenses. Over the last four years, they have laughed with me, cried with me, questioned me, and pushed me to think differently. Thank you for that.

In addition to my cohort, Nicole has been the most supportive colleague and dedicated friend as I worked on this research. Without her, this process would not only have been less manageable, but also much less fun. I thank her for always showing me the positive side of things.

Thank you also to my colleagues at the College of Business Administration at the University of Rhode Island. I cannot express my appreciation for you opening your classrooms for this research and also opening your minds to the possibility of implementing changes to benefit our students.

Finally, to all of my students: past, current, and future - thank you. You were my inspiration for this research and the reason I continually strive to become a better educator and researcher. I hope I continue to inspire you as much as you inspire me. 


\section{DEDICATION}

To my amazing family: dad, mom, Diane, and James. You mean more to me than you will ever know. Thank you for your continued love and support. I could not have done this without you, nor would I have had the confidence to try. We don't get to choose our families, but I would happily choose each of you every day for the rest of my life. 


\section{TABLE OF CONTENTS}

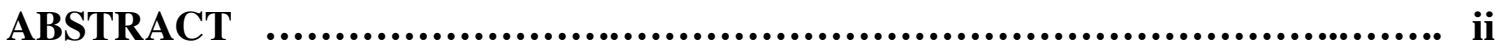

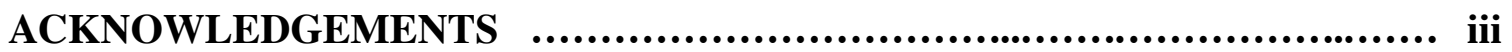

DEDICATION

TABLE OF CONTENTS $\quad$............................................................ v

LIST OF TABLES

LIST OF FIGURES ................................................................. xiii

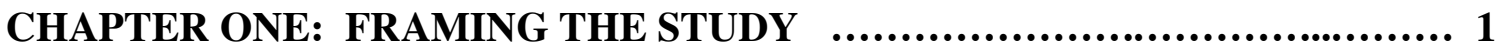

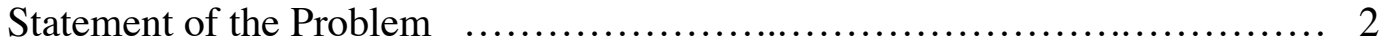

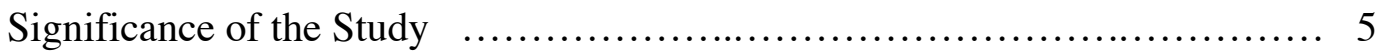

CHAPTER TWO: THEORETICAL FRAMEWORK …....................... 8

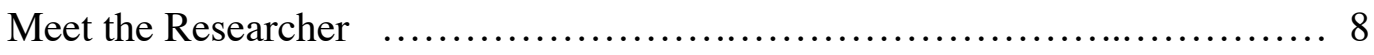

Connecting Published Theories to My Research ............................ 11

Learning as a Sociocultural Experience: Vygotsky and Bandura ...... 12

Constructivism as a Learning Approach: Piaget, Vygotsky, and

Von Glasersfeld .......................................... 14

Inquiry-Based Learning and Activating Prior Knowledge $\ldots \ldots \ldots \ldots \ldots . . . .19$

Connections to College Mathematics Education $\ldots \ldots \ldots \ldots \ldots \ldots \ldots . . . . . . .20$

Adult Learning Theories: McCluskey, Spear, and Grow ............. 22

Personal Theoretical Framework ......................................... 30

CHAPTER THREE: REVIEW OF RELATED LITERATURE $\quad \ldots \ldots \ldots \ldots \ldots . . . .33$

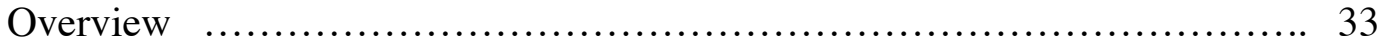

Common Principles, Perceptions, and Practices in College Mathematics ..... 36

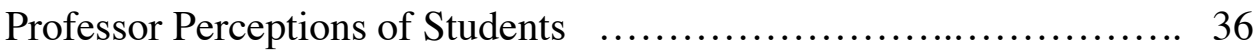

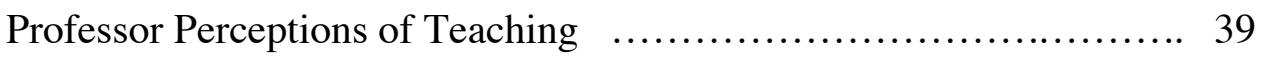

Current Practices in Curriculum ................................. 44 
Student Perspectives on College Mathematics

Students' Understanding of Their Readiness for College Mathematics...50

K-12 Mathematics Versus College Mathematics: An Overview ............ 53

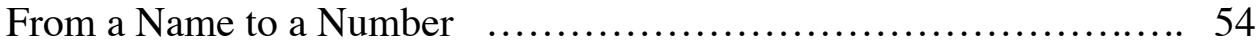

From Personalized Construction to Rote Replication ............... 57

College Readiness ............................................... 59

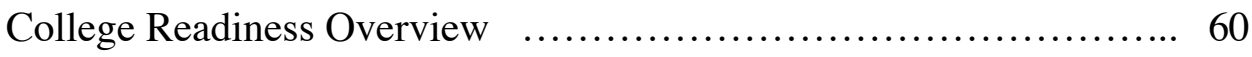

Higher Education Throughout History $\quad \ldots \ldots \ldots \ldots \ldots \ldots \ldots \ldots \ldots \ldots . \ldots 1$

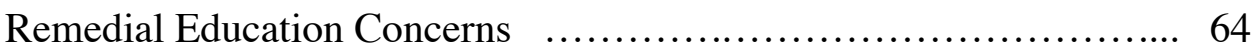

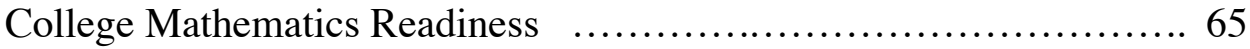

Student Success in College Mathematics: A Visual Representation ......... 67

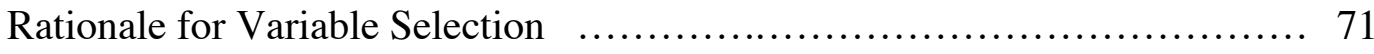

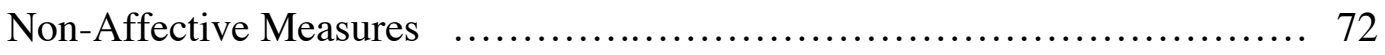

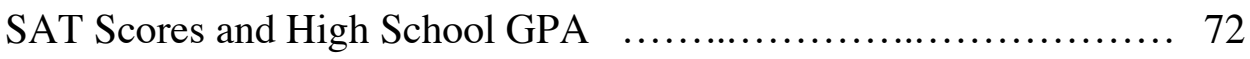

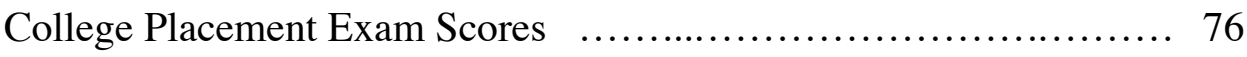

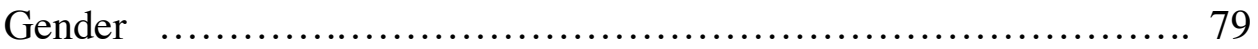

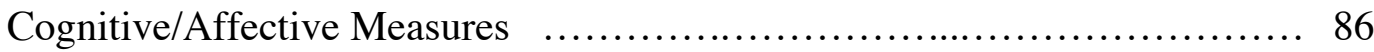

Time Devoted to Mathematics/Course Attendance $\ldots . \ldots \ldots \ldots \ldots . . . . .86$

Self-Efficacy/Confidence and Attitudes About Mathematics ......... 88

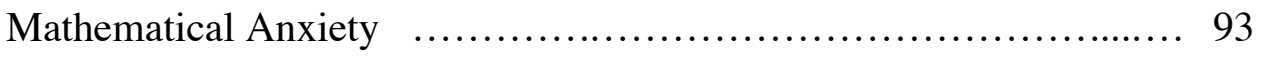

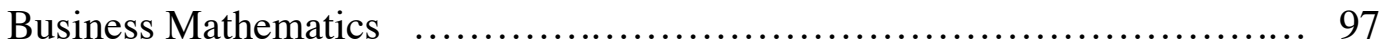

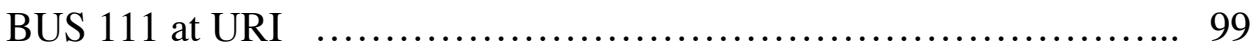

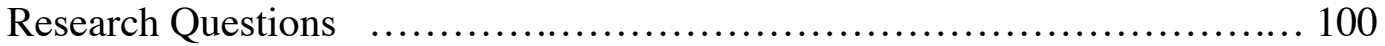

CHAPTER FOUR: RESEARCH DESIGN AND METHODOLOGY $\ldots . \ldots . . . .102$

Arriving at a Quantitative Methodological Approach ...................... 102

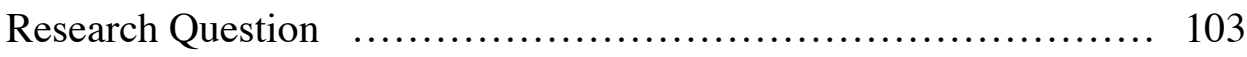

Philosophical/Theoretical Worldview $\ldots \ldots \ldots \ldots \ldots \ldots \ldots \ldots \ldots \ldots . \ldots 104$ 
Intended Audience ............................................... 106

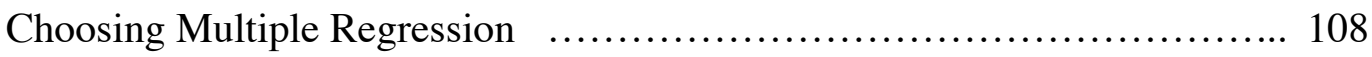

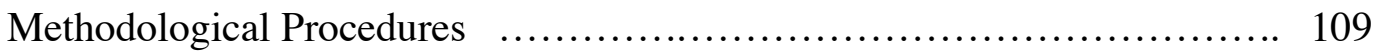

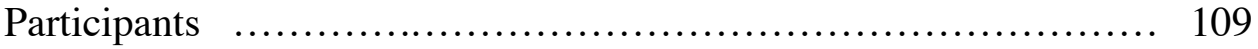

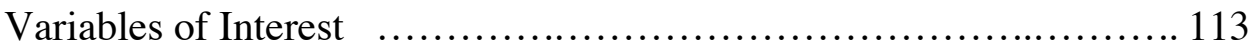

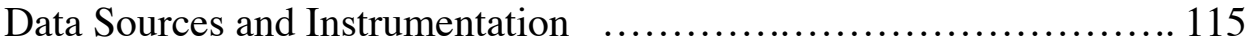

Attitudes Towards Mathematics Inventory $\quad \ldots \ldots \ldots \ldots \ldots \ldots \ldots . \ldots 116$

Mathematics Anxiety Scale ................................. 117

Data Collection .................................................. 118

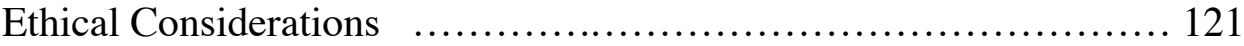

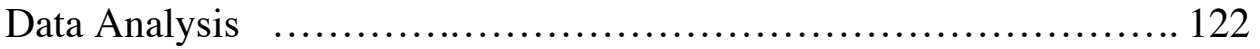

Limitations of Multiple Regression and Survey Design $\ldots \ldots \ldots \ldots \ldots \ldots \ldots \ldots \ldots . \ldots 124$

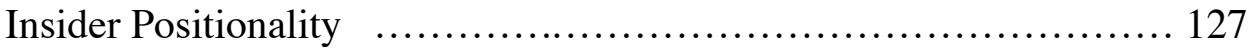

CHAPTER FIVE: FINDINGS/RESULTS ...................................... 129

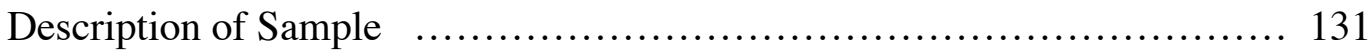

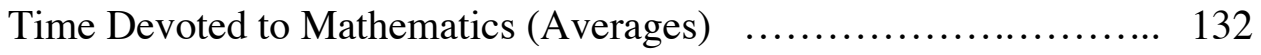

High School GPA, SAT Score, and Placement Exam Averages ...... 134

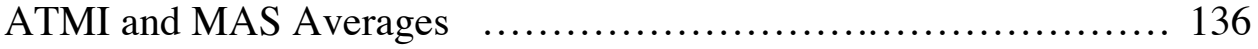

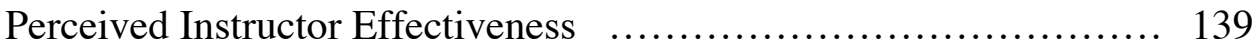

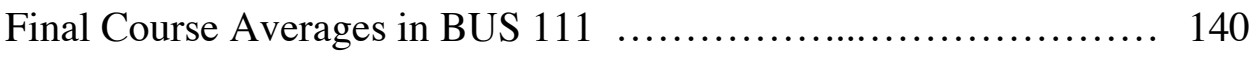

Multicollinearity and Group Means Concerns $\quad \ldots \ldots \ldots \ldots \ldots \ldots \ldots \ldots . . \ldots 143$

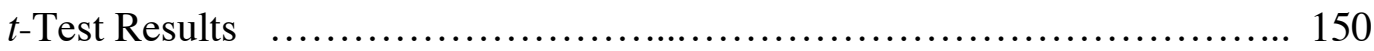

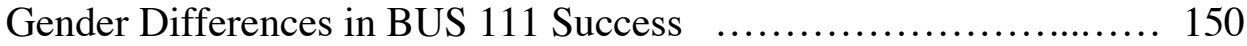

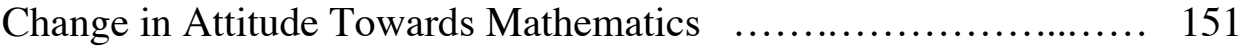

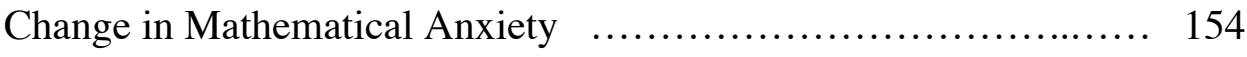

Change in Perceived Instructor Effectiveness $\quad \ldots \ldots \ldots \ldots \ldots \ldots \ldots \ldots \ldots . \ldots \ldots$

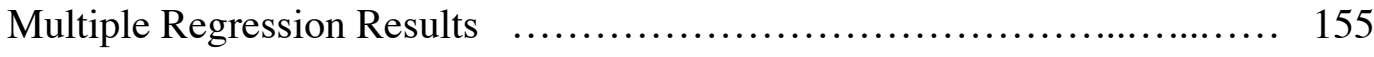


Multiple Regression Assumptions Satisfied

Enter-All/Simultaneous Results

Step-Wise Results 169

Block-Wise/Hierarchical Results 177

Non-Affective vs. Affective Factors 181

Individual Exams 189

Gender-Specific Results 195

Instructor-Specific Results 202

Other Noteworthy Results 211

Correlational Results 211

Perceived Instructor Effectiveness and ATMI 211

Perceived Instructor Effectiveness and MAS 212

Perceived Instructor Effectiveness and Time Spent $\ldots \ldots \ldots \ldots \ldots \ldots 213$

Perceived Instructor Effectiveness and Course Average ............ 213

Concluding Remarks .......................................... 214

CHAPTER SIX: IMPLICATIONS AND DISCUSSION $\ldots \ldots \ldots \ldots \ldots \ldots \ldots \ldots$

Policy Recommendations ............................................ 219

Change in Focus: From College-Readiness to Student-Readiness ... 219

Personalizing Instructional Environments (Reduction in Class Size)... 221

Instruction and Curriculum Practices in College Business Math ..... 227

Implementing Instructor Evaluations $\ldots \ldots \ldots \ldots \ldots \ldots \ldots \ldots \ldots \ldots . \ldots \ldots$

Changing Placement Exam Procedures $\quad \ldots \ldots \ldots \ldots \ldots \ldots \ldots \ldots \ldots . \ldots . \ldots . \ldots 243$

Current Reform Efforts Implemented to Promote Readiness $\quad \ldots . . . \ldots \ldots \ldots \ldots . .251$

Bridging the Gap Between High School and College $\quad . . . . . \ldots \ldots \ldots . . .252$

On-Campus Review and Support Prior to Enrollment $\ldots \ldots \ldots \ldots \ldots \ldots .254$

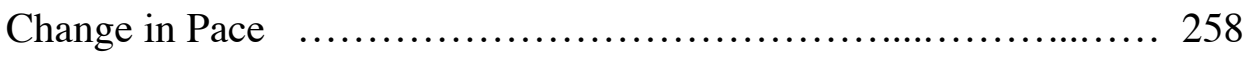

Professional Experiences and Connections to My Research ................ 260 


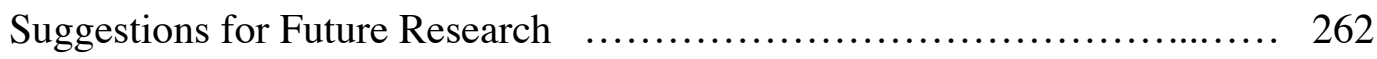

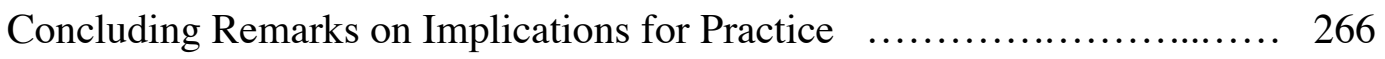

APPENDIX A: Beginning of the Semester: Survey Consent Form and Questions ... 269

APPENDIX B: End of the Semester: Survey Consent Form and Questions ........ 272

APPENDIX C: Attitudes Towards Mathematics Inventory (ATMI) ............... 275

APPENDIX D: Mathematics Anxiety Scale (MAS) …....................... 280

APPENDIX E: E-mail Sent to Students Prior to Fall 2015 Semester ............... 282

APPENDIX F: Sample Questions from URI's Mathematics Placement Exam ... 283

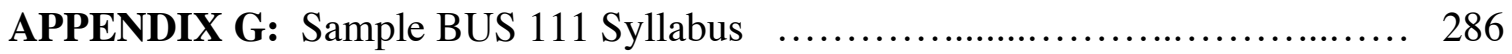

APPENDIX H: Approval Letter to Reproduce and Use ATMI _................... 292

APPENDIX I: Approval Letter to Reproduce and Use MAS _................... 293

APPENDIX J: Verbal Scripts Read to Participants. .............................. 294

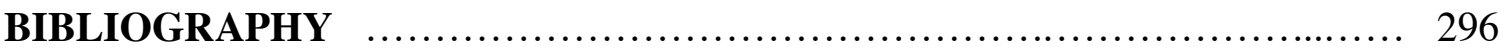




\section{LIST OF TABLES}

Table 1. Grow's Staged Model of Self-Directed Learning .......................... 26

Table 2. Differences Between High School and College Mathematics Courses ...... 59

Table 3. Business Major Ethnicity/Race and Gender Breakdown ................ 112

Table 4. URI Mathematics Placement Score Breakdown ......................... 134

Table 5. Breakdown of Students' Final Letter Grades in BUS 111 ............... 141

Table 6. Final Averages in BUS 111 and Placement Results ................... 142

Table 7. Breakdown of Individual Exam Grades and Final Averages ............. 149

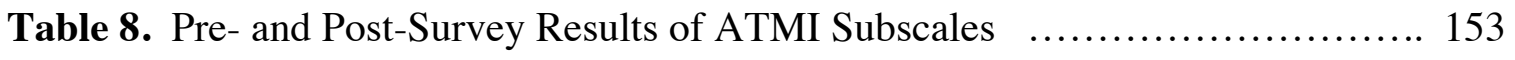

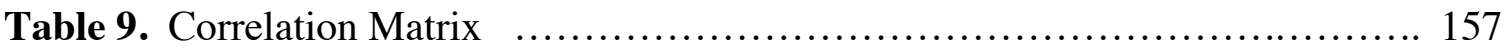

Table 10. SPSS ANOVA Table for Enter-All MR Results $\quad \ldots \ldots \ldots \ldots \ldots \ldots \ldots \ldots . \ldots 161$

Table 11. SPSS Model Summary for Enter-All MR Results .................... 161

Table 12. SPSS Coefficients Table for Enter-All MR Results $\quad \ldots \ldots \ldots \ldots \ldots \ldots \ldots . \ldots 162$

Table 13. SPSS ANOVA Table for Enter-All MR Results with Math Emotions ..... 166

Table 14. SPSS Model Summary for Enter-All MR Results with Math Emotions ... 167

Table 15. SPSS Coefficients Table for Enter-All MR Results with Math Emotions ... 167

Table 16. SPSS ANOVA table for Step-Wise MR Results $\quad \ldots \ldots \ldots \ldots \ldots \ldots \ldots \ldots . \ldots \ldots 171$

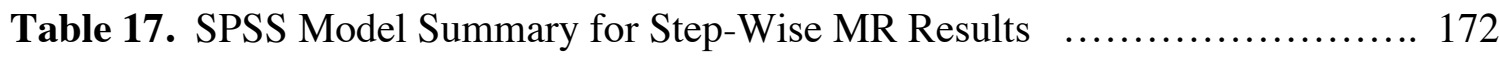

Table 18. SPSS Coefficients table for Step-Wise MR Results $\quad \ldots \ldots \ldots \ldots \ldots \ldots \ldots \ldots 172$

Table 19. SPSS ANOVA Table for Step-Wise MR Results with Math Emotions .... 174

Table 20. SPSS Model Summary for Step-Wise MR Results with Math Emotions ... 175

Table 21. SPSS Coefficients Table for Step-Wise MR Results with Math Emotions ..176

Table 22. SPSS ANOVA Table for Block-Wise MR Results $\ldots \ldots \ldots \ldots \ldots \ldots \ldots . \ldots 179$

Table 23. SPSS Model Summary for Block-Wise MR Results .................. 180

Table 24. SPSS Coefficients Table for Block-Wise MR Results $\quad \ldots \ldots \ldots \ldots \ldots \ldots . \ldots 181$

Table 25. SPSS ANOVA Table for Non-Affective Measures in MR Results $\quad \ldots . . .183$ 
Table 26. SPSS Model Summary for Non-Affective Measures in MR Results .... 184

Table 27. SPSS Coefficients Table for Non-Affective Measures in MR Results .... 184

Table 28. SPSS ANOVA Table for Affective/Cognitive Measures MR Results ..... 185

Table 29. SPSS Model Summary for Affective/Cognitive Measures MR Results ... 186

Table 30. SPSS Coefficients Table for Affective/Cognitive Measures MR Results ... 187

Table 31. SPSS ANOVA Table for Affective Measures MR with Math Emotions .... 188

Table 32. SPSS Model Summary/Coefficients Table for Males MR Enter-All ..... 196

Table 33. SPSS Model Summary/Coefficients Table for Males MR Step-Wise ..... 197

Table 34. SPSS Model Summary/Coefficients Table for Females MR Enter-All .... 199

Table 35. SPSS Model Summary/Coefficients Table for Females MR Step-Wise ... 200

Table 36. SPSS Model Summary/Coefficients Table for Instructor 1 MR Enter-All ... 203

Table 37. SPSS Model Summary/Coefficients Table for Instructor 1 MR Step-Wise.. 204

Table 38. SPSS Model Summary/Coefficients Table for Instructor 2 MR Enter-All ... 206

Table 39. SPSS Model Summary for Instructor 2 in MR Step-Wise Results ....... 207

Table 40. SPSS Coefficients Table for Instructor 2 in MR Step-Wise Results _... 208

Table 41. SPSS Model Summary for Instructor 3 in MR Step-Wise Results ....... 209

Table 42. SPSS Coefficients Table for Instructor 3 in MR Step-Wise Results $\ldots . . .210$

Table 43. Paired-Samples t-test for Predicted and Actual Observations ........... 216 


\section{LIST OF FIGURES}

Figure 1. Concept Map Leading to Research Questions $\quad \ldots \ldots \ldots \ldots \ldots \ldots \ldots \ldots \ldots . \ldots$

Figure 2. Some of the Changes Faced in Students' Transition to College …........ 53

Figure 3. Visual Representation of Student Success in College Mathematics ........ 68

Figure 4. Selecting a Quantitative Research Design ............................. 108

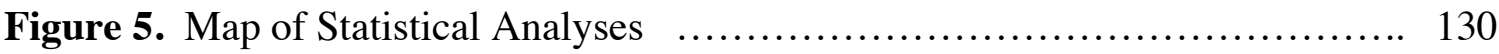

Figure 6. Sample Demographics: Gender and Race of Participants ............... 131

Figure 7. National Demographics: Gender and Race of Business Students ....... 131

Figure 8. Hours Per Week Students Expected to Spend on BUS $111 \quad \ldots \ldots \ldots \ldots \ldots . . \ldots 132$

Figure 9. Number of BUS 111 Classes Students Expected to Miss …............. 132

Figure 10. Hours Per Week Students Reported Spending on BUS 111 ............ 133

Figure 11. Number of BUS 111 Classes Students Reported Missing …........... 133

Figure 12. Distribution of Participants' Mathematics Placement Scores ............ 135

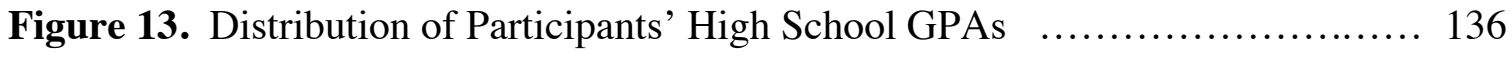

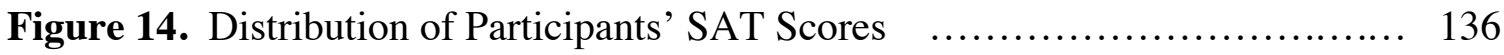

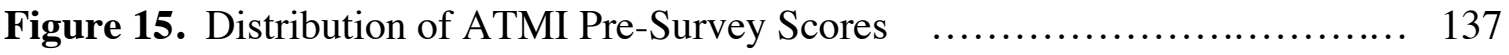

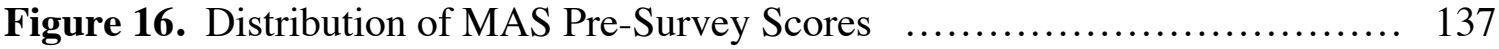

Figure 17. Distribution of ATMI Post-Survey Scores ........................ 138

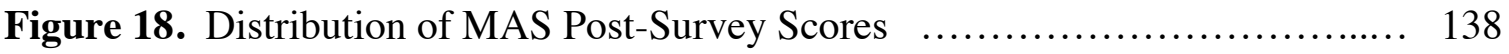

Figure 19. Distribution of Students' Initial Perception of Instructor Effectiveness ... 139

Figure 20. Distribution of Students' Final Perception of Instructor Effectiveness ... 140

Figure 21. Distribution of Students' Final Averages in BUS 111 ................ 141

Figure 22. Final Averages in BUS 111 and Placement Results $\quad \ldots \ldots \ldots \ldots \ldots \ldots \ldots . \ldots 142$ 
Figure 23. ATMI Pre- and Post-Survey Subscale Changes $\quad \ldots \ldots \ldots \ldots \ldots \ldots \ldots \ldots \ldots . \ldots \ldots$

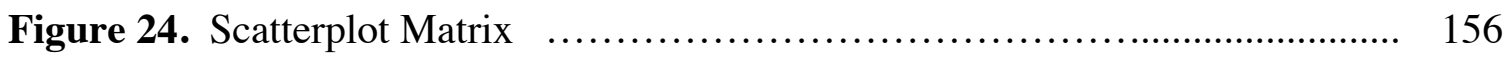

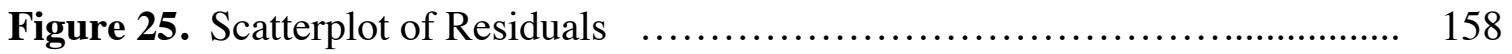

Figure 26. Histogram of Residuals in Dependent Variable $\ldots . \ldots \ldots \ldots \ldots \ldots \ldots \ldots \ldots . . \ldots 159$

Figure 27. Normal P-P Plot of Regression Standardized Residual ............... 159

Figure 28. SPSS ANOVA Table, Model Summary, and Coefficients Table for

Exams in MR Results 


\section{CHAPTER ONE: FRAMING THE STUDY}

Mathematics education is an imperative component of the general education curriculum in the United States (Parker, 2005; Perini, Silver, Strong, \& Thomas, 2004; Tobias, 1987). Each year, thousands of students in America graduate high school and enter college with dreams of preparing for enjoyable, rewarding careers. Many studies have revealed that students are severely unprepared in making the transition to college, especially for mathematics courses (Barnes, Cerrito, \& Levi, 2004; Corbishley \& Truxaw, 2010; Hammerman \& Goldberg, 2003; Perini et al., 2004; Taylor, 2008; Thiel, Perman, \& Brown, 2008; Zelkowski, 2011). General mathematical competency, critical thinking, and problem solving skills are necessary in many occupations today (Ballard \& Johnson, 2004; Kesici \& Erdogan, 2009; Mesa, 2012; Reisel, Jablonski, Hosseini, \& Munson, 2012; Thiel et al., 2008; Tobias, 1987; Zelkowski, 2011). Furthermore, there is a widespread philosophical belief that "the study of mathematics offers students [an] opportunity to discover, create, and communicate" (Parker, 2005, p. 23). In recent years, research has shown that students who possess a strong mathematical understanding will not only have access to more opportunities for academic success, but will also be granted more opportunities throughout their careers. Success in college mathematics courses is a strong predictor of retention in college as well as outlooks for career growth and financial success in the working world (Corbishley \& Truxaw, 2010; Hall \& Ponton, 2005; Kesici \& Erdogan, 2009; Mesa, 2012; Parker, 2005; Perini et al., 2004; Taylor, 2008; Thiel et al., 2008).

At the same time, it is no secret that mathematics has historically been seen as one of the most challenging academic content areas - especially in college. Based on current trends, it is likely that in the $2015-2016$ academic year, over $25 \%$ of all college freshmen will fail their first college mathematics course (Bahr, 2012; Pugh \& Lowther, 2004). A number of news and other media outlets frequently report that our nation's mathematics scores are plummeting, students are entering the workforce mathematically unprepared, 
and the majority of the United States population seems to dislike or even fear mathematics (Davis \& Shih, 2007; Frost, Coomes, \& Lindebald, 2009; Hammerman \& Goldberg, 2003; Reisel et al., 2012; Tobias, 1987).

\section{Statement of the Problem}

College freshmen report great struggles throughout their mathematics courses and therefore often choose majors that require the fewest number of mathematics credits or mathematics-based coursework (Hall \& Ponton, 2005; Perini et al., 2004; Smith \& Schumacher, 2005; Zelkowski, 2011). Specifically, research posits that students tend to resort to majors and career choices outside of science, technology, engineering, mathematics (STEM), and business fields, to pursue a degree that requires less rigorous mathematics courses (Long, Iatarola, \& Conger, 2009; McDuffie \& Graeber, 2003; Smith \& Schumacher, 2005). Many students struggle with mathematics and, even when choosing elective courses, they tend to avoid classes that involve mathematical thinking or mathematics-based applications. Mathematics author and educator Sheila Tobias found that:

Americans apparently believe... that mathematical ability is a very rare talent, possessed by only a few and utterly impossible to attain if one is not born with a gift for it; hard work, then, has little to do with increasing mathematical understanding. And, with this perception, American teenagers continue to sink below their international peers in mathematical performance. (Tobias, 1987, p. 236-237)

This perception still tends to be held by many American students today (Corbishley \& Truxaw, 2010; Kesici \& Erdogan, 2009; Mesa, 2012).

Research suggests that most college freshmen lack confidence in mathematics and are unaware of how to be successful in a college-level course, often leading to anxiety and failure (Barnes et al., 2004; Corbishley \& Truxaw, 2010; Zelkowski, 2011). The literature examined, which is described in more detail in chapter three, also posits that 
many college students do not feel adequately prepared for their college-level mathematics courses. Their mathematical anxiety, attitudes towards mathematics, and perceptions about the subject are closely linked to their grades in college mathematics courses (Barnes et al., 2004; Hall \& Ponton, 2005; Kesici \& Erdogan, 2009; Samad, Tuah, \& Haron, 2009; Zelkowski, 2011). Further, the same student may have vast differences in success taking the same course with different instructors (Corbishley \& Truxaw, 2010; Hiebert \& Grouws, 2007; Marzano, Gaddy, \& Dean, 2000; McDuffie \& Graeber, 2003; Mesa, 2012; Okoro, 2014).

While many quantitative studies have investigated factors that predict success in college mathematics, the majority of this research has focused on variables such as gender, SAT scores, percentile rank in high school, and high school GPA (Bridgeman, Pollack, \& Burton, 2008; Kesici \& Erdogan, 2009; Smith \& Schumacher, 2005; Taylor, 2008). Much of the research has focused on remedial mathematics courses or mathematics courses designed for STEM majors (Bahr, 2012; Hagedorn, Siadat, Fogel, Nora, \& Pascarella, 1999; Hall \& Ponton, 2005; Mesa, 2012). A number of qualitative studies have investigated effects of attitudes towards mathematics, mathematical anxiety, and confidence in mathematical ability (Barnes et al., 2004; Hall \& Ponton, 2005; Mesa, 2012; Samad et al., 2009). However, there is a distinct lack of research that examines how these affective and cognitive variables can be used to predict success in business mathematics courses. Acquiring a better understanding of how these factors play a role in college students' success in business mathematics could help practitioners better prepare students with study strategies, curriculum designs, and instructional changes that would maximize learning opportunities in business programs.

College freshmen majoring in business at the University of Rhode Island (URI) are experiencing this mathematical struggle. These students must successfully complete a foundational business mathematics course (BUS 111: Introduction to Business Analysis and Applications) in order to proceed in URI's College of Business 
Administration degree program. For the last decade, this course has had a failure rate of approximately 31\% (P. Boyd-Ferguson, personal communication, March 9, 2015). Thus, nearly one in every three students who enters URI with dreams of earning a degree in business must either retake this foundational course, thus spending extra time and money at the university, or change their major to one with more achievable mathematics requirements. A preliminary mathematics course (MTH 110: Mathematical Foundations for Business Analysis) is offered to help prepare students for BUS 111, but many students do not choose to take this remedial course for fear of falling behind in the business degree program.

Therefore, the purpose of this research study was to examine what factors predict student success in a foundational business mathematics course (BUS 111) at URI. With a dependent variable of final average in BUS 111, various independent variables (gender, high school GPA, mathematics SAT score, university mathematics placement test score, number of hours devoted to mathematics outside of class each week, number of BUS 111 classes missed, attitudes towards mathematics, perceived instructional effectiveness, and mathematical anxiety) were examined to see which combination of variables could be used to best predict student success in BUS 111. Investigating this relationship can help students understand how to maximize their chances for success in business mathematics. Further, it can help URI's College of Business instructors, advisors, and support staff better teach and advise students by providing more targeted strategies for achievement and retention.

\section{Significance of the Study}

There is currently a distinct lack of research that examines the relationship between success in college business mathematics courses and student attitudes, mathematical anxiety, perceived instructor effectiveness, and time devoted to the subject. Insight into student attitudes and perceptions may help reveal the predictors of success in business mathematics, allowing for better advising and specific study strategy 
recommendations for students. The quantitative, statistical study described here has attempted to fill this gap in the literature by investigating the possible predictors of mathematics success in a foundational college business course (BUS 111) through multiple regression and correlational analysis. The resulting predictor equations and regression coefficients could help inform departmental curricular and instructional changes that could ultimately lead to more students finding success in business mathematics. Business is a major increasing in popularity, with approximately 367,000 students earning a business degree out of the total 1.791 million degrees conferred in 2012 (U.S. Department of Education, National Center for Education Statistics, 2015). Thus, approximately $20 \%$ of all college graduates are earning a degree in a business field, making it the most popular major in the United States.

While this multiple regression analysis was exploratory in nature to investigate which variables were significant predictors, any results obtained could be used to inform future practice. If the current placement test used by the university was not found to be a strong predictor of success in BUS 111, a new process may need to be designed and implemented to better inform and prepare students. If mathematics SAT score or high school GPA were found to be strong predictors, then the College of Business may need to reexamine the admissions requirements. If gender was a strong predictor, the College may need to reexamine the current curriculum and instruction to look for potential gender bias. If the number of classes missed over the semester or the number of hours spent on mathematics outside of class per week were strong predictors, professors might consider requiring or at least encouraging more homework, and students could be made aware of this predictive relationship upon starting the course. If student attitude towards mathematics, confidence, or mathematical anxiety were strong predictors, students could be made aware of this connection and provided with tools or strategies to help them address these factors.

Despite the results, performing this research can promote positive changes for 
URI's College of Business students, faculty, and support staff alike. The predictor equations presented in chapter five can help college students at URI understand how to increase their opportunities for success in business mathematics. Students can be provided with targeted strategies to help them proceed confidently in the College of Business. Student advisors can be made aware of the predictive relationships discovered and can learn how to use these equations to better advise students. Further, as discussed in chapter six, these relationships can be used to inform further research and future decisions for the mathematics curriculum and instructional practices in the College of Business at the University of Rhode Island. 


\section{CHAPTER TWO: THEORETICAL FRAMEWORK}

In this chapter, I describe my personal theoretical framework as well as the existing theories relating to this study. Specifically, I examine socio-cultural and constructivist learning and teaching theories as well as adult learning theories that frame my research. I then describe my views as a pragmatic, student-centered researcher. I believe it is impossible, however, to completely detach what we say and write from who we are. Therefore, I feel it is only appropriate to begin with a brief introduction of who I am as a student, researcher, and educator. The concept map on the following page (Figure 1) presents an overall diagram of how I arrived at my research questions, which are presented in chapter three.

\section{Meet the Researcher}

I am a white, middle-upper-class, determined female. I generally use "educator" as the first noun to describe myself. And I love (really, really love) mathematics. In spite of being successful throughout my academic mathematical journey, I have suffered from anxiety and fear in school throughout my entire life. I grew up in a small, suburban town in Ohio and moved to Rhode Island with my family during high school. I took advanced mathematics courses throughout middle school and high school and was often one of very few females in those advanced classes. I graduated from the University of Rhode Island in 2009 with a double major in Mathematics and Secondary Education. I thoroughly enjoyed learning higher-level mathematics, but it never came easily to me: I always felt compelled to study for hours each evening in order to earn high grades and I rarely felt confident in my ability to perform mathematics or teach the subject to others, though both activities were my passions. Before I began each new mathematics course, I 


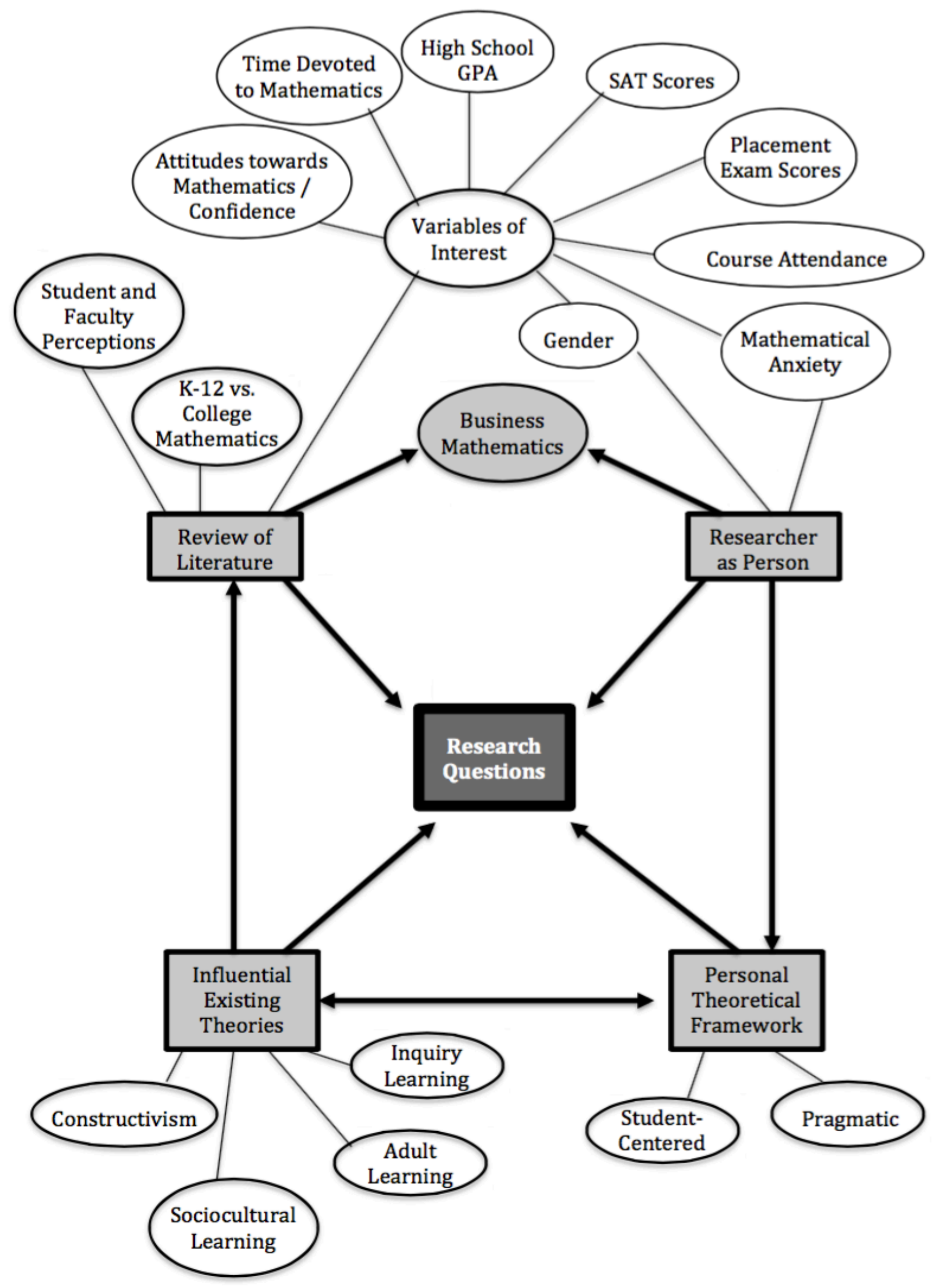

Figure 1. Concept Map Leading to Research Questions 
felt nervous about what was to come and whether I could succeed in my new mathematical journey.

Unsure whether high school teaching was for me (or whether I was cut out for high school teaching), I entered URI's Master's degree program in mathematics upon graduation. Immediately, I realized that my favorite component of the Mathematics Master's program was having the opportunity to teach college freshmen introductory mathematics courses. As a result of this realization, I began a second Master's degree in Secondary Education in 2010. In 2012, I completed both Master's degrees and entered the joint Ph.D. in Education program between the University of Rhode Island and Rhode Island College. At that point, I had just started a new job as a Learning Specialist at URI, where I helped individual students learn about self-assessing techniques, study skills, advocacy, and how to lower academic anxiety. Though I loved the job, I missed teaching mathematics.

In 2013, I was hired by my current employer, the College of Business Administration at URI, to teach undergraduate business mathematics courses. Specifically, I was asked to teach MTH 110 (a remedial mathematics course providing students with foundations required for business mathematics), BUS 111 (a business calculus course required for admission into the College of Business), BUS 210: Managerial Statistics (an introductory business statistics course), and BUS 211: Managerial Decision Support Systems (an advanced business statistics course focusing on multiple regression analysis, specifically designed for students in the management specialization). It is here that I have found my home. I genuinely look forward to coming to work everyday and investigating new techniques to improve myself as an educator and help my students learn about the value and beauty of mathematics. I learn more from my students each day than I ever learned through formal education. I usually consider myself both a student and an educator in all contexts through my daily work. I see research opportunities everywhere I look as I constantly seek new ways to help my 
students and improve my teaching practices. The University of Rhode Island, its students, faculty, and staff are extremely important to me, and I hope to give back to this community by researching ways to enhance student success.

\section{Connecting Published Theories to My Research}

In the following sections, I describe the existing theories that connect closely to my research in college mathematics education, based on my personal theoretical framework as a student-centered educator. Having a strong understanding of these underlying theories, as well as recognizing the weaknesses in each theory, was essential to understanding the data I collected and analyzed in chapters five and six. Specifically, I focus on Vygotsky's theory of socio-cultural learning (Vygotsky, 1978), which builds off

of Dewey's recognition of the importance of using reflection and personal experiences to drive learning outcomes (Dewey, 1938). I also describe constructivism as an approach to teaching and learning (Fosnot \& Perry, 2005; Piaget, 1964; Von Glasersfeld, 2005; Vygotsky, 1978), inquiry-based learning and the activation of prior knowledge (Levy \& Petrulis, 2012; Marzano et al., 2000; Ormrod, 2011); as well as various applicable theories regarding adult learning (Knowles, 1988; McCluskey, 2007; Merriam \& Brockett, 2007; Merriam, Caffarella, \& Baumgartner, 2007). Analyzing these existing theories leads into my personal theoretical framework, which provides an underlying structure for this study.

\section{Learning as a Socio-Cultural Experience: Vygotsky and Bandura}

In the beginning of the twentieth century, psychologist Lev S. Vygotsky introduced a socio-cultural approach to learning, emphasizing that social interactions and cultural experiences influence a person throughout every stage of development and guide their meaning making processes (Kozulin, 1994; Vygotsky, 1978). Society, cultural norms, and personal experiences greatly impact the way in which all individuals create meaning and also influence how each student learns and makes sense of the world around them (Cobb, 2005; Dewey, 1938; Fosnot \& Perry, 2005; Vygotsky, 1978). Humans are 
social beings. We long for acceptance and are deeply influenced by those around us in all that we do. We are constantly adapting to the changing culture and the socially accepted norms of our world. Vygotsky believed that "every function in the [student]'s development appears twice: first, on the social level, and later on the individual level; first between people... and then inside the [student]" (Vygotsky, 1978, p. 57, emphasis in original). In other words, we are not born as individuals who develop into social beings over time; rather, we are born as social beings and gradually grow into individuals. Therefore, the current lecture method of instruction present in many college mathematics and business mathematics courses, which often lacks social opportunities and peer interaction, is likely to be limiting student learning.

Similar to Vygotsky, psychologist Albert Bandura theorized that social interactions and modeling lead to learning (Bandura, 1986). While Vygotsky focused on the importance of language as a tool for development, Bandura examined how novices model the behaviors of others as they develop. Bandura introduced what is known as social cognitive theory, which states that learning occurs as individuals observe others, interpret various behaviors, and interact with their peers (Bandura, 1986; Ormrod, 2011). The environment influences individuals and individuals influence the environment. Furthermore, Bandura recognized that self-efficacy plays a major role in learning (Bandura, 1986; Bandura, 1997). He found that learners with low self-efficacy, or those who believed that they were unlikely to reach a goal, were less likely to persist or try new things. Learners with high self-efficacy, which he defined as "the belief in one's capabilities to organize and execute the courses of action required to manage prospective situations" were more likely to feel in control through new learning experiences and thus more likely to succeed at learning new behaviors or completing challenging tasks (Bandura, 1997, p. 3). In both Vygotsky and Bandura's research, the incorporation of some social interaction was pivotal to learning.

Most people learn best through a combination of critical dialogue, deep reflection, 
and connection to personal experiences (Bandura, 1986; Dewey, 1938; Fosnot \& Perry, 2005; Jaeger, 2013; Schön, 1983; Von Glasersfeld, 2005; Vygotsky, 1978). Even at the college level, students need social opportunities to help guide their thinking and construct new knowledge. By relying on the professor as the sole giver of information, it would be natural for college students to start to believe that knowledge is external and cannot be independently created. So, after college, upon entering the workforce, how can we expect these graduates to construct their own knowledge, create original products, think critically, or solve authentic problems? Mathematics professors could help facilitate the learning process from a socio-cultural or social cognitive frame by encouraging classroom discourse, welcoming questions and explanations of experiences, fostering personal connections, and promoting social group work and innovative thinking.

A limitation of socio-cultural learning is that it focuses on the group before the individual, which challenges some of the current competitive, egocentric educational settings. Some educators believe that because each learning experience is likely to be different for each student, a more competitive environment would foster a deeper desire to learn (Frost et al., 2009; Levy \& Petrulis, 2012; Long et al., 2009). Many college classrooms (as well as many K-12 classrooms) adapt a deficit-thinking, meritocracybased climate and encourage competition over cooperation; leading students to believe that those who work the hardest are most likely to succeed. This neglects all cultural and social components of learning and opportunities for success in school. Vygotsky (1978) instead posits that learning is a social experience that cannot possibly be isolated from all cultural contexts. Therefore, educators must embrace opportunities for discourse and cultural connections.

\section{Constructivism as a Learning Approach: Piaget, Vygotsky, and Von Glasersfeld}

Teaching should help enhance learning and development by providing students with opportunities to construct a deep, personal understanding of a topic (Bandura, 1986; Dewey, 1938; Fosnot \& Perry, 2005; Von Glasersfeld, 2005; Vygotsky, 1978). Without 
giving students time to generate their own meanings and make connections (either independently or socially through interactions with others), it will be difficult for learning to occur. The underlying idea of constructivist theory is that "learning is a process of constructing meaning; it is how people make sense of their experience" (Merriam et al., 2007, p. 291). Therefore, in constructing new knowledge, students benefit from having time to reflect on their personal experiences and discuss their connections and questions with others.

Scientist Jean Piaget is often considered the father of constructivism (Piaget, 1964; Sjøberg, 2010). Unlike Vygotsky, who focused on social elements of constructivism, Piaget instead originally examined constructivism on an individual level (Sjøberg, 2010). Though Piaget was a scientist who was not researching educational applications of his studies, many educators cite his work and apply his theories. He was interested in the nature of knowledge, believing that building knowledge took more than observation and innate development (Piaget, 1964). Piaget believed that learning occurred as individuals adapted to the world around them (Ormrod, 2011; Von Glasersfeld, 2005). Individuals, then, constructed knowledge through assimilation (using existing schema to make sense of a new concept) or accommodation (creating a new schema or modifying an existing schema to make sense of a new concept) to the external world (Ormrod, 2011; Piaget, 1964; Sjøberg, 2010).

Vygotsky, who was introduced in the previous section, was heavily influenced by Piaget. He believed, however, that learning could not occur in isolation from direct social interaction with others and, in fact, that much learning occurred because of social interactions (Vygotsky, 1978). A contemporary of these two influential constructivist theorists was Ernst von Glasersfeld. Von Glasersfeld added yet another component to social constructivism, which was the importance of inquiry and environment in social learning experiences (Cobb, 2005). He theorized that knowledge was not created externally or identically for different learners. He believed "when we intend to stimulate 
and enhance a student's learning, we cannot afford to forget that knowledge does not exist outside a person's mind" (Von Glasersfeld, 2005, p. 5). Further, von Glasersfeld stressed the importance of trial and error in learning so that students could see various results of diverse behaviors and ask questions as they learned and adapted. As a constructivist, he understood that the educator's role was to provide opportunities for students to create knowledge. Knowledge could not be given to learners (Cobb, 2005; Von Glasersfeld, 2005).

Educator and physicist Svein Sjøberg (2010) provides an overview of core components to understanding constructivism as a learning approach. Five of his components are fundamental in my own appreciation of constructivism in college mathematics environments:

1. "Knowledge is actively constructed by the learner, not passively received from the outside. Learning is something done by the learner, not something that is imposed on the learner" (Sjøberg, 2010, p. 3).

2. "Learners come to the learning situation... with existing ideas about many phenomena. Some of these ideas are ad hoc and unstable; others are more deeply rooted and well developed" (Sjøberg, 2010, p. 3).

3. Learners have their own "ideas about the world, but there are also many similarities... in their ideas. Some of these ideas are socially and culturally accepted and shared" (Sjøberg, 2010, p. 3).

4. The ideas described above are not always mathematically accurate and "may be persistent and hard to change" (Sjøberg, 2010, p. 3).

5. Teachers must "take the learner's existing ideas seriously if they want to change or challenge [them]" (Sjøberg, 2010, p. 3).

Currently, many college mathematics professors engage in direct instruction and lecturing, where learning is assumed to occur through transmission of ideas and feedback on assessments, requiring students to learn mathematics without personal connections 
(Ormrod, 2011). College professors should instead allow students to discuss their culturally-based attitudes about mathematics, share their personal experiences, discover the mathematics involved in those experiences through exploratory social interactions, and together construct strategies to solve realistic problems. By understanding students' perceptions about mathematics and realizing students' potential anxiety towards the subject due to previous experiences, professors could help their college students reconsider and possibly reconstruct their views on the value of the subject. Once the subject is seen as valuable in authentic learning situations, students are more likely to be able to apply mathematical skills in new contexts, earn higher grades, and feel successful (Cobb, 2005; Dewey, 1938; Fosnot \& Perry, 2005).

At the University of Rhode Island, roughly $47 \%$ of all students who took a freshmen-level pre-calculus course during the Fall of 2014 earned failing grades (D. Libutti, personal communication, January 16, 2015). In most of these courses, a behaviorist model of teaching exists, where the assumption is that listening to the professor speak "will result in learning” (Fosnot \& Perry, 2005, p. 9). Students are treated like machines: the professor feeds them information and they are expected to memorize and replicate these processes on an exam. The goal seems to be to get students to remember the information deemed important by the professor, not to help students construct and develop a true understanding of or appreciation for mathematics (Fosnot \& Perry, 2005; Kohlberg \& Mayer, 1972; Von Glasersfeld, 2005).

From the eyes of a college professor, a difficulty of utilizing constructivism in the classroom may be that it initially requires more time and flexibility than traditional lecturing. Professors often feel as though they must "get through" as many topics as possible, and therefore class time must be devoted to giving students as much information as they can in a limited amount of time (Ironsmith, Marva, Harju, \& Eppler, 2003; Long et al., 2009). Professors do not want to "waste" class time by not engaging in fast-paced direct instruction where students act as silent observers. While it may be true that less 
material can initially be "covered" in a constructivist classroom, students will likely gain greater knowledge and understanding on the topics that are presented (Fosnot \& Perry, 2005). Professors would likely spend less time re-teaching material, as students would have a better opportunity to truly comprehend the information the first time if they were to construct the knowledge independently and then build deeper connections through discourse.

Speaking from a constructivist frame, college mathematics professors must provide opportunities for students to build, develop, and explore their own mathematical knowledge (Dewey, 1938; Fosnot \& Perry, 2005). Rather than lecturing in front of the classroom and expecting knowledge to seep into students' minds through cultural transmission, professors should present challenging problems that require students to discuss possibilities with their peers, make connections, and develop strong problem solving skills. Errors made in mathematics often lead to deeper understanding, compelling discussions, and meaningful analysis, which can greatly facilitate student learning. However, currently in college classes, students are so concerned with getting the correct answer that they neglect to recognize the skills they are developing as they work through problems (Perini et al., 2004; Rittenhouse, 1998). Professors can change this by emphasizing the importance of the process rather than the final product and by dissecting both correct and incorrect solutions obtained with enthusiasm and encouragement. This constructivist approach may also help students understand that developing problem solving skills and an appreciation for the value of mathematics is more important than getting the "right" answer (Fosnot \& Perry, 2005; Rittenhouse, 1998). One of the most powerful tools in any classroom, which greatly supports this development and enhances learning, is reflection (Brown, 1987; Dewey, 1938; Vygotsky, 1978). Students must be given time to practice independently, interact with peers, and reflect on the conversations, the learning, and the experiences that occurred if they are to move from dependent to independent learners who are capable of applying mathematical 
concepts outside of the classroom.

\section{Inquiry-Based Learning and Activating Prior Knowledge}

Inquiry learning in a classroom environment typically involves asking questions that both encourage higher-level thinking and help students think critically about how they might approach seeking new information or independently constructing new knowledge (Levy \& Petrulis, 2012; Marzano et al., 2000; Ormrod, 2011). Inquiry-based instruction allows students to explore a new topic in a way that is both authentic and meaningful, often through ill-posed problems or in-depth projects. Generally, the instructor will ask many questions throughout the process to encourage deeper thinking and understanding. Some researchers see inquiry learning in college "as the means of fostering in students the critical, reflexive... qualities needed for positive agency in a profoundly uncertain, complex world" (Levy \& Petrulis, 2012, p. 86). Inquiry learning is strongly tied to constructivism, as the key goal is to provide an opportunity for students to create their own knowledge through experience. Though inquiry learning is a relatively common strategy in elementary grades, it is less common in secondary grades and is rarely seen in college instruction. However, educational leadership professors Philippa Levy and Robert Petrulis (2012) believe that "students' engagement in inquiry... is essential for developing their self-belief and capabilities as active participants in the (co-) creation of meaning and knowledge" (p. 87).

Similar to engaging in inquiry learning, activating prior knowledge is another method which offers students the opportunity to make connections to personal experiences. Activating a student's prior knowledge is the process of asking questions or discussing topics that students are already familiar with before introducing a new concept (Marzano et al., 2000; Ormrod, 2011). This allows students to see connections between what they already know and what they are about to learn, which can lead to higher interest, lower anxiety, and deeper understanding. By asking questions that remind students of what they already know and pushing them to think deeper about that topic, 
instructors can help their students feel more confident about exploring a new or challenging mathematical or business-based concept.

\section{Connections to College Mathematics Education}

Contemporary research findings (Levy \& Petrulis, 2012; Perini et al., 2004; Thiel et al., 2008) imply that in college-level mathematics, students often do not see themselves as active meaning makers. Students rely on the professor to provide knowledge rather than feeling capable of constructing knowledge on their own. They are not builders, but merely receivers of information. Through inquiry-based lessons that activate students' prior knowledge, students are more likely to serve as active participants in the classroom (Levy \& Petrulis, 2012; Marzano et al., 2000; Ormrod, 2011). Students need a supportive learning environment where they feel free to ask questions and be curious about the mathematics in their lives. Since mathematical anxiety and attitudes regarding mathematics likely play a role in student success, developing student confidence should be a goal of mathematics professors (Hall \& Ponton, 2005; Kesici \& Erdogan, 2009). As constructivist educator Eleanor Duckworth (2006) posits, "having confidence in one's ideas does not mean 'I know my ideas are right'; it means 'I am willing to try out my ideas"' (p. 5). By allowing students to develop their own questions and thoughts about mathematics in business and work collaboratively to explore those questions in a safe environment, they can develop a genuine curiosity about the subject and gain confidence in their abilities to generate hypotheses, reason, and problem-solve (Thiel et al., 2008; Wittrock, 1986).

Educational psychologist Ann Brown suggests "all active learning involves selfregulation" (1987, p. 68). I believe that by helping students develop problem-solving skills and gain confidence in their abilities through inquiry learning and the activation of prior knowledge, instructors will also help lead students towards self-regulation, as they will be less fearful of tackling business-based mathematical challenges on their own. Therefore, college mathematics educators must implement a curriculum that allows 
students to become more confident, self-directed learners. Knowing how to solve a problem in the classroom does not necessarily indicate that a student will be able to access that knowledge and apply it to a real life situation, unless learning is constructed in a personal, meaningful way (Brown, 1987; Dewey, 1938; Vygotsky, 1978). I do not believe this meaningful construction is possible in a teacher-centered, lecture-based classroom that does not encourage inquiry or value previous learning experiences.

Students do not arrive as "blank slates" in college mathematics courses. College instructors must understand and appreciate the fact that student attitudes, levels of anxiety, and views about mathematics likely influence their ability to be successful in the college classroom. If professors realize that there is more to students than their previous exam scores and GPA, I believe a more constructivist, socio-cultural, student-centered classroom approach may be possible. Thus, I have chosen affective and cognitive variables to investigate in my multiple regression analysis for this dissertation, as explained in more detail in the following chapter. If student attitudes or anxiety towards mathematics explain some of the variability in a business mathematics course grade, professors may start to realize that a behaviorist, instructor-centered approach is likely not conducive to student learning. This research has allowed me to explore the degree to which these affective variables influence a student's grade. If business mathematics professors adapt constructivist, inquiry-based lessons into their teaching or develop methods to activate students' prior knowledge, I believe students may find it easier to make personal connections to mathematics, lower their anxiety, and understand the value of mathematics in their lives.

\section{Adult Learning Theories: McCluskey, Spear, and Grow}

Though many of the theories described above can be applied to the majority of learners at all stages of development, most of the research used to develop those theories

involved students in a K-12 environment who were under the age of 20. Even the limited research performed in college settings has focused mainly on learners between the ages 
of 18 and 22. As of 2011 , over $36 \%$ of all students enrolled in institutions of higher education nationally were over the age of 25 (Center for Post-Secondary and Economic Success, 2011). Therefore, various theories on andragogy, or "the art and science of helping adults learn" (Knowles, 1988, p. 43) and adult learning processes, rather than just pedagogy and child development, must be considered. A few of these influential theories are presented in this section.

Adult learners bring a variety of experiences to the college classroom that could potentially contribute to their learning and meaning making processes (Knowles, 1988; Merriam \& Brockett, 2007; Merriam et al., 2007). As students enter college, a number of situational, institutional, and dispositional barriers must often be faced. Situational barriers include the high cost of courses at institutions of higher education, time management concerns, and ensuring loved ones are cared for while they pursue their degree (Knowles, 1988; Merriam et al., 2007). Similarly, institutional barriers include the location of the college and the new schedule of courses, as well as the challenges that these changes might present. Finally, dispositional barriers consist of how adult learners view their journey to college. Many adults who enroll in higher education courses feel unsure of their academic ability or have negative learning experiences from their past that get in the way of their current learning processes (Merriam et al., 2007).

One of the greatest barriers students seem to face when entering post-secondary education, regardless of their age, is being able to find the time to finish everything they need to accomplish (Hall \& Ponton, 2005; Kesici \& Erdogan, 2009; McCluskey, 2007; Merriam \& Brockett, 2007; Merriam et al., 2007). According to McCluskey's Theory of Margin, developed by adult educator Howard McCluskey (2007), adult learners must figure out a way to discover an appropriate balance between their load, or their responsibilities, and their power, or how much control they have over their load and how to overcome the potential barriers to their achievement. In order to discover this balance and find success in higher education, learners must be given the support and 
encouragement they need in order to continue. Similar to socio-cultural and constructivist views, adult learning theorists argue that "learners must connect what they have learned from current experiences to those in the past as well as see possible future implications" (Merriam et al., 2007, p. 223).

Similar to Dewey (1938), Vygotsky (1978), and von Glasersfeld (2005), adult educator George Spear believes that every learning experience a student encounters is influenced by their environment, prior knowledge, and random occurrences (Merriam et al., 2007). In higher education, professors can use Spear's philosophy to recognize the potential obstacles and strengths that each student brings to the table, help each student define their goals, and discuss these experiences and goals before delving into learning. Instructors cannot make connections for students, but should offer opportunities for dialogue and reflection that encourage adult learners to relate the new knowledge to past and current experiences (Merriam et al., 2007). This concept aligns with McCluskey's Theory of Margin, indicating that there is likely more on every student's plate than the college courses they enroll in, and that this must be recognized and validated before educators can prepare a student for independent, self-directed learning. "Learning in adulthood means becoming more self-directed and autonomous" (Merriam et al., 2007, p. 120). Therefore, a key goal in many adult learning theories is to help students become self-directed learners (Merriam et al., 2007). Self-directed learning occurs when a student can plan, carry out, and evaluate their own learning experiences, with little or no help required from a teacher.

Setting goals and activating prior knowledge often lead to self-direction, and are therefore imperative components of adult learning. Adult learning theorist Gerald Grow created a model to help instructors understand how to best support learners on their journey to self-regulation. By setting clear expectations and recognizing the prior knowledge with which students enter college courses, professors can help students move through Grow's Staged Model of Self-Directed Learning (Merriam et al., 2007). Though 
Grow recognizes that most students enter higher education with some degree of intrinsic motivation, he posits that they likely start off by being fairly dependent upon the instructor as the "giver of information". As represented in Table 1 below, in this first stage, the instructor is the expert. After some time, learners become more interested in the material and the instructor's role is to help keep them interested and motivated (Merriam et al., 2007). In the next stage, learners begin to become more involved with the knowledge development and need the instructor to facilitate learning. Finally, students can become self-directed and use the instructor as a consultant when needed (Merriam et al., 2007). Therefore, by being clear in expectations, reminding students of their capabilities, and providing plenty of feedback and support, professors can help students become more confident and self-directed in their learning.

A general limitation to contemporary and foundational research theories in education is that pedagogy models and research on pedagogical best practices typically examine students in K-12 environments. Similarly, in most adult learning theories, students over the age of 25 are considered. Thus, many college students between the ages of 18 and 24 appear to sometimes be neglected in the existing theories. Many higher education researchers complain that typical pedagogical practices in K-12 settings

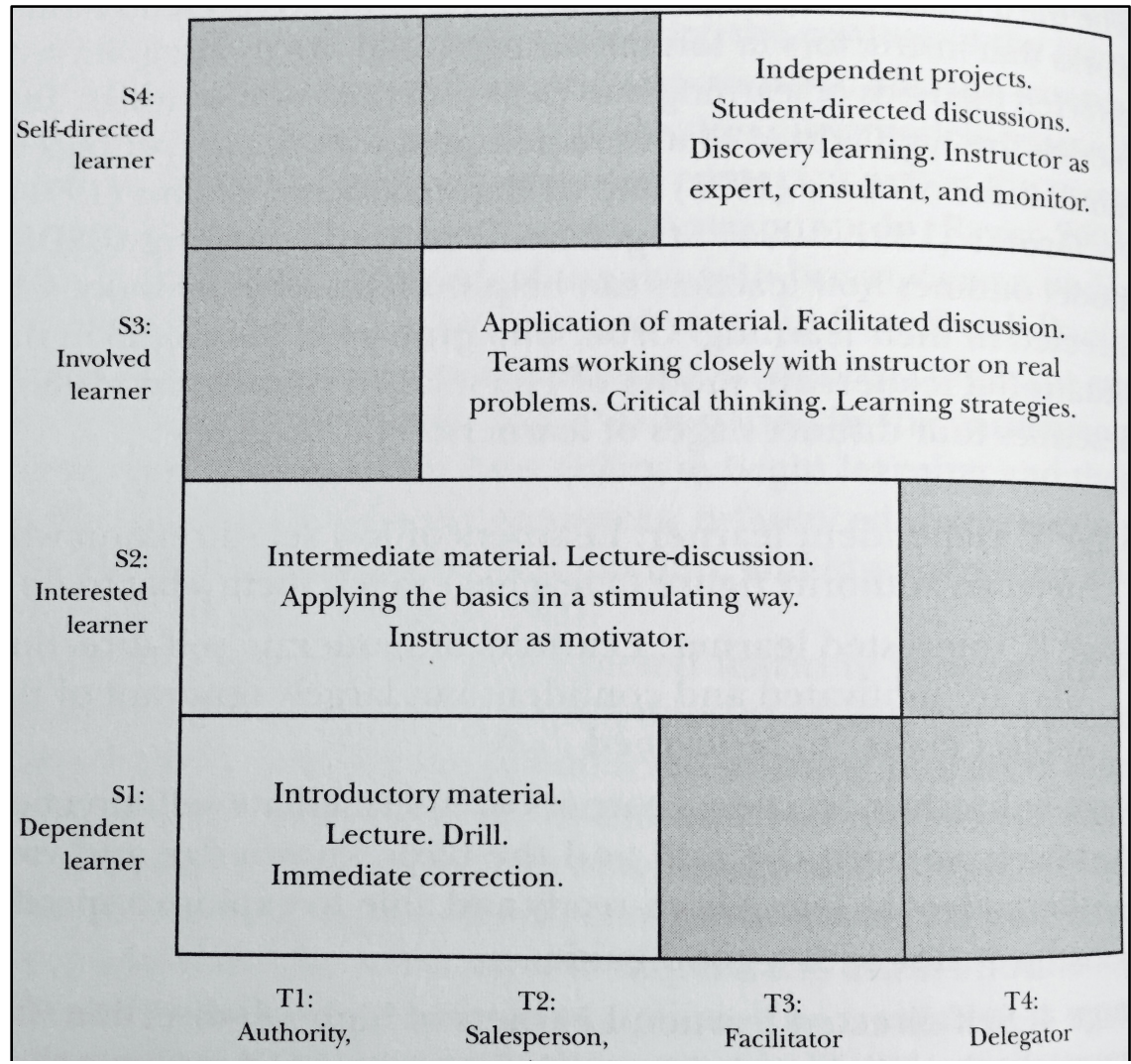


Table 1. Grow's Staged Model of Self-Directed Learning (reprinted from Merriam et al., 2007)

are too juvenile for college students while many professors are unaware of adult learning theories (Kesici \& Erdogan, 2009). Thus, an appropriate balance of pedagogical best practices and an understanding of andragogy and adult learning must be examined and understood when working with this population of college learners. However, connecting personal experiences to new learning, constructing knowledge based on experiences and social interactions, and engaging in frequent discourse and reflection are considered beneficial to all learners regardless of age (Dewey, 1938; Merriam et al., 2007; Schön, 1983; Vygotsky, 1978; Von Glasersfeld, 2005).

\section{Adult Learning Theory and Connections to Eliciting Change Among Professors}

While trying to elicit change among college mathematics professors, it is also important to understand adult learning theories and consider how professors may approach learning new techniques and potentially shifting their own teaching methods. Mathematics and business mathematics professors are expert mathematicians. This expert status often leads to a blind spot, as they are not used to being told they need additional training in a field other than mathematics. However, the majority of professors are not expert educators, so development in this area is needed in order to promote student learning (Anderson, 1967; Berliner, 2004; Bransford, 2000). By understanding how adults process new information and tackle learning something for the first time, I believe I could help promote change in college business mathematics professors' teaching practices.

In the past, researchers have investigated the idea of mathematics professors having what is known as an "expert blind spot" (Nathan, Koedinger, \& Alibali, 2003, p. 645; Nathan \& Petrosino, 2003). This concept highlights the fact that once an educator is 
a true expert of a concept, they often struggle to remember how novices are able to learn that concept. Specifically:

...educators with advanced subject-matter knowledge of a scholarly discipline tend to use the powerful organizing principles, formalisms, and methods of analysis that serve as the foundation of that discipline as guiding principles for their students' conceptual development and instruction, rather than being guided by knowledge of the learning needs and developmental profiles of novices. (Nathan \& Petrosino, 2003, p. 906)

Unfortunately, educators such as college professors are often unaware of this blind spot and struggle to understand how students learn concepts which, to the experts, seem trivial. Because the concepts and skills are so effortless for the experts, when students are unable to grasp these concepts, the experts tend to believe the student is simply incapable of understanding, rather than realizing that the way the subject is being presented may need to be re-examined (Nathan et al., 2001).

According to adult educator Malcolm Knowles (1988), adults need to understand why they are learning something new and also need to feel responsible for their decision whether to move forward with an innovative concept. Further, the past experiences of these adult learners must be recognized and validated before they will be ready to learn new information. Therefore, college mathematics professors must understand the importance and benefits of reflective, student-centered, constructivist teaching and learning practices. They must also understand that it is ultimately their decision to implement changes in their own practice, as they are the only ones in charge of their classrooms (Knowles, 1988). Further, many professors do have experience teaching (regardless of how effective that teaching may have been), which needs to be recognized before change can take place. By respecting professors, validating their experiences, and acknowledging their autonomy, they are more likely to be open to new ideas and willing to try out new strategies (Knowles, 1988). 
Sociologist Jack Mezirow posits that adult learning is often a transformational process (Merriam et al., 2007). According to his theory, learning is a three-phase process, which often begins with a "disorienting dilemma" that causes disruption and encourages change (Merriam et al., 2007, p. 105). In the case of college mathematics education, the disorienting dilemma could be a presentation demonstrating the lack of student learning and retention in college mathematics. Once the professors realize their students are often not truly learning under the current conditions, the transformational process would have room to begin. According to Mezirow, first, the professors must reflect on their own assumptions about teaching and learning in college; second, they must engage in discussions with others to validate their thoughts and contemplate change; finally, praxis must occur, where the professors take action to make change in their course and reflect on the outcomes (Merriam et al., 2007; Schön, 1983). I believe that ongoing professional development with critical dialogue and time for individual and collegial reflection could allow for this transformational learning process among professors.

College professors, as with other adult learners, need to believe that what they are learning about matters: teaching with a more student-centered, inquiry-based approach will help them become better at their jobs as instructors and will lead to more meaningful learning, and this needs to be made clear to them from the start. Further, by having access to more teaching strategies and a better understanding of how students learn, they will be able to confront future situations that may arise in the classroom with more confidence and poise. To get there, professors must realize that there is room to improve: they are not expert educators (Anderson, 1967; Bransford, 2000). Knox's Proficiency Theory states that adults are most motivated to learn when they recognize that their current level of proficiency is lower than their desired level of proficiency (Merriam et al., 2007). Therefore, professors must have an opportunity to make small changes in their classroom and reflect on those changes as they move forward, with the support of other 
faculty members or department chairs. These small changes can help professors determine what will work for them and what methods they feel most successful with, but they must be given a space to reflect on these changes and discuss the impact they are seeing if they are to stay motivated to stick with these changes (Merriam et al., 2007; Schön, 1983). Thus, frequent department meetings and professional development opportunities focusing on teaching, reflection, and learning would be helpful in encouraging college mathematics professors to implement more student-centered teaching practices.

\section{Personal Theoretical Framework}

In addition to the published theories presented above, I am approaching this research and the corresponding analysis of the findings with a pragmatic, studentcentered framework. As a pragmatic researcher, I seek to find answers to research questions that can be directly applied in educational settings (Creswell, 2014). I believe a key purpose of research is to identify current problems and then discover solutions to those problems that can ultimately be used to better educational practices. By running various statistical analyses, described in greater detail in chapter four, I hope to find regression models that can be used to inform students and instructors of the factors that can help predict and influence student success in business mathematics at the University of Rhode Island.

Further, I believe the student plays a vital role in constructing his or her own learning; the student is not a receptacle upon which an instructor can transmit knowledge (Frankenstein, 1997; Piaget, 1964; Von Glasersfeld, 2005; Vygotsky, 1978). Studentcentered, constructivist classrooms that allow students to reflect on their educational experiences are imperative to learning (Dewey, 1938; Hiebert \& Grouws, 2007). Mathematics educator Catherine Fosnot (1996) emphasized that "teachers who base their practice on [student-centered learning] reject the notion that meaning can be passed on to learners via symbols or transmission, that learners can incorporate exact copies of teachers' 
understanding for their own use or... out of context” (p. ix). College mathematics professors often use a behaviorist teaching approach, which requires students to learn mathematics out of context and in disjointed pieces (Frankenstein, 1997; Johnson, 2007; Mesa, 2012). But "knowledge is not created and recreated in the fragmented forms in which most... subjects are presented. Mathematics occurs in contexts, integrated with other knowledge of the world" (Frankenstein, 1997, p. 13). Student-centered theorists argue that learners must be provided with opportunities to reflect on their views of mathematics and explore their experiences with and attitudes towards the subject if they are to be successful (Dewey, 1938; Fosnot \& Perry, 2005; Hiebert \& Grouws, 2007; Von Glasersfeld, 2005).

As a student-centered educator, I believe there is constantly a plethora of thoughts and ideas occurring inside each student's mind, which can greatly influence their learning. I believe professors should regularly reflect on their teaching practices and their perception of the student learning that occurred or may have failed to occur (Schön, 1983). In my own practice, I try to implement the ALACT model of reflection after each lesson (Korthagen, 2001). In this model, the following five steps are recommended: (1) Action in the learning situation, (2) Looking back and reflecting on those actions, (3) Awareness of the main issues that may have occurred, (4) Construction of possible alternatives for the future, and (5) Trial of the alternatives (Korthagen, 2001). As a result of working with my major professor, Kees de Groot, as both an undergraduate and graduate student, I have come to consider four main components of students' actions in learning situations, based on the Gestalt model of therapy. Gestalt therapy emphasizes the importance of reflection in practice (Perls, Hefferline, \& Goodman, 1951). In educational practice, while working with Kees, I try to reflect on what students may have been wanting, doing (or acting), feeling, and thinking during classes. These may or may not coincide with the wanting, acting, thinking, and feeling of the instructor. However, these components are essential to 
consider as I reflect on each potential learning experience and plan for future learning opportunities.

I believe that in order for learning to take place, the student's personal thinking processes must be at the center of the learning experience (Dewey, 1938; Fosnot \& Perry, 2005; Frankenstein, 1997; Von Glasersfeld, 2005; Vygotsky, 1978). As described in the review of literature that follows, current quantitative research that examines mathematics success for business students focuses on mathematics grades the students received, scores on standardized tests, and past GPAs (Bridgeman et al., 2008; Smith \& Schumacher, 2005). Students are more than test scores. Therefore, I have chosen to examine affective and cognitive variables that focus on the student, such as attitudes towards mathematics (Tapia, 1996), mathematical anxiety (Mahmood \& Khatoon, 2011; Tobias \& Weissbrod, 1980, Tobias, 1987), perceived effectiveness of instructor (Cobb, 2005; Hiebert \& Grouws, 2007; Mesa, 2012), time devoted to mathematics (Parker, 2005), and confidence (Hall \& Ponton, 2005). 


\section{CHAPTER THREE: REVIEW OF RELATED LITERATURE}

In this chapter, I explain some of the most prominent principles, perceptions, and practices that currently exist in college mathematics. I focus on the differences in these perceptions between professors and students. I then analyze some of the differences commonly observed between mathematics in K-12 education and mathematics in college courses. Finally, I describe and define each of the variables I investigated in this research and present my research questions, which frame the remainder of this study.

\section{Overview}

Education is the opportunity to construct meaning through inquiry, curiosity, personal connections, and reflection (Dewey, 1938). A student cannot be given knowledge. Knowledge must be constructed through a combination of experience and frequent reflection (Dewey, 1938; Fosnot \& Perry, 2005). Therefore, the leading role in learning belongs to the student, not the instructor. The role of an educator is to provide learners with a space to discuss experiences and consider how they might construct new knowledge from such experiences. Thus, in mathematics, it is important for students to have opportunities to discuss problems with their peers and then test a variety of problem-solving methods in authentic contexts. In college classes, often after 12 years or more of formal mathematics education, students arrive with previously constructed perceptions about the subject. Professors should recognize that these past experiences and opinions are likely to influence a student's achievement and learning behavior in the course.

A number of studies have examined the perceptions that college mathematics professors have about their incoming students (Blanchard, 2008; Corbishley \& Truxaw, 2010; Johnson, 2007; McDuffie \& Graeber, 2003; Mesa, 2012; Zelkowski, 2011). Their findings are described in the next section. Furthermore, because of the recognized importance of mathematical literacy and competency in the working world, coupled with the general lack of preparedness that young adults in the United States seem to have to 
apply mathematical concepts to everyday situations, the overall performance of college freshmen in mathematics courses has also been closely examined and described below (Corbishley \& Truxaw, 2010; Frost et al., 2009; Long et al., 2009; Reisel et al., 2012; Zelkowski, 2011).

Over the past two decades, some qualitative research has been devoted to student attitudes towards mathematics and their mathematical anxiety, as these factors seem to be linked to student achievement (Hall \& Ponton, 2005; Kesici \& Erdogan, 2009; Parker, 2005; Tobias, 1987; Thiel et al., 2008). Most literature focuses on the problems with the current conditions of mathematics in higher education (Ballard \& Johnson, 2004; Blanchard, 2008; Corbishley \& Truxaw, 2010; Davis \& Shih, 2007; Hall \& Ponton, 2005; Johnson, 2007; Reisel et al., 2012). A key weakness in the literature is the general lack of proposed solutions to these problems. While some broad, systemic solutions are offered (Frost et al., 2009; Long et al., 2009; Thiel et al., 2008; Zelkowski, 2011), most emphasize K-12 teaching solutions; very few focus on proposed changes in higher education.

Most quantitative research on success in college mathematics has focused on test scores and demographics (Marcus, Fukawa-Connelly, Conklin, \& Fey, 2008; Smith \& Schumacher, 2005; Truell \& Woosley, 2008). Studies have shown that male students tend to outperform their female counterparts in mathematics and business courses (Berube \& Glanz, 2008; Leaper, Farkus, \& Brown, 2012; Smith \& Schumacher, 2005) and affluent students tend to outperform students from inner-city and lower-income regions (Long et al., 2009). Further, students who have higher mathematics SAT scores and high school GPAs are likely to earn higher grades in college mathematics courses (Bridgeman et al., 2008; Epstein, 2009; Long et al., 2009; Marcus et al., 2008; Sawyer, 2013; Smith \& Schumacher, 2005). These results are not entirely surprising, and these factors fall out of the locus of control of both professors and students by the time they enter college courses. Little quantitative research exists that examines how affective and 
cognitive factors influence success in business mathematics courses - a gap I hope to have started to address with this study.

In this review of related literature, as previewed above, I begin by examining current principles and practices in college mathematics courses. I then analyze some of the key differences between high school and college mathematics and introduce the difference between college-readiness and what I call student-readiness. Specifically, I examine how many researchers and practitioners focus on what students need to do to prepare for college (what I define as college-readiness) while few examine the importance of colleges being adequately prepared for new and current students (what I define as student-readiness). Finally, I describe my rationale for choosing the variables examined in this study, specifically the significance of gender, mathematics SAT scores, high school GPA, scores on college placement exams, time devoted to mathematics outside of class, number of course absences, attitudes towards mathematics (especially self-efficacy and confidence), and mathematical anxiety in relation to success in college mathematics and business courses.

\section{Common Principles, Perceptions, and Practices in College Mathematics}

\section{Professor Perceptions of Students}

A growing number of researchers have recently examined the perceptions and expectations that college professors tend to hold about their incoming freshmen (Blanchard, 2008; Corbishley \& Truxaw, 2010; McDuffie \& Graeber, 2003; Zelkowski, 2011). Generally, professors have reported feeling as though their incoming students are vastly unprepared for college-level mathematics courses. This view of a lack of preparedness in higher-level mathematics is common for professors in economics and business departments, as well as in science, technology, engineering, and mathematics (STEM) fields (Ballard \& Johnson, 2004; Blanchard, 2008; Reisel et al., 2012; Smith \& Schumacher, 2005; Zelkowski, 2011). 
To express their frustration, one large group of professors from the University of Washington wrote a formal complaint letter to the University President in 2008, claiming that the incoming freshmen were inappropriately unprepared for their mathematics-based courses at the university (Blanchard, 2008). The professors complained that they felt forced to "dumb down" the material presented in order to accommodate the majority of freshmen, whom they found could not perform what the professors considered to be basic mathematics in engineering, economics, business, science, and mathematics courses. Professors at colleges and universities across the nation often share these frustrations (Ballard \& Johnson, 2004; McDuffie \& Graeber, 2003; Reisel et al., 2012; Zelkowski, 2011).

In one study, designed to examine students' perceived mathematical competency and college-readiness, high school mathematics teacher Jeffrey Corbishley and mathematics professor Mary Truxaw (2010) asked 22 college mathematics professors at the University of Connecticut to rate various aspects of their students' mathematical ability on a five-point scale, where one indicated very low mathematical ability and five indicated high mathematical ability. The mean for overall perceived ability was a 2.17 out of 5 (Corbishley \& Truxaw, 2010). In terms of having the specific ability to reason and generalize, faculty rated the incoming freshmen a mean of 1.7 on the same five-point scale. This is a very low perception of ability to reason, and most mathematics professors surveyed considered these reasoning skills to be amongst the most important for incoming freshmen to possess. College professors specifically noted students' inabilities to use and understand fractions, work with positive and negative values, perform arithmetic, and recall multiplication tables without a calculator (Corbishley \& Truxaw, 2010).

According to a recent study by mathematics education specialist and researcher Vilma Mesa (2012), however, mathematics faculty members may have misaligned perceptions of their students' expectations in mathematics. Mesa surveyed 25 professors 
and 777 students at a large, suburban community college and discovered that professors, in general, had “a more negative perception of students' self-concept in mathematics than their students did" (Mesa, 2012, p. 61). Professors tended to believe that their freshmen did not care whether they understood the material that was being presented to them, as long as they were able to earn a good grade. Mesa (2012) posited, however, that students believed the grades they earned on exams were more important to their professors than any other coursework, primarily because the exams were generally worth such a large percentage of the overall grade. Thus, perhaps students only paid more attention to their scores when they realized that what their professors seemed to care most about were grades. This grade-influenced focus and belief was most likely to appear in developmental or freshman-level mathematics courses, rather than more advanced courses (Mesa, 2012).

Mathematics professor Pete Johnson (2007) performed a longitudinal, qualitative study analyzing developmental mathematics courses. He discovered that over one third of all college students in the United States were enrolled in what have been designated as "remedial" or "developmental" mathematics courses, indicating that the material presented in the courses was supposed to have been covered in a typical high school curriculum. Because the material presented in these courses is not considered to be “college-level," students often do not receive college credit for taking these courses (DeBerard, Julka, \& Spielsman, 2004; Hall \& Ponton, 2005; Johnson, 2007; Mesa 2012; Zelkowski, 2011). Students become frustrated when they enroll in and pay for courses covering material they were exposed to previously in high school, but often still struggle to successfully complete these courses (Johnson, 2007).

Many professors believe that the students enrolled in remedial courses are not ready for college and therefore should not be enrolled at the university. Full-time professors often avoid teaching developmental or freshmen-level courses, as they are usually larger in class size and the students who take these courses tend to submit lower 
teacher evaluation scores (J. Baglama, personal communication, January 23, 2015; Barth, Liu, \& Wells, 2009; Feldman, 1984; Guder, Malliaris, \& Jalilvand, 2011). Since senior faculty members have more input regarding the classes they teach, graduate students or adjunct faculty members generally teach these developmental courses. In the business department at the University of Rhode Island, for example, lecturers or non-tenured track faculty members typically teach the freshmen-level courses. General outlooks on teaching responsibilities in the eyes of professors are explored in more detail in the following section.

\section{Professor Perceptions of Teaching}

Dr. Amy McDuffie from Washington State University and Anna Graeber from the University of Maryland (2003) discovered that many college professors - especially in mathematics - prefer to have complete control over what they are teaching and therefore do not like to deviate from the syllabus, despite levels of student interest or understanding of the material. They often claim they have "too much curriculum to cover" to be bothered with time-consuming projects or inquiry-based learning (DeBerard et al., 2004, p. 14). However, many college freshmen come into a mathematics course expecting to receive personal attention and build relationships with their peers and instructors during class, complementary to what they experienced in middle school and high school, which most college professors are either not adequately prepared to provide (McDuffie \& Graeber, 2003; Nathan \& Petrosino, 2003), or are not willing to provide (DeBerard et al., 2004; Hagedorn et al., 1999).

Many professors teach with the intent to prepare students for more advanced, subsequent courses, especially in mathematics (Mathematical Association of America, 2012). They often believe the purpose of their course is to ensure students have the information and skills they need to continue in mathematics, as if each student has the goal of becoming an expert mathematician. However, nearly all students enrolled in business mathematics courses are not seeking a future career as a mathematician, but that 
of an accountant, financial advisor, marketer, or other business-related occupation (Barth et al., 2009). Despite the high failure rates in college mathematics courses, many professors go over the same concept, in exactly the same way, over and over again, and expect their students to get more out of it each time (Anderson, 1967; Nathan et al., 2001). If students are not understanding nor retaining the material, I wonder: are the instructors actually "covering" those concepts? More importantly, what is the point of simply covering mathematical skills and concepts; shouldn't mathematics educators instead be trying to uncover the beauty and relevance of mathematics to students (Hawkins, 2000, p. 79, as cited in Duckworth, 2006, p. 7)?

Unfortunately, many professors generally do not find teaching to be a priority in their professions (DeBerard et al., 2004; McDuffie \& Graeber, 2003; Thiel et al., 2008). A limitation in the current higher educational system is that promotion and tenure requirements at most universities across the United States focus on professors' research efforts and innovative publications, not on their teaching practices. Some professors believe that "teaching effectiveness, not publications, should be the primary criterion for promotion," but until that is the case, teaching will likely remain secondary to their research (McDuffie \& Graeber, 2003, p. 332). Of course, some mathematics professors are still extremely passionate about their teaching practices and have a deep desire to improve (McDuffie \& Graeber, 2003).

What the contemporary research fails to recognize is that with little extrinsic motivation to become a better instructor, college mathematics professors must often rely on intrinsic motivation if they wish to improve their teaching practices. Nothing in their degree programs explicitly prepares them for effective teaching. They are expected to learn and master this complex skill on their own. A "desire to be excellent" is a key component to becoming an expert teacher, but often, the focus on research pushes professors towards a desire to be excellent researchers rather than expert educators (Berliner, 2004, p. 15; McDuffie \& Graeber, 2003; Nathan \& Petrosino, 2003). Expertise 
takes time and sincere effort to gain (Berliner, 2004; Nathan et al., 2001). Therefore, college mathematics professors tend to spend more time honing in on the domain that they are already considered to be an "expert" in - mathematics - rather than focusing on their less-expert (perhaps even novice) status as an educator.

One problem with having content experts teach college-level mathematics or business mathematics courses is that being an expert mathematician does not indicate that one is qualified to teach mathematics (Anderson, 1967; Bransford, 2000; Gess-Newsome, Southerland, Johnston, \& Woodbury, 2003; Martin-Connell, 2014; Nathan et al., 2001; Nathan \& Petrosino, 2003). One of the biggest challenges in college mathematics instruction is professors' general lack of pedagogical knowledge and instructional training. Most tenured faculty members in business and STEM departments hold a doctorate degree in their field. However, only a handful of college professors outside of the education field hold some sort of teaching certificate. In fact, many receive no official pedagogical training at all (Anderson, 1967; Nathan et al., 2001). Effectively developing and presenting material to college freshmen requires pedagogical knowledge and a deep understanding of learning and developmental processes (Hofer \& Pintrich, 1997; McDuffie \& Graeber, 2002; Nathan \& Petrosino, 2003; Vygotsky, 1978). Just as students need to prepare themselves (and receive support to help them prepare) for college, colleges need to ensure the institution and its faculty members are prepared for students. Professors, despite their level of expertise in the content, may not understand how to articulate mathematical concepts to their students: "no academic degree in itself qualifies an individual to teach effectively at any level unless this preparation is accompanied by a genuine interest in teaching" (Anderson, 1967, p. 14).

With little to no training to show them how to teach effectively, professors are often forced to rely on the practical teaching knowledge they gain by being in front of a group of students. This is another key weakness of the current higher education teaching system. Many college mathematics professors resort to lecturing; even knowing that it 
may not be the most effective delivery method, because it is what they are used to and comfortable with (Gess-Newsome et al., 2003; Nathan \& Petrosino, 2003). It is not that college professors do not want their students to learn and be successful; it is that they sometimes do not know how. Professors were often able to find success in lecture-based mathematics courses themselves, so they assume all (or at least most) students will be able to learn and succeed this way as well. They often believe that they can simply give information to their students to replicate, and that this mimicking and replication will somehow result in learning.

However, "knowing how experts... behave does not help in getting someone to that point... simply copying expertise alone is likely to result in an inappropriate conservatism and lack of innovation" (Munby, Russell, \& Martin, 1997, p. 890). College mathematics classrooms must be redesigned and college professors must be made aware of various teaching strategies if the goal is to provide learning opportunities to all students. Incoming college freshmen are often criticized for not having the mathematical background necessary for professors to teach courses the way they are accustomed to teaching them (Blanchard, 2008; DeBerard et al., 2004). Rather than changing their course or altering their teaching approach to meet the needs of these new students, faculty members currently tend to lower their expectations or fail a higher percentage of freshmen (Corbishley \& Truxaw, 2010; Thiel et al., 2008). These "solutions" place the blame on the students and do not do anything to actually help students or professors learn.

Reflection is a cornerstone to all educational experiences. Not only is it vital that students are provided with a time and place to reflect, but it is equally important for professors to be reflective practitioners (Schön, 1983). Influential theorist Donald Schön defined the importance of both "reflection-on-action", where practitioners reflect on their work after-the-fact, and "reflection-in-action", where practitioners reflect and adapt in the moment (Ferry \& Ross-Gordon, 1998, p. 98; Imm, Fosnot, Dolk, Jacob, \& Stylianou, 2012; 
Schön, 1983). Both of these skills are essential for an educator to be considered a true expert. Many practitioners will reflect on their actions, but reflecting in action is a more challenging task and takes sincere dedication and practice (Ferry \& Ross-Gordon, 1998; Imm et al., 2012; Schön, 1983). Expert practitioners should not only be able to plan for future situations, but should also be able to change their plans at any time based on arising needs. Schön warned practitioners that simply gaining experience is not enough; without reflection, the experience is not meaningful and fails to lead to improvement in practice. Following Dewey, Schön understood that the "significance of experience is realized [only] in reflection" (Martin-Connell, 2014, p. 14).

Reflection is not a simple or straightforward process: it requires time and dedication, especially in the beginning. Schön argues that even if college mathematics and business mathematics professors were to recognize their expert blind spots and become expert educators, unlike mathematics which is fairly stable as a content area, education and pedagogical best practices change with each new group of students, so constant reflection and adaptation are required (Schön, 1983). However, reflection can be uncomfortable for many experts as it can highlight mistakes and shortcomings. Schön warns that often when professors (as well as students) reflect, "they tend to focus on the mismatch of traditional patterns of practice and knowledge to features of the practical situation - complexity, uncertainty, instability, uniqueness, and value conflict - of whose importance they are becoming increasingly aware” (Schön, 1983, p. 18).

Some barriers to reflection exist in higher education settings. For example, as an institutional barrier, most professors teach in isolation and have few direct opportunities to discuss their teaching with other professors or incentives to reflect on their practices (Jaeger, 2013). Many spend their time teaching and planning for instruction alone and use social opportunities to discuss research opportunities. Professors often believe their responsibility should be "doing" rather than "thinking about doing”, which further prevents many of them from reflecting on their teaching practices (Jaeger, 2013, p. 97). 
While there has been little research performed on business mathematics specifically, those studies that have analyzed business mathematics have not indicated differences in teaching practices from those of other mathematics professors (Pritchard, Saccucci, \& Potter, 2010; Truell \& Woolsey, 2008).

\section{Current Practices in Curriculum}

In considering new policies for higher education, one must recognize that instruction is not the only problem in college mathematics and business education. The current curriculum at many colleges and universities does not seem to be designed in a way that is intended to enhance student learning (Gess-Newsome et al., 2003; Johnson, 2007). Researcher and educator Mercedes McGowen (2006) found that "the intended curriculum - the course content as outlined in the syllabus... is not necessarily the implemented curriculum - what is actually taught" in freshmen level courses because of the general neglect for students' past experiences and ideas about the subject (p. 22, emphasis in original). In many institutions of higher education, the current mathematics curriculum (including the business mathematics curriculum) focuses on unconnected skills development and abstract concept memorization. This memorization and replication practice is generally in place to serve needs of professors in more advanced, subsequent courses, such as calculus (Mathematical Association of America, 2012). This is also true in entry-level business mathematics courses, which serve to prepare business majors for business calculus or advanced business statistics courses. Even if students master these skills, they generally do not know when to use them in real situations outside of the classroom, nor do they accurately recall the skills in subsequent courses.

Many mathematics educators and business educators, at some point in their careers, encounter the question: “Am I ever going to use this?" from their students. Researcher Pete Johnson (2007) discovered that the honest answer to this question, in the majority of freshmen-level college mathematics courses, should be "no, you likely won't ever use this; unless you are a math major." Students not majoring in mathematics were 
found to rarely, if ever, use what was taught in their college mathematics courses in future courses or in entry-level occupations. If they did need the skills, they were retaught them. How can our society allow educators to continue presenting material that is disconnected from actual application and irrelevant to the majority of the students they teach?

In business mathematics, professors and administrators sometimes struggle to effectively measure the quality of the curriculum and instruction (Pritchard et al., 2010). Using twelve semesters of data consisting of student evaluations of teaching, New England professors Robert Pritchard, Michael Saccucci, and Gregory Potter (2010) found that quality and effectiveness of the instruction in business courses did not improve over time, though professors gained more experience in teaching each year. This is the case at many business colleges, though the Association to Advance Collegiate Schools of Buisness (AACSB) requires accredited institutions "to demonstrate continuous improvement in teaching within their colleges of business" (Association to Advance Collegiate Schools of Business, 2015; Pritchard et al., 2010, p. 280). Professors often argue that the single measurement typically used (student evaluations of teaching, which are generally administered at the end of the course) are inadequate in measuring effectiveness and quality. Thus, it seems business mathematics courses may not currently be sufficiently measured for the effectiveness of their curriculum or quality of instruction, though no alternatives are being offered (Pritchard et al., 2010; Whitworth, Price, \& Randall, 2002).

Further, some professors claim that students score professors more favorably on the evaluations if the course is easier, the instructor holds lower expectations, or if the instructor cancels class frequently (Barth et al., 2009; Guder et al., 2011). Professors Michael Barth, Jun Liu, and William Wells reported that "there often is a perception that rigorous academic standards lower student evaluations of teaching" (Barth et al., 2009, p. 94). They found that business courses that were heavy in quantitative analysis and 
computation, such as business calculus, economics, accounting, and finance, were taught by professors who earned lower evaluations from students. However, students also earned significantly lower grades in these courses than in their qualitative business courses, such as marketing and management (Barth et al., 2009). This begs the question: do low course grades lead to lower instructor evaluation scores, or are these courses taught by ill-equipped instructors deserving of low evaluation scores, and thus simultaneously leading to lower grades? Are students coming in with negative attitudes towards mathematics and therefore the quantitative business instructors are destined to be hated and deemed ineffective by their students, regardless of their efforts? Barth, Liu, and Wells (2009) do not attempt to examine any causal relationships in their research, but they indicate that it seems little is being done to improve teaching quality or curriculum effectiveness in business courses.

The curriculum in business mathematics courses cannot be examined without the role of the instructor and vice versa. Students need an instructor whom they can trust to effectively deliver the material they will need in future courses and in their careers. According to the AACSB (2015), college business education must provide students with the quantitative skills and interpretations they may need in order to proceed in various business situations with confidence and understanding. Business educator James Okoro believes, "education programs succeed only to the extent to which the quality of the personnel engaged in the education process carry out their individual responisbilities... the success of any curriculum is directly related to the qualification of the [instructor]" (Okoro, 2014, p. 575-576).

An additional element where professors in mathematics and business departments need to focus attention and effort is the perspectives about learning mathematics that students bring into their courses from prior experiences in K-12 schooling. While much of the current literature focuses on what students could do to better prepare themselves for college and the expectations of their professors (increasing their college-readiness), 
there is little discussion on what I have referred to as student-readiness, or how professors could better understand the perspectives and needs of their students. I examine this concept more in the following section.

\section{Student Perspectives on College Mathematics}

Overall, professors tend to believe freshmen are unprepared for college mathematics. Some college professors have reported feeling as though students "get by in high school without doing much mathematics... and this learned trait in high school carries over" (Zelkowski, 2011, p. 29). So, how do incoming students view mathematics in higher education? How are they impacted by the current state of mathematics education and the debate on college-readiness? One limitation of the current research is that students are often not included in discussions on what it means to be college-ready, though they are the ones most impacted by the construct. However, a growing body of research suggests that students are entering college apprehensive of their ability to be successful, especially in mathematics (Hall \& Ponton, 2005; Kesici \& Erdogan, 2009; Tobias, 1987).

In 2005 , less than $25 \%$ of high school seniors performed at or above proficiency in mathematics on the National Assessment of Educational Progress (NAEP) (Corbishley $\&$ Truxaw, 2010). Yet, many of the "non-proficient" students were still entering college the following year. In a quantitative study, mathematics education professor Dr. Jeremy Zelkowski (2011) discovered that $85 \%$ of students who completed what were considered to be the minimum graduation requirements for high school were told that they would need remediation in college, or were predicted to fail an entry-level college mathematics course. These students were consequentially much less likely to earn a college degree. Therefore, there may be a vast difference between students who are "college eligible" (or have met the minimum mathematics requirements for high school) and students who actually feel "college ready" (Zelkowski, 2011, p. 28, emphasis added). Students (and instructors) are often unaware of the difference between these two constructs. In the 
current K-16 educational system, completing all of the graduation requirements for high school does not necessarily seem to indicate that a student is well prepared for college. Freshmen mathematics and business mathematics courses often "move along at a pace many students find impossible to maintain" (McGowen, 2006, p. 22). Besides academic competency, students must also be equipped with effective study skills, a personal, effective time management system, and a strong understanding of self. They must recognize how they learn best and understand how to effectively self-assess their abilities and reflect on their learning goals and outcomes in order to be successful in college. However, these vital skills are generally not explicitly taught in high schools (Frost et al., 2009).

Zelkowski (2011) also found a discrepancy between the beliefs of high school mathematics teachers and the beliefs of college mathematics professors when it came to how prepared students were for college (college-readiness). Specifically, $37 \%$ of high school mathematics teachers reported feeling that their college-going students were very well prepared for college, but only $4 \%$ of college professors agreed (Zelkowski, 2011). Neither of these percentages is very high, and they represent vastly different expectations of students. On the other side of this argument, $32 \%$ of college mathematics professors felt students were not at all prepared for college, though only $9 \%$ of high school teachers agreed (Zelkowski, 2011). No one seems to be asking whether colleges are properly prepared for students (student-readiness).

These messages get passed on to students. In high school, students believe they are being prepared for college and trust when their teachers tell them they are collegeready. In college, however, professors often have a different connotation of readiness, and students may feel overwhelmed by the unanticipated differences in teaching and learning practices (Frost et al., 2009; Long et al., 2009). In my opinion, this indicates that colleges are not adequately prepared to meet the needs of incoming students. College professors are frequently disappointed by the general lack of preparedness they see with 
freshmen, and students recognize and often internalize this disappointment, damaging their self-efficacy and increasing anxiety, which can lower their chances of being able to find success in mathematics courses (Corbishley \& Truxaw, 2010; Hall \& Ponton, 2005; Tobias, 1987). Therefore, self-efficacy, anxiety levels, and past experiences are specific readiness factors I chose to examine in this research, and are described in further detail below.

\section{Students' Understanding of Their Readiness for College Mathematics}

According to Corbishley and Truxaw's research (2010), the vast majority of entering college freshmen at the University of Connecticut during the 2010 school year reported that they felt unprepared for the college workload. Only $9 \%$ of students surveyed reported feeling prepared for their college courses in general. Only $6 \%$ said that they felt prepared specifically for their college mathematics courses (Corbishley \& Truxaw, 2010). In a similar survey of freshmen at the University of Louisville, over $40 \%$ of students reported believing that their college mathematics courses were too demanding. Specifically, they noted that their professors "frequently, usually, or always" expected them to know things that they were never previously exposed to in high school (Barnes et al., 2004, p. 27).

Instead of problem solving, meaning making, knowledge construction, and real world applications, college freshmen in mathematics and business mathematics courses are often asked to do routine practice and formula memorization, generally with little or no ties to the importance of these skills in their actual lives. This often contrasts with how students approach learning in elementary and secondary education settings (Frost et al., 2009; McGowen, 2006; Zelkowski, 2011). Few studies have examined ways of eliminating this behaviorist teaching approach in college courses or the negative effects of this approach. Without personal connections and opportunities for exploratory problem solving, students are unlikely to make sense of the importance of mathematics in their lives. 
Students start to develop attitudes towards mathematics and beliefs about its value long before entering college. Unfortunately, many children grow up around adults and peers who do not enjoy (or even fear) mathematics (Blaszczynski, 2001; Tobias, 1987). Many students believe from an early age that they will never be good at mathematics because their parents were not good at mathematics, or they claim to hate the subject and can only justify the belief with the idea that "I've just always hated math" or "I'm not good at math" (Blaszczynski, 2011, p. 3; McGowen, 2006). When students grow up in a social environment that promotes a strong dislike of mathematics, they often fabricate justifications as to why they believe it has no value or relevance in their lives (Vygotsky, 1978). These cultural justifications and social memories lead to strong beliefs about mathematics that are difficult to change (McRaney, 2011; Okoro, 2014; Sjøberg, 2010). Because these notions are socially influenced, it is often easier to think about mathematics in a way that is considered to be socially and culturally acceptable (McRaney, 2011; Von Glasersfeld, 2005; Vygotsky, 1978). Unfortunately, the American culture has constructed a relatively negative understanding of the usefulness of mathematics that is passed on to our children, leading many to believe they will never be ready for or successful in college mathematics (Corbishley \& Truxaw, 2010; McGowen, 2006).

Students in college mathematics courses also report differences in their experiences based on the instructor (Hiebert \& Grouws, 2007; Johnson, 2007; McDuffie \& Graeber, 2003; Okoro, 2014). Two students with similar mathematical skill sets taking the exact same course may have extremely diverse success levels under different professors (Okoro, 2014). Thus, it is important to examine the role of the instructor when investigating student success in college. Specifically, "the nature of classroom mathematics teaching significantly affects the nature and level of students learning" (Hiebert \& Grouws, 2007, p. 371). Students may experience different opportunities to learn under different instructors in high school and in college. Unlike many high school 
teachers, however, with the professional freedom granted to most post-secondary educators, students may not be aware that different college professors may teach the same course very differently. This is only one of many differences between high school and college courses. In the next section, I describe some of the key changes students face when making this transition to college.

\section{K-12 Mathematics versus College Mathematics: An Overview}

Unlike other transitions throughout a student's life, the transition from high school to college requires a young person to undergo many of the most challenging changes that they may ever face, all within an extremely short period of time. Two significant changes include changes in lifestyle (living with roommates, sudden distance from parents and family, new sleeping patterns, different eating habits, etc.) and changes in environment (campus, dorm, community, classrooms, friends, teachers, etc.). See the Venn diagram below for a visual representation of these changes (Figure 2). These changes are often pointed out to students during college seminars and orientation sessions. What seems to rarely be examined in high school, or thoroughly explained to students as they enter college, is the likely change in academic rigor that they will encounter (Zelkowski, 2011).

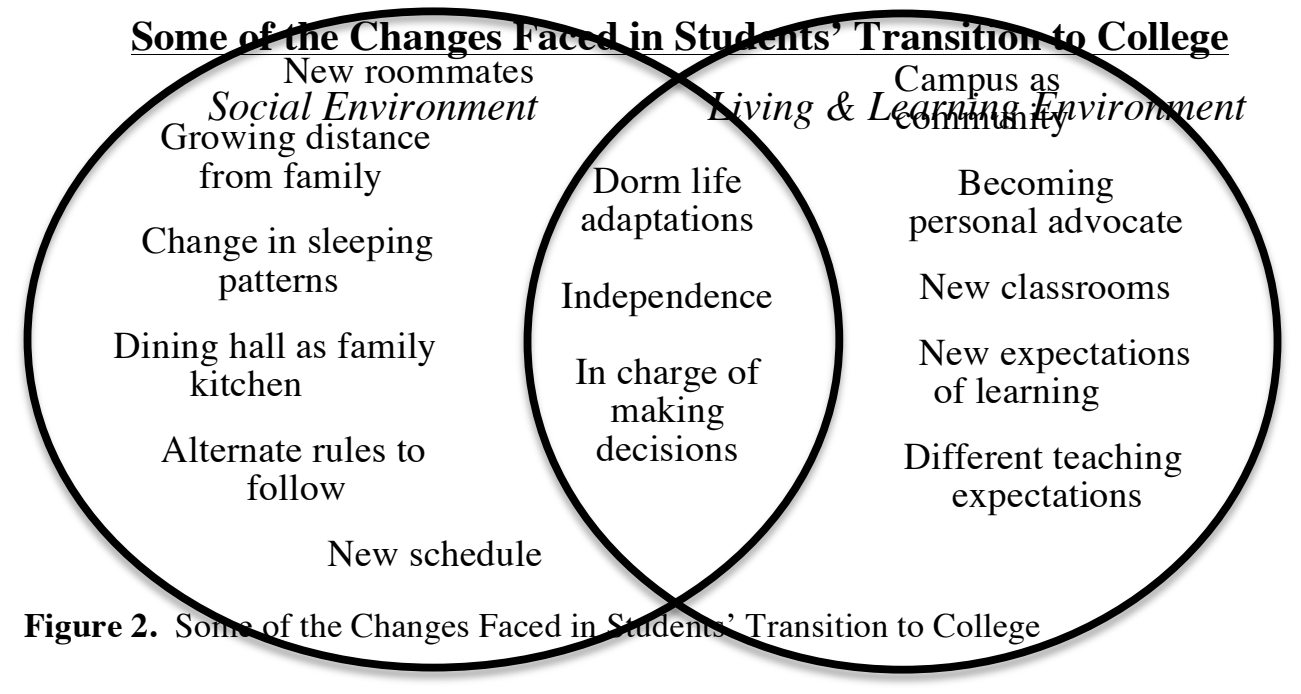


Any one of these changes could cause a student severe stress. However, with all of these obstacles presented to students at the same time, the challenge that they must face in this transition from high school to college is extremely intense. While some high school teachers seem to use scare tactics to warn students that certain behaviors will not be acceptable in college, specific academic expectations are seldom explained or practiced (Frost et al., 2009; Zelkowski, 2011). Many college professors, for example, expect students to learn certain content independently. This sudden, usually unanticipated, academic change forces students to not only quickly understand how they learn best but also how to accommodate their personal learning needs, often for the first time, in preparation for class.

\section{From a Name to a Number}

High school and middle school mathematics courses vary across the nation, though certain practices seem to be common in many schools (Davis \& Shih, 2007; Frost et al., 2009; Long et al., 2009; Zelkowski, 2011). In many elementary and middle school classrooms, students are exposed to "open-ended investigations, explication of procedures, completed examples, and... problems" for students to try on their own (Davis \& Shih, 2007, p. 339). K-12 teachers often utilize activities that involve technology and interactive group work, and present creative, flexible applications (such as projects) to serve as assessment methods (Davis \& Shih, 2007; Frost et al., 2009). Many teachers in elementary and secondary settings also try to ensure students have time to practice mathematical concepts during class, not just at home for homework. Further, behavioral issues are frequently reported in high schools (Alexander, Mundrake, \& Brown, 2009; Frost et al., 2009; Zelkowski, 2011). These trends differ greatly from most college mathematics courses, where few behavioral issues are reported and nearly all practice is expected to be completed outside of class, independently.

Many college freshmen have reported in personal communications with me that one of the main reasons the transition from high school to college is so challenging for 
them is because they feel as though they have gone from being a name to a number. This is an analogy I have heard over and over as both an undergraduate student and now as an educator in college. Students frequently feel as though everyone knew them in high school and, with small mathematics classes, their teachers and peers noticed if they were absent, upset, or confused. Many of these students enter college courses expecting a similar sense of community where their voices and faces are known and appreciated. However, often freshmen mathematics courses consist of lectures with well over 50 students per class (Hall \& Ponton, 2005; Reisel et al., 2012). At URI, freshmen mathematics courses generally range from 48-180 students per section (J. Baglama, personal communication, March 25, 2015). In freshmen business mathematics courses at URI, class sizes are typically between 45 and 60 students. This is fairly representative of freshmen class sizes nationwide, though upper-level courses have fewer students (Okoro, 2014). The professor of such large sections is unlikely to know individual student names or take attendance and students are likely unprepared for such a dramatic shift in classroom culture.

College mathematics and business professors often believe that the majority of their incoming freshmen are already independent, intrinsically motivated, self-directed learners (Davis \& Shih, 2007). However, educational psychologists Barbara Hofer and Paul Pintrich posit that many students in college believe that there can only be one "correct" answer in mathematics and, above all else, "it is important to be able to get the answer quickly" (Hofer \& Pintrich, 1997, p. 126). They may believe that mathematical knowledge is external and must be given to them directly by the instructor; it cannot be constructed or even understood independently. Therefore, it would seem likely that students may also believe that the only meaningful knowledge comes from whatever the professor tells them - not what they may be able to construct or develop on their own. By lecturing and assigning problems that require independent work outside of class, professors assume freshmen are developmentally prepared to: independently learn 
material that is not covered directly in the course, use various critical thinking skills to build connections among these concepts, and trust themselves enough to start constructing their own meanings. After working closely with their peers and receiving instructional support in high school mathematics, are these students developmentally ready for such a sudden shift towards independence? Are colleges prepared to support students with these needs?

A general lack of student voice and engagement in college mathematics and business mathematics courses may cause many students to lose interest in mathematics (Thiel et al., 2008). However, this seems to be common practice in higher education. At the University of Chicago, $93 \%$ of college mathematics professors reported using lecture most or all of the time in the classroom, $77 \%$ said they rarely or never asked their students to reflect on or write about mathematics, and $63 \%$ said they rarely or never asked students to work in groups during class (Davis \& Shih, 2007). This lecture-based, teacher-centered style of instruction is a common weakness in higher education, and is often very different from what students were exposed to in their elementary school, middle school, and high school mathematics courses. Furthermore, these practices may not be conducive to student learning (Fosnot \& Perry, 2005; Vygotsky, 1978), as:

1. Students are typically more familiar with an active learning model from their K-12 experiences and thus may struggle to learn with new teaching practices and classroom climates in place (Long et al., 2009).

2. Most students learn best through discourse and connections made to personal experiences (Cobb, 2005; Dewey, 1938; Von Glasersfeld, 2005; Vygotsky, 1978).

\section{From Personalized Construction to Rote Replication}

Educator Paul Cobb (2005), a contemporary social constructivist, defines mathematical learning as the "process of active construction that occurs when [students] engage in classroom mathematical practices, frequently while interacting with others" (p. 
41). Many (though certainly not all) K-12 teachers allow their students to develop new strategies and work in groups to solve problems while the teacher supports new discoveries, answers questions, and poses innovative, deeper questions, especially in elementary grades (Davis \& Shih, 2007; Zelkowski, 2011). Many certified educators agree that encouraging classroom discourse, asking questions, and providing some form of differentiated instruction when needed helps facilitate student learning (Cobb, 2005; Von Glasersfeld, 2005; Vygotsky, 1978). Yet these practices are absent in many college mathematics and business mathematics classrooms. The majority of college mathematics and business mathematics courses are lectures: the professor talks at students while very little learner engagement or peer interaction occur (Davis \& Shih, 2007; McGowen, 2006; Whitworth et al., 2002).

Frequently, "high school teachers [accuse] college faculty of using archaic instructional approaches [and] college faculty blame high school teachers for failing to... teach mathematics content" (Frost et al., 2009, p. 228). Specifically, college professors often accuse high school teachers of coddling students and holding them to low expectations, therefore unsuccessfully preparing them for more advanced, college-level work. High school teachers claim professors do not care about the individual student and put more effort into their research than their teaching. Regardless of the truths that may exist in these notions, this ineffective blame game has continued over the last few decades as instructors at different curricular levels struggle to agree on the true purpose of mathematics education and simultaneously fail to communicate effectively across K16 environments. Communication between secondary and post-secondary educators is limited across the United States (Bilsky, 2011). As these two groups blame one another, the students become the victims: stress develops as students struggle to abandon the understanding they gained about what it meant to learn mathematics in high school and are forced to develop new understandings of what learning mathematics looks like in college. 
The following table (Table 2) summarizes, in very general terms, my understanding of how many students, and instructors alike, tend to view the overall differences between high school and college-level mathematics courses (Davis \& Shih, 2007; Frost et al., 2009; Long et al., 2009; Zelkowski, 2011). While these characteristics are not the same in every course, or in every school, or with every student/instructor, this table provides a general overview of the vast differences that are likely to exist. With these broad differences in mind, it is important to consider ways to help students successfully make the transition to college and learn how to be successful in college mathematics and business mathematics courses.

\begin{tabular}{|c|c|c|}
\hline & High School & College \\
\hline Environment & $\begin{array}{l}\text { Warm and inviting } \\
\text { Few students per class } \\
\text { Personalized } \\
\text { Student-centered }\end{array}$ & $\begin{array}{l}\text { Cold and impersonal } \\
\text { Many students per class } \\
\text { Anonymous } \\
\text { Teacher-centered }\end{array}$ \\
\hline Role of Instructor & $\begin{array}{c}\text { Focus on pedagogy } \\
\text { Facilitator } \\
\text { Co-constructor of information }\end{array}$ & $\begin{array}{l}\text { Focus on content } \\
\text { Lecturer } \\
\text { Giver of information }\end{array}$ \\
\hline Role of Students & $\begin{array}{c}\text { Explore/ask questions } \\
\text { Participant } \\
\text { Co-constructor of information }\end{array}$ & $\begin{array}{c}\text { Accept/answer questions } \\
\text { Observer } \\
\text { Receiver/replicator of information }\end{array}$ \\
\hline Role of Assessment & $\begin{array}{l}\text { Assess to provide feedback } \\
\text { Assess to evaluate teaching } \\
\text { Learning occurs in class }\end{array}$ & $\begin{array}{l}\text { Assess to judge ability } \\
\text { Assess to "weed out" weak links } \\
\text { Learning occurs out of class }\end{array}$ \\
\hline
\end{tabular}

Table 2. Differences Between High School and College Mathematics Courses (Davis \& Shih, 2007; Frost et al., 2009; Long et al., 2009; Zelkowski, 2011)

\section{College Readiness}

College readiness is difficult to define. With Common Core State Standards (Common Core State Standards Initiative, 2015) and President Obama's Race to the Top (U.S. Department of Education, 2009) initiatives being implemented across the nation, there has been a recent push to more clearly define this concept. For some, the notion of 
college readiness implies that the minimum high school graduation requirements have been met (Zelkowski, 2011). For others, it involves the additional attainment of study skills and research abilities (Conley, 2007). With multiple beliefs about what it means to be college-ready, there is also great disagreement on whether high schools are currently preparing students for college (Zelkowski, 2011).

This discrepancy on what college readiness means is a limitation to the current literature. However, after researching definitions and comparing those to my own connotations of college-readiness as it affects students in business mathematics courses, I found a definition that I used to frame my construct of this concept for the purposes of my study. The definition of college-readiness I used is "the level of preparation a student needs in order to enroll and succeed - without remediation - in a credit-bearing general education course at a postsecondary institution" (Conley, 2007, p. 5). My only hesitation with this definition is that it puts all of the responsibility on the student, and no responsibility on the institution where the student will attend. Therefore, I believe it is appropriate to also discuss student-readiness, which I will define as the level of preparation that college faculty, staff members, and the institution in general need in order to ensure students are able to enroll and succeed in credit-bearing courses with the appropriate instruction and support. I continue the discussion on college-readiness versus student-readiness in chapter six where I discuss the implications of the findings from this study. For now, I turn to the history of student access to higher education and readiness for college.

\section{College Readiness Overview}

Earning a college degree has recently become a necessity for many careers in the United States and abroad (Brock, 2010; Conley, 2007). Over the last few decades, the number of Americans seeking a degree from an institution of higher education has risen exponentially, and in many homes across the nation, it has become an expectation that children will attend college immediately after graduating from high school. At the same 
time, college professors often complain that entering freshmen are not prepared for college-level work, as discussed above (Corbishley \& Truxaw, 2010; Thiel et al., 2008; Zelkowski, 2011). Many claim this is a growing epidemic, which stems from recently lowered expectations in primary and secondary schools. However, college-readiness is not a recently developing concern; it has been an issue for decades (Snyder, 1993).

Changes in higher education admission and enrollment policies have occurred over time, but determining who is ready for college and how to prepare students for college have remained challenges for many years.

College-readiness and student-readiness are issues of debate across the nation. With this in mind, the purpose of this section is to: (1) briefly describe the changes in access to higher education throughout history as well as the current state of accessibility; (2) discuss contemporary concerns with remedial/developmental courses in colleges across the nation; and (3) present the issues arising specifically in regards to remedial mathematics education in college.

\section{Higher Education Throughout History}

Access to higher education has changed substantially over the last few centuries. From the late nineteenth century through much of the twentieth century, most American colleges were controlled by religious groups or founded through land grants under the Morrill Act to promote agricultural advances (Snyder, 1993). Less than $1 \%$ of all 18-24 year old Americans were attending college in 1870, and the vast majority of those students were white males who came from extremely wealthy families (Brock, 2010; Snyder, 1993). Students could be denied access for a variety of reasons during this time period, and selecting which students would attend a certain college was largely left for the university administrators to decide. Discriminatory acts and general public opinions about women and African Americans kept many people belonging to these groups from seeking higher education opportunities. However, "in part, the lack of diversity [also] reflected the fact that for much of the nation's history, a college education was not 
needed to make a decent living" (Brock, 2010, p. 110-111). This is no longer the case. Today, college graduates will earn, on average, $66 \%$ more over their lifetime than someone with only a high school diploma (Brock, 2010). College graduates are also more likely to have access to health care and receive retirement benefits. Many companies require job-seeking candidates to obtain a college degree before consideration for employment, so attending an institution of higher education has become increasingly essential for a growing number of Americans.

The 1960s brought great cultural and social change to the United States, especially with the promotion of the Civil Rights Movement. When Lyndon Johnson passed the Higher Education Act of 1965, federal financial assistance became available to students in need, which also increased rates of attendance at universities (Brock, 2010). During this time, enrollment at institutions of higher education rose by $120 \%$. The population was also growing rapidly, but approximately $35 \%$ of all $18-24$ year old Americans were attending college by 1969 (Snyder, 1993). "Open enrollment" or "open admission" became a developing trend in the late 1960s and early 1970s, where colleges, starting with City University of New York (CUNY), required only a high school diploma from students in order to grant admission to the university (Brock, 2010; Conley, 2007). This increased access for underprivileged students, especially those who were racially or ethnically diverse, in an attempt to reduce discrimination. Further, women began attending college and entering the workforce in much greater numbers (Brock, 2010; Snyder, 1993). Many colleges, especially community colleges, began adapting similar open admissions policies to increase access to higher education.

Since the 1960s, access to higher education has grown substantially, a higher percentage of high school graduates are attending college, and the population of those attending has become increasingly diverse. In 1965, total college enrollment was approximately 5.9 million and by 2005 , the enrollment totals had grown to over 17.5 million students (Brock, 2010). Attending an institution of higher education has 
gradually become conventional in the United States over the last half century. "Although access to higher education has increased substantially over the past forty years, student success in college - as measured by persistence and degree attainment - has not improved at all" (Brock, 2010, p. 110, emphasis in original). Opening doors for more students without being adequately prepared to support those students academically can be detrimental.

With the National Commission on Excellence in Education's publication of $A$ Nation at Risk: The Imperative for Educational Reform in 1983, there was a nationwide call to increase the requirements and selectivity of colleges. At that time, it was reported that "one-fifth of all 4-year public colleges in the United States must accept every high school graduate within the State regardless of program followed or grades" (U.S. Department of Education, National Commission on Excellence in Education, 1983, p. 16). Today, few large universities run with open enrollment. This practice is largely left to community colleges (Snyder, 1993). Instead, the majority of four-year universities and research-based institutions are more selective in their admissions decisions and examine student test scores, high school GPAs, etc. before offering admission. With President Obama's recent push to redefine "college readiness," as well as his goal to provide students free access to higher education (specifically, two free years at a community college), opportunities may become available to many students who otherwise would not have financially had the option to attend college. These opportunities depend on the results of the 2016 elections and the corresponding changes. A policy change like this could also lead to a greater number of students in need of remedial education while in college, as there is often a positive correlation between students taking remedial courses and students from lower socioeconomic classes (Belfield \& Crosta, 2012; Deberard et al., 2004; Long et al., 2009).

\section{Remedial Education Concerns}

A small portion of college professors and university administrators believe that 
remedial education should be left to community colleges. There is a push to encourage underprepared students to attend two-year preparatory programs before enrolling in a four-year institution (Belfield \& Crosta, 2012; Brock, 2010). Several university officials feel as though students should be required to pass a college entrance exam with certain skills evaluated, or should transfer proof of the attainment of those skills from a community college before being admitted into the university. However, "undergraduates who begin at four-year colleges and universities are about twice as likely to complete a postsecondary degree as undergraduates who begin at two-year institutions" (Brock, 2010, p. 114). Thus, providing students with an opportunity to enroll in four-year institutions from the start is likely to increase the probability that those students will earn a college degree. As of 2010, educational researcher Thomas Brock discovered that approximately $42 \%$ of all students enrolled in community colleges would require remedial education in either reading, writing, or mathematics, and that the students who required this instruction were much less likely to complete a college degree. In four-year institutions nationwide, $78 \%$ of students who do not need remedial coursework end up graduating within 8.5 years, however, only $52 \%$ of students who do require remedial courses graduate in that time (Brock, 2010).

Readiness specifically for college mathematics courses has been of particular concern for the past two decades (Corbishley \& Truxaw, 2010; Long et al., 2009; Parker, 2005; Reisel et al., 2012; Thiel et al., 2008). Students are not entering college sufficiently prepared to be successful in mathematics or mathematics-based courses. Universities nationwide seem to still be surprised by this lack of preparedness and continually blame elementary and secondary educators. However, there is much action that can be taken in higher education to help students succeed in college.

\section{College Mathematics Readiness}

There is currently a demand for workers in jobs that require a degree in science, technology, engineering, or mathematics (STEM) (Corbishley \& Truxaw, 2010; Parker, 
2005; Reisel et al., 2012; Thiel et al., 2008). As the future generation begins to encounter authentic social and cultural dilemmas, having a working knowledge of mathematics and problem solving is essential for good citizenship. However, as of 2008, less than half of all of the students in the United States who entered college as a STEM major actually completed a STEM degree (Parker, 2005; Reisel et al., 2012; Thiel et al., 2008). The result is a "decrease in the number of American college graduates who have the skills, especially in mathematics, to power a workforce that can keep the country at the forefront of innovation" (Thiel et al., 2008, p. 45). Thus, increasing the number of students with STEM degrees has become a nationwide goal (Corbishley \& Truxaw, 2010; Parker, 2005; Reisel et al., 2012).

One current obstacle to awarding more STEM degrees is the severe discontinuity between the mathematics curriculum in K-12 education and the corresponding curriculum in higher education, as described in the previous section (Bilsky, 2011; Calcagno \& Long, 2008; Corbishley \& Truxaw, 2010). Upon entering college, many professors agree that they expect freshmen to be "independent, self-reliant learners who recognize when they are having problems and know when and how to seek help from professors, students, or other sources" (Conley, 2007, p. 7). However, few students are independently able to do this immediately after high school.

There is international research indicating that students who were successful in mathematics in high school will not necessarily be equally successful in their mathematics courses in college (Britton, Daners, \& Stewart, 2007). Students' past experiences and backgrounds therefore often cause them to enter higher education unprepared for their college courses. However, this should not imply that those students should be banned access from a college degree. It is true that they will embark on their educational journey "with different skills and abilities, varying personal motivation and objectives, and diverse external commitments that will influence their ability to succeed, but... what happens to them after they arrive on campus is at least as important as what 
happened before" (Brock, 2010, p. 115-116, emphasis in original). There are policy changes that institutions of higher education could implement that would enhance remedial education and simultaneously foster student learning opportunities, which I discuss in chapter six: implications and discussion.

\section{Student Success in College Mathematics: A Visual Representation}

Many factors influence a student's readiness and ability to be successful in college mathematics and business mathematics courses. In the image on page 68 (Figure 3), I have tried to capture this complex process in a visual design intended as an analogy. The overall concept in this visual representation of student success is that students soak up their prior experiences in mathematics and schooling with little effort (like a sponge). While these experiences may start as distinct, soon they may become difficult to tell apart and begin to blend together (like individual droplets of water) to form an overall view on mathematics. After absorbing experiences, they construct perceptions and thoughts. Therefore, students may struggle to recall exactly how their perceptions about mathematics or preconceived notions initially developed. The size of each water droplet is scaled based on my current perceptions of the relative importance of each experience, based on conversations with students and peers as well as the current literature.

By perceptions, I mean student thoughts that are more consciously developed based on experiences. By preconceived notions, I mean student thoughts that may develop unconsciously, perhaps due to social factors, cultural environment, or less direct experiences (McRaney, 2011; Von Glasersfeld, 2005; Vygotsky, 1978). Through my personal experiences both being a college student and working with college students in mathematics, combined with the current literature available, I strongly believe that each of these elements and experiences can influence a student's attitude towards mathematics (in terms of the usefulness, relevance, and value they attach to the subject), their selfefficacy and confidence in their own mathematical ability, as well as their level of anxiety in mathematics. All of these affective factors also impact each other, as indicated 


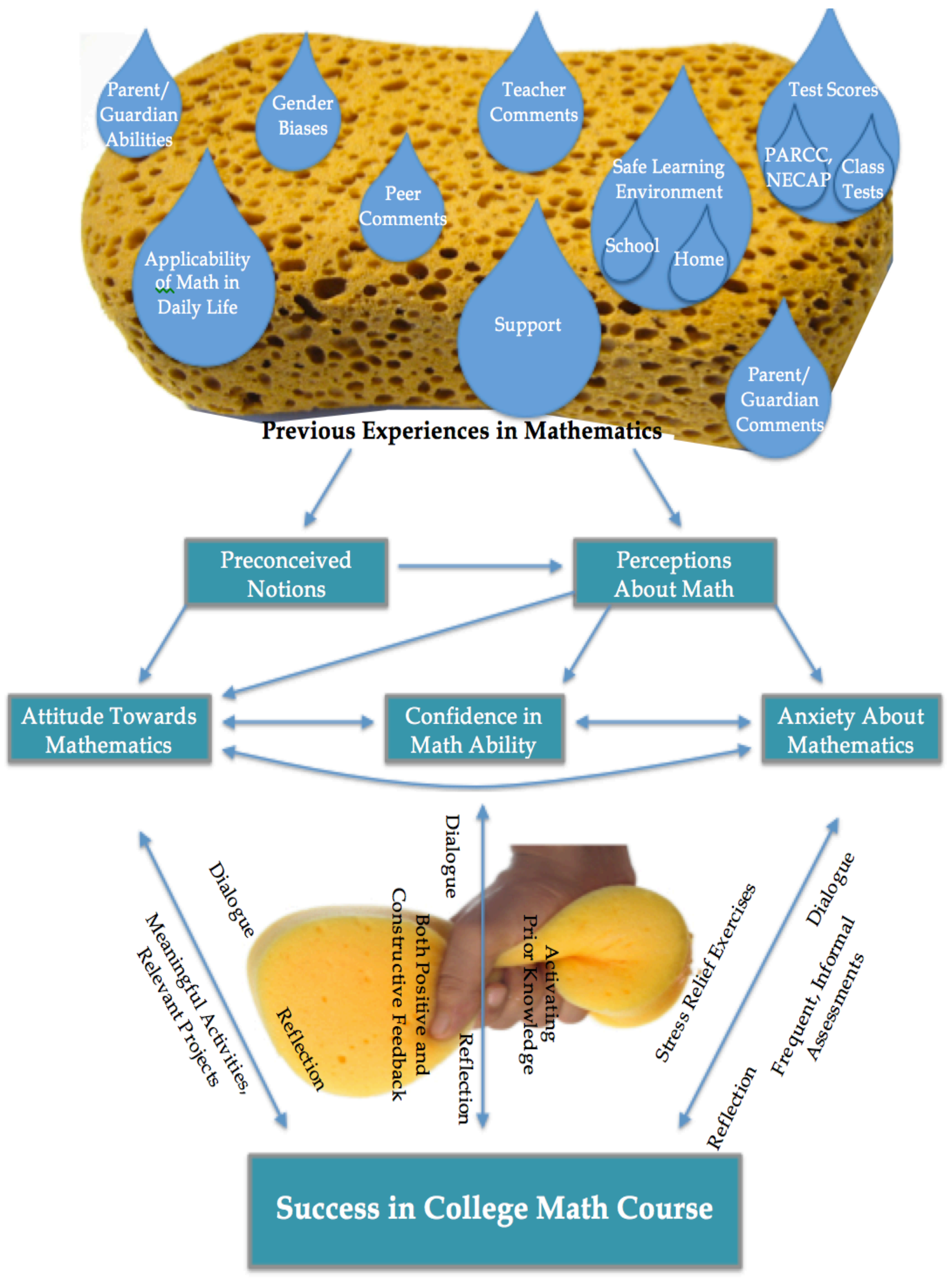

Figure 3. Visual Representation of Student Success in College Mathematics 
by the arrows in the image. Therefore, my research design investigated student selfefficacy, attitudes, and mathematical anxiety as they take business mathematics courses.

I do not think it is possible for all students to address these issues on their own. To help enhance student achievement in mathematics, professors should recognize and discuss these elements with students. Extending this metaphor, I believe it is the role of college mathematics professors to "squeeze the sponge" in order to help students understand their perceptions of mathematics and find success. Without squeezing the sponge every so often, it may grow mold or start to fall apart. The sponge will also get heavy and it will become difficult to add new liquid to it (for example: new attitudes or confidence). Unlike a behaviorist, I believe this sponge is pliable and constantly changing with new material added, mixed together, and squeezed out. Further, it takes awhile for the sponge to completely dry out and become ready to use again. Similarly, allowing students to understand their prior experiences, self-efficacy, anxiety, and perceptions about mathematics takes time and energy on the part of the instructor and students.

Squeezing the sponge requires more effort than just letting it sit and soak in the surrounding liquid. Thus, a behaviorist model of lecturing at students is not likely an effective method of instruction. Dialogue and reflection (Dewey, 1938) are key elements in recognizing one's opinions towards mathematics and how those opinions may have been formed or may change as they move forward. I believe college instructors should introduce activities and utilize frequent, informal assessments to help students lower their mathematical anxiety and provide useful, meaningful feedback on these assessments to help students learn and develop their knowledge. Further, professors should activate prior knowledge in the classroom to help students gain confidence and feel prepared to move forward, engage in reflective conversations, and utilize meaningful learning activities and authentic projects to show students the value and relevancy of the mathematics they are learning.

This model does not encapsulate all aspects of student success in college 
mathematics, but can serve as a helpful visual as one considers the multi-faceted process of student achievement and constructing and reconstructing knowledge. One limitation of this model is that it does not include the non-academic experiences that occur during college. For example, students are trying to decide on a major, learning to live under new conditions, and building a personal and professional network. These factors may also influence a student's success in any given course. Further, though I generally focus on the professor's role in helping enhance student opportunities for success, coaches, advisors, peers, or family members could also foster conversations to lower anxiety or increase self-efficacy. Self-directed students may be able to critically reflect on their experiences on their own. Even with these limitations in the design, I believe having a general visual model to share with students and instructors could help both parties make sense of how complicated the learning process is and how vital past experiences are in a student's journey through college mathematics. Further, this model begins to explain why I chose the variables I investigated throughout this study.

Throughout the remainder of this chapter, I provide a general summary and analysis of some of the popular contemporary research on college mathematics, which leads to my variable selection in this research. Specifically, I examine the contemporary literature on SAT scores, high school GPA, mathematics placement exam scores, gender differences in college, the number of classes students miss, the time students devote to mathematics in college, mathematical confidence and attitudes, and mathematical anxiety. I then identify the limitations that exist in choosing this specific selection of variables.

\section{Rationale for Variable Selection}

When considering college readiness, one must examine the role of self-efficacy and anxiety, as these often play a role in a student's ability to be successful in gateway mathematics courses. Here, I define gateway courses as courses that students must successfully complete in order to continue into more advanced coursework required for 
degree completion. Often, remedial or developmental courses serve as gateway courses in college. Acquiring a better understanding of how such affective and cognitive factors play a role in college students' success in mathematics could help practitioners better prepare students with study strategies and curricular designs that would maximize learning opportunities.

Therefore, the purpose of this study was to investigate what factors best predict student success in a foundational, gateway, business mathematics course (BUS 111) at the University of Rhode Island (URI). I examined various independent variables to see which combination of factors could be used to best predict my dependent variable of interest: BUS 111 course average. Most existing research on success in college mathematics has focused on test scores and demographics, which is where this review of the literature regarding the variable selection will begin (Reisel et al., 2012; Smith \& Schumacher, 2005). For example, Bryant College mathematics professors Richard Smith and Phyllis Schumacher (2005) discovered that males tend to outperform females in business mathematics courses. Furthermore, students who earn higher mathematics SAT/ACT scores, high school GPAs, and scores on college mathematics placement exams are also likely to earn higher grades in college mathematics courses than their peers (Bridgeman et al., 2008; Long et al., 2009; Smith \& Schumacher, 2005). With these facts in mind, I too have included non-affective variables such as mathematics SAT score, high school GPA, college placement exam score, and gender in my analysis. These variables are discussed in detail below.

\section{Non-Affective Measures}

\section{SAT Scores and High School GPA}

Nearly all large, four-year colleges and universities in the United States consider students' high school grade point averages (GPA) and standardized test scores before granting admission (Epstein, 2009; Kobrin \& Patterson, 2011; Lang, 2007; Marsh, Vandehey, \& Diekhoff, 2008; Sawyer, 2013). There is an ongoing debate about whether 
SAT/ACT scores or high school grades are a better predictor of student success in college. However, research shows that both indicators, especially when considered together, can explain at least some of the variance in college freshmen year GPA (Epstein, 2009; Gehring, 2001; Kobrin \& Patterson, 2011; Marsh et al., 2008; Sawyer, 2013). Therefore, both SAT scores and high school GPA were important indicators to examine in this research.

Originally, the SAT was designed by the Educational Testing Service and the President of Harvard University to encourage colleges to accept students based on their intellect rather than their social and financial status (Epstein, 2009). The test has been losing its popularity over the last decade as many claim it is poorly aligned to high school curriculums and the wealthy still seem to have an unfair advantage, as students from higher socioeconomic backgrounds can afford to take the SAT multiple times and take special, expensive preparatory courses to enhance their scores (Doubleday, 2013; Epstein, 2009). The current version of the SAT consists of three different sections, each with possible scores ranging from 200 to 800: mathematics, critical reading, and writing. The College Board, which now owns the SAT and helped create the new Common Core State Standards (CCSS), claims that students who earn a 1550 score or higher (out of 2400) are much more likely to earn a B- average or better as college freshmen and are also more likely to graduate with a college degree (Doubleday, 2013). For the SAT administered in 2013, only $43 \%$ of students reached the benchmark 1550 score, indicating they were ready for college-level work (Doubleday, 2013). In response, the College Board plans to better align the test to the CCSS over the next few years.

Even with these criticisms, however, most college-going students are still taking the SAT and are commonly required to submit their scores to potential colleges in order to be considered for admission. This is because colleges have found that "the SAT almost always has positive predictive value" of student achievement (Epstein, 2009, p. 13). Though sometimes weak, SAT scores generally show a positive correlation with 
student overall GPA in college. Specifically, recent research at public universities across the United States has reported correlation coefficients ranging from $r=0.35$ (Sawyer, 2013) to $r=0.44$ (Marsh et al., 2008) up to $r=0.62$ (Kobrin \& Patterson, 2007), with higher correlations reported when only freshmen year GPA is considered, rather than overall college GPA. In one study examining over 150,000 students from 109 colleges and universities, researchers found that each of the three SAT scores were statistically significant predictors of freshmen year GPA with $p<0.01$ (Kobrin \& Patterson, 2007). However, these researchers noted that the predictive quality was much greater when high school GPA was also included in the model.

Over the last decade, a growing body of research has claimed that high school GPA is a better predictor of student grades in college than SAT scores (Belfield \& Crosta, 2012; Epstein, 2009; Kobrin \& Patterson, 2007; Sawyer, 2013). However, due to popular trends of social promotion and grade inflation in K-12 education, some standardized measure of ability is usually considered necessary for college admission (Britton et al., 2007; Marsh et al., 2008; Sawyer, 2013). Economics professor David Lang (2007) found that high schools use a wide variety of methods to calculate student GPA, making it an unreliable (and often invalid) measure of student ability. After investigating 232 of the United States's largest school districts, Lang found that in many cases "there are incentives for [high school] students to enroll in less rigorous classes than they should or to avoid taking an additional class" due to GPA calculation procedures (Lang, 2007, p. 37). Mirroring Lang's findings, some universities are discovering that "it is increasingly difficult to rely on students' results from [high] school in order to be able to give appropriate advice at enrollment time" (Britton et al., 2007, p. 867). Specifically, over $80 \%$ of students who received passing grades in high school mathematics courses are generally being placed into a remedial mathematics course in college. Researchers claim that inflated high school grades lead many students to believe they will earn similar high scores in college with the same level of effort, which is often 
not the case. Therefore, universities generally feel compelled to ask students to include their standardized test scores when applying for admission as well (Britten et al., 2007; Lang, 2007).

Using both high school GPA and SAT scores is the current trend in postsecondary education. While examining the relationships between students' first-year college GPA and their corresponding high school GPA and SAT scores, researcher Richard Sawyer (2013) reported correlations of between $r=0.36$ and $r=0.48$ for high school GPA, between $r=0.35$ and $r=0.44$ for SAT/ACT scores, and between $r=0.46$ and $r=0.54$ when high school GPA and SAT/ACT scores were considered jointly. Sawyer (2013) analyzed data from 192 institutions over a four-year period. He also discovered that high school GPA was a better predictor for students who earned a between a 2.0 and 3.5 GPA during their freshmen year, but that SAT/ACT scores were more predictive for students who earned a 3.5 GPA or higher. Furthermore, high school GPAs were a stronger predictor for students who earned higher SAT/ACT scores (Sawyer, 2013). He recommended that researchers and universities continue to consider both predictors when investigating freshmen-year GPA in college, which is one of the reasons both variables were considered in this research.

At the University of Rhode Island, both standardized test scores and high school GPA are considered when admissions decisions are made. As of the Fall 2015, the average ACT score among admitted students was a 25 and the average SAT score was a 1668 ("University of Rhode Island Office of Admission”, 2015). Specifically, the average mathematics SAT score was a 565, the average critical reading score was a 547, and the average writing score was a 551 (each out of 800). Most students accepted during the 2015 school year earned a high school GPA of between 3.4 and 4.0 (“University of Rhode Island Office of Admission”, 2015). In addition, all accepted URI students are required to take at least 18 college-preparatory classes in high school including: four years of English, three years of mathematics, two years of science, two 
years of history, and two years of a foreign language.

\section{College Placement Exam Scores}

Given the criticisms of both standardized test scores (ACT/SAT) and high school GPAs, many colleges and universities across the globe require students to take an entrance exam upon admission to the university in order to determine which mathematics course would be best aligned with their current ability (Foley-Peres \& Poirier, 2008; Reisel et al., 2012; Smith \& Schumacher, 2005). Students are often surprised by their placement recommendation; they generally expect to be placed into a higher/more challenging course than what is suggested. Past research has shown, in fact, that "students' high school mathematics curriculum [is] not a significant predictor of their college mathematics placement recommendation" (Davis \& Shih, 2007). Therefore, it is not surprising that incoming freshmen are regularly placed into mathematics courses different than what they might have expected after high school. Many colleges and universities across the nation use enforced mathematics placement exams to help ensure students are placed into a course that is appropriate for their skill level (Foley-Peres \& Poirier, 2008; Reisel et al., 2012; Smith \& Schumacher, 2005).

Many recent studies have investigated the use of placement tests for college mathematics courses (Bisk, Fowler, \& Perez, 2013; Foley-Peres \& Poirier, 2008; Reisel et al., 2012; Smith \& Schumacher, 2005). Most research has found that using a proctored, enforced placement test helps accurately place students into the mathematics course for which they are best prepared and in which they are most likely to be successful (Bisk et al., 2013; Foley-Peres \& Poirier, 2008; Reisel et al., 2012; Smith \& Schumacher, 2005). With this in mind, I believe it is important to ensure that the current placement test at URI is a valid, reliable measure of student mathematical ability, and that the corresponding policies and procedures currently in place are appropriate, clear, and effective. Further, the placement exam should accurately reflect the expectations of the prerequisite skills a student is expected to need in each mathematics course. Therefore, I 
have included students' university placement exam scores in this investigation of business mathematics success.

Not everyone is in support of enforcing a placement exam for college mathematics courses. Some believe a placement exam labels students and inhibits them from selfassessing their abilities (Jacobson, 2006) or lowers their confidence in mathematics (Britton et al., 2007; Davis \& Shih, 2007). Enforced, proctored placement exams for mathematics, while beneficial to many, may not be the best solution for every incoming college student. As educational researcher Eric Jacobson (2006) notes, a student who earns a low placement score but has "high motivation and willingness to work may, through extra effort, be able to jump ahead and succeed in higher-level courses than those prescribed" (p. 157). If the system in place is highly restrictive, then this group of students may miss opportunities for advancement. Often times, enforced placement exams also place students into classes less advanced than what they would have expected or what they would have chosen on their own, if given the option. Therefore, while students are generally more likely to be successful in the course they are placed into through a placement exam, they may then have some catching up to do upon completing that course in terms of their academic program (Reisel et al., 2012). Students who require additional mathematics courses are therefore sometimes less likely to complete a degree in a STEM or business program, as financial or emotional burdens may prevent them from staying at the university for more than four years (Jacobson, 2006).

Upon completion of a placement exam, approximately one in every three college freshmen is found to be in need of a remedial/developmental mathematics course, which generally does not count for college credit (Davis \& Shih, 2007; Jacobson, 2006). After feeling successful in mathematics in high school and being told they are in need of remediation in college through a placement exam, a student's confidence in their mathematical ability can be damaged (Britton et al., 2007; Davis \& Shih, 2007). Placing students in a course they can be successful in from the beginning, however, can increase 
their confidence once they are in the course and are performing well. Further, taking preliminary courses can help prepare students for the required follow-up courses in their majors, which they are also more likely to be successful in with appropriate initial placement (Ballard \& Johnson, 2004; Britton et al., 2007).

Currently, URI requires all incoming freshmen to take a placement exam during their summer orientation in order to determine which mathematics course will suit them best. This exam has only been proctored and enforced since the summer of 2015. Prior to this implementation, over the past decade, nearly $40 \%$ of all URI freshmen had failed their first mathematics course at the university (D. Libutti, personal communication, January 16, 2015). In response, the current placement exam is broken into three tiers: Tier A, Tier B, and Tier C. Tier A consists of mostly pre-algebra and introductory algebra material, Tier B consists of more advanced algebraic topics, and Tier $\mathrm{C}$ consists of trigonometry and precalculus material (J. Baglama, personal communication, March 25, 2015). Sample questions are included in Appendix F ("University of Rhode Island Department of Mathematics", 2015). Students who do not answer at least seven of the ten Tier A questions correctly are placed into a remedial, non-credit bearing mathematics course at URI (MTH 099). Students who move through Tier A successfully but do not answer at least seven of the ten Tier B questions correctly are placed into college algebra or finite mathematics courses (MTH 101, MTH 107, or the like). Students who move through Tier B but do not answer at least seven of the ten Tier C questions correctly are placed into precalculus courses (MTH 110 or MTH 111). Finally, students who complete Tiers A and B and answer seven or more of the Tier C questions correctly are placed into calculus (BUS 111, MTH 131, or MTH 141). Students are able to practice and prepare for the placement exam on a home computer before taking the assessment on campus, if they wish to (J. Baglama, personal communication, March 25, 2015).

\section{Gender}

Though some studies have debunked the idea that gender plays a significant role 
in a student's academic achievement (Frankenstein, 1997; Perini et al., 2009; Sanders \& Peterson, 1999), many students still believe that males tend to outperform their female peers in mathematics, business, and science courses (Berube \& Glanz, 2008; Blaszczynski, 2001; Hall \& Ponton, 2005). Further, some researchers have shown that success factors for male and female college students vary in mathematics-based courses, such as business courses (Alexander et al., 2009; Leaper et al., 2012; Smith \& Schumacher, 2005). Therefore, I have chosen to examine gender as one of my variables of interest for this dissertation work.

Though the gender gap in mathematics achievement has narrowed over the last 20 years, the number of females majoring in and pursuing mathematics-based careers has not increased at the same speed (Berube \& Glanz, 2008; Leaper et al., 2012; Paris \& Decker, 2012; Sanders \& Peterson, 1999). In business-related fields specifically, even though $42 \%$ of all MBA students are women, only $3.4 \%$ of the Fortune 100 Company CEOs are females (Paris \& Decker, 2012). In a recent study of 439 students in a freshmen-level business mathematics course, male participants reported that they felt males alone possessed business leadership characteristics, while female participants believed that both men and women had leadership potential, though males were more likely fit for leadership roles (Paris \& Decker, 2012). Research has consistently shown that a student's experiences in K-12 mathematics courses will help them develop their attitudes towards mathematics and determine their ability in the subject: "differences in math achievement are not biological, but the product of social and cultural factors, expectations, and confidence levels" (Sanders \& Peterson, 1999, p. 48).

With these gender gaps in mind, it is important to consider various theories and empirical studies related specifically to how college students learn and the differences that may exist between male and female students. Popular theories and models on student learning in college, developed by William Perry in 1970, Mary Field Belenky and her colleagues in 1986, and Patricia King and Karen Kitchener in 1981, as well as some of 
the limitations of those models, are described briefly below. Forms of Development in College Students (Perry, 1970)

In the late 1960s, educational psychologist William Perry (1970) developed a model on the epistemological development of undergraduate college students. He found that students tend to move through a continuum as they age and develop, consisting of four key stages: dualism, multiplicity, contextual relativism, and constructed knowledge (Perry, 1970). Students in the dualism stage believe that professors or other authority figures have the knowledge and that it must be given to students. In the multiplicity stage, knowledge becomes less black and white to students and questions regarding what truth and knowledge are begin to develop (Perry, 1970). Only once students reach the contextual relativism stage can genuine learning start to occur, as students realize that support is needed in order for solutions to exist and that "truth" may not be the same for all individuals. The final stage, constructed knowledge, is where experience and personal reflection begin to play a key role in a student creating his or her own knowledge (Perry, 1970). Similar to Grow's Staged Model of Self-Directed Learning, explained in the previous chapter, this final stage leads to self-directed learning and critical dialogue.

Perry offered a comprehensive model to describe how college students learn and create meaning. He also theorized that students react to new experiences through either assimilation, where they are able to make connections to prior knowledge, or accommodation, when no prior knowledge is available, similar to Jean Piaget (Hofer \& Pintrich, 1997; Piaget, 1964). While Perry's model (1970) explains how students in college develop their intricate "ways of knowing", there are weaknesses to his theory. The major limitations of this model are that (1) the study was performed at Harvard University, an elite private school that was likely not representative of all college students in terms of socioeconomic status, race, or past achievement, and, perhaps more importantly, (2) only males were included in Perry's study. In response to these key limitations, human development specialist Mary Field Belenky (1986) and her colleagues 
studied how adult women construct knowledge through various stages of development in college.

Women's Ways of Knowing (Belenky, Clinchy, Goldberger, \& Tarule, 1986)

Though similar to Perry's model (1970), Belenky found some key differences in women's "ways of knowing" throughout higher education that are important to recognize (Belenky et al., 1986, p. 3). According to Belenky's model, women tend to grow and develop through a five-step continuum, similar to Perry's four-stage model, with steps including: silence, received knowledge, subjective knowledge, procedural knowledge, and constructed knowledge (Belenky et al., 1986). While often feeling silenced in initial college experiences, most women believe the professors have the knowledge, the influence, and the power. During this first stage, women generally have little confidence and do not believe they have any authority or a voice worthy of being heard. In the received knowledge phase, they still do not question authority, but begin to feel more capable of receiving (though still not creating) knowledge on their own (Belenky et al., 1986).

During the subjective knowledge stage of Belenky's model, college women begin to search for answers within themselves and believe that their own experiences are important in building understanding. They begin to develop their voice, but still often lack confidence. By the time they reach procedural knowledge, women realize that knowledge must be gained or built, not given, and they start to question the beliefs they held in earlier stages (Belenky et al., 1986). Finally, similar to Perry's (1970) model and Grow’s Staged Model (Merriam et al., 2007), women reach a stage of constructed knowledge, where they find power in their voice and their own personal experiences and realize that they can create and question their own knowledge, leading to self-direction and self-regulation of learning.

A limitation to Belenky's (1986) model is that she researched mostly older women who were returning to college after some time; no men were included in her 
research. The research was also performed over 25 years ago, so recent replications of her findings should be performed to ensure present-day students still follow these general phases of development. However, the students in Belenky's research represented a variety of races, socioeconomic statuses (though all participants were still privileged to some degree as college students), and were between 16 and 60 years of age (Belenky et al., 1986). Thus, this was more representative than Perry's research with mostly wealthy, young, white males. Even with these limitations in mind, both of these models focus on college students and how male and female students learn and develop. Therefore, both were essential to consider while analyzing and understanding my own research with college students. Professors King and Kitchener focused on both male and female college students and researched specifically how students develop their reflective capacities and reasoning skills. Their reflective judgment model is described in the following section.

\section{Reflective Judgment Model (King \& Kitchener, 1981)}

In the 1980s, higher education professors Patricia King and Karen Strohm Kitchener developed a comprehensive model to describe how people approach and evaluate various ill-structured problems, or problems that do not necessarily have a clear or unique answer (King \& Kitchener, 1981; King \& Kitchener, 1993; King \& Kitchener, 2004). They continue to develop and test their Reflective Judgment Model (RJM) today, as do many other researchers in higher education. Since the "real world problems" that business students must solve are often ill-structured or ill-posed, it is important to consider King and Kitchener's staged model for college students' development as well. The reflective judgment model focuses on how students reflect on these problems and the potential solutions they approach, knowing that no single solution is available. Though the RJM has seven stages, they are often broken into three main categories to consider: pre-reflective thinking (consisting of stages 1,2, and 3), quasi-reflective thinking (consisting of stages 4 and 5), and reflective thinking (consisting of stages 6 and 7), 
which show similar results as Perry and Belenky's models (King \& Kitchener, 1993; King \& Kitchener, 2004).

Pre-reflective thinkers are often unable to understand that ill-structured problems even exist, as they believe that all questions have definite answers, which can be either discovered through direct observation or given from authority figures (King \& Kitchener, 1993). Many high school students (and younger students) are on this level of thinking, and often college freshmen who are not given opportunities to reflect and discuss uncertainties in classroom settings are also stuck in this stage of thinking. Other college students have generally developed beyond this stage and are instead considered quasireflective thinkers who recognize that knowledge is not always certain and must be constructed, not given (King \& Kitchener, 1981; King \& Kitchener, 2004). Thinkers on this level still may struggle to approach ill-structured problems, as they are "perplexed about how to form a judgment when faced with uncertainty" (King \& Kitchener, 1993, p. 31), recognizing that knowledge is context-specific and subject-dependent. While most college freshmen are in these stages of reflective thinking, King and Kitchener (1993) found no significant differences in development between the genders in reflective capacities.

Typically only doctoral students and advanced college graduates are found to be on the final reflective thinking stage (King \& Kitchener, 1981; King \& Kitchener, 1993). Here, knowledge is personally constructed and opposing viewpoints are considered, respected, and evaluated. It is in this level of thinking where "one's understanding of reality is not given but must be actively constructed and that knowledge must be understood in relationship to the context in which it was generated" (King \& Kitchener, 1993, p. 32). Since most college students are not yet at this stage of reflective thinking, it is important for college professors to recognize that students need opportunities to reflect on and discuss ill-structured problems in the classroom to enhance their development and reflective abilities. Reflective thinking should be encouraged through cooperative group 
work, classroom dialogue, and personal connections to the problems and solutions posed (King \& Kitchener, 1993).

With all of the facts presented above in mind, I too have used independent variables including mathematics SAT score, high school GPA, college mathematics placement exam score, and gender in my analysis. These variables and their relationship to college mathematics success have been examined in the past and generally have been shown to explain at least some of the variance in student mathematics achievement. However, since little quantitative research exists that examines how affective factors might also influence course success, I hope to have addressed this gap with my research. My rationale for choosing each of these cognitive and affective variables (the amount of time a student devoted to mathematics each week, the number of mathematics classes that student missed, the student's attitudes towards mathematics, and the student's level of mathematical anxiety) is explained below.

\section{Cognitive/Affective Measures}

\section{Time Devoted to Mathematics/Course Attendance}

Contemporary literature reveals that as students enter college, they are often unaware of how much time they will need to devote to mathematics in order to be successful in mathematics-based courses (Barnes et al., 2004; Zelkowski, 2011). Many college professors do not collect suggested homework assignments or regularly grade informal assessments. Further, while attendance is required in high school, many professors do not take attendance. This newfound freedom forces students to make decisions about whether to attend class and how much time they should spend working on the subject outside of class. Sometimes, it takes students a while to find the right balance, though very few researchers have explored this concept. An increasing number of college mathematics professors tend to label this adjustment time as a lack of preparedness, which they frequently blame on high school teachers, and many professors carry the belief that it is not their responsibility to help students find this balance (Barnes 
et al., 2004; Zelkowski, 2011). Many middle school and high school teachers provide hands-on learning experiences with opportunities for guided practice during class time. The general notion in these grade levels tends to be that most of the learning happens inside the classroom, which is often not the case in college (Zelkowski, 2011). This may contribute to why college freshmen fail to realize that they will frequently be required to do much of the learning and assigned work in college on their own, separate from class time.

In general, students entering college are often unaware of the changes in expectations of how they should spend their time. Researchers Barnes, Cerrito, and Levi (2004) discovered that only $4 \%$ of freshmen at the University of Louisville expected to spend five or more hours per week on mathematics outside of class, though the course syllabus for each class explicitly stated that students would need to spend between six and nine hours per week outside of class in order to be successful. Nearly $10 \%$ of the incoming students surveyed reported that they did not expect to spend any time outside of class working on or studying for mathematics, while another $25 \%$ of students expected to spend less than an hour per week on mathematics (Barnes et al., 2004). Unfortunately, this misunderstanding about the workload in college leads many students to fail their freshmen year mathematics courses as they try to adjust to new expectations and responsibilities.

A key limitation of the existing literature regarding attendance and time spent on mathematics is the lack of focus on business mathematics courses. Therefore, I believe it was important to examine how much time business students reported spending on mathematics over the course of the semester and whether this corresponded to their course average. Specifically, during the first week of the Fall 2015 semester, I asked students how many BUS 111 class sessions they predicted they would miss and how many hours per week they planned to spend outside of BUS 111 class working on mathematics. This allowed students to start thinking about these questions and 
considering their plan for the semester, while also allowing me to gauge how students perceived the workload and their initial notions on the importance of attendance in a college business mathematics course. During the last week of the semester, I asked students to record how many BUS 111 mathematics classes they actually missed in total and how much time, on average, they spent working on mathematics outside of class each week. I compared this pre- and post-survey data to look for significant differences over time. I also included these factors as variables in my multiple regression model to see if they explained any of the variance in course average, which I explain further in chapter four where I discuss my methodology.

\section{Self-Efficacy/Confidence and Attitudes About Mathematics}

Self-efficacy is the "personal belief in capability to organize and execute actions to produce outcomes" (Hall \& Ponton, 2005, p. 27). While lowering self-efficacy seems to occur with little effort (and is often unintended), increasing a student's self-efficacy, especially by the time they reach college, tends to be seen as more of a challenge. Most people associate self-efficacy with confidence, and a general notion among professors is that confidence is up to the student: the professor has little control over improving or damaging a student's self-efficacy (Corbishley \& Truxaw, 2010). Below, I describe ways in which self-efficacy is generally constructed or deconstructed in college mathematics as well as how I examined this construct and its potential to impact student achievement in business mathematics through my own research.

Many high schools across the nation have been increasing the number of mathematics courses required for graduation in an attempt to ensure students are better prepared for college (Davis \& Shih, 2007; Long et al., 2009; Reisel et al., 2012). This has been happening, in varying degrees, since the introduction of A Nation At Risk in 1983. Unfortunately, increasing the number of required courses sometimes leads to "course credit inflation": high school transcripts with certain mathematics courses listed that do not accurately reflect the content of the curriculum in that course (Long et al., 
2009, p. 5). Students are taking courses titled Algebra 2, for example, though the curriculum includes what has historically been considered Pre-Algebra or Algebra 1 material. Furthermore, due to the corresponding trends of social promotion and course grade inflation, which are still present in many K-12 schools, students sometimes receive passing grades in these courses without actually having learned the content (Long et al., 2009). As these inflations are leading to false expectations and are thus not doing our nation's students any favors, some policy makers are hopeful these issues will be suppressed with the implementation of the Common Core State Standards, though that remains to be seen.

Students who fall victim to social promotion and/or course credit inflation are often unaware of the corresponding effects. They believe they have sufficiently demonstrated knowledge in a course and are therefore prepared to advance to the next class, or begin their first course in college. However, those students who are entering colleges with transcripts inaccurately reporting that they have demonstrated a certain level of mathematical competency are often unprepared for the college courses that follow (Davis \& Shih, 2007; Long et al., 2009; Reisel et al., 2012; Smith \& Schumacher, 2005). As these students start college and struggle with the material in their first mathematics course, they become frustrated with their inability to earn the high grades they were accustomed to earning in high school. Social promotion often causes students to overestimate their abilities and subsequently sign up for college mathematics courses for which they are inadequately prepared (Barnes et al., 2004; Davis \& Shih, 2007; Reisel et al., 2012). As students enter these college-level mathematics courses and realize that they do not understand the material presented, their confidence diminishes and anxiety levels rise.

After experiencing a series of frustrations and failures in college-level mathematics courses, many students also lose trust in mathematics instructors at both the high school and college level. They therefore begin to doubt the value and relevancy of 
mathematics in their lives. This lack of preparedness and confusion after high school "success" can lead to low self-efficacy and lack of confidence among incoming college freshmen as they enter mathematics courses (Kesici \& Erdogan, 2009). Unable to trust high school transcripts alone, many colleges and universities require students to take an entrance exam to determine which mathematics course would be most aligned with their current ability, as described in greater detail earlier in this chapter (Reisel et al., 2012; Smith \& Schumacher, 2005).

The number of students being placed specifically into developmental or remedial mathematics courses has grown exponentially over the past few decades (Barnes et al., 2004; Bisk et al., 2013; Hall \& Ponton, 2005; Hammerman \& Goldberg, 2003; Reisel et al., 2012). Being placed in such a course carries a certain stigma, as students begin to wonder: What needs to be developed? What about my mathematical skill set needs to be remedied? The mathematics course designed to prepare students for BUS 111 at URI, MTH 110, is a remedial course and thus many students avoid taking it. While students earn college credit for taking MTH 110, it does not count towards their degree completion, nor does it count as a general education mathematics course should they decide to switch majors. The self-efficacy of students in remedial courses is generally very low, often leading to failing grades (Barnes et al., 2004). Being told they need development can lower self-efficacy and cause students to believe they are incapable of performing well in mathematics. Not surprisingly, a high percentage of students fail these courses, as low self-efficacy leads to a negative self-fulfilling prophecy (Taylor, 2008; Waycaster, 2004). These students also tend to hold negative attitudes towards mathematics and their instructors even after moving into more advanced courses. Many students resent being required to take these courses, especially when they know that they will not receive college credit (Hammerman \& Goldberg, 2003). However, as students enter these courses, they often also realize that they truly are in need of this remediation, 
leading them to develop low confidence in their ability to accurately assess their own skill set and be successful in mathematics or business mathematics courses.

Other students enroll in more advanced courses, such as BUS 111, only to discover that they may be in need of remedial help, which can lead to frustration and a severe blow to their mathematical self-efficacy (Kesici \& Erdogan, 2009). Current literature reveals that even students in non-remedial mathematics courses are at high risk of failing during their freshmen year due to a general lack of confidence in mathematical ability (Hall \& Ponton, 2005). However, student success in college mathematics courses has been found to be positively correlated with a student's corresponding success (in terms of retention and GPA) in college in general and thus was essential to examine (Hall \& Ponton, 2005; Smith \& Schumacher, 2005).

In 2005, researchers Hall and Ponton carried out a mixed-methods study that examined the self-efficacy of college freshmen enrolled in remedial mathematics courses. The researchers discovered that previous performance and perceived mathematical ability were key elements for success in college mathematics. Students who have not previously been successful in mathematics are more likely to feel nervous about their college mathematics course and are therefore less likely to choose majors in business, STEM, or other mathematics-based fields (Reisel et al., 2012). In addition, Hall and Ponton (2005) discovered that students who are enrolled in higher-level courses, such as calculus or statistics/probability, tend to feel much more confident in their mathematical abilities than their peers who are enrolled in "developmental" or remedial courses. Students in developmental courses also tend to hold negative attitudes towards mathematics and their instructors, often failing to see the relevancy of mathematics in their daily lives. However, students in the United States in general, regardless of their placement, lack confidence in mathematics (Tobias, 1987).

Current research investigating the impact of positive attitudes in college students suggests that a strong correlation exists between attitude (especially confidence) about a 
course and corresponding course grade (Hall \& Ponton, 2005; Kesici \& Erdogan, 2009; Tapia \& Marsh, 2004). Developing a positive attitude towards mathematics and increasing students' mathematical self-efficacy has consequently become a recent goal of many educators. Research has shown that students in middle school and high school who enjoy and value mathematics are more likely to earn high grades in their mathematics courses (Tapia \& Marsh, 2004). Further, mathematics researchers Martha Tapia and George Marsh (2004) found that "attitudes toward mathematics, especially enjoyment, confidence, and perceived usefulness of mathematics influence persistence in mathematics" in middle school and high school (p. 4). This is likely to be true with students in higher education settings as well. However, most college students are not asked about nor encouraged to reflect on their self-efficacy or perceptions of mathematics (Corbishley \& Truxaw, 2010; Frankenstein, 1997; Thiel et al., 2008). Therefore, in my research, I felt it was appropriate to examine college student attitudes towards mathematics, including confidence, to see the impact those attitudes may have had on student achievement in BUS 111.

\section{Mathematical Anxiety}

Typically, as a student's confidence in mathematics decreases, the anxiety they feel about mathematics simultaneously increases. Mathematical anxiety is generally defined as "the panic, helplessness... and mental disorganization that arises among some people when they are required to solve a math problem" (Tobias \& Weissbrod, 1980, p. 65). A typical notion about anxiety held by professors is that if students work hard and study mathematics, they should not feel anxious. During interviews for a qualitative research study in the Midwest, one professor claimed, "I'm sure if [students] understood [mathematics], they'd be less anxious and maybe they wouldn't hate it so much" (Mesa, 2012, p. 61). If students do feel anxious, professors often believe it is not their role to ease that anxiety, nor do they have much control over it (Kesici \& Erdogan, 2009). I disagree. Below, I describe some of the common triggers of anxiety and how I measured 
anxiety in my own research to examine how it may be related to student achievement in business mathematics.

Often, students in college-level courses experience severe mathematical anxiety because they are not prepared "in terms of workload expectations, high standards of many college mathematics faculties, and skills necessary for complex mathematical thinking" (Corbishley \& Truxaw, 2010, p. 73). This anxiety can be detrimental to overall student achievement: students who exhibit higher mathematical anxiety are less likely to be successful in mathematics courses (Corbishley \& Truxaw, 2010). When a student feels confident about their mathematical knowledge and competency, they are more likely to stay calm during mathematics and approach new problems with a level of comfort or even excitement, rather than nervousness. This allows them to reason logically through a variety of problems at multiple levels of difficulty (Kesici \& Erdogan, 2009).

As stated in the previous section, many college freshmen are currently being placed into "developmental" or "remedial" mathematics courses due to low placement test scores and a perceived lack of college readiness. Unfortunately, students in these courses tend to exhibit more anxiety and less confidence than their peers who are taking non-remedial courses (Hall \& Ponton, 2005). In the early 1990s, educational researcher Linda Serra Hagedorn and her colleagues (1994) discovered that over $40 \%$ of college freshmen across the nation were failing their developmental mathematics courses. That number has not significantly decreased in recent years (Reisel, et al., 2012). Educators Frost, Coomes, and Lindebald (2009) found that only about $30 \%$ of students who were taking remedial mathematics courses at Washington State University were expected to receive a passing grade. This low passing percentage is mirrored at URI (A. Armstrong, personal communication, July 23, 2015).

Too often, students are turned away from majoring in business or STEM fields because of their negative experiences or persistent failure in developmental mathematics 
courses (Hall \& Ponton, 2005; Johnson, 2007; Parker, 2005; Reisel et al., 2012). These extremely high student failure rates also lead already anxious students to develop even more anxiety and negativity towards mathematics (Frost et al., 2009; Hagedorn et al., 1999; Hammerman \& Goldberg, 2003; Tobias, 1987). Some students taking BUS 111 at URI take remedial mathematics over the summer to prepare for the course if they do not feel ready for college mathematics or do not place into BUS 111. These students especially seem to report feeling anxious when approaching problems and describe negative experiences in previous mathematics courses. This is not surprising, as past experiences with failure tend to lead to high levels of anxiety in mathematics (Taylor, 2008).

Professors Sahin Kesici and Ahmet Erdogan (2009) performed a mixed-methods study to investigate success in various college mathematics courses. The researchers found that when students could not see the applicability of the mathematics they were learning, they were more likely to feel anxious. Similarly, when professors used the same delivery methods or displayed a negative attitude towards students, it led to mathematical anxiety amongst students. Students who were given a task that they believed was purposeful or relevant to their lives, on the other hand, were less likely to give up on the task and more likely to develop effective problem solving skills (Kesici \& Erdogan, 2009).

Similar to Hall and Ponton's findings (2005), Kesici and Erdogan (2009) performed a mixed-methods study to investigate the relationship between course grades and anxiety in mathematics. They discovered that mathematical anxiety was negatively correlated with performance in mathematics courses (Kesici \& Erdogan, 2009). Further, they found that many students suffered from mathematics anxiety during college because of their high school instruction, stress from exams, and experiences with failure, which inhibited their overall ability to be successful (Kesici \& Erdogan, 2009). College students' attitudes towards mathematics were also strongly negatively correlated with 
their corresponding levels of anxiety in mathematics. College students with high anxiety tended to depend more on the instructor and were often unable to self-regulate their learning, causing them to believe mathematics was externally known and not connected or relevant to their lives outside of the classroom (Kesici \& Erdogan, 2009; Tobias \& Weissbrod, 1980).

Researchers, professors, and students alike generally recognize that mathematical anxiety is one of the most frequently occurring academic anxieties, and can be detrimental to a student's learning experience (Corbishley \& Truxaw, 2010; Kesici \& Erdogan, 2009). In such a math-phobic culture, when I tell people I teach mathematics in college, typical responses include: "Oh I hated math" or "Wow, you must be loved" (sarcastically) or "Why would you choose to do that?" or sometimes just "Better you than me." In a study conducted in 2003 , researchers discovered that anxiety levels in some students could predict mathematical performance and motivation better than actual mathematical ability (Ironsmith, Marva, Harju \& Eppler, 2003). Therefore, lowering mathematical anxiety could lead to higher student achievement in college business mathematics courses, and deserves special attention. For this reason, I included mathematics anxiety as one of the variables in my dissertation. I believe anxiety negatively affects many students and may be a strong predictor of success in college mathematics courses:

The well-being of our nation depends on the ability of our youth to succeed with mathematics. For this to happen we must make mathematics visible by destroying myths, overcoming anxieties, and removing barriers. Once mathematics is out in the open, unencumbered by mystery and obfuscation, fear will diminish and confidence will increase. (Tobias, 1987, p. xviii)

\section{Business Mathematics}

According to the National Business Education Association (1995), “computational skills are essential for students as they become citizens, consumers, wage 
earners, employees, employers, investors, inventors, and entrepreneurs. Making decisions in each of these various roles requires quantitative calculations" (p. 55). Thus, business courses focusing on computational skills are required for most freshmen who want to major in business across the nation (Blaszczynski, 2001; Smith \& Schumacher, 2005). Colleges of business have found mathematical ability to be a "critical filter" for students to access higher-level jobs in the business field (Blaszczynski, 2001, p. 2). As a result of this important finding, at URI, similar to many universities, students must successfully complete a business mathematics course (BUS 111) before continuing their degree program in the College of Business.

As explained above, a number of studies have examined the perceptions that professors and students hold about readiness for college mathematics (Blanchard, 2008; Corbishley \& Truxaw, 2010; Johnson, 2007; McDuffie \& Graeber, 2003; Zelkowski, 2011). Over the past two decades, some qualitative research has also been devoted to student self-efficacy in mathematics, student's attitudes towards mathematics, and mathematical anxiety, as these factors seem to be linked to student achievement (Hall \& Ponton, 2005; Kesici \& Erdogan, 2009; Parker, 2005; Thiel et al., 2008). Few studies examine business mathematics courses, though business is currently the most popular major in the United States (U.S. Department of Education, National Center for Education Statistics, 2015). Most literature seems to focus on the problems with the current conditions of mathematics in higher education (Ballard \& Johnson, 2004; Blanchard, 2008; Corbishley \& Truxaw, 2010; Hall \& Ponton, 2005; Johnson, 2007; Reisel et al., 2012).

A key weakness in the current literature is the general lack of proposed solutions to these issues. While some general solutions are offered (Frost et al., 2009; Long et al., 2009; Thiel et al., 2008; Zelkowski, 2011), most emphasize K-12 teaching solutions; very few focus on proposed changes in higher education. Those that do offer solutions in higher education (for example: suggestions to increase student engagement, help students 
feel less anxious, or offer professional development on pedagogical practices) suggest changes that are too broad to be applied without further, detailed suggestions on implementation (Frost et al., 2009; Thiel et al., 2008). For example, specific programs designed to lower mathematical anxiety in college or sample curricular plans that enhance student self-efficacy are missing. Further, the general lack of agreement on what it means to be college-ready and how to adequately prepare students is a limitation of the current literature. Few researchers have instead investigated the idea of student-readiness and the lack of adequate preparation available for colleges to better prepare for incoming freshmen.

Another limitation in the contemporary literature is the lack of research regarding business mathematics courses. Because business is the most popular major at many large universities, most business programs offer their own mathematics courses, separate from the typical mathematics department. These courses often focus on applications that require real-world problem solving and mathematical literacy, which may not be highlighted in other mathematics courses that emphasize formula recall and repetition (Smith \& Schumacher, 2005). Therefore, more research on students' experiences in business mathematics is necessary to help ensure students are being effectively served in this major.

The existing research that examines student success in business mathematics has found limited results (Samad et al., 2009; Smith \& Schumacher, 2005; Truell \& Woosley, 2008). Researchers Samad, Tuah, and Haron found that students' attitudes, family backgrounds, and the method of lecture they were exposed to impacted the course grades of many students majoring in business in Malaysia (2009). Mathematics professors Truell and Woosley found that mathematics SAT scores were a good predictor of graduation rates for business majors at a large university in the Midwestern United States (2008). Similarly, in 2005, mathematics professors Schumacher and Smith performed a multiple regression analysis to search for variables that best predicted mathematics GPA 
for actuarial business students at Bryant College in Rhode Island. The researchers examined mathematics SAT scores, verbal SAT scores, high school percentile ranks, grades earned in college calculus courses, and scores on the college's mathematics placement exam as predictor variables. They found that differences existed in the results between male and female actuarial students. However, the authors indicated it was likely that other confounding variables, such as attitude and perceptions, played a significant role in a student's success (Smith \& Schumacher, 2005). They encouraged future researchers to include these variables in a multiple regression model, which my study has done.

\section{BUS 111 at URI}

BUS 111 is a foundational, gateway mathematics course required for all URI business majors. Students who do not take and pass this course while simultaneously maintaining at least a 2.5 cumulative GPA will not be permitted into the College of Business. Historically, the failure rate in the course has been approximately $31 \%$ each semester (D. Libutti, personal communication, January 16, 2015). Topics explored in the course include: mathematics of finance (time value of money), linear programming, technology in business, break-even analysis, cost-benefit analysis, quadratic and exponential functions in business, differentiation, optimization methodology, and applications of optimization in business. See Appendix G for a sample syllabus from a typical BUS 111 course.

\section{Research Questions}

There is currently a distinct lack of research that examines the relationship between success in college business mathematics courses and student attitudes, mathematical anxiety, perceptions of instructional effectiveness, and time devoted to the subject. The little research that has been performed in this area has produced results that are limited to small case studies in countries other than the United States (Samad et al., 2009), or are limited to non-affective measures and are thus inconclusive (Smith \& 
Schumacher, 2005; Truell \& Woosley, 2008). Insight on student attitudes, confidence, and perceptions may help reveal other predictors of success in business mathematics, allowing for better advising and possible curricular and instructional changes. The overarching research question that was explored in this study was: What factors best predict success in a foundational business mathematics course (BUS 111 at URI)? Follow-up questions were:

1. Are these predictive factors different for male and female students?

2. How do student attitudes towards mathematics change after taking BUS 111 at URI?

3. How does student mathematical anxiety change after taking BUS 111 at URI?

4. What is the relationship between perceived instructional quality and success in the BUS 111 course at URI? 


\section{CHAPTER FOUR: \\ RESEARCH DESIGN AND METHODOLOGY}

In preparing for this dissertation research, I explored and considered many

methodologies and reviewed current literature to better understand which methods were most frequently used in analyzing student success in college mathematics and business courses, as well as the strengths and limitations of those designs. In this chapter, I explain the rationale for my overall choice of quantitative methodology for my dissertation considering my research questions, my philosophical worldview, and my intended audience. I then describe my specific methodology and research design (multiple regression analysis using survey data). I also examine the details of my data collection and analysis procedures including the specific instruments and surveys used to investigate each of the variables. Finally, I describe some of the limitations of multiple regression analysis as well as my insider position as a past student and current instructor at the institution where I conducted research (the University of Rhode Island), and then how I addressed this issue throughout my data collection and analysis.

\section{Arriving at a Quantitative Methodological Approach}

Many factors must be considered when determining an appropriate methodology for research. Methodology should be chosen according to the research question being addressed, the researcher's worldview, and the intended audience (Creswell, 2014; Fraenkel, Wallen, \& Hyun, 2011; Patton, 2002). Therefore, it is important that a researcher does not necessarily deem herself a "quantitative researcher" or a "qualitative researcher" and then develop questions that involve those methods; rather, she should be open to choosing methodologies that best fit the questions that develop naturally in her work, her philosophical worldview, and her anticipated audience.

\section{Research Question}

Researchers should ensure that their research question guides their methodology and not the other way around (Creswell, 2014; Fraenkel et al., 2011). Typically, questions that require an inductive analysis are best examined with a qualitative research design, 
whereas questions that are more deductive in nature are better addressed with a quantitative design (Creswell, 2014; Fraenkel et al., 2011; Patton, 2002). Thus, only once the researcher has identified the specific question or set of questions that he or she wants to investigate can the corresponding methodological procedures be effectively determined.

If the overarching research question in a study focused on the experiences of students within a certain culture or classroom, for example, qualitative methods such as a case study or ethnography with data sources such as interviews and observations would likely be an appropriate corresponding methodology (Patton, 2002). If the research question instead focused on differences in test scores before and after a specific treatment within a certain group, quantitative methods such as paired $t$-tests would likely be a more appropriate methodology (Fraenkel et al., 2011; Huck, 2012; Weiss, 2008). Specifically, if the question includes an interest in "the identification of factors that influence an outcome, $\ldots$ or understanding the best predictors of outcomes, then a quantitative approach is best" (Creswell, 2014, p. 20). Mixed-methods research designs are often employed to collect and interpret the results of connected quantitative and qualitative data. These designs are generally used when the research question posed cannot be answered using quantitative or qualitative methods alone (Creswell, 2014; Fraenkel et al., 2011; Patton, 2002).

Throughout my work as an instructor in the College of Business Administration (CBA) at the University of Rhode Island (URI), questions have naturally developed that I would like to investigate and shed light on through rigorous research. The overarching question that I was always most interested in researching was: What factors best predict success in a foundational, business mathematics course (BUS 111 at URI)? Therefore, according to Creswell (2014), quantitative methods needed to be employed. Specifically, because I was interested in more than one independent variable and was exploring possible predictive relationships among these variables, multiple regression best addressed 
my research question (Fraenkel et al., 2011; Huck, 2012; Weiss, 2008). Further, since I was investigating factors such as attitudes and feelings of a specific population, quantitative survey research was the recommended design (Creswell, 2014; Fraenkel et al., 2011).

\section{Philosophical/Theoretical Worldview}

As introduced in chapter two (theoretical framework), in my personal and professional life, I tend to see the world from both a post-positivist and a pragmatic lens. As a post-positivist, I generally believe that outcomes can often be linked to specific causes (Creswell, 2014). I seek to develop explanations through research that can be used to describe the relationships amongst certain phenomena. As a pragmatic researcher, I seek to find answers to research questions that can be directly applied in educational settings (Creswell, 2014). I believe one of the key purposes of research is to identify current problems and then offer solutions or clarity to those problems that can ultimately be used to improve educational practices. Thus, in my dissertation research, I hoped to find quantitative regression models that could be used to inform students, instructors, and advisors of the factors that can help predict student success in business mathematics at URI. I hope that, with the support of my findings, instructional or curricular changes can be implemented as needed.

In addition to my pragmatic, post-positivist worldview, I also believe that true teaching and learning cannot take place without considering the experiences, beliefs, and perspectives of the students in the classroom. The student plays a vital role in constructing his or her knowledge; the student is not a passive object upon which an instructor can simply impart information through lecturing (Frankenstein, 1997; Von Glasersfeld, 2005; Vygotsky, 1978). As a student-centered practitioner and researcher, I argue that learners must be provided with opportunities to reflect on their experiences in mathematics and explore their attitudes towards the subject if they are to be successful. Most of the current quantitative research that examines mathematics success for college 
students focuses on grades the student previously received, scores on standardized tests, and GPA (Bridgeman et al., 2008; Smith \& Schumacher, 2005; Samad et al., 2009; Truell \& Woosley, 2008).

Students are more than test scores. Most colleges require standardized test scores and high school GPAs for admission. From my student-centered stance, I believe students' previous experiences and perceptions of mathematics play a significant role in their achievement in college mathematics courses. Therefore, I chose to examine affective and cognitive variables that focused on the student, such as perceived effectiveness of their instructor (Thiel et al., 2008), student attitudes towards mathematics (Hall \& Ponton, 2005; Tapia, 1996), student level of mathematical anxiety (Ironsmith et al., 2003;

Mahmood \& Khatoon, 2011; Tobias, 1987; Tobias \& Weissbrod, 1980), the time a student devoted to mathematics (Corbishley \& Truxaw, 2010; Parker, 2005), and student confidence (Hall \& Ponton, 2005) in this analysis.

\section{Intended Audience}

Researchers must also keep their intended audience in mind when choosing the appropriate methodology (Creswell, 2014). In higher education, qualitative, quantitative, and mixed-methods designs are common, though in some higher education departments, certain methodologies tend to be more highly valued than others (Guido, Chávez, \& Lincoln, 2010). Therefore, as a researcher interested in investigating college student achievement in a business mathematics course, it was important for me to understand which methodological research designs were most valued in these corresponding departments (namely: college business departments and college mathematics departments).

My main goal in analyzing the results of this study and writing this dissertation was to elicit change as necessary in the foundational mathematics courses in the College of Business Administration (CBA) at URI. Now that my data has been analyzed, I hope to present my findings during our annual Fall conference and offer potential implications for 
practice while also suggesting future research. The Dean of the CBA as well as the Assistant Dean and fellow faculty members are very interested in enhancing student opportunities for learning in the College. Currently, the faculty and administrators in the College of Business are very numbers-oriented and generally place greater value on large, generalizable, quantitative research. These studies tend to carry more importance in the CBA and thus, researchers who carry out these types of research designs are more likely to be recognized.

This is not to say that staff and faculty members in the CBA are not interested in learning about the experiences of their students. Quite the contrary, in fact: many professors in this college are constantly seeking innovative ways to reach more of their students and enhance their teaching practices. However, before they are willing to enact major change, most are interested in seeing data supporting the fact that the change(s) implemented will benefit the majority of their students. Some have expressed concern that changes may only help a small handful of students and may actually have a negative effect on other students. Therefore, I believe if I can first present this quantitative data, which both represents the significant factors of student achievement from a large sample of students and also supports my claim that student achievement depends on more than past GPAs and SAT scores, the CBA will be more likely to support future research (either qualitative or quantitative) I propose. After this dissertation is complete and my results have been shared, I believe I will have their support in investigating other issues in the college. For example, in future studies, I would like to explore potential curricular design issues, instructor effectiveness, and general student learning experiences in the College of Business Administration. These issues may be better explored using qualitative or mixedmethods research designs.

Considering my overarching research question, philosophical/theoretical worldview, and specific intended audience, according to research experts (Creswell, 2014; Fraenkel et al., 2011), a quantitative multiple regression research design was the best 
methodological choice for this research. Much energy and deliberation went into arriving at this research approach and various alternatives were considered and discussed with my colleagues and peers. The figure on the following page (Figure 4) visually represents how I was originally led to this general methodological strategy based on each of the elements discussed above.

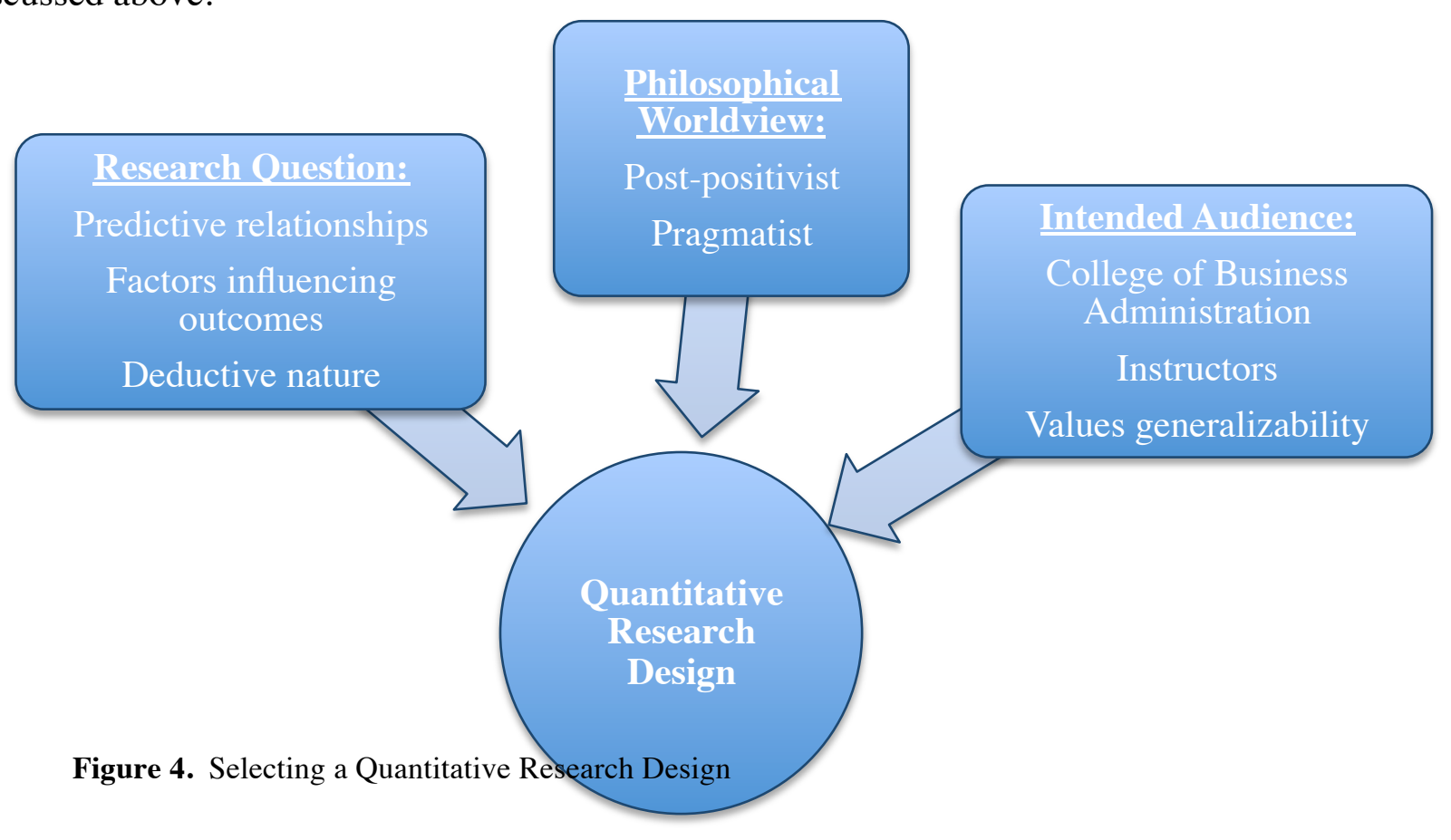

\section{Choosing Multiple Regression}

I was interested in exploring predictive, quantitative relationships in this dissertation using multiple independent variables. Thus, multiple regression was the best choice for overall methodology (Huck, 2012; Weiss, 2008). Multiple regression is a statistical procedure which yields an equation that can be used to predict values of the dependent variable of interest given values of the statistically significant independent variables included in the model (Chen, Ender, Mitchell, \& Wells, 2003; Hair, Anderson, Tatham, Black, 1998; Huck, 2012; Kuter, Nachtsheim, \& Neter, 2003; Weiss, 2008). Multiple regression allows the researcher to determine how much of the variance in the chosen dependent variable can be explained by each of the selected, significant independent variables. Ultimately, using multiple regression allowed me to determine 
"the degree to which each independent variable contribute[d] to successful predictions" while holding all other independent variables constant (Huck, 2012, p. 380).

Specifically, my regression model has allowed me to identify how much of the variance in students' BUS 111 final course grade can be explained by: their attitudes towards mathematics, their mathematical anxiety, their high school GPA, the time they devoted to mathematics each week during the semester, the number of BUS 111 classes they missed, their gender, the score they earned on the URI mathematics placement exam, and their mathematics SAT score. Further, collecting survey data and using existing data from the University of Rhode Island (with the permission of the IRB, the College of Business Administration, the student participants, and the BUS 111 instructors) allowed me to sample a relatively large number of students $(n=247)$. According to the U.S. Department of Education National Center for Education Statistics, in 2012, 52\% of all undergraduate business majors were male, $64 \%$ were white, $12 \%$ were Black, $9 \%$ were Hispanic, 7\% were Asian, and 8\% identified as "Other" (Siebens \& Ryan, 2012). As my sample is fairly representative of college students in business mathematics nationwide (see the next section for specific comparisons with this sample), generalizability to some degree could also be achievable.

\section{Methodological Procedures}

\section{Participants}

BUS 111 is a foundational, calculus-based mathematics course required for all business majors. Students who do not pass this course are not permitted into the College of Business. Historically, the failure rate in the course has been approximately $31 \%$ (D. Libutti, personal communication, January 16, 2015). I invited all students who were enrolled in BUS 111 at the University of Rhode Island (URI) during the Fall 2015 semester to participate in this research. This group initially consisted of 266 students in six sections with three different instructors (an ANOVA analysis was run to determine whether significant differences existed between the three instructors on each variable). 
This was a convenience sample, as I teach for the College of Business and thus had direct access to these students and their instructors. However, it was also purposive, because the population I was interested in was undergraduate business majors enrolled in entry-level college mathematics courses (especially at URI), so this sample was very representative of my intended population (Fraenkel et al., 2011). These students were mostly between the ages of 18 and 22 years old and the majority of them were in their freshmen year at URI. If students were under the age of 18 , they were excluded from the study, however only eight students were excluded for this reason. Other than this exclusion, as long as the student was enrolled in a section of BUS 111 at the time of the study, they were invited to participate.

By surveying students in a classroom setting, the response rates were likely higher than if other methods were used (Fraenkel et al., 2011). When students are asked to take a survey during a pre-scheduled event that they do not have to plan around, they are more likely to be willing to participate. Students were told of the positive, informative purpose of the survey (to examine factors predicting success in their course), which also encouraged their participation (Fraenkel et al., 2011; Huck, 2012). However, I ensured students were aware that their participation would not in any way affect their grade in BUS 111 or their academic standing (see the email sent to students in Appendix E and the verbal scripts in Appendix $\mathbf{J}$ for more details). According to statistician Daniel Soper (2006), the minimum sample size needed to test this number of predictor variables (8) and still maintain a medium to high effect size in multiple regression was 113 students (other sources recommend 20 participants per independent variable; Hair et al., 1998). Each of the initial 266 students in BUS 111 were invited to participate in the survey, with a final total of 247 total participants: 224 who completed the pre-survey, 202 who completed the post-survey (only 258 students were enrolled in the course during the administration of the post-survey), and 179 completing both the pre- and post-survey. This final matched number of 179 participants accounts for students who chose not to 
participate in the study, students who were absent during survey administration, students who dropped the course, students who only completed one of the two surveys, and students who were under the age of 18 . These response rates of $84.2 \%$ on the pre-survey and $78.3 \%$ on the post-survey are considered adequate samples (Fraenkel et al., 2011). I worked closely with the instructors of this course, so gaining access to this group was relatively easy and I was provided students' e-mail contact information through the university's eCampus system. While I have taught BUS 111 in the past, I did not teach this course at the time of the study in order to eliminate the possibility of coercion and conflict of interest.

The setting of this survey was the University of Rhode Island, a large rural university in the Northeast. The sex distribution of the sample was typical of the College of Business Administration (CBA) at URI: $36 \%$ of the participants were female and $64 \%$ were male. The ethnic breakdown and socioeconomic distribution of the sample were fairly representative of URI, where roughly $69 \%$ of students typically identify as White, $8 \%$ are Hispanic, $5 \%$ are Black, $3 \%$ are Asian, $3 \%$ identify as two or more races or "Other", $2 \%$ are non-residential aliens, and the remaining $10 \%$ chose not to disclose (D.

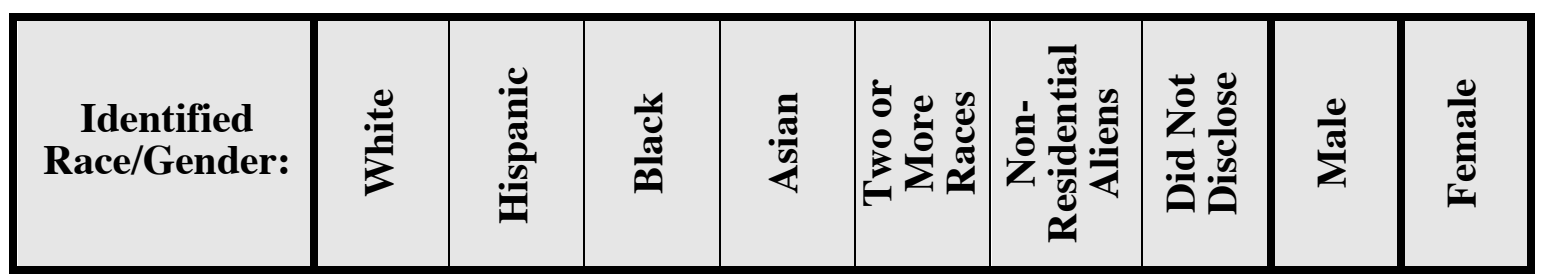

Libutti, personal communication, January 16, 2015). The majority of the students in the CBA come from middle class or upper-middle class families. Sometimes in the College of Business, racial diversity is actually greater than the rest of URI due to a number of grants and foundations in place designed to increase the number of students from racially diverse backgrounds in business. Unfortunately, however, many students from these racially diverse backgrounds start in MTH 101 or MTH 110 rather than BUS 111. Thus, 


\begin{tabular}{|c|l|l|l|l|l|l|l|l|l|}
\hline $\begin{array}{c}\text { All Business } \\
\text { Students in the } \\
\text { U.S. }\end{array}$ & $64 \%$ & $9 \%$ & $12 \%$ & $7 \%$ & $1 \%$ & $6 \%$ & $1 \%$ & $52 \%$ & $48 \%$ \\
\hline $\begin{array}{c}\text { All Students } \\
\text { Attending URI }\end{array}$ & $69 \%$ & $8 \%$ & $5 \%$ & $3 \%$ & $3 \%$ & $2 \%$ & $10 \%$ & $46 \%$ & $54 \%$ \\
\hline $\begin{array}{c}\text { Students in this } \\
\text { Research }\end{array}$ & $84 \%$ & $6 \%$ & $2 \%$ & $3 \%$ & $<1 \%$ & $3 \%$ & $1 \%$ & $64 \%$ & $36 \%$ \\
\hline
\end{tabular}

these percentages varied slightly in my sample, where $84.38 \%$ were White, $5.8 \%$ were

Hispanic, 2.23\% were Black, 3.13\% were Asian, $0.45 \%$ identified as two or more races, $2.88 \%$ were non-residential aliens, and $1.14 \%$ chose not to disclose. The setting of this study and the demographics of the participants were fairly representative of business students across the nation (Siebens \& Ryan, 2012; Smith \& Schumacher, 2005; Truell \& Woosley, 2008). The table below shows the comparative racial demographics of this study:

Table 3. Business Major Ethnicity/Race and Gender Breakdown ("University of Rhode Island Office of Admission”, 2014; U.S. Department of Education, National Center for Education Statistics, 2015)

Over the course of the semester and during planning meetings before the semester began, the BUS 111 instructors shared course materials and used very similar methods to assess students. The level of collaboration among the instructors was high and often they would share projects, exams, and quizzes for consistency across sections. Still, because different instructors often have different teaching practices, different relationships with students, and various assessment strategies, I performed an ANOVA on each variable to examine whether statistically significant differences existed between students under the three different instructors (Huck, 2012; Weiss, 2008). The results of this ANOVA and other findings are presented in chapter five (findings/results).

\section{Variables of Interest}

Eight independent variables were examined in this study as predictors. First, gender was included, as research shows significant gaps in business mathematics 
achievement often exist between male and female students (Smith \& Schumacher, 2005). Second, high school GPA was obtained and standardized, if necessary, to fit a 4.0 scale. Third, mathematics SAT score was examined. If students took the ACT instead of the SAT, these test scores were also standardized to fit the same scale. However, the SAT is more prominent in the Northeast and only 12 participants (4.86\% of participants) in this study took the ACT. Fourth, student scores (numeric averages) on the university's department-generated mathematics placement test were obtained and analyzed. All business students were asked to complete the proctored placement test on a computer during summer orientation. See chapter three for more details on URI's current placement procedure. Questions on this assessment ranged from pre-algebra to precalculus material and students were not permitted to use a calculator or other resources (see Appendix F for sample placement exam questions; "University of Rhode Island Department of Mathematics", 2015). Fifth, a student's attitude towards mathematics was examined using the Attitudes Towards Mathematics Inventory, which is described in detail below. Sixth, a student's mathematical anxiety was measured using the Mathematics Anxiety Scale, which is also described below. Seventh, the average number of hours per week a student spent on mathematics outside of class, as reported by the student, was examined to see if this was related to their course grade. Finally, the number of BUS 111 classes missed over the course of the semester, also reported by the student, was included, as multiple literature sources posit that college students tend to earn higher grades when they devote more time to the subject (Hall \& Ponton, 2005; Parker, 2005).

The main dependent variable of interest in this study was success in the foundational business mathematics course (BUS 111) at URI. For this research study, I used the term success to describe a passing grade in the BUS 111 course (a grade of C or better, which equates to a $72.5 \%$ or above), though numeric averages have been included in the regression model for more accurate predictions. I have chosen this procedure for 
measuring success because if a student does not receive a passing grade in this course, they are not permitted to continue on in a College of Business degree program without retaking the course. Many students who earn below a $\mathrm{C}$ decide to switch out of the business major and start a new major at URI or transfer to a different university (F. Budnick, personal communication, January 3, 2015). Furthermore, the current Common Core State Standards and the curriculum used in most K-12 schools across the nation implements the Partnership for Assessment of Readiness for College and Careers (PARCC) assessment to evaluate whether students are prepared for college. According to the PARCC administrators and PARCC documentation, students who earn a 4 (out of 5) or above in mathematics on this assessment "have approximately a 0.75 probability of earning college credit by attaining at least a grade of C" in freshmen-level college mathematics courses and are thus deemed "college- and career-ready" ("PARCC College- and Career-Ready Determination Policy", 2013, p. 4). Therefore, using a grade of $\mathrm{C}$ or better to indicate success seems complementary to both URI's College of Business and PARCC standards.

I also examined the relationship between the students' perceived effectiveness of the BUS 111 instructor and each of the independent variables using correlational analysis. The purpose of the multiple regression analysis was to examine possible predictive relationships between these independent variables and the dependent variables, as described below.

\section{Data Sources and Instrumentation}

A few different instruments were used in this study. First, I obtained permission from the Institutional Review Board (IRB) at URI to access data from the university's student information system, called eCampus, such as identified gender, mathematics SAT scores, and high school GPA. I also received their general approval to conduct this research study. Course averages in BUS 111 were obtained via SAKAI (a common Collaboration and Learning Environment which allows instructors to track students' 
grades throughout the semester) and/or the instructor's personal grade book, if SAKAI was not used. The mathematics department provided me with student scores on the placement exam.

I also used a combination of pre-existing scales and inventories to examine students' attitudes towards mathematics and students' mathematical anxiety (see Appendix C and Appendix D). Authors' permission for use of these materials was obtained (see Appendix H and Appendix I). Students were also asked for permission to access their demographic data in eCampus and their grade information in SAKAI and use their responses to these survey materials. Students were asked to complete a short questionnaire asking them to report the number of hours they devoted or planned to devote to their BUS 111 course each week outside of class, how many BUS 111 classes they missed or expected to miss throughout the semester, and their perceived effectiveness of the instructor (see Appendix A and Appendix B). The instruments used to measure students' attitudes towards mathematics (including self-confidence) and mathematics anxiety were the Attitudes Towards Mathematics Inventory (ATMI) and the Mathematics Anxiety Scale (MAS), respectively, described below.

\section{Attitudes Towards Mathematics Inventory}

The ATMI was originally designed by professor Martha Tapia to assess student attitudes towards mathematics using a series of forty Likert-scale questions ranging from "strongly agree" to "strongly disagree" (see Appendix C for a copy of this inventory). These questions were designed to measure four different facets of student attitude in mathematics: self-confidence, value, enjoyment, and motivation (Tapia, 1996). Attitude towards mathematics was defined as a student's feelings or thoughts towards mathematics, specifically examining the value a student attaches to the subject and their confidence level (Tapia \& Marsh, 2004). The ATMI asks student participants to rate statements such as "I believe I am good at solving math problems" and "I can think of 
many ways that use math outside of school" (Tapia \& Marsh, 2004, p. 21) to measure their self-efficacy in mathematics and the value they attach to the subject.

The ATMI has a reliability coefficient of 0.97 with college students (Tapia, 1996), which is considered very strong (Fraenkel et al., 2011). Both content and construct validity of the instrument have been confirmed. Content validity was established by receiving expert opinions and feedback, namely from experienced educators and learning specialists (Tapia, 1996). Construct validity was established with item homogeneity through the Statistical Analysis System software (SAS) and factor analysis (Tapia, 1996). The instrument consists of eleven negatively phrased statements and twenty-nine positively phrased statements. To score the negatively phrased statements, "strongly disagree" corresponds to a score of five and "disagree", "neutral", "agree", and "strongly agree" correspond to scores of four, three, two, and one, respectively (Tapia \& Marsh, 2004). To score the positively worded statements, the reverse scoring method is used, so that a high final score corresponds to a favorable attitude towards mathematics.

\section{Mathematics Anxiety Scale}

The MAS was designed to assess student anxiety in mathematics using a series of fourteen Likert-scale questions ranging from "strongly agree" to "strongly disagree" (see Appendix D for a copy of the scale; Mahmood \& Khatoon, 2011). This instrument was designed as a revision of the Mathematics Anxiety Rating Scale (MARS) to better suit older students (high school seniors and college students). Mathematical anxiety was defined as "the panic, helplessness, paralysis and mental disorganization that arises among some people when they are required to solve a math problem" (Tobias \& Weissbrod, 1980, p. 65). The MAS asks student participants to rate statements such as "I feel worried before entering a mathematics class" and "I am afraid to ask questions in math class" (Mahmood \& Khatoon, 2011, p. 178) to measure their anxiety based on the constructs of mathematical anxiety described in more detail in chapter three. 
This instrument has a Cronbach's alpha internal reliability coefficient of 0.87 with college students and a split-halves reliability coefficient of 0.89 (Betz, 1978; Mahmood \& Khatoon, 2011), which are considered strong (Fraenkel et al., 2011). Content, construct, and criterion validity were confirmed by Mahmood and Khatoon (2011), who first worked with mathematics educators and other experts to ensure the instrument was measuring mathematics anxiety, and then worked with test participants to verify the results until the fourteen final questions were agreed upon. The MAS consists of seven positively worded statements and seven negatively worded statements. To score the positively worded statements, "strongly disagree" corresponds to a score of five and "disagree", "neutral", "agree", and "strongly agree" correspond to scores of four, three, two, and one, respectively (Mahmood \& Khatoon, 2011). To score the negatively worded statements, the reverse scoring method is used, so that a high final score corresponds to high mathematics anxiety.

\section{Data Collection}

During the first and last week of class in the Fall 2015 semester, all students in BUS 111 were invited to take the survey and complete the inventories presented in Appendices A through D, as described above. Frequent quizzes and in-class assessments were typical in the BUS 111 course, so few students were expected to be absent (15 of the 266 students, or $5.6 \%$, were absent during the pre-survey administration and 27 of the 258 students, or $10.5 \%$ were absent during the post-survey administration). Students who were absent during the pre- and post-surveys did not have an opportunity to participate. Though 266 students were initially enrolled in BUS 111 at the time of the pre-survey administration, only 258 students were enrolled in the course during the post-surveys, and eleven of those students were not yet enrolled during the pre-survey administration. Therefore, paired preand post-results for those students were not available. However, students who completed only one of the two surveys were still included in the multiple regression analysis with their 
final course average included, as this analysis did not require both pre- and post-survey results.

Students were asked to use their university ID number as an initial identifier, but were assured that the surveys would not be examined until final grades had been submitted to encourage their honesty. General information regarding the study was provided to students via e-mail prior to the first class of the semester. Specifically, an e-mail was sent to all BUS 111 students from the researcher one week before classes began (see Appendix E). Then, during the first week of classes and again during the last full week of classes, a short cover letter and consent form described the study to the participants in detail and explained their choice in participation (see Appendices A and B). The researcher read certain portions of the consent form to the students for clarity before administering the surveys (see the verbal scripts submitted to the IRB in Appendix J). Because two different instruments were being used, there was a chance that the order in which students completed the inventories may have influenced the results (Fraenkel et al., 2011). To account for this potential instrumentation threat to internal validity, half of the total number of students surveyed were randomly chosen to complete the ATMI first and the other half completed the MAS first. Students were not aware of these random assignments, as both inventories were given together with the consent form simultaneously, just in varying orders from student to student.

An SPSS worksheet was created and student responses were entered into the worksheet with student ID numbers used as initial identifiers. Student pre- and postresponses to the three survey questions, their ATMI results, and their MAS results were inputted into SPSS as variables “Time_Spent_Pre"/“Time_Spent_Post"(time expected to spend/spent working on mathematics for BUS 111 outside of class per week), “Attendance_Pre"/ "Attendance_Post" (number of BUS 111 classes expected to miss/missed over the course of the semester), "Instructor_Pre"/ "Instructor_Post" (perceived effectiveness of the instructor), "Math_Attitude_Pre"/ "Math_Attitude_Post" 
(confidence and attitude towards mathematics from the ATMI responses), and "Math_Anxiety_Pre"/“Math_Anxiety_Post" (mathematical anxiety from the MAS responses), respectively.

Then, the same ID numbers were run through URI's PeopleSoft software on eCampus to obtain gender (dummy coded with " 0 " indicating male and " 1 " indicating female), high school GPA, mathematics SAT score, and score on the university's placement exam, which were added to the SPSS worksheet. These were inputted as variables: "Gender", "HS_GPA", "Math_SAT_Score”, and "Placement_Score”, respectively. Finally, student final averages from the instructors' BUS 111 online grade books ("BUS111_Course_Average") were entered along with which of the three instructors they were assigned ("Instructor"). Upon completion of this step, student identities were no longer needed, so student ID numbers were eliminated from the worksheet, recoded as a random number. The scores for each variable were used together as predictors in the initial multiple regression analysis against the dependent variable, final average in BUS 111.

\section{Ethical Considerations}

There were few anticipated possibilities of harm or deception for the people who participated in this study. My research questions were stated up front and my reasoning for performing this research was openly shared with my participants. However, there were a few issues of confidentiality with this study. I surveyed students from URI's College of Business, where I am an instructor. However, none of the students surveyed had me as their instructor at the time of the data collection or analysis. I assured students that the data would not be analyzed until after final course grades were submitted and refusal to participate in the study would in no way affect their grade in the course or their academic standing.

Furthermore, in order to align survey data with course grades, I needed to ask for and obtain student ID numbers, as explained above. I kept a list of the assigned numbers 
in a separate, locked file in my private office in order to protect confidentiality after entering the data. Names were never used. A question on the survey/consent form requested permission to use students' responses in the research study (see Appendices A and B). If a student left this question blank or did not sign the consent form, their responses were not used in the analysis. Students also were reminded that they had the right to withdraw from the study at any time if they decided they did not want their information to be used. One student did exercise this right and withdrew their consent via email.

\section{Data Analysis}

To address the overarching research question, multiple regression was used to identify significant predictor variables and to examine the overall predictive relationship among these variables (Fraenkel et al., 2011; Huck, 2012; Weiss, 2008). Once student ID numbers were removed from SPSS so that students were no longer identifiable, an initial multiple regression analysis was run with all of the independent variables to examine the overall predictive relationship. Initial procedures were also run in SPSS to ensure normally distributed variables and to look for multicollinearity. It was anticipated, for example, that high correlations may have existed between mathematics SAT score and high school GPA, as well as attitudes towards mathematics and mathematical anxiety (Hall \& Ponton, 2005; Smith \& Schumacher, 2005). Thus, precautions needed to be taken in examining relationships with these variables, as severe multicollinearity leads to less precise estimates of the predictor's impact on the dependent variable, while holding other variables constant (Kutner et al., 2002; Weiss, 2008). Finally, during the initial data analysis process, means and standard deviations for each variable were computed in order to describe the overall nature of each predictor variable examined, examine normality of the data, and to better understand the specific sample chosen. The results obtained are described in detail in chapter five (the presentation of the findings and results). 
I began by using simultaneous ("enter all”) multiple regression, rather than stepwise or hierarchical, so that I could determine which of the variables examined, if any, were useful predictors of BUS 111 final course grade. After the initial multiple regressions were run in SPSS, the independent variables which had already been tested and found to be predictive in previous research (gender, mathematics SAT scores, placement exam scores, and high school GPA) were placed in the model first to determine how much of the variance in student BUS 111 grades could be predicted by the other, less researched variables. I proceeded by placing each of the other independent variables into the model in various combinations, to see which were the strongest predictors.

To address the first research sub-question, I ran a series of two-sample $t$-tests in order to determine whether significant differences existed between males and females on each of the predictor variables. If significant differences existed on multiple independent variables, I planned to create two regression models on the dependent variable, one specifically for males and one for females, to see if the models differed and yielded higher $\mathrm{R}^{2}$ values. Current literature suggests that the models may have been different based on gender and therefore I knew I may have been able to produce higher coefficients of determination for the multiple regression equations by separating the genders (Berube \& Glanz, 2008; Blaszczynski, 2001; Leaper et al., 2012; Smith \& Schumacher, 2005).

Similarly, to address the second and third research sub-questions, I ran a series of paired $t$-tests to determine whether statistically significant differences existed in students' ATMI and MAS scores before and after taking the BUS 111 course. This allowed me to see how students felt upon entering the course and how those feelings may have changed over time upon finishing the course. Analyzing these results also helped me paint a general picture of students who were taking BUS 111 so that I could better understand the sample in question. To address the final research sub-question, I examined the 
correlation coefficients describing the relationships between students' perceived instructional quality and: their success in the course, their ATMI scores, and their MAS scores after taking the course.

After controlling for the non-cognitive/non-affective variables (mathematics SAT score, high school GPA, gender, and mathematics placement exam score), which have each been shown to influence mathematics grades in college to some degree (Smith \& Schumacher, 2005; Truell \& Woosley, 2008), I hypothesized that students' attitudes towards mathematics, the number of hours they spent on mathematics outside of class per week, their class attendance, and their mathematical anxiety would be significant in predicting their achievement in BUS 111. Before conducting this research, I also anticipated that how students perceived the effectiveness of their BUS 111 instructor would positively correlate with success in the course and negatively correlate with their mathematical anxiety. I expected students' mathematical anxiety and attitudes towards mathematics might change over the course of the semester. I also hypothesized that significant differences may have existed between mathematical success in male and female students, as supported by current literature (Smith \& Schumacher, 2005; Truell \& Woosley, 2008).

\section{Limitations of Multiple Regression and Survey Design}

While using a quantitative approach allowed me to survey a relatively large sample and determine predictive relationships, multiple regression and correlation analyses have their limitations. I examined eight independent variables that I chose based on the current literature available as well as my theoretical framework/personal worldview. Inherent bias exists in the variables I chose to examine (Creswell, 2014). Nonetheless, there were likely other factors, which I did not include in my model, which might also have influenced each student's achievement in mathematics. In other words, their final average in BUS 111 was likely not entirely due to the eight specific variables I named. A student's course grade may have been impacted by their experiences outside of academia, their advocacy 
skills, their innate ability in mathematics, access they had to tutoring, their socioeconomic status, study skills, extracurricular activities, level of parental involvement, sleeping/eating habits, etc. These factors may have also impacted their course grade, and I did not include these variables in my model.

Further, timing always plays a limiting role in survey research, as the results represent only a snapshot of the specific times in which the students were surveyed (Fraenkel et al., 2011). If students had recently had a particularly good or poor experience in mathematics, had a good or bad experience with the instructor, broke up with their significant other, forgot to eat lunch, failed an exam in another course, pulled an allnighter to write a paper, got in a fight with their roommate, etc., then they may have answered the survey questions differently than they would have on a different day or under diverse circumstances. The results of my multiple regression analysis may have been affected by these confounding factors, which could have impacted the overall internal validity and reliability of this research (Fraenkel et al., 2011; Kutner et al., 2003). These personal student details will remain unknown in this multiple regression analysis, as the participants were not observed or interviewed for more detailed information, as they might have been in a qualitative or mixed-methods methodological design.

The results of survey research are only ever as good as the specific survey instruments used. I chose instruments with high reliability and validity measures, but I used these instruments simultaneously, which may have impacted the results, as explained in more detail above. Finally, I assume students have responded honestly to the survey questions I presented, but lack of honesty in self-reported results could be another limitation (Creswell, 2014; Fraenkel et al., 2011). I tried to ensure honesty by preserving confidentiality, waiting until after course grades were reported to run the analyses, and using student ID numbers rather than names to protect participants' privacy throughout the study. 
A potential delimiting factor, which may also pose a threat to internal validity, is students trying to "please" the researcher due to subject attitudes and characteristics (Fraenkel et al., 2011). For example, students may have responded to the surveys administered in a particular way because they thought certain results would be more desirable to the researcher. I may have prevented this, at least to some degree, by not teaching this BUS 111 course during the time of the research and by assuring students that the post-surveys would not be opened or analyzed until the final semester grades had been submitted. Waiting until the end of the semester, however, posed a potential mortality threat to internal validity, as students took this post-survey during the last full week of classes (Fraenkel et al., 2011). Students who decided to drop the course before the end of the semester, perhaps due to struggle, were not included in the sample. This may have caused final averages to appear inflated.

Another delimitation of this study was the specific sample selected. The sample was chosen through convenience sampling and thus the results that come out of this study may not be able to be generalized to populations outside of URI's College of Business students. I have made no attempts to generalize further and have only made suggestions for students, staff, and faculty members within this community. It is possible that these results are generalizable to other business schools and colleges or to other majors for students at URI who are required to take a similar entry-level mathematics course. However, my goal was to better prepare URI business students for their mathematics courses, which is why this sample was chosen.

\section{Insider Positionality}

As an instructor for the College of Business Administration and as a University of Rhode Island graduate, I have an insider position leading me to carry certain beliefs and expectations, which I needed to consider as I collected and analyzed this data. While I am usually assigned to teach sections of BUS 111 myself, I did not teach any sections of this course at the time of the study. This way, none of the students who were enrolled in BUS 
111 would have me as their instructor during the Fall of 2015 when this data was collected, which accounts for some of my researcher positionality. Still, I had a priori expectations about what I might find in my research, which I clarified above as hypotheses.

As I analyzed the data collected, I kept these limitations in mind. As a postpositivist, I hoped to find relationships that may help explain achievement in BUS 111 . However, I was not performing an experimental study, and with many factors in place that were not controlled for, I could not assume that my findings would prove causal relationships between any of the variables (Fraenkel et al., 2011). Further, as a pragmatic researcher, I hoped to develop models that could be applied to educational settings. A regression equation has been produced through the multiple regression analysis that could be used to predict student achievement (see chapter five for details). Using a relatively large sample size $(n=247)$, the regression equation can help instructors understand some of the many factors that may influence a student's outcome in the BUS 111 course. Still, I would not expect this equation to predict exact averages for all students taking BUS 111. For some students, the equation may not be predictive at all (Weiss, 2008). As a studentcentered researcher, I also know that I cannot expect that the variables, which I found to be significant in my model, will have the same degree of significance with each individual student or group of students. Still, I believe that gaining insight on some of the likely predictors of achievement will allow instructors and advisors to help guide students on their journeys through business mathematics with the tools they may need in order to find success. 


\section{CHAPTER FIVE: FINDINGS/RESULTS}

All students enrolled in BUS 111 at the University of Rhode Island during the Fall 2015 semester were invited to take a pre-survey during the first week of classes and a post-survey during the last week of classes, as described in the previous methodology chapter. A total of 179 students volunteered to participate in both surveys, with a total of 224 completing the pre-survey and 202 completing the post-survey. Thus, there were 247 total unique participants $(224+202-179$ overlapping $)$. Once entered into SPSS, those results were analyzed according to the research questions posed in chapter three (the review of the related literature). Those research questions are restated and addressed throughout the remainder of this chapter and other observations about the specific findings of this research are identified and analyzed.

Specifically, I begin this chapter with descriptive statistics about each of the variables examined as well as other descriptive, demographic information about the sample to present an overall picture of who these participants were. Then, I describe the average time students predicted they would spend on mathematics over the course of the semester versus the time they actually reported spending. I then examine their average high school GPAs, SAT scores, and placement exam results. Following that, I address potential concerns with multicollinearity and group differences. Then, I discuss the results of the various paired $t$-tests and analyze those differences. I follow by examining the results of various multiple regression analyses: first, I verify that the assumptions for multiple regression were met, then, I examine the enter-all (simultaneous) results, followed by the step-wise results, and ending with the block-wise (hierarchical) results. I ran separate multiple regression analyses for: (1) non-affective measures and affective or cognitive measures; (2) each of the three individual exams in BUS 111; (3) male students and female students; and (4) each of the three BUS 111 instructors. Thus, these results and the corresponding equations are also discussed. Finally, I describe the results of the correlational analyses, looking at the relationship between perceived instructor 
effectiveness and: students' ATMI scores, students' MAS scores, how much time students devoted to mathematics, and their BUS 111 final averages. Below, I have constructed a map (see Figure 5) outlining the remainder of this chapter.

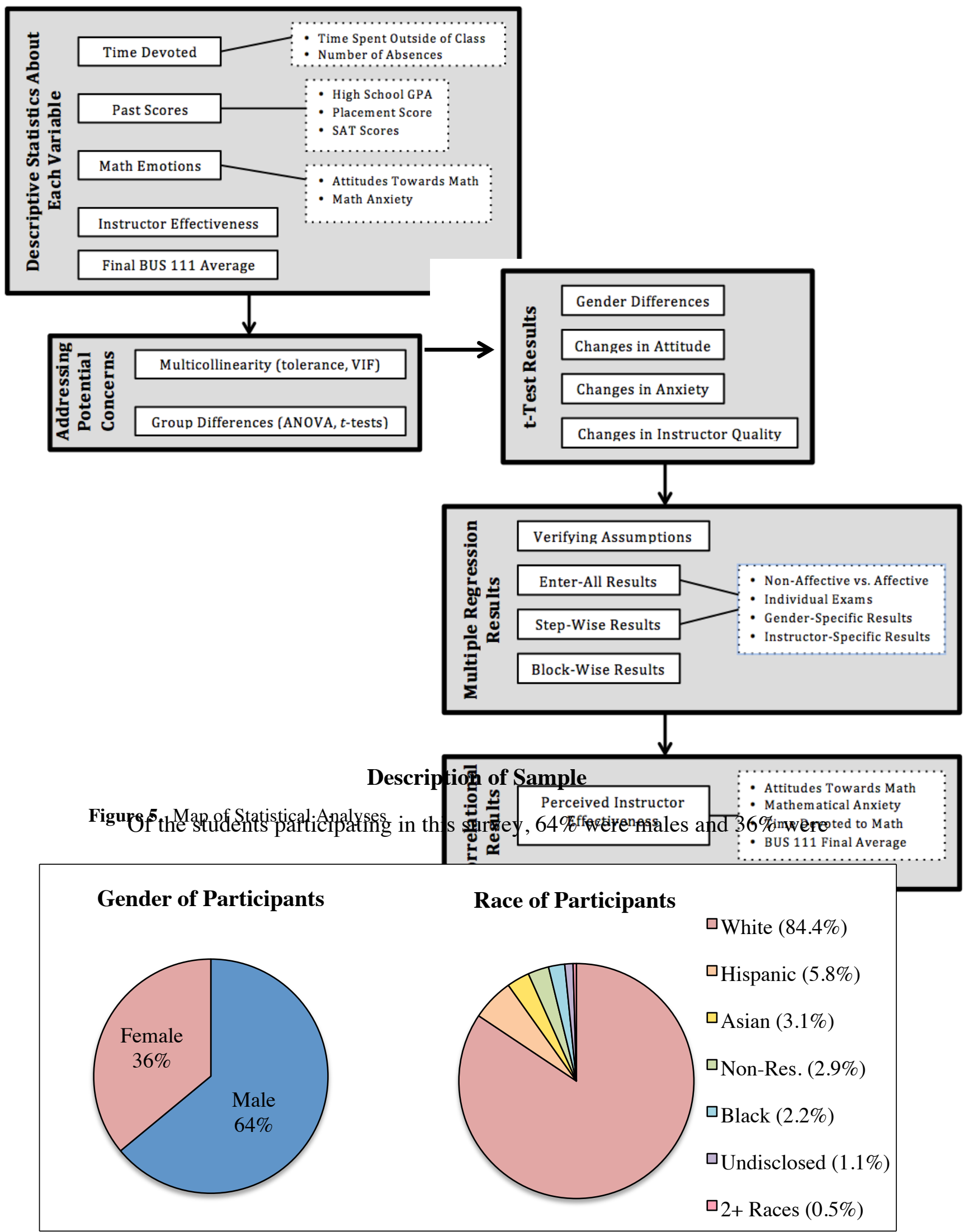

Figure 6. Sample Demographics: Gender and Race of Participants 
females. In addition, $84.38 \%$ of the participants were White, $5.8 \%$ were Hispanic, $2.23 \%$ were Black, 3.13\% were Asian, $0.45 \%$ identified as two or more races, $2.88 \%$ were nonresidential aliens, and $1.14 \%$ chose not to disclose racial information. See the charts below (Figure 6) for a visual representation of the demographics of this sample.

As described in chapter four, this sample was fairly representative of national statistics for business students. In the pie charts in Figure 7, shown below, the national demographics are presented for comparative purposes.

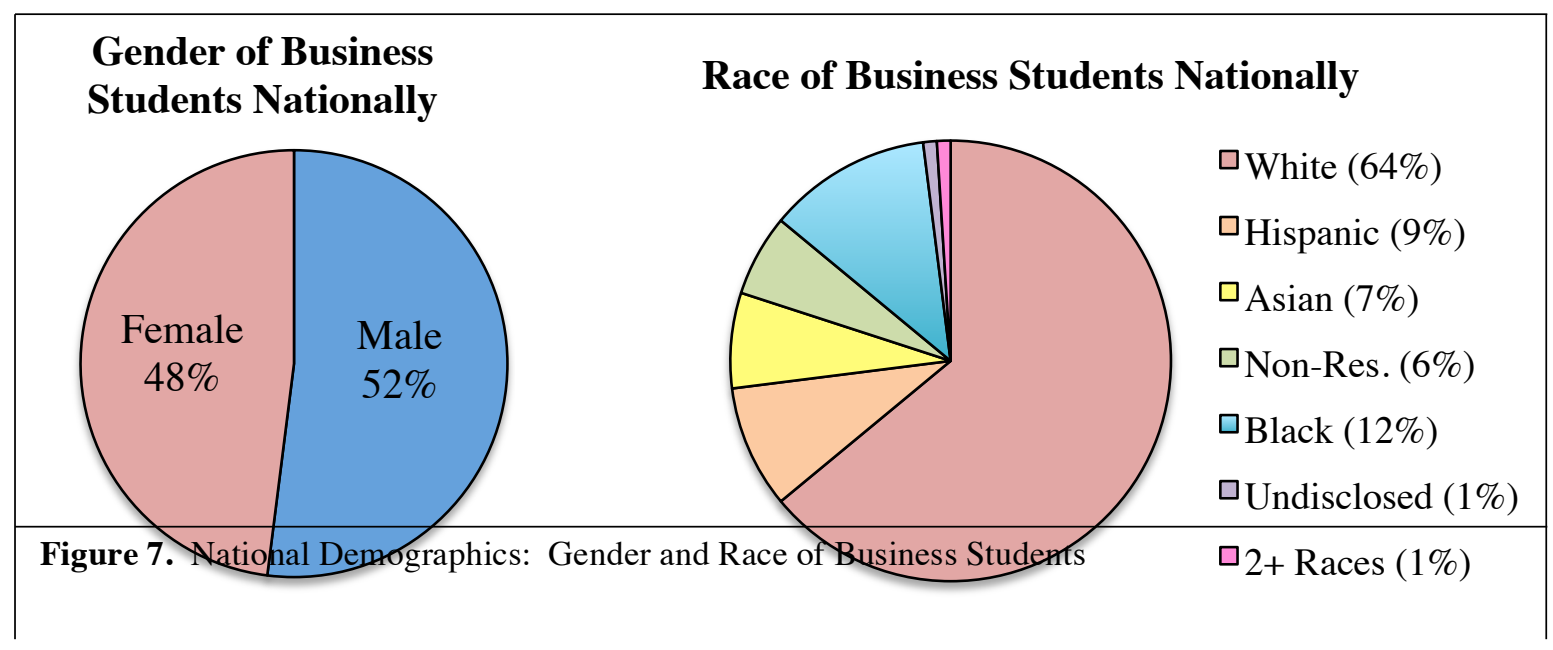




\section{Time Devoted to Mathematics (Averages)}

On the surveys given during the first week of the semester, students were asked to report the number of BUS 111 classes they expected to miss during the semester and how many hours per week they anticipated they would spend on BUS 111 outside of class. On average, students expected to spend between three and four hours (mean $=3.79$ hours) per week working outside of class and expected to miss fewer than two classes during the semester $($ mean $=1.13$ classes $)$. On the BUS 111 syllabus (which was explained to students during the first class of the semester, two days before this presurvey was administered), the BUS 111 instructors indicated that students should expect to spend 6-9 hours per week on BUS 111 outside of class. Less than $20 \%$ of students expected to spend that much time, and less than $25 \%$ reported actually spending that much time. The graphs below (Figures 8 and 9) show the general distribution of the number of hours students expected to spend on mathematics outside of class time and the number of classes students expected miss over the course of the semester, respectively.

On the post-surveys given at the end of the semester, students were asked to selfreport how many hours per week, on average, they spent working on BUS 111 outside of

\section{Expected Hours Spent Distribution}

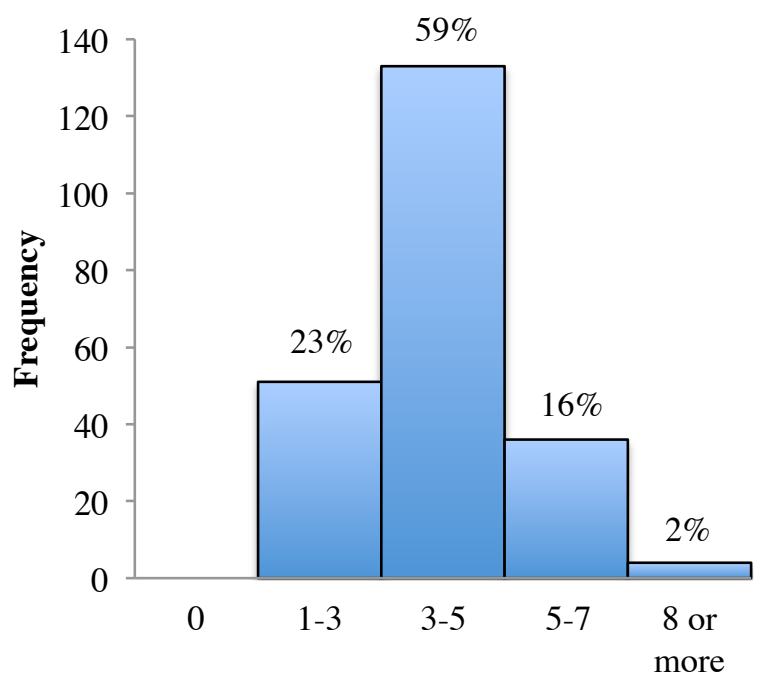

Predicted Hours Spent Per Week

Figure 8. Hours Per Week Students Expected to Spend on BUS 111

\section{Expected Absences Distribution}

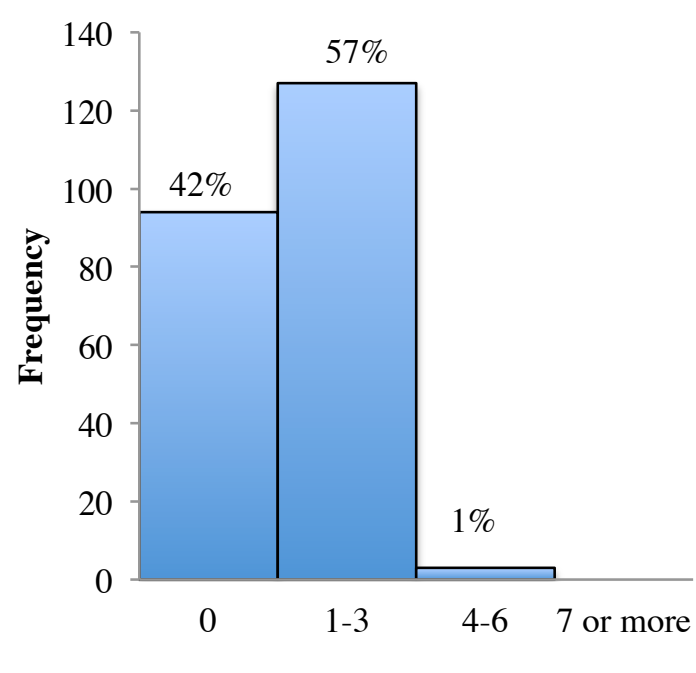

Predicted Number of Absences

Figure 9. Number of BUS 111 Classes Students Expected to Miss 
class and the actual number of BUS 111 classes they missed. On average, students spent between three and four hours per week working on mathematics outside of class (mean = 3.51 hours) and reported missing between one and two classes over the course of the semester $($ mean $=1.59$ classes $)$. After matching pre- and post-survey results, paired $t$-tests revealed significant differences between how many hours students originally expected to spend on BUS 111 each week and how much time they actually spent on the course $(t=$ 3.109; $p=0.002)$. Similarly, significant differences existed between the number of classes students expected to miss versus how many classes they actually missed over the course of the semester $(t=-3.939 p=0.000)$. Specifically, students spent less time than anticipated working on mathematics and missed more classes than they originally predicted. The graphs below (Figure 10 and Figure 11) show these general post-survey distributions of time spent and classes missed, respectively.

\section{High School GPA, SAT Score, and Placement Exam Averages}

All students admitted into the College of Business Administration at URI are required to submit high school transcripts and standardized test scores. The majority of these students take the SAT, but the ACT is also accepted. Since this is only the first year URI's mathematics department has enforced the placement exam in a proctored setting, business faculty and staff members were unsure of the validity of the placement exam. Thus, business majors were still not required to take this placement test for 
admission and so, $23 \%$ of all BUS 111 students did not choose to take the placement exam and instead chose their initial classes based on their high school coursework and SAT results (T. Bella \& K. Conlon, personal communication, October 13, 2015).

Of the BUS 111 student participants who did take the placement exam, the average score was a 3.5 out of 7 . This means that the average placement group was between group B and group B/C (see Table 4). As described in chapter three, on the mathematics placement exam, there are 7 categories of placement. Those groups are described again very briefly in Table 4 below:

\begin{tabular}{|c|c|c|}
\hline $\begin{array}{l}\text { Placement } \\
\text { Group }\end{array}$ & $\begin{array}{l}\text { Numeric } \\
\text { "Score" }\end{array}$ & Suggested Course(s) \\
\hline A & 1 & \multirow{2}{*}{$\begin{array}{l}\text { MTH } 099 \\
\text { (Basic Algebra and Trigonometry) }\end{array}$} \\
\hline $\mathrm{A} / \mathrm{B}$ & 2 & \\
\hline $\mathrm{B}$ & 3 & \multirow{2}{*}{$\begin{array}{l}\text { MTH 101, MTH } 107 \\
\text { (College Algebra or Finite Mathematics) }\end{array}$} \\
\hline $\mathrm{B} / \mathrm{C}$ & 4 & \\
\hline $\mathrm{C}$ & 5 & \multirow{2}{*}{$\begin{array}{l}\text { MTH 110, MTH } 111 \\
\text { (Mathematical Foundations for Business or Pre-Calculus) }\end{array}$} \\
\hline $\mathrm{C} / \mathrm{D}$ & 6 & \\
\hline $\mathrm{D}$ & 7 & $\begin{array}{l}\text { BUS 111, MTH 131, MTH } 141 \\
\text { (Business Analysis and Applications or Calculus) }\end{array}$ \\
\hline
\end{tabular}

Table 4. URI Mathematics Placement Score Breakdown

Note: Courses listed in bold, italicized font are designed for URI's College of Business Administration 
According to the mathematics department and the table above, students who want to enroll in BUS 111 should be placing into group D. Of all of the participants enrolled in BUS 111 over the Fall 2015 semester who took the placement exam, only $0.5 \%$ (one student) placed into group D. In fact, almost all of the students who took the placement test placed into lower groups, indicating they should have been enrolled in lower-level courses, according to the exam. The overall placement distribution is shown in the chart below (Figure 12).

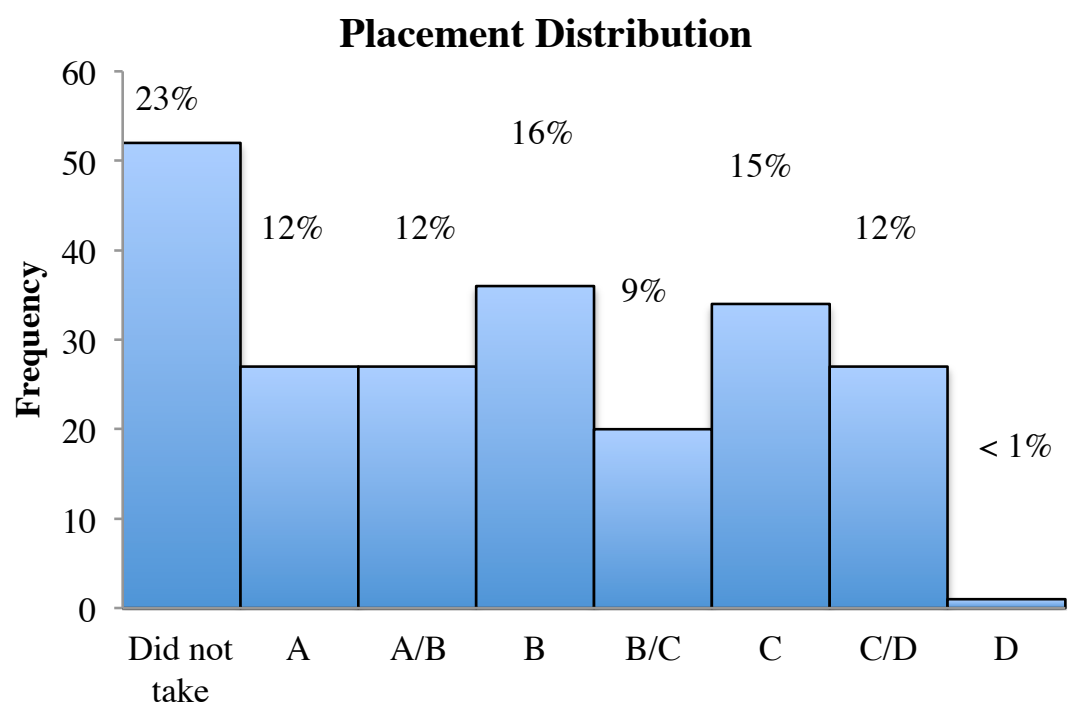

Placement Group

Figure 12. Distribution of Participants' Mathematics Placement Scores

The average high school GPA of students sampled from BUS 111 was a 3.31 (standard deviation, $\sigma=0.451$ ) on a 4.6 scale, which is the scale currently used by the URI admissions department (“University of Rhode Island Office of Admission”, 2015). Some high schools do not use the typical 4.0, 4.3, or 4.6 scales to calculate GPA, so these scores were normalized by URI admissions to fit the 4.6 scale (Huck, 2012; Weiss, 2008). This 3.31 out of 4.6 average translates to a GPA of approximately 2.88 on a 4.0 scale, and is lower than the URI admissions average of 3.48. The average mathematics SAT score was a 562 out of $800(\sigma=57.635)$, which is higher than the average URI 
student, who earned a 559 on the mathematics portion of the SAT ("University of Rhode Island Office of Admission", 2015). The average total SAT score of this sample was a 1458 out of 2400 . Students who took the ACT (only $4.86 \%$ of the sample) earned an average of 25 out of 36 on the mathematics portion as well a total composite score of 25 out of 36, which is typical for URI students ("University of Rhode Island Office of Admission", 2015). ACT scores were standardized to fit the same scale as the SAT. The distribution of high school GPAs and SAT scores for this sample are shown below (Figure 13 and Figure 14, respectively).

\section{and MAS Averages}

\section{High School GPA Distribution}

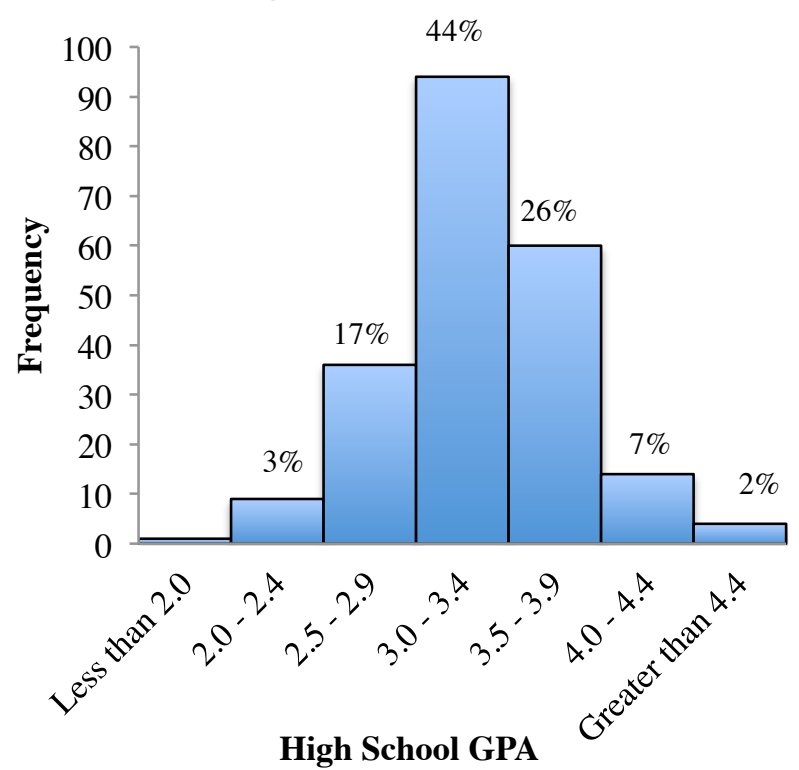

SAT Distribution

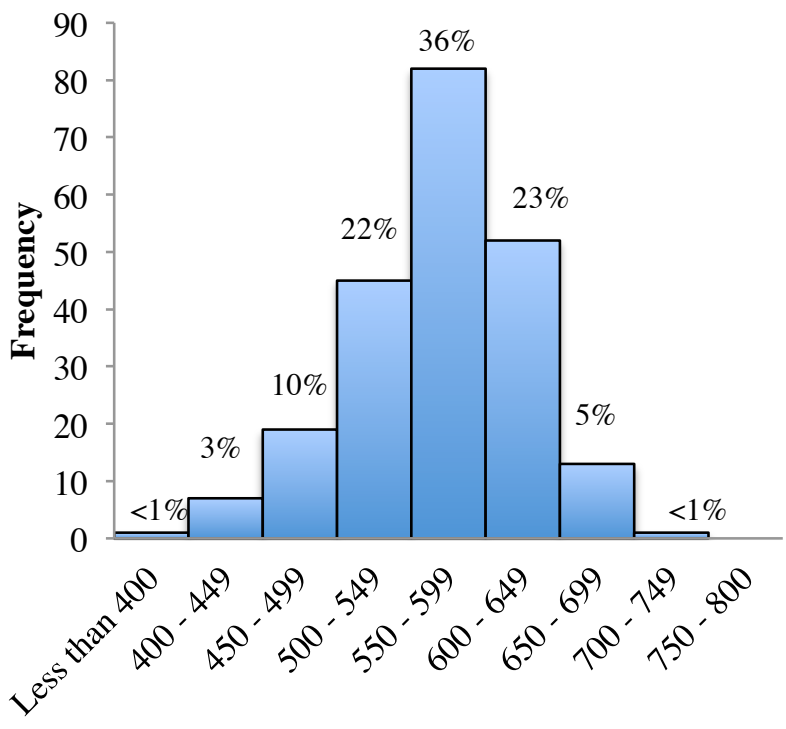

Mathematics SAT Scores

The Attitudes Towards

Mathematics Inventory (ATMI) has 40 Likert-scale questions that range in scoring value from 1-5 (see Appendix C). Thus, the lowest possible score (indicating a very unfavorable attitude towards mathematics) is a 40 and the highest possible score (indicating a very favorable attitude towards mathematics) is a 200. Of the students sampled, the average ATMI score on the pre-survey was a $142.21(\sigma=19.8)$, which 
indicates a relatively positive initial attitude towards mathematics. Similarly, the Mathematics Anxiety Scale (MAS) has 14 Likert-scale questions that range in scoring value from 1-5 (see Appendix D). Thus, the lowest possible score (indicating low mathematical anxiety) is a 14 and the highest possible score (indicating high mathematical anxiety) is a 70. Of the students sampled, the average MAS score on the pre-survey was a $37.61(\sigma=8.6)$, which indicates a relatively moderate level of mathematical anxiety. The graphs below (Figure 15 and Figure 16) show the general

Figure 15. Distribution of ATMI Pre-Survey Scores

Figure 16. Distribution of MAS Pre-Survey Scores distribution of students' pre-ATMI scores and pre-MAS scores, respectively.

At the end of the semester, the average ATMI score on the post-survey was a

\section{Pre-ATMI Distribution}

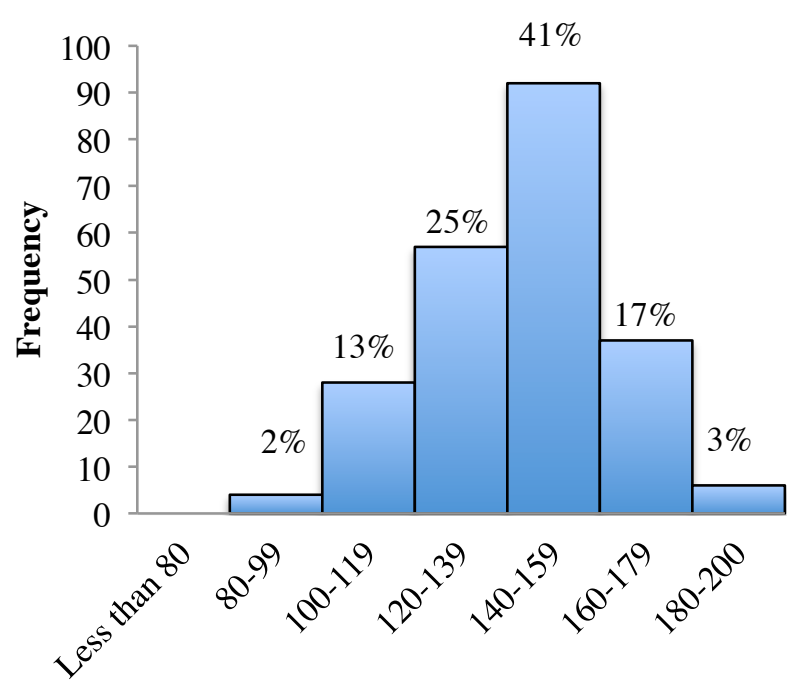

ATMI Score
Pre-MAS Distribution

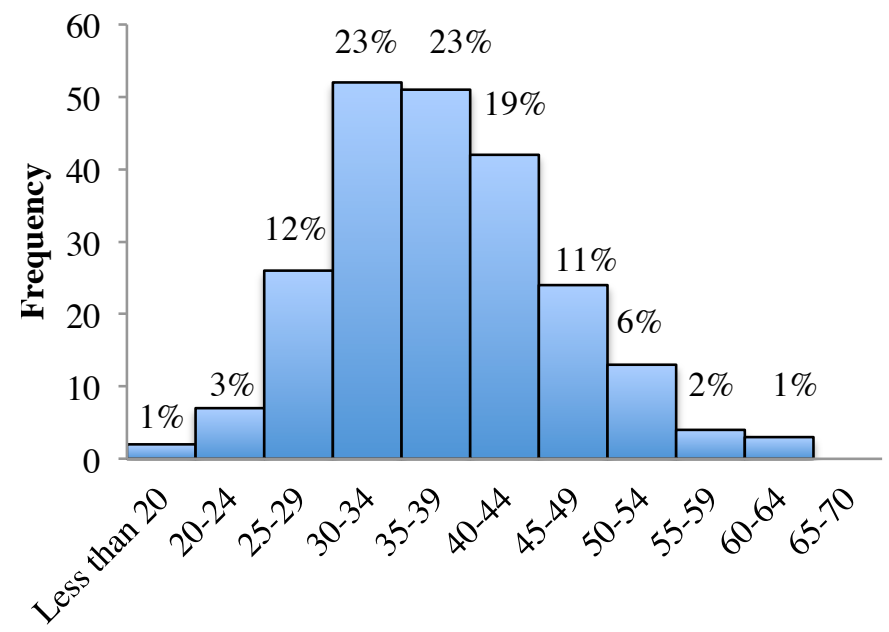

MAS Score

$141.65(\sigma=22.7)$, which continues to indicate a relatively positive attitude towards mathematics upon completion of BUS 111. However, these are slightly less favorable attitudes towards mathematics than existed before the class began. Similarly, the average MAS score on the post-survey was a $37.48(\sigma=9.7)$, which also continues to indicate a relatively moderate level of mathematical anxiety. In general, average mathematical 
anxiety was slightly lower upon completion of BUS 111 than it was before the class began. The graphs below (Figure 17 and Figure 18) show the general distribution of students' post-survey ATMI scores and MAS scores, respectively. The specific, paired changes in the ATMI and MAS results are described in detail in the following section.
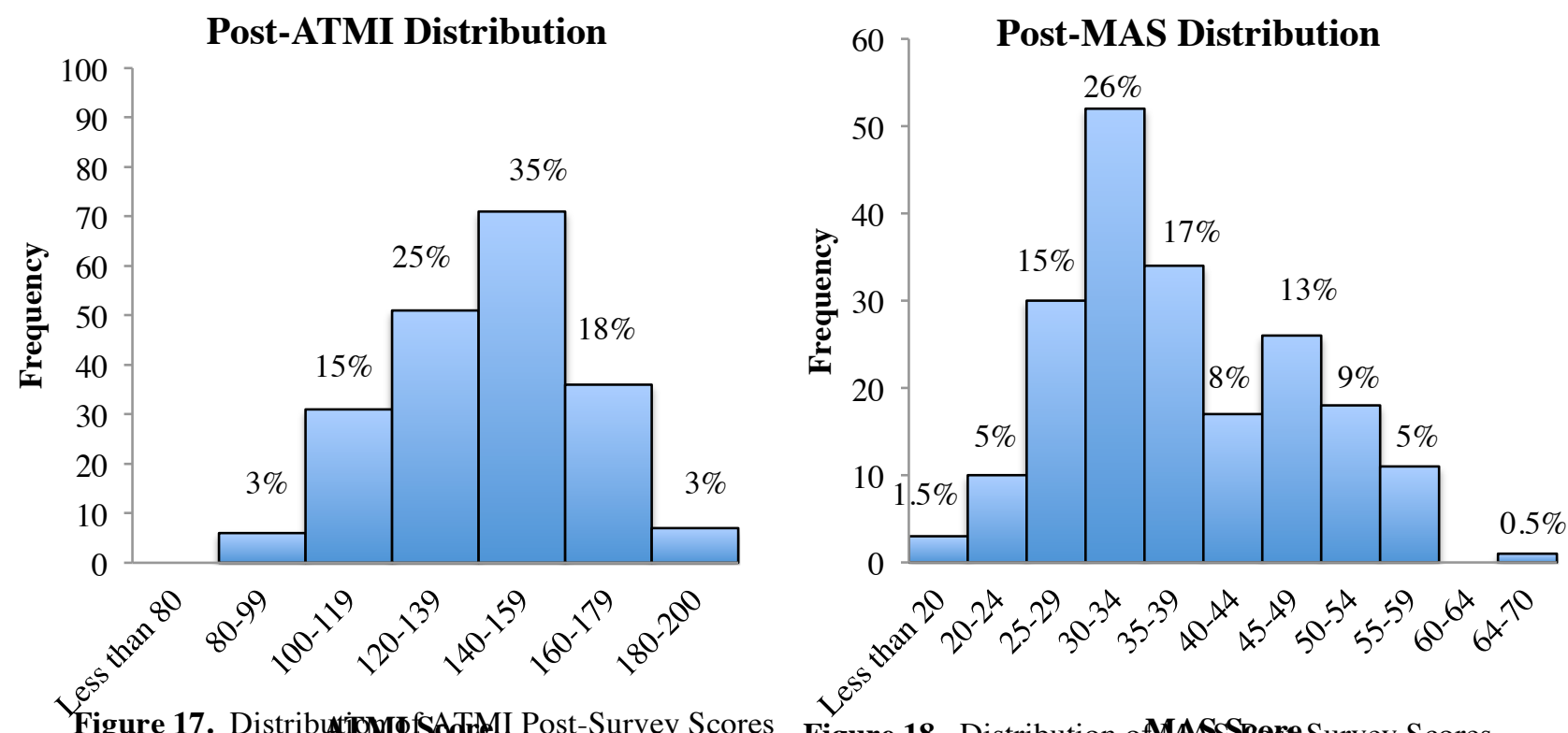

Figure 18. Distribution oMASSSPegreSurvey Scores As described in the

methodology chapter, both of these instruments were shown to have high reliability in other research studies (Betz, 1978; Mahmood \& Khatoon, 2011; Tapia, 1996). Specifically, the ATMI was shown to have an internal reliability of $\alpha=0.97$ (Tapia, 1996) and the MAS was shown to have an internal reliability of $\alpha=0.87$ (Betz, 1978; Mahmood \& Khatoon, 2011). Still, it was necessary to check the reliability of these instruments for this specific research to ensure they were reliable measures with this sample. Thus, reliability statistics were run in SPSS on each instrument. Similar results were found as in previous research with these instruments. With this sample, the ATMI had a Cronbach's alpha reliability rating of $\alpha=0.956$ and the MAS had a Cronbach's alpha reliability rating of $\alpha=0.912$, which are both considered extremely strong and indicate high reliability (Fraenkel et al., 2011).

\section{Perceived Instructor Effectiveness}


In the beginning of the semester, participants in BUS 111 were asked how effectively they believed their instructor would be able to deliver the course material on a 1-5 scale, with 1 being not effective and 5 being very effective. On average, students rated their instructors a score of 4.28. Specifically, Instructor 1 was rated 4.54 out of 5 on average $(n=114)$, Instructor 2 was rated 4.09 out of 5 on average $(n=83)$, and Instructor 3 was rated 3.78 out of 5 on average $(n=27)$. Thus, after the first two meetings with their instructors, more students tended to perceive Instructor 1 as effective. However, nearly all students rated their instructor's effectiveness with a 4 or 5 in the beginning of the semester. See the chart below (Figure 19) to observe the general distribution of perceived instructional quality.

$50 \%$

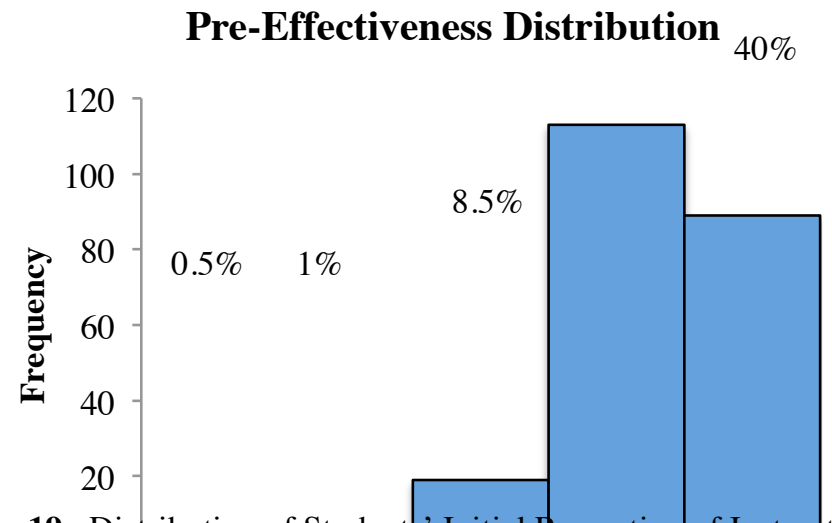

Figure 19. Distribution of Students' Initial Perception of Instruqtor Effectiveness
1
2
3
4
5

On the post-surveys, pafteqpiafds Instrectskedfegtivamefow effectively they believed their instructors presented the material over the course of the semester. On average, students rated their instructors a 4.22 out of 5 . Instructor 1 was rated 4.57 on average $(n=$ 106), Instructor 2 was rated 3.9 on average $(n=79)$, and Instructor 3 was rated a 3.53 on average $(n=17)$. Thus, after the entire semester with the instructors, more students still tended to perceive Instructor 1 as the most effective. Interestingly, though the overall averages were approximately the same, in the post-surveys, there were a larger number of low ratings. The specific statistical changes in how students perceived their instructor's 
effectiveness over the course of the semester are described in the following section. See the chart below (Figure 20) to observe the distribution of perceived instructional quality at the end of the semester.

Figure 20. Distribution of Students' Final Perception of Instructor Effectiveness

\section{Final Course Averages in BUS 111}

Upon completion of the course, BUS 111 instructors were asked to send students' final grades to the researcher. While letter grades were provided, course averages (rounded to two decimal places) were specified as well, in hopes of leading to more accurate prediction equations. The overall course average for all students during the Fall 2015 semester was a $74.593 \%$ (corresponding to a "C" letter grade) The overall distribution of the grades is shown below (Figure 21). Additionally, six students $(2.256 \%)$ withdrew from the course or dropped the course before the end of the semester. Thus, these final averages may appear slightly inflated, as those students who drop the course generally do so because they are struggling with the course material. Below the graphs is a table (Table 5) detailing the overall final course grades in BUS 111. The table has a bolded line indicating that all students below the line earned unsuccessful grades.

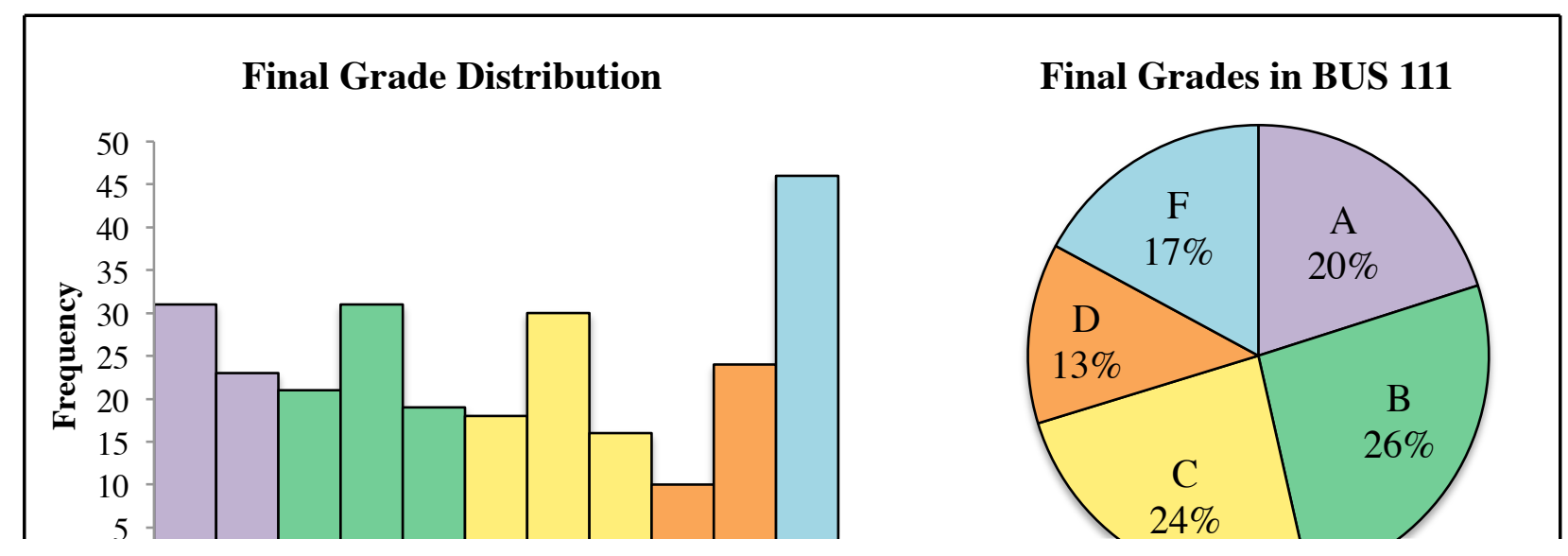


Figure 21. Distribution of Students' Final Averages in BUS 111

\section{Placement exam}

scores were examined for general validity and accuracy. In addition to the correlations and regressions investigating placement scores, described later in this chapter, I also examined the average final course grade in BUS 111 for each placement group. I found the following results:

\begin{tabular}{|c|cl|}
\hline Placement Group & \multicolumn{2}{|c|}{ Average Course Grade } \\
\hline Did not take & 66.601 & (D) \\
\hline A & 70.429 & (C-) \\
\hline A/B & 73.257 & (C) \\
\hline B & 70.620 & $(\mathrm{C}-)$ \\
\hline B/C & 82.003 & $(B-)$ \\
\hline
\end{tabular}

Table 5. Breakdown of Students' Final Letter Grades in BUS 111

\begin{tabular}{|l|ll|}
\hline $\mathrm{C}$ & 83.383 & $(\mathrm{~B})$ \\
\hline $\mathrm{C} / \mathrm{D}$ & 87.169 & $(\mathrm{~B}+)$ \\
\hline $\mathrm{D}$ & 95.610 & $(\mathrm{~A})$ \\
\hline
\end{tabular}

\begin{tabular}{|c|c|c|c|c|}
\hline $\begin{array}{l}\text { Letter Grade } \\
\text { Earned }\end{array}$ & $\begin{array}{l}\text { Number of } \\
\text { Students }\end{array}$ & $\begin{array}{l}\text { Percentage of } \\
\text { Students }\end{array}$ & $\begin{array}{l}\text { Number of } \\
\text { Students }\end{array}$ & $\begin{array}{l}\text { Percentage of } \\
\text { Students }\end{array}$ \\
\hline A & 31 & $11.524 \%$ & \multirow{2}{*}{54} & \multirow{2}{*}{$20.074 \%$} \\
\hline A- & 23 & $8.550 \%$ & & \\
\hline $\mathrm{B}+$ & 21 & $7.807 \%$ & \multirow{3}{*}{71} & \multirow{3}{*}{$26.394 \%$} \\
\hline B & 31 & $11.524 \%$ & & \\
\hline B- & 19 & $7.063 \%$ & & \\
\hline $\mathrm{C}+$ & 18 & $6.691 \%$ & \multirow{2}{*}{48} & \multirow{2}{*}{$17.844 \%$} \\
\hline $\mathrm{C}$ & 30 & $11.152 \%$ & & \\
\hline C- & 16 & $5.948 \%$ & \multirow{4}{*}{96} & \multirow{4}{*}{$35.688 \%$} \\
\hline $\mathrm{D}+$ & 10 & $3.717 \%$ & & \\
\hline $\mathrm{D}$ & 24 & $8.922 \%$ & & \\
\hline $\mathrm{F}$ & 46 & $17.100 \%$ & & \\
\hline
\end{tabular}

Table 6. Final Averages in BUS 111 and Placement Results 
Thus, it seems that on average, students in this research who took the mathematics placement exam and earned higher placement scores also earned higher final grades in BUS 111. Students who did not take the placement exam were, on average, unsuccessful in the course (earning a $\mathrm{C}$ - or lower). This may be easier to see in the following graph (Figure 22), plotting placement group against final average earned in BUS 111:

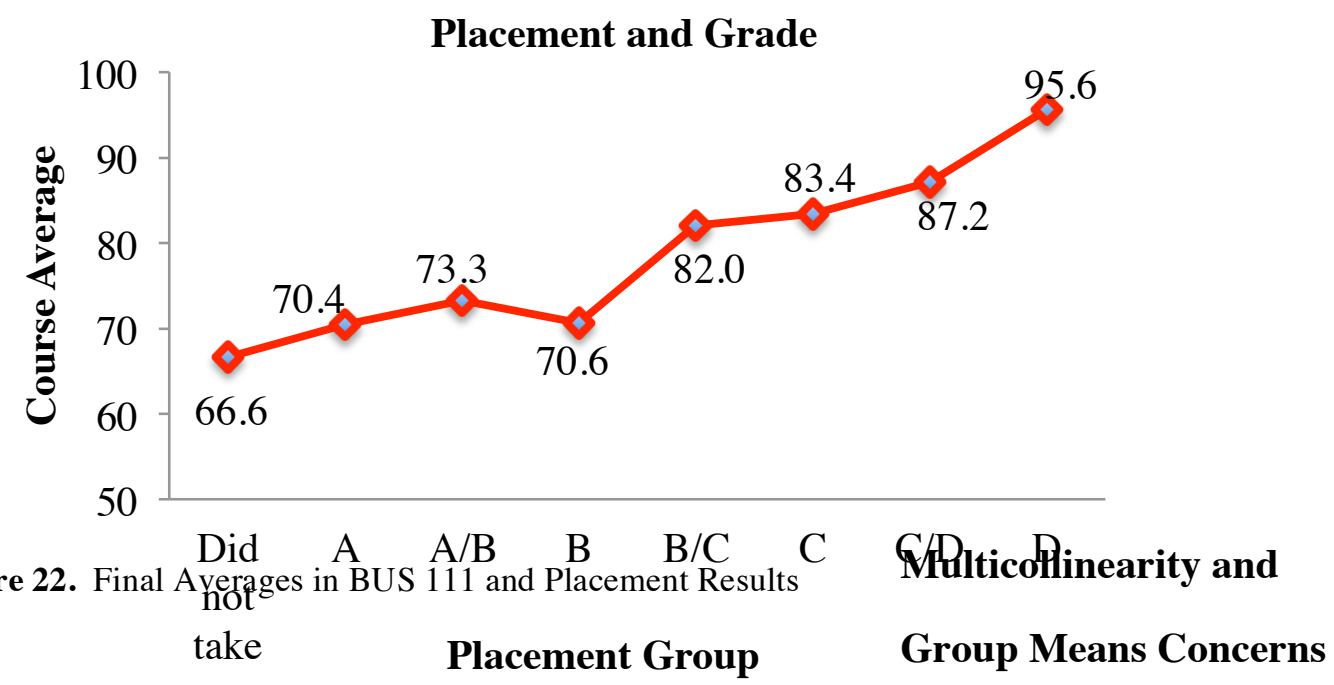

Many of the predictor variables examined in this research were anticipated to correlate with one another on a statistically significant level $(\alpha=0.01)$. Therefore, multicollinearity was an initial concern and statistics were performed in SPSS to determine whether the regression analysis was affected by these correlations (Chen et al., 2003; Leaper et al., 2012). Strong correlations among the predictor variables can lead to less accurate predictions in the multiple regression analysis (Hair et al., 1998; Huck, 2012; Weiss, 2008).

\section{Correlations and Multicollinearity}

Significant correlations among some of the independent variables did exist. As anticipated, student participants' ATMI results were strongly, negatively correlated with their MAS results $(r=-0.879 ; p=0.000)$, indicating that, in general, students with higher levels of mathematical anxiety also tended to have less favorable overall attitudes 
towards mathematics. In addition, students' mathematics placement exam scores were negatively correlated with their mathematical anxiety $(r=-0.319 ; p=0.000)$ and were positively correlated with: students' attitudes towards mathematics $(r=0.273 ; p=$ 0.000), students' mathematics SAT scores $(r=0.385, p=0.000)$, and students' high school GPAs $(r=0.200, p=0.008)$. Further, the student participants' SAT scores were negatively correlated with their mathematical anxiety levels $(r=-0.203, p=0.003)$. In general, students with lower test scores from high school tended to hold less favorable attitudes towards mathematics and had greater mathematical anxiety.

On the post-surveys, the amount of time student participants' reported working on mathematics over the course of the semester was negatively correlated with post-survey ATMI results $(r=-0.242 ; p=0.001)$ and positively correlated with post-survey MAS results $(r=0.308 ; p=0.000)$, indicating that students who spent more time working on the course also tended to have less favorable attitudes towards mathematics and higher levels of mathematical anxiety. Similarly, on the post-surveys, the amount of time participants reported working on mathematics over the course of the semester was negatively correlated with both their SAT scores $(r=-0.235 ; p=0.000)$ and their placement scores $(r=-0.259, p=0.001)$, indicating that those with lower test scores tended to spend more time working on mathematics. Finally, students' high school GPAs were negatively correlated with their self-reported number of absences $(r=-0.282 ; p=$ 0.000), indicating that students with lower high school GPAs tended to miss more BUS 111 classes than their peers.

As recognized from the low correlation coefficients presented, even though these correlations were all statistically significant, the majority of the correlations were fairly weak (most were between $-0.3<r<0.4$ ). Before specifically examining collinearity statistic requirements using SPSS, the rule of thumb is generally that correlation coefficients between $-0.7<r<0.7$ will likely not warrant regression model concerns (Myers, 1990). Thus, the only correlation that initially concerned me in terms of 
multicollinearity was the strong, negative relationship between student attitudes towards mathematics and their mathematical anxiety.

Because of these correlations, tolerance levels and variance inflation factors (VIF) were examined in SPSS to determine whether certain variables needed to either be eliminated from the model or combined with other variables due to multicollinearity concerns (Huck, 2012; Myers, 1990). A variance inflation factor measures how much of the variance in the regression coefficients is due to multicollinearity, or strong correlations between some of the independent variables. Comparably, "tolerance refers to the percent of variance associated with a particular predictor that cannot be accounted for by the other predictors. Tolerance values above 0.10 are generally considered adequate" but tolerance values above 0.20 are preferred (Leaper et al., 2012, p. 275-276). Similarly, VIF statistics that are below five are considered acceptable in regression models, and VIF scores greater than ten require further investigation or modifications (Kutner et al., 2003; Myers, 1990). In addition, it is usually desirable to have the average VIF score of all of the independent variables relatively close to one.

In the initial, simultaneous multiple regression model, using all of the independent variables (see the next section for exact details), tolerance statistics were all above 0.23 and VIF scores were all below 4.5, creating an average VIF score of 2.03, which were considered acceptable. However, only mathematical anxiety and attitudes towards mathematics (as measured by the MAS and ATMI, respectively) were even close to reaching these limits. All other tolerance statistics were above 0.6 and all other VIFs were below 1.6 creating an average VIF of 1.25, which would be considered very good. This was not surprising, since these two variables were found to be so strongly correlated with each other $(r=-0.879 ; p=0.000)$. By combining these measures, I was able to reduce the effects of multicollinearity on the overall regression model. Specifically, once these were measured as a single variable, labeled "Math_Emotions" in SPSS, all tolerance statistics were above 0.65 and all VIF scores were below 1.535 , creating an 
average VIF score of only 1.21, which are all considered very good. Therefore, combining these affective variables allowed me to develop a more robust model. In the description of the multiple regression analyses below, I therefore describe regression models using both attitudes towards mathematics and mathematical anxiety as separate predictors as well models using a combination of these measures, which I indicate as the mathematical emotions predictor (calculated as MAS score subtracted from ATMI score).

There were also correlations, as predicted, between each of the independent variables and the dependent variable: final course average (note that this is one of the required assumptions of linear regression, and is therefore described in more detail in the following section). Final averages in BUS 111 were positively correlated with students' high school GPAs $(r=0.507 ; p=0.000)$, attitudes towards mathematics $(r=0.489 ; p=$ $0.000)$, the university's placement scores $(r=0.386 ; p=0.000)$, and SAT scores $(r=$ 0.227; $p=0.000)$. This indicates that students with higher SAT scores, GPAs, and placement scores tended to earn higher grades in BUS 111. Additionally, students with more favorable attitudes towards mathematics tended to earn higher final grades. In terms of the four facets of student attitudes towards mathematics, as measured by the ATMI, those with highest levels of confidence tended to earn higher BUS 111 final grades $(r=$ 0.436; $p=0.000)$. Final averages in BUS 111 were negatively correlated with students' anxiety levels in mathematics $(r=-0.452 ; p=0.000)$, and number of classes missed over the course of the semester $(r=-0.451 ; p=0.000)$. This indicates that students with higher levels of mathematical anxiety and students who missed a greater number of classes tended to earn lower grades in BUS 111. These correlations with the dependent variable led me to believe that the regression model would likely be statistically significant, as it further confirmed the assumption of linear relationships between the independent variables and the dependent variable.

Group Differences: Repeaters and Instructors 
Eighteen of the 224 initial participants (7.3\%) were taking BUS 111 for the second time. The reason they were retaking the course was not specifically provided, but most students only re-take the course after earning a C- or lower the first time (termed an "unsuccessful completion"), as students must receive a $\mathrm{C}$ or better in this course in order to continue in a College of Business degree program. Because these students may have had different experiences and thus may have had different responses on the surveys, $t$ tests were run in SPSS to determine whether significant differences existed in this group on each of the variables. The $t$-tests revealed only one significant difference in all of the pre-survey variables between students who were taking BUS 111 for the first time and those who had taken BUS 111 before. Specifically, students who were repeating BUS 111 had significantly lower high school GPAs (mean $=2.83$ on a 4.6 scale) than those students taking BUS 111 for the first time (mean $=3.35$ on a 4.6 scale; $p=0.000$ ). There were no other initial significant differences between these two groups.

On the post-surveys, results were again similar for students who were retaking BUS 111. The post-survey $t$-test results revealed only two new statistically significant differences between students who were taking BUS 111 for the first time and those who had taken the course before. Specifically, students who were repeating BUS 111 had significantly lower attitudes towards mathematics on the post-surveys than students who were taking BUS 111 for the first time, though there was no significant difference on the initial survey. Repeating students reported an average post-ATMI score of 126.5 whereas first time students reported an average post-ATMI score of $142.96(p=0.000)$. In addition, repeating students reported an average post-MAS score of 43.69 versus first time students' average post-MAS score of 36.95, indicating students who were retaking BUS 111 had significantly higher levels of mathematical anxiety after taking the course again $(p=0.000)$. Other than these variables, there were no significant differences between these groups and, specifically, those who were repeating the course did not earn significantly different final grades in BUS 111. 
Three different instructors were assigned to teach BUS 111 when this research was performed: I will refer to them as Instructor 1, Instructor 2, and Instructor 3. To examine the potential differences in student responses amongst the different instructors, ANOVA analyses were performed in SPSS (Weiss, 2008). On the pre-surveys, only the students' perception of their instructor's effectiveness was significantly different among the different instructors at the $\alpha=0.01$ significance level. However, using the Tukey HSD post-hoc test to examine these differences in SPSS, only Instructor 1 was significantly different in terms of how students perceived her effectiveness. Recall from the previous section that Instructor 1 was perceived to be the most effective. The other two instructors were not significantly different from each other on this variable.

On the post-surveys, the instructors were also significantly different on: the amount of time their students reported working on mathematics outside of class each week, students' perceived instructor effectiveness, and students' ATMI and MAS scores. Specifically, students reported spending significantly more time in Instructor 2's class (by approximately 1.89 hours per week) than in the other two instructors' courses ( $p=$ 0.000). Only Instructor 2 was significantly different on this variable. Similarly, and mirroring the pre-surveys, only Instructor 1 was significantly different from the others in terms of how students perceived her effectiveness, with her again being seen as significantly more effective than the other two instructors $(p=0.000)$. Only Instructor 1 and Instructor 2 were significantly different from one another in terms of their students' $\operatorname{ATMI}(p=0.001)$ and MAS scores $(p=0.000)$. Students displayed more favorable attitudes towards mathematics and lower levels of anxiety in Instructor 1's course (ATMI mean $=146.51 ;$ MAS mean $=35.17)$ than in Instructor 2's course $($ ATMI mean $=134.37$; MAS mean $=40.89)$. Multiple comparisons in SPSS revealed that Instructor 3 was not significantly different from the other instructors on these variables.

Significant differences were also found to exist between the BUS 111 instructors and the students' final grades. Instructors submitted their final averages as well as their 
students' scores on the three course exams. The instructors used very similar exams and each exam covered the same topics. Averages for each of these assessments (only for students who chose to participate in this research) are shown in the table below (Table 7):

\begin{tabular}{|c|c|c|c|c|c|}
\hline Instructor & $\begin{array}{c}\text { Number of } \\
\text { Students }\end{array}$ & $\begin{array}{c}\text { Exam 1 } \\
\text { Average }\end{array}$ & $\begin{array}{c}\text { Exam 2 } \\
\text { Average }\end{array}$ & $\begin{array}{c}\text { Exam 3 } \\
\text { Average }\end{array}$ & $\begin{array}{c}\text { Course } \\
\text { Average }\end{array}$ \\
\hline 1 & 122 & 77.31 & 75.34 & 70.31 & 77.01 \\
\hline 2 & 93 & 82.18 & 66.67 & 64.84 & 72.75 \\
\hline 3 & 29 & 70.03 & 65.24 & 52.88 & 65.98 \\
\hline Overall & 244 & 78.30 & 70.83 & 66.15 & 74.07 \\
\hline
\end{tabular}

Table 7. Breakdown of Individual Exam Grades and Final Averages

While the table shows some disparities in grades overall, not all of these disparities in grades were different on a statistically significant level. On exam one, Tukey HSD post-hoc tests revealed that only Instructor 2 and Instructor 3 were significantly different from one another $(p=0.001)$; on exam two, only Instructor 1 was significantly different from the other two instructors $(p=0.034$ for Instructor $2 ; p=0.006$ for Instructor 3); and on exam three, only Instructor 1 and Instructor 3 were significantly different from each other $(p=0.003)$. Similarly, in terms of final course grades, only Instructor 1 and Instructor 3 had final averages that were significantly different from one other $(p=0.008)$. With these differences in mind, separate multiple regression analyses for each instructor will be considered later in this chapter.

\section{$t$-Test Results}

\section{Gender Differences in BUS 111 Success}

Male and female students were different from each other at a statistically significant level on a few variables from the pre-surveys and the data gathered from admissions. Females earned statistically significantly higher GPAs in high school (by about 0.303 points $)$ than their male counterparts $(p=0.000)$. Females also expected to miss, on average, 0.41 fewer BUS 111 classes over the course of the semester than males $(p=0.006)$, as determined by the pre-survey. On the post-surveys, there were no 
significant differences between the results of females and the results of males in BUS 111. This suggests that, though females anticipated they would miss fewer classes than their male peers at the beginning of the semester, in the end, they missed approximately the same number of classes (on average).

Significant differences also existed between males and females in their final BUS 111 grades. Females scored higher on the third exam of the semester $($ mean $=73.85)$ than their male counterparts (mean $=61.73)$ at a statistically significant level $(p=0.000)$. Additionally, females earned higher overall averages in BUS 111 by about 8.22 percentage points than males $(p=0.000)$. Because of these differences, multiple regression statistics were run on the BUS 111 group as a whole and then multiple regression statistics were also run on males and females separately to see if different independent variables were significant for each gender (similar to Smith \& Schumacher, 2005). With such significant differences in the dependent variable, it was necessary to examine the two genders separately to determine whether higher $\mathrm{R}^{2}$ values could be achieved. The results of each of these analyses are explained in the section on multiple regression found later in this chapter.

\section{Change in Attitude Towards Mathematics}

Research Question Addressed: How do student attitudes towards mathematics change after taking BUS 111 at URI?

As described above, BUS 111 students' overall ATMI scores were, on average, lower on the post-surveys than they were on the pre-surveys, indicating that students had more favorable attitudes towards mathematics before taking the course than they did upon completion of the course. However, this change needed to be tested for statistical significance. A paired samples $t$-test was run on the ATMI variable in SPSS to determine whether students' attitudes towards mathematics significantly changed after taking BUS 111. The paired sample $t$-test revealed that students' attitudes towards mathematics did not significantly change $(p=0.303)$. This suggests that the BUS 111 course did not 
statistically affect students' overall attitudes towards mathematics. This may indicate that, without specific course goals in place to change student attitude, student attitudes tend to remain stable.

As explained in more detail in chapter three, the ATMI consists of four subscales to measure various facets of student attitude towards mathematics: self-confidence, value/relevance, enjoyment, and motivation (Tapia, 1996). Paired samples $t$-tests were run with student participants on each of these four subscales to determine whether significant differences existed on any single facet of student attitude. Though their overall attitudes may not have changed significantly, it was possible that significant changes existed on one or more of the individual subscales. On average, students' confidence on the pre-survey was 52.97 out of 75 ( $70.63 \%$ confident) and on the postsurvey was a 51.73 out of 75 (68.97\% confident). Similarly, students' value of mathematics on the pre-survey was a 39.69 out of $50(79.38 \%)$ and on the post-survey was a 39.62 out of 50 (79.24\%). Students' average enjoyment of mathematics on the presurvey was a 33.91 out of $50(67.82 \%)$ and on the post-survey was a 33.63 out of 50 (67.26\%). Finally, students' motivation levels were, on average, a 16.43 out of 25 $(65.72 \%)$ on the pre-surveys and a 16.10 out of $25(64.40 \%)$ on the post-surveys. Thus, each individual subscale of attitude measurement decreased after taking BUS 111. See the graph below (Figure 23) for a visual representation of these values.

\section{Changes in ATMI Sub-Scales}

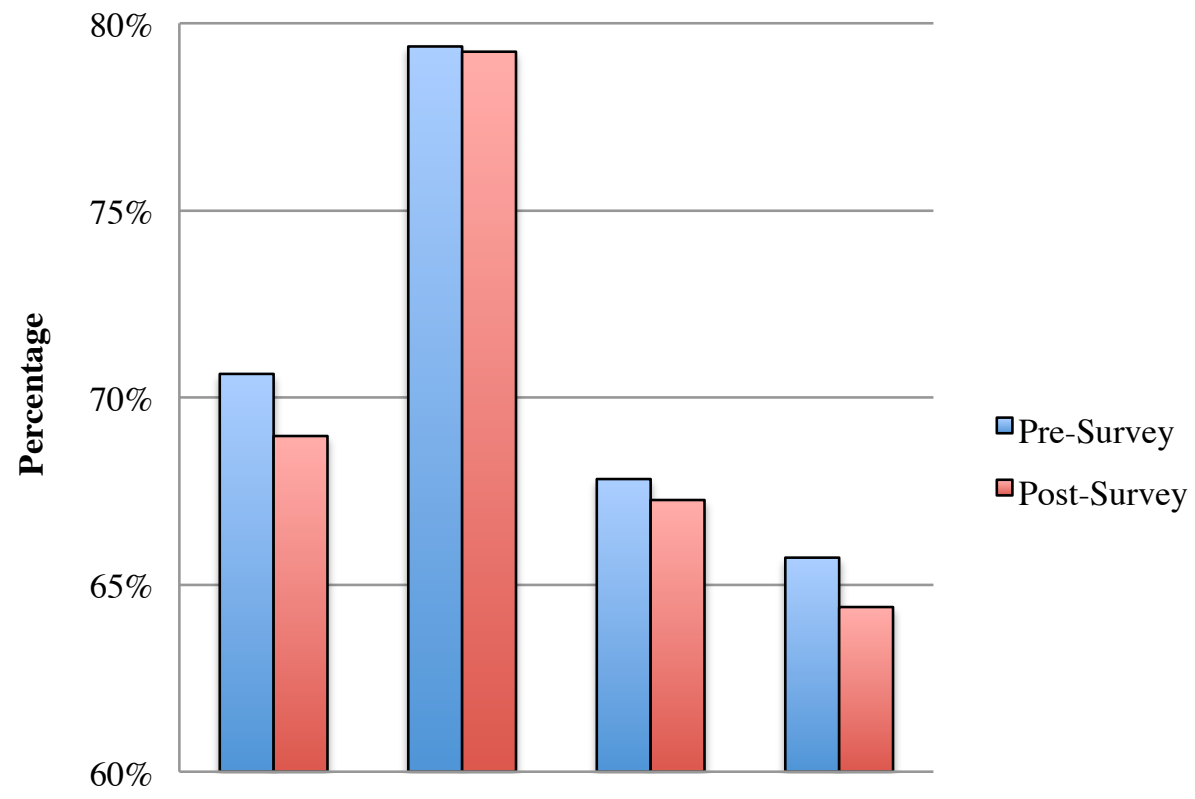


Figure 23. ATMI Pre- and Post-Survey Subscale Changes

Therefore, I could conclude that on average, student participants had lower overall levels of confidence in mathematics, saw mathematics as a less valuable and less enjoyable subject, and had lower motivation levels in mathematics after completing BUS 111 than they did before the course began. However, a paired samples $t$-test run in SPSS revealed that the only statistically significant change (at the $\alpha=0.05$ significance level) in these four attitude subscales was student confidence (see Table 8 below for a more detailed breakdown of each of these changes). Student confidence levels in mathematics were significantly lower at the end of the semester than they were at the beginning of the semester $(p=0.040)$. Additionally, ANOVA tests in SPSS revealed that statistically significant differences existed between students' post-survey confidence levels in Instructor 1's class versus the confidence levels in the other two instructors' classes. Specifically, Instructor 1's students felt significantly more confident $(p=0.001)$ than students in Instructor 2 and Instructor 3's classes, with arithmetic means of 54.29 (72.39\%) in Instructor 1's class and means of only $48.12(64.16 \%)$ and $51.67(68.89 \%)$ in Instructor 2's class and Instructor 3's class, respectively. Interestingly, no such differences existed in these students' confidence levels at the beginning of the semester in BUS 111.

\begin{tabular}{|c|c|c|c|c|}
\hline $\begin{array}{c}\text { ATMI } \\
\text { Subscale }\end{array}$ & $\begin{array}{c}\text { Pre-Survey } \\
\text { Average }\end{array}$ & $\begin{array}{c}\text { Post-Survey } \\
\text { Average }\end{array}$ & Change & $\boldsymbol{p}$-value \\
\hline Confidence & $70.63 \%$ & $68.97 \%$ & $-1.66 \%$ & 0.040 \\
\hline Value & $79.38 \%$ & $79.24 \%$ & $-0.14 \%$ & 0.821 \\
\hline Enjoyment & $67.82 \%$ & $67.26 \%$ & $-0.56 \%$ & 0.432 \\
\hline Motivation & $65.72 \%$ & $64.40 \%$ & $-1.32 \%$ & 0.207 \\
\hline
\end{tabular}




\begin{tabular}{|c|c|c|c|c|}
\hline ATMI Total & $71.51 \%$ & $70.90 \%$ & $-0.61 \%$ & 0.303 \\
\hline
\end{tabular}

Table 8. Pre- and Post-Survey Results of ATMI Subscales

Change in Mathematical Anxiety

Research Question Addressed: How does student mathematical anxiety change after taking BUS 111 at URI?

As described above, students' MAS scores were, on average, slightly higher on the pre-surveys than they were on the post-surveys, indicating that they were more anxious about mathematics before the course began. This is not entirely surprising, as most of these students were freshmen who were unfamiliar with college mathematics courses. A paired samples $t$-test was run on this variable to determine whether students' mathematical anxiety levels significantly changed after taking BUS 111. The $t$-test revealed that students' mathematical anxiety did not significantly change $(p=0.912)$. This suggests that BUS 111 did not significantly impact how anxious students felt about mathematics. This may indicate that student anxiety levels are difficult to change, or that no actions were taken in an attempt to lessen student anxiety in the course. This is explored in more detail in chapter six (discussion and implications).

\section{Change in Perceived Instructor Effectiveness}

On average, students tended to rate their perception of their instructor's effectiveness higher at the beginning of the semester than they did at the end of the semester. A paired $t$-test was also run on this variable to determine whether students' perceptions of their instructor's effectiveness significantly changed after completing the course. The test revealed that how students perceived their instructor's effectiveness did not significantly change from the first week of the semester to the last week of the semester $(p=0.207)$, indicating that students generally stuck with their initial perceptions of their instructors. This suggests that students may make decisions about their instructor's effectiveness early on in the semester. First impressions may stick with students throughout the 15-week course. 


\section{Multiple Regression Results}

Overarching Research Question Addressed: What factors best predict success in a foundational business mathematics course (BUS 111 at URI)?

\section{Multiple Regression Assumptions Satisfied}

As with all statistical tests, certain assumptions had to be satisfied in order to run

multiple regression analyses and avoid errors or misleading results (Huck, 2012; Osborne $\&$ Waters, 2002). First, multiple regression assumes that a linear relationship exists between each of the independent variables and dependent variable. Typically, if a linear relationship is not present, then the resulting regression equations will actually underestimate the relationship between the variables (Osborne \& Waters, 2002). This assumption was tested using a scatterplot matrix and a correlation matrix. In the scatterplot matrix, I was looking for fairly linear relationships between the predictors and BUS 111 final course average. As shown on the following page (Figure 24), these relationships appear fairly linear, but more inspection was required, as is often the case, because not all of the independent variables were continuous. 
Thus, in the correlation matrix, I was checking to make sure that significant correlations existed between the dependent variable and each independent variable, which was satisfied (all $p \leq 0.001$ ). These specific correlations were discussed in more detail in the previous section, and can be seen in the last row or last column of the correlation matrix (Table 9). Additionally, I recognized that some of the $p$-values 


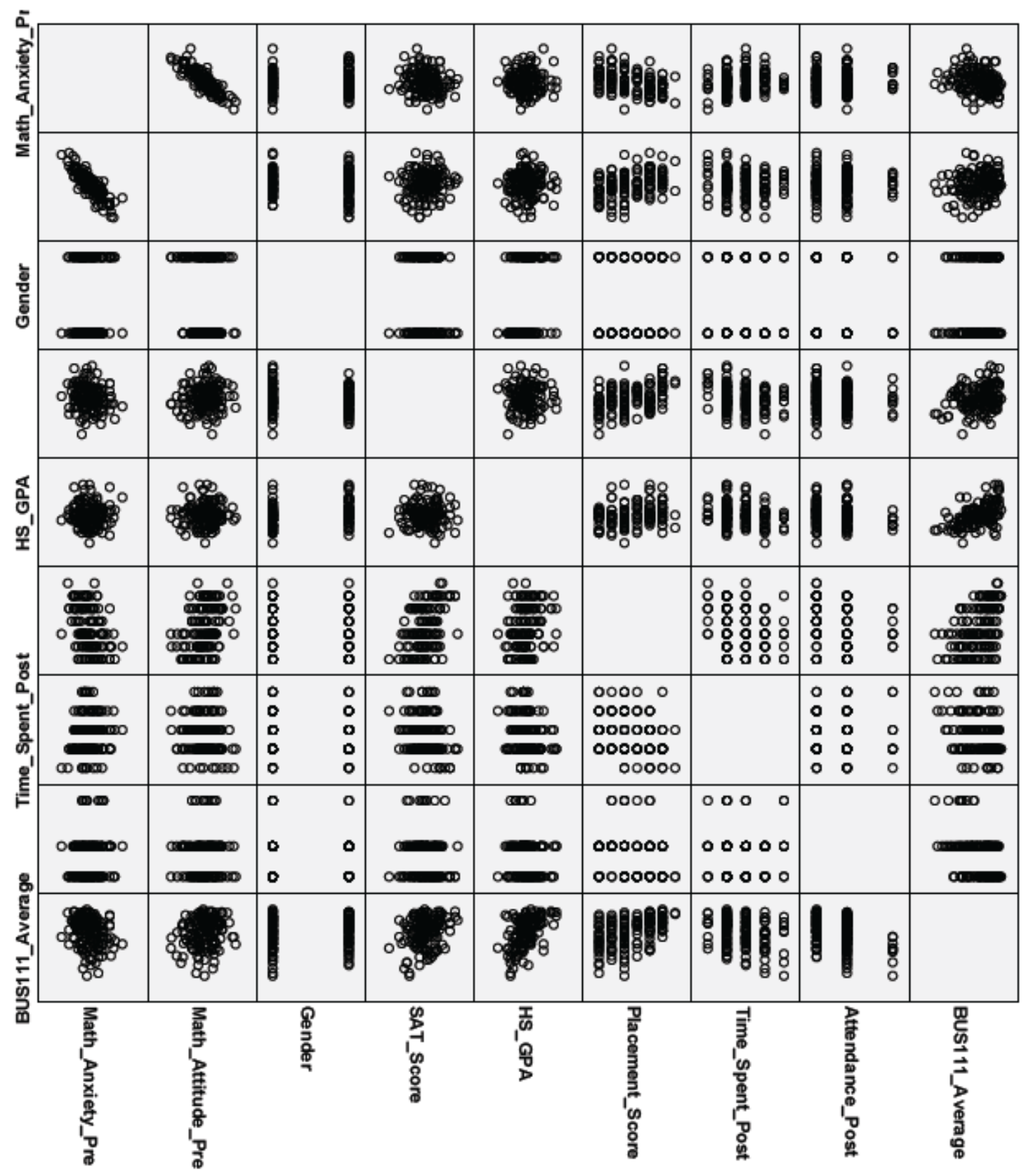

Figure 24. Scatterplot Matrix

between the independent variables were 0.000 , which could indicate multicollinearity. However, they can be correlated to some degree, as the regression analysis accounts for this. Typically, as mentioned above, correlation coefficients of $|r|>0.7$ warrant concern. So, again, only the relationship between attitudes towards mathematics and mathematical 
anxiety posed a potential concern. This correlation matrix is shown in full on the following page, labeled Table 9 .

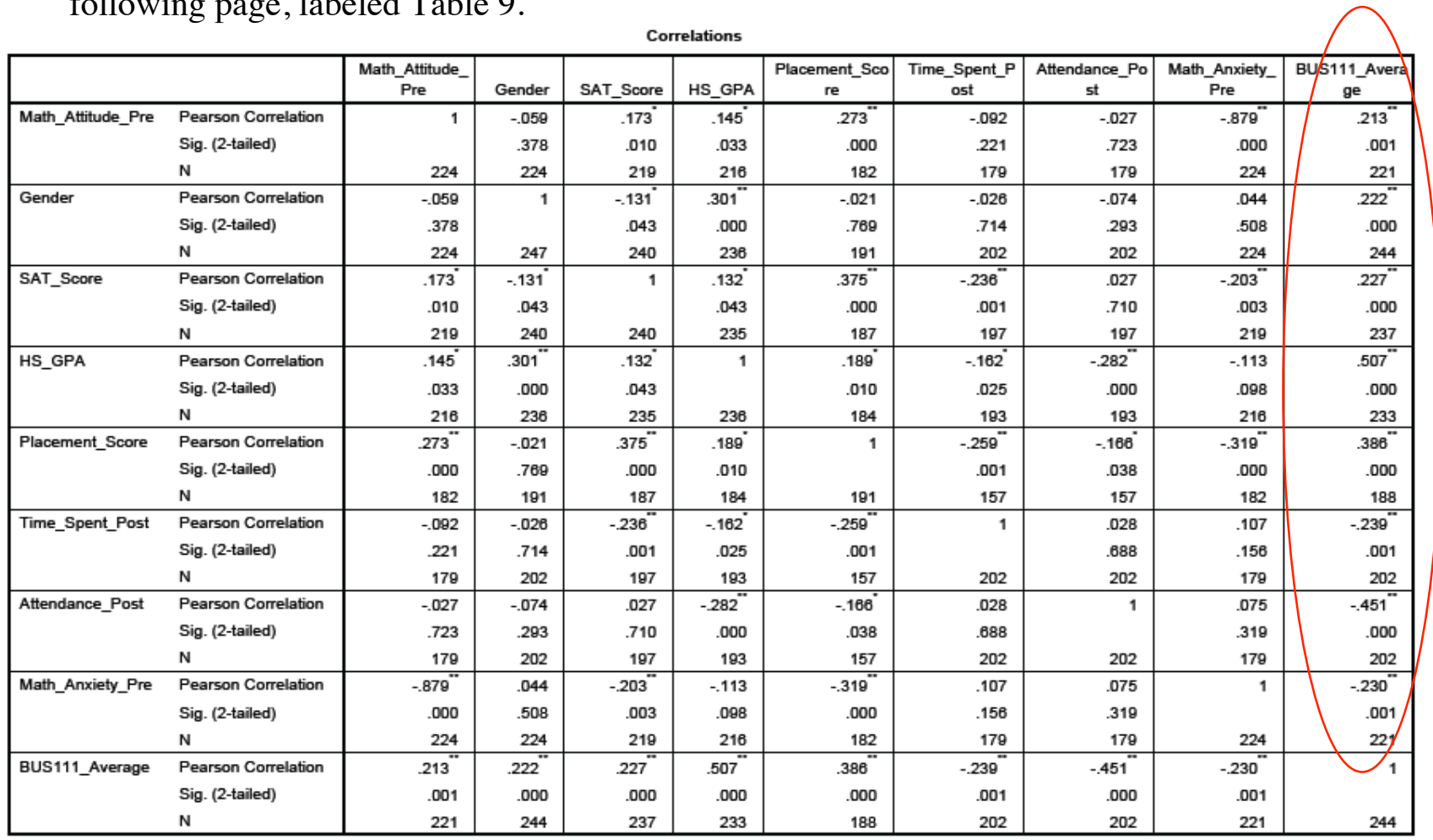

$\approx$. Correlation is significant at the 0.05 level (2-tailed).

$\approx x$. Correlation is significant at the 0.01 level (2-tailed).

This assumption is closely tied to the assumption of independent residuals and independent observations, also required for multiple regression analyses (Huck, 2012; Osborne \& Waters, 2002). The independent observations assumption is generally met by design, as it was here, because this was not a longitudinal study and thus each participant was independent. Though pre- and post-surveys were analyzed in a different part of this research, only one of these two results was used for the multiple regression analysis. To further confirm independent residuals and a linear relationship, I examined the residual scatterplot in SPSS, which shows standardized predicted $y$-values on the $x$-axis and standardized residuals on the $y$-axis. Since there seemed to be no obvious pattern in this graph, with the results roughly centered around zero (see Figure 25), I was able to move forward with the multiple regression (M. Shim, personal communication, January 2015).

Dependent Variable: BUS111_Average

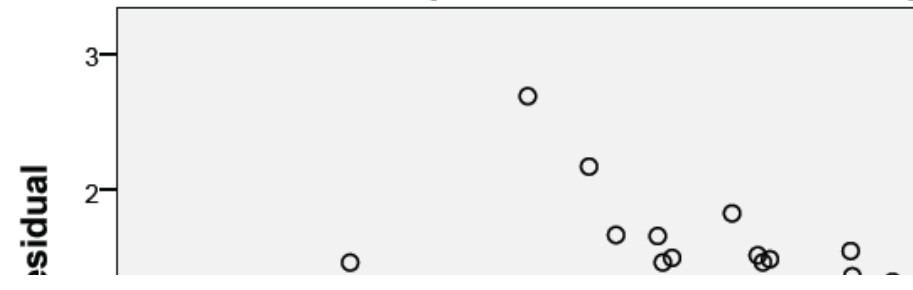


Figure 25. Scatterplot of Residuals

Additionally, this scatterplot shows that as the predicted values increase, the variance of the residuals stays relatively constant, which confirms another assumption of multiple regression, known as homoscedasticity (Huck, 2012). Homoscedasticity refers to the errors in each of the independent variables having relatively equal variance.

Finally, an assumption of multiple regression analysis is that the residual values will be normally distributed. To verify this assumption, I analyzed a histogram of the residuals and found it to be relatively normal (see Figure 26 below). Further, the normal P-P plot (also shown below, Figure 27) was fairly linear. The kurtosis for each of the variables was also examined to investigate normality. Each kurtosis level was between -2 and 2, which is generally considered acceptable for normality (George \& Mallery, 2010). Histogram

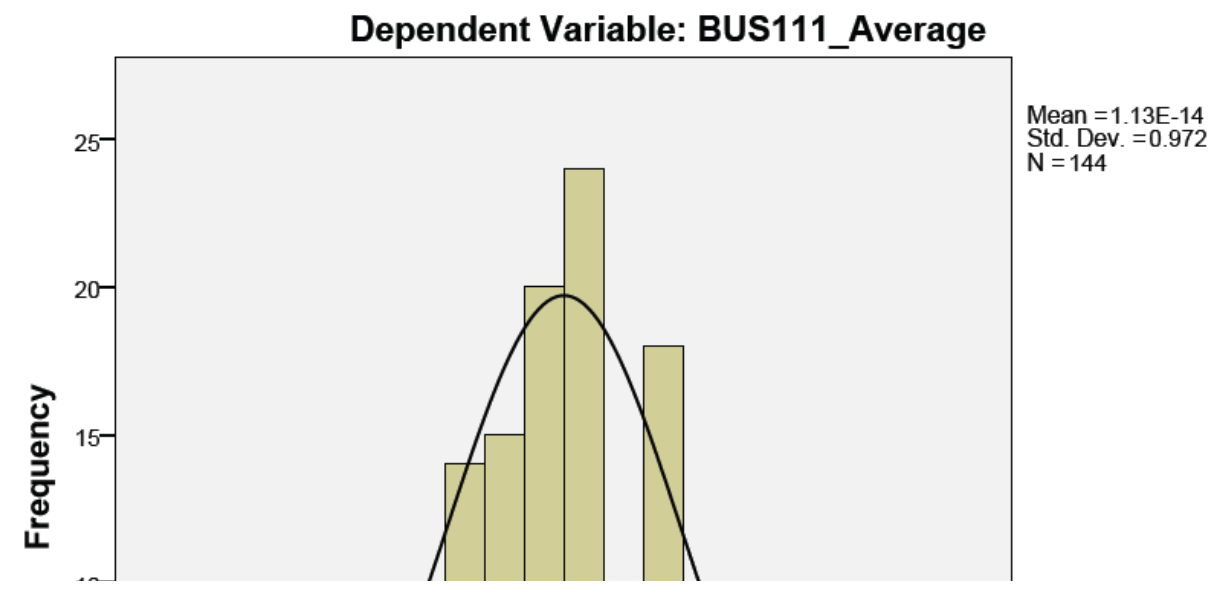


Figure 26. Histogram of Residuals in Dependent Variable

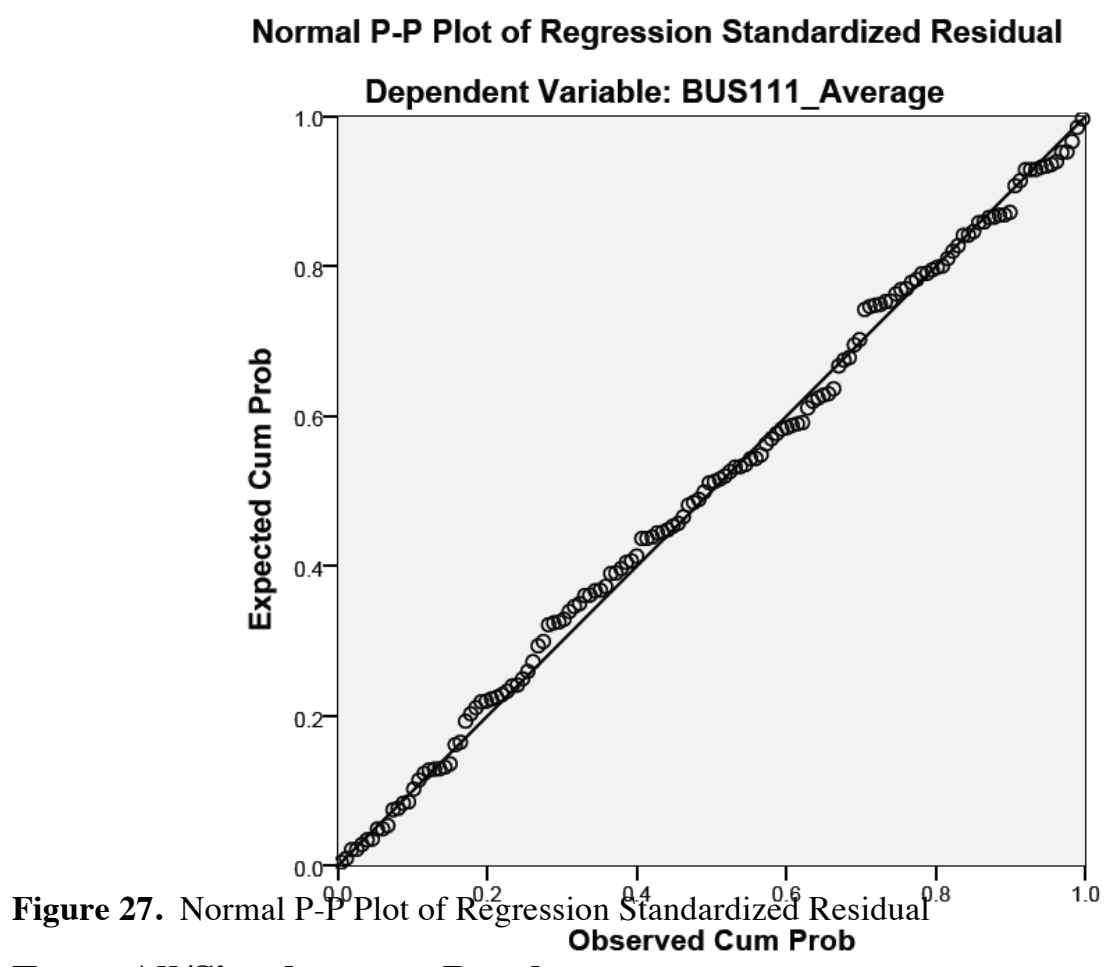

\section{Enter-All/Simultaneous Results}

Initially, all independent variables (gender, mathematics SAT score, high school GPA, placement score, number of absences, hours spent outside of class on mathematics per week, student attitudes towards mathematics as measured by their ATMI score, and student levels of mathematical anxiety as measured by their MAS score) were entered into SPSS to determine which, if any, were significant predictors of BUS 111 course average and to examine whether the model as a whole was significant in making 
predictions. The null hypothesis and alternative hypothesis for this analysis were as follows:

$\mathrm{H}_{0}$ : The regression model is not significant for making predictions about overall BUS 111 average; none of the variance in BUS 111 average can be explained by the combination of these variables because all coefficients are zero.

$\mathrm{H}_{\mathrm{A}}$ : The regression model is significant for making predictions about overall BUS 111 grade; some of the variance in BUS 111 average can be explained by the combination of these variables because at least one coefficient does not equal zero.

This overarching null hypothesis was tested using an ANOVA analysis, the results of which are shown in Table 10 below (Huck, 2012; Osborne \& Waters, 2002; Weiss, 2008). As shown in this table, the $F$-statistic from the ANOVA was $F(8,135)=14.023$ with $p=0.000$, so the null hypothesis was rejected and I was able conclude that the model, using all of the independent variables, was significant in making predictions about the dependent variable, BUS 111 final course average.

ANOVA $^{\text {a }}$

\begin{tabular}{|ll|l|r|r|r|r|}
\hline \multicolumn{2}{|l|}{} & \multicolumn{1}{|c|}{$\begin{array}{l}\text { Sum of } \\
\text { Model }\end{array}$} & \multicolumn{1}{|c|}{ df } & Mean Square & $\mathrm{F}$ & Sig. \\
\hline 1 & Regression & 11664.229 & 8 & 1458.029 & 14.023 & $.000^{\mathrm{b}}$ \\
& Residual & 14036.470 & 135 & 103.974 & & \\
& Total & 25700.699 & 143 & & & \\
\hline
\end{tabular}

a. Dependent Variable: BUS111_Average

b. Predictors: (Constant), Attendance_Post, Math_Attitude_Pre, Time_Spent_Post, Gender, SAT_Score,

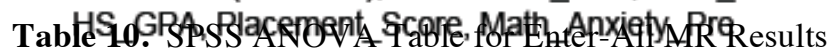

Knowing that the model was significant, I then examined the regression coefficient $(R)$ as well as the coefficient of determination $\left(R^{2}\right)$ value for this enter-all analysis. As shown in Table 11 below, using each of the independent variables produced an $\mathrm{R}^{2}=0.454$, indicating that $45.4 \%$ of the variance in BUS 111 course grade could be explained by this regression model (Huck, 2012; Weiss 2008). Being able to explain this 
amount of variability in the dependent variable is not only statistically significant, but also has great practical significance to advisors and BUS 111 instructors and students.

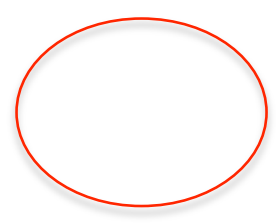

Table 11. SPSS Model Summary for Enter-All MR Results

Additionally, the standard error of the estimate was about 10.2, indicating that the observed BUS 111 averages differed from the values predicted using this model by about 10.2 points. The next piece of output to be analyzed in SPSS was the model itself, that is, the specific regression equation that uses all eight of these independent variables to make predictions about students' final course average in BUS 111. Those results are printed in Table 12 below:

\begin{tabular}{|c|c|c|c|c|c|c|c|c|}
\hline \multirow[b]{2}{*}{ Mod } & & \multicolumn{2}{|c|}{ Unstandardized Coefficients } & \multirow{2}{*}{$\begin{array}{c}\begin{array}{c}\text { Standardized } \\
\text { Coefficients }\end{array} \\
\text { Beta }\end{array}$} & \multirow[b]{2}{*}{$t$} & \multirow[b]{2}{*}{ Sig. } & \multicolumn{2}{|c|}{ Collinearity Statistics } \\
\hline & & $\mathrm{B}$ & Std. Error & & & & Tolerance & VIF \\
\hline \multirow[t]{9}{*}{1} & (Constant) & 27.415 & 23.602 & & 1.162 & .247 & & \\
\hline & Math_Anxiety_Pre & -.220 & .210 & -.140 & -1.043 & .299 & .224 & 4.467 \\
\hline & Math_Attitude_Pre & -.018 & .091 & -.027 & -.203 & .840 & .234 & 4.273 \\
\hline & Gender & 2.082 & 1.828 & .077 & 1.139 & .257 & .878 & 1.139 \\
\hline & SAT_Score & .038 & .020 & .134 & 1.856 & .066 & .771 & 1.296 \\
\hline & HS_GPA & 11.794 & 2.243 & .370 & 5.259 & .000 & .817 & 1.224 \\
\hline & Placement_Score & 1.427 & .634 & .183 & 2.250 & .026 & .610 & 1.640 \\
\hline & Time_Spent_Post & -.647 & .460 & -.095 & -1.407 & .162 & .878 & 1.139 \\
\hline & Attendance_Post & -2.227 & .661 & -.224 & -3.368 & .001 & .917 & 1.091 \\
\hline
\end{tabular}

Table 12. SPSS Coefficients Table for Enter-AII MR Results

From this output, I was able to build and analyze the regression equation if all of the independent variables were used. I will define these variables (and continue to use these same variables for the remainder of this chapter) as follows:

Let $\hat{y}=$ predicted final average in BUS 111

$$
\begin{aligned}
& x_{1}=\text { mathematical anxiety (initial MAS score) } \\
& x_{2}=\text { attitudes towards mathematics (initial ATMI score) }
\end{aligned}
$$




$$
\begin{aligned}
& \left.x_{3}=\text { gender (dummy coded with " } 0 "=\text { male and " } 1 "=\text { female }\right) \\
& x_{4}=\text { mathematics SAT score } \\
& x_{5}=\text { high school GPA } \\
& x_{6}=\text { mathematics placement score } \\
& x_{7}=\text { number of hours spent on mathematics outside of class per week } \\
& x_{8}=\text { number of absences over the course of the semester }
\end{aligned}
$$

Then the regression equation is given as:

$$
\hat{y}=27.415-0.22 x_{1}-0.018 x_{2}+2.082 x_{3}+0.038 x_{4}+11.794 x_{5}+1.427 x_{6}-0.647 x_{7}-2.227 x_{8}
$$

With this equation in mind, I first draw attention to the fact that the $\hat{y}$ - intercept is 27.415. Mathematically, this would typically indicate that if all of the independent variables were equal to zero, we could still expect a student to receive a final course grade in BUS 111 of a $27.415 \%$. In this particular model (and in many regression models in social science fields), however, I want to note that this result is not possible, for the minimum SAT score is 200 , the minimum ATMI score is 40 , the minimum MAS score is 14 , and the minimum placement score is 1 . Thus, earning a zero on these measures is not possible. Further, someone with a GPA of zero would not be admitted to the university, as they likely would not have graduated from high school.

The standardized coefficients (Beta) in a multiple regression model represent which of the predictors are the most important in the model (Weiss, 2008). Specifically, these represent the anticipated change in BUS 111 average using standardized scores corresponding to a change of one standard deviation in that predictor variable, while holding everything else constant (Huck, 2012). Looking at the absolute value of these coefficients, we see that the order of significance in this model, starting with the most significant, is: (1) high school GPA, (2) number of absences, and (3) placement score, 
which are all statistically significant predictors on their own, while holding everything else constant, followed by (4) mathematical anxiety, (5) SAT score, (6) time devoted to mathematics outside of class, (7) gender, and (8) attitude towards mathematics. Since the $p$-values for mathematical anxiety, attitudes towards mathematics, gender, SAT scores, and time spent on mathematics outside of class are all above 0.05 , these variables may not be explaining a significant amount of the variability in course grade on their own, though the model as a whole including them is significant. These standardized coefficients tell us only the order of importance of the variables, as they can be compared to each other directly in standardized form.

The unstandardized coefficients (B) in a multiple regression model explain how much of a change we would expect to see in BUS 111 course average given one unit change of each independent variable, while holding every other variable constant (Huck, 2012). Thus, these coefficients cannot be directly compared to each other (a one point increase in SAT score, measured out of 800 , is very different from a one point increase in GPA, measured out of 4.6, for example). Therefore, using this simultaneous model, we can interpret each of the individual unstandardized coefficients using their specific scales. We would expect a lower grade of 0.22 points in BUS 111 for each additional point scored on the MAS and a 0.018 point decrease in final grade for each additional point on the ATMI. Gender was dummy coded with male = "0" and female = " 1 ", thus, it is interpreted slightly differently (Huck, 2012). Since the unstandardized coefficient for gender is positive, being a female tends to have a positive effect on BUS 111 course average while holding everything else constant. Specifically, females can expect to earn about 2.082 points higher than their male counterparts in this model.

Similarly, we would expect students to earn an additional 0.038 points in the course for each additional point earned on the mathematics portion of the SAT. Since the SAT is scaled in tens, it might be easier to think of this as a 0.38 point increase in course grade for each 10 point increase on the SAT or a 3.8 point increase in course grade for 
each 100 point increase on the SAT. So, someone with a 600 on the mathematics portion of the SAT could expect to earn about 3.8 percentage points higher in BUS 111 than someone with a 500 SAT score, according to this model. We would also expect to see a higher grade of 11.794 points for each point on their high school GPA and 1.427 points higher for each point on the placement exam. This placement coefficient is not a very large increase, considering there are only seven levels of the placement exam. This means that, according to this model, someone who earned a one (group A) on the placement exam would only expect to earn about 8.562 points less in BUS 111 than someone who earned a seven (group D) on the placement exam. We would also expect to see a 0.647 point drop in course average for each extra hour spent on the course. This is interesting and may indicate that students who struggle with the material feel obligated to spend more time working on it outside of class. Finally, we could expect a drop of 2.227 points in course average for each class missed over the semester. Thus, a drop of a letter grade (or about ten points) could be expected to occur after four or five absences.

Using this regression equation would indicate that a male student enrolled in BUS 111 who: scored a 35 on the MAS and a 140 on the ATMI, earned a 580 on the mathematics portion of the SAT and a 3.7 GPA in high school, earned a three (group B) on the placement exam, spent about 3 hours per week working on mathematics outside of class, and missed 2 classes during the semester, would earn a predicted grade in BUS 111 of about a:

$$
\begin{aligned}
\hat{y}=27.415- & 0.22(35)-0.018(140)+2.082(0)+0.038(580)+11.794(3.7) \\
& +1.427(3)-0.647(3)-2.227(2) \\
=80.758 & ( \pm 10.2) \quad \text { (Thus, a letter grade of B-) }
\end{aligned}
$$

\section{Reducing Multicollinearity}

The only problem with the enter-all model described above is the potential bias due to multicollinearity because mathematical anxiety and attitudes towards mathematics were so strongly correlated. Though all VIF scores were below 4.5, which is considered 
acceptable, producing a stronger model with lower VIF statistics was desirable (Kutner et al., 2003; Myers, 1990). Therefore, mathematical anxiety and attitudes towards mathematics were combined as a single predictor "mathematical emotions". The same overarching hypothesis was tested using an ANOVA analysis, the results of which are shown below (Huck, 2012; Osborne \& Waters, 2002; Weiss, 2008). As shown in Table 13 , the $F$-statistic from the new ANOVA is $F(7,144)=17.724$ with a $p$-value of $p=$ 0.000 , so the null hypothesis was easily rejected. I was able conclude that the new simultaneous model, using all of the independent variables, but combining attitudes and anxiety as one predictor, was also significant in making predictions about the dependent variable: BUS 111 final course average.

ANOVA $^{\mathrm{a}}$

\begin{tabular}{|ll|l|r|r|r|r|}
\hline \multicolumn{2}{|c|}{} & \multicolumn{1}{|c|}{$\begin{array}{l}\text { Sum of } \\
\text { Model }\end{array}$} & \multicolumn{1}{|c|}{ df } & Mean Square & $\mathrm{F}$ & Sig. \\
\hline 1 & Regression & 14530.421 & 7 & 2075.774 & 17.724 & $.000^{\circ}$ \\
& Residual & 16864.838 & 144 & 117.117 & & \\
& Total & 31395.259 & 151 & & & \\
\hline
\end{tabular}

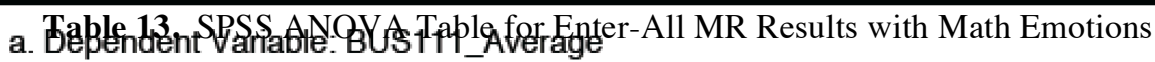

b. Predictors: (Constant), Attendance_Post, Time_Spent_Post, Gender, Math_Emotions, SAT_Score, HS_GPA, Placentben Excrenined the $\mathrm{R}^{2}$ value for this new, modified enter-all analysis. As shown

in Table 14 below, using these seven independent variables produced an $R^{2}=0.463$, indicating that $46.3 \%$ of the variance in BUS 111 course grade could be explained by this regression model (Huck, 2012; Weiss 2008). This is a greater amount of the variability than was explainable with the equation separating anxiety and attitudes, and, because of the removal of the concerns about multicollinearity, is a better model than the first one presented.

Model Summary

\begin{tabular}{|l|c|r|r|r|r|r|r|r|}
\hline & & & & & \multicolumn{4}{|c|}{ Change Statistics } \\
\cline { 6 - 10 } Model & $\mathrm{R}$ & R Square & $\begin{array}{c}\text { Adjusted R } \\
\text { Square }\end{array}$ & $\begin{array}{c}\text { Std. Error of the } \\
\text { Estimate }\end{array}$ & $\begin{array}{c}\text { R Square } \\
\text { Change }\end{array}$ & F Change & df1 & df2 \\
\hline 1 & $.680^{2}$ & .463 & .437 & 10.82206 & .463 & 17.724 & 7 & 144 \\
\hline
\end{tabular}

a. Predictors: (Constant), Attendance_Post, Time_Spent_Post, Gender, Math_Emotions, SAT_Score, HS_GPA, Placement_Score

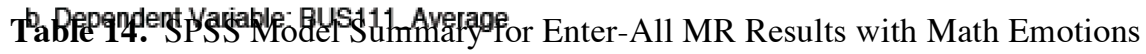


In this case, the standard error of the estimate is about 10.8 , indicating that the observed BUS 111 averages could be expected to differ from the values predicted using this model by about 10.8 points, or one letter grade. The specific regression equation that uses all seven of these independent variables to make predictions about students' final course average in BUS 111 was then examined. Those results are printed in Table 15:

\begin{tabular}{|c|c|c|c|c|c|c|c|c|}
\hline \multicolumn{9}{|c|}{ Coefticients $^{a}$} \\
\hline \multirow{2}{*}{\multicolumn{2}{|c|}{ Model }} & \multicolumn{2}{|c|}{ Unstandardized Coefficients } & \multirow{2}{*}{$\begin{array}{c}\text { Standardized } \\
\text { Coefficients }\end{array}$} & \multirow[b]{2}{*}{$\mathrm{t}$} & \multirow[b]{2}{*}{ Sig. } & \multicolumn{2}{|c|}{ Collinearity Statistics } \\
\hline & & $\mathrm{B}$ & Std. Error & & & & Tolęrance & VIF \\
\hline \multirow[t]{8}{*}{1} & (Constant) & 10.913 & 14.775 & & .739 & .461 & & \\
\hline & Gender & 2.950 & 1.879 & .102 & 1.569 & .119 & .891 & 1.122 \\
\hline & SAT_Score & .028 & .020 & .095 & 1.381 & .169 & .781 & 1.280 \\
\hline & HS_GPA & 12.345 & 2.256 & .363 & 5.472 & .000 & .848 & 1.180 \\
\hline & Placement_Score & 1.277 & .650 & .149 & 1.966 & .051 & .652 & 1.534 \\
\hline & Time_Spent_Post & -.440 & .471 & -.060 & -.934 & .352 & .890 & 1.124 \\
\hline & Math_Emotions & .088 & .035 & .166 & 2.491 & .014 & .841 & 1.190 \\
\hline & Attendance_Post & -3.078 & .632 & -.306 & -4.872 & .000 & .945 & 1.058 \\
\hline
\end{tabular}

Table 15. SPSS Coefficients Table for Enter-AIIMR Results with Math Emotions

From this output, I was able to build and analyze this new regression equation if all of the independent variables were used with attitudes and anxiety combined as mathematical emotions. I will define these new variables as follows (note that $x_{1}$ and $x_{2}$ have been combined to produce $x_{1,2}$, and all other variables remain the same):

Let $\quad \hat{y}=$ predicted final average in BUS 111

$x_{1,2}=$ mathematical emotions (attitudes and anxiety)

$x_{3}=$ gender (dummy coded with " 0 " = male and " 1 " = female)

$x_{4}=$ mathematics SAT score

$x_{5}=$ high school GPA

$x_{6}=$ mathematics placement score

$x_{7}=$ number of hours spent on mathematics outside of class per week

$x_{8}=$ number of absences over the course of the semester 
Then the new regression equation is given as:

$$
\hat{y}=10.913+0.088 x_{1,2}+2.95 x_{3}+0.028 x_{4}+12.345 x_{5}+1.227 x_{6}-0.44 x_{7}-3.078 x_{8}
$$

The standardized coefficients (Beta) in this model show that the order of significance in this equation, starting with the most significant variable, is: (1) high school GPA, (2) number of absences, and (3) mathematical emotions, which are all statistically significant predictors on their own, while holding everything else constant, followed by (4) placement score, (5) gender, (6) SAT score, and finally (7) time devoted to mathematics outside of class. Unlike the original enter-all model, here, the $p$-value for mathematical emotions had $p<0.05$, and thus was significant. However, university placement score, gender, mathematics SAT scores, and time spent on mathematics outside of class were all above 0.05. Therefore these variables, though the model as a whole including them was considered significant, may not be explaining a significant amount of the variability in course grade. This will be addressed in the following section.

The unstandardized coefficients (B) in this model tell us that we would expect a 0.088 point increase in final grade for each additional point in students' mathematical emotions. We would also expect to see a higher grade of 12.345 points for each point on their high school GPA and 1.227 points higher for each point earned on the placement exam. Since the unstandardized coefficient for gender is positive, being a female still tends to have a positive effect on BUS 111 course average while holding everything else constant. Specifically, females can expect to earn about 2.95 points higher than their male counterparts in this model. Similarly, we would expect students to earn an additional 0.028 points in the course for each additional point earned on the mathematics portion of the SAT, or a 2.8 point increase in course grade for each 100 point increase on the SAT. We would also expect to see a 0.44 point drop in course average for each extra hour spent on the course and a drop of 3.078 points in course average for each class 
missed over the semester. Thus, a letter grade decrease could be expected to occur after about three absences.

\section{Step-Wise Results}

Once these initial results were determined, variables were entered into the model in a step-wise action to investigate whether the affective, cognitive variables were more or less significant in student success than the non-affective test scores. Especially since some of the variables in the enter-all models were shown to not be significant, it was important to consider a step-wise model, which adds variables into the model one at a time and includes only the most significant variables. For this reason especially, stepwise multiple regression is the most widely used among researchers in social science fields (M. Shim, personal communication, March 2013). Step-wise multiple regression produces the most parsimonious result, as it determines a significant regression equation using the fewest number of predictors. After each new variable is entered, an ANOVA analysis is run to determine whether adding in the new variable helped explain a statistically significant amount of variability in BUS 111 average (Huck, 2012). If the new variable entered into the model is unable to explain significantly more of the dependent variable's variance (in other words, if the change in $\mathrm{R}^{2}$ is not statistically significant), then it will be removed from the model to produce a more efficient result with fewer variables. The order in which the predictors are entered is based on correlations with the dependent variable, and variables are added and deleted at each step to determine the best model. Relying on fewer predictors often makes the equation more practical to use, as only a few data points need to be obtained from students and entered into the model in order to predict their BUS 111 final average. Thus, the results of the step-wise multiple regression are analyzed in this section.

Similar to the simultaneous method, the null hypothesis and alternative hypothesis for this analysis were as follows: 
$\mathrm{H}_{0}$ : The regression model is not significant for making predictions about overall BUS 111 average; none of the variance in BUS 111 average can be explained by the variables selected in a step-wise fashion because all of the coefficients are zero.

$\mathrm{H}_{\mathrm{A}}$ : The regression model is significant for making predictions about overall BUS 111 grade; some of the variance in BUS 111 average can be explained by the variables selected in a step-wise fashion because at least one of the coefficients is not equal to zero.

This regression model hypothesis was tested using ANOVA analysis as well and the results are shown below. As shown in Table 16 below, the $F$-statistic in the final step (Model 3) was $F(3,140)=33.084$ with $p=0.000$, so the null hypothesis was rejected and I was able to conclude that the new model, using the three independent variables selected in the step-wise analysis (high school GPA, placement score, and number of classes missed), was significant for making predictions about BUS 111 average.

\begin{tabular}{|c|c|c|c|c|c|c|}
\hline \multicolumn{7}{|c|}{ ANOVA $^{a}$} \\
\hline \multicolumn{2}{|c|}{ Model } & $\begin{array}{l}\text { Sum of } \\
\text { Squares }\end{array}$ & df & Mean Square & $\mathrm{F}$ & Sig. \\
\hline \multirow[t]{3}{*}{1} & Regression & 6466.372 & 1 & 6466.372 & 47.739 & $.000^{b}$ \\
\hline & Residual & 19234.326 & 142 & 135.453 & & \\
\hline & Total & 25700.699 & 143 & & & \\
\hline \multirow[t]{3}{*}{2} & Regression & 9494.060 & 2 & 4747.030 & 41.300 & $.000^{c}$ \\
\hline & Residual & 16206.639 & 141 & 114.941 & & \\
\hline & Total & 25700.699 & 143 & & & \\
\hline \multirow[t]{3}{*}{3} & Regression & 10661.805 & 3 & 3553.935 & 33.084 & $.000^{d}$ \\
\hline & Residual & 15038.894 & 140 & 107.421 & & \\
\hline & Total & 25700.699 & 143 & & & \\
\hline
\end{tabular}

a. Dependent Variable: BUS111_Average

b. Predictors: (Constant), HS_GPA

c Tabedictors: (Constant) HS $_{\text {T }}$ GPA Placement Score

d. Predictors: (Constant), HS_GPA, Placement Score, Attendance Post

Knowing that the model was significant, I examined the regression coefficient as

well as the $\mathrm{R}^{2}$ value for this step-wise analysis. As shown in Table 17 below, using only the independent variables high school GPA, placement score, and number of absences 
produced an $\mathrm{R}^{2}=0.415$, indicating that $41.5 \%$ of the variance in BUS 111 course grade could be explained by this regression model (Huck, 2012; Weiss 2008). This is still a great amount of variability that can be explained, and with this model, only three predictors would need to be known in order to predict course grade in BUS 111. It is important to note that with only GPA, only $25.2 \%$ of the variability was accounted for, and only $36.9 \%$ was explained with the addition of placement score. So, an additional $5.4 \%$ of the variance here was explained by the third variable entered into the step-wise model: how many class a student missed over the semester. Thus, time devoted to the BUS 111 course was still statistically significant in explaining overall course average.

Model Summary

\begin{tabular}{|l|l|r|r|r|}
\hline Model & $\mathrm{R}$ & $\mathrm{R}$ Square & $\begin{array}{c}\text { Adjusted R } \\
\text { Square }\end{array}$ & $\begin{array}{c}\text { Std. Error of the } \\
\text { Estimate }\end{array}$ \\
\hline 1 & $.502^{\mathrm{a}}$ & .252 & .246 & 11.63843 \\
2 & $.608^{\mathrm{b}}$ & .369 & .360 & 10.72104 \\
3 & $.644^{\mathrm{c}}$ & 415 & .402 & 10.36439 \\
\hline
\end{tabular}

a. Predictors: (Constant), HS_GPA

b. Predictors: (Constant), HS_GPA, Placement_Score

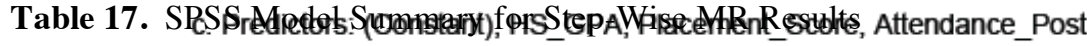

Additionally, the standard error of the estimate was about 10.36, indicating that the observed BUS 111 averages differed from the values that would be predicted using this model by about 10.36 points, or about one letter grade. The next piece of output to be analyzed in SPSS was the actual model or the regression equation that used these three independent variables to make predictions about students' final course average in BUS 111. Those results are printed below, in Table 18:

\begin{tabular}{|c|c|c|c|c|c|c|c|c|}
\hline \multicolumn{9}{|c|}{ Coefficients $^{\mathrm{a}}$} \\
\hline \multirow{2}{*}{\multicolumn{2}{|c|}{ Model }} & \multicolumn{2}{|c|}{ Unstandardized Coefficients } & \multirow{2}{*}{$\begin{array}{c}\begin{array}{c}\text { Standardized } \\
\text { Coefficients }\end{array} \\
\text { Beta } \\
\end{array}$} & \multirow[b]{2}{*}{$t$} & \multirow[b]{2}{*}{ Sig. } & \multicolumn{2}{|c|}{ Collinearity Statistics } \\
\hline & & B & Std. Error & & & & Tolerance & VIF \\
\hline \multirow[t]{2}{*}{1} & (Constant) & 24.603 & 7.948 & & 3.095 & .002 & & \\
\hline & HS_GPA & 15.983 & 2.313 & .502 & 6.909 & .000 & 1.000 & 1.000 \\
\hline \multirow[t]{3}{*}{2} & (Constant) & 23.759 & 7.324 & & 3.244 & .001 & & \\
\hline & HS_GPA & 13.436 & 2.188 & .422 & 6.141 & .000 & .949 & 1.054 \\
\hline & Placement_Score & 2.744 & .535 & .352 & 5.132 & .000 & .949 & 1.054 \\
\hline \multirow[t]{2}{*}{3} & (Constant) & 31.056 & 7.418 & & 4.187 & .000 & & \\
\hline & HS_GPA & 12.490 & 2.134 & .392 & 5.852 & .000 & .931 & 1.074 \\
\hline & 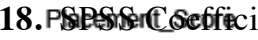 & ents Tab4effc & r Step-Wise & MR Resultss & 4.635 & .000 & .918 & 1.089 \\
\hline & Attendance_Post & -2.190 & .664 & -.220 & -3.297 & .001 & .938 & 1.066 \\
\hline
\end{tabular}

a. Dependent Variable: BUS111_Average 
From this output, I was able to build and analyze the regression equation if only these three independent variables were used. I will define these variables as they were defined in the previous section. Then the multiple regression equation for the step-wise model is given as:

$$
\hat{y}=31.056+12.490 x_{5}+2.435 x_{6}-2.190 x_{8}
$$

With this model, we see that all of the variables chosen are statistically significant at the $\alpha=0.001$ level, and the multicollinearity restrictions are easily satisfied for each, with all tolerance statistics above 0.91 and all VIF scores below 1.09 with an average VIF of only 1.076, which are considered very good (Kutner et al., 2003; Myers, 1990). Thus, this is likely a better model to use than the enter-all models, as it is more efficient and has higher statistical significance, though it is only able to explain $41.5 \%$ of the variance in BUS 111 grade, rather than 45.4\%. I examined step-wise regression results combining mathematical anxiety and attitudes towards mathematics as well, to compare these models with fewer collinearity concerns. Those results are explained later in this section.

First, in Table 18, above, the unstandardized coefficients (B) in this regression model indicate that we would expect students to earn an additional 12.49 percentage points in the course for each additional point on their high school GPA and 2.435 more points for each point earned on the placement exam. This means that a student who earned a 3.8 GPA in high school would expect to earn about 12.5 more points in BUS 111 than someone with a high school GPA of 2.8 , or that a student who earned a 3.8 GPA in high school would expect to earn about 1.25 more points in BUS 111 than someone with a high school GPA of 3.7. Finally, we could expect a drop of 2.19 points in course average for each class a student missed over the semester.

Using this step-wise regression equation would indicate that a student enrolled in BUS 111 who earned a 3.2 GPA in high school and a 4 (group B/C) on the placement exam and missed two classes during the semester, would earn a predicted grade in BUS 111 of about a: 


$$
\begin{aligned}
\hat{y} & =31.056+12.490(3.2)+2.435(4)-2.190(2) \\
& =76.384 \quad( \pm 10.36) \quad \text { (Thus, a letter grade of } \mathrm{C})
\end{aligned}
$$

\section{Reducing Multicollinearity}

Because mathematical anxiety and attitudes towards mathematics were so strongly correlated, I also wanted to run a step-wise regression using the combination of these predictors ("mathematical emotions") in an attempt to reduce the effects of multicollinearity and thus potentially change the final model. The same overarching hypothesis was tested using an ANOVA analysis, the results of which are shown below (Huck, 2012; Osborne \& Waters, 2002; Weiss, 2008). As shown, the $F$-statistic from the new ANOVA was 29.164 with $p=0.000$, so the null hypothesis was rejected and I was able conclude that the model, now using four independent variables selected in the stepwise analysis (high school GPA, number of classes missed, placement score, and now mathematical emotions), was significant for making predictions about BUS 111 average.

\begin{tabular}{|c|c|c|c|c|c|c|}
\hline & & $\begin{array}{l}\text { Sum of } \\
\text { Squares }\end{array}$ & df & Mean Square & $\mathrm{F}$ & Sig. \\
\hline \multirow[t]{3}{*}{1} & Regression & 7701.689 & 1 & 7701.689 & 48.758 & $.000^{\mathrm{b}}$ \\
\hline & Residual & 23693.570 & 150 & 157.957 & & \\
\hline & Total & 31395.259 & 151 & & & \\
\hline \multirow[t]{3}{*}{2} & Regression & 11250.294 & 2 & 5625.147 & 41.606 & $.000^{c}$ \\
\hline & Residual & 20144.965 & 149 & 135.201 & & \\
\hline & Total & 31395.259 & 151 & & & \\
\hline \multirow[t]{3}{*}{3} & Regression & 13302.761 & 3 & 4434.254 & 36.273 & \\
\hline & Residual & 18092.499 & 148 & 122.247 & & \\
\hline & Total & 31395.259 & 151 & & & \\
\hline \multirow[t]{2}{*}{4} & Regression & 13891.093 & 4 & 3472.773 & 29.164 & $.000^{\mathrm{e}}$ \\
\hline & $\begin{array}{l}\text { Residual } \\
\text { eppexamine }\end{array}$ & $\begin{array}{l}17504.166 \\
\text { the } \\
313995.259\end{array}$ & $\begin{array}{c}147 \\
\text { coefficie }\end{array}$ & $\begin{array}{c}119.076 \\
\text { t }\end{array}$ & he coeffi & ont s \\
\hline
\end{tabular}

ANOVA $^{\mathrm{a}}$

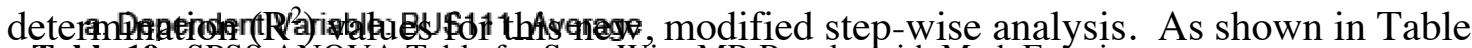
Table 19. SPSS ANOVA Table for Step-Wise MR Results with Math Emotions 20 below, using gnly the independent yariables high school GPA, placement score,

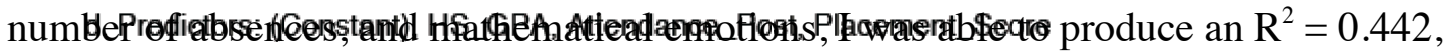
e. Predictors: (Constant), HS_GPA, Attendance_Post, Placement_Score, Math_Emotions 
indicating that $44.2 \%$ of the variance in BUS 111 course grade could be explained by this regression model (Huck, 2012; Weiss 2008). This is a greater amount of the variability than was explainable with the previous step-wise equation separating anxiety and attitudes, and, because of the removal of the concerns about multicollinearity, is an even better model than the first. Here, with GPA alone, only $24.5 \%$ of the variability was accounted for, and only $35.8 \%$ was explained with the addition of how many classes a student missed over the semester. An additional $8.4 \%$ of the variance here was explained by placement score and the students' mathematical emotions, so time devoted to the course and how students perceive mathematics are statistically significant in explaining overall BUS 111 course average.

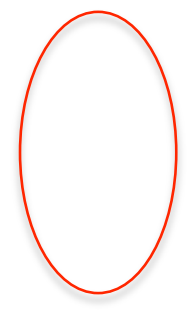

Table 20. SPSS Model Summary for Step-Wise MR Results with Math Emotions

In this case, the standard error of the estimate was about 10.9. The specific regression equation that uses these four independent variables to make predictions about students' final course average in BUS 111 was then examined. Those results are printed in Table 21, below:

Coefflclents $^{\mathrm{a}}$

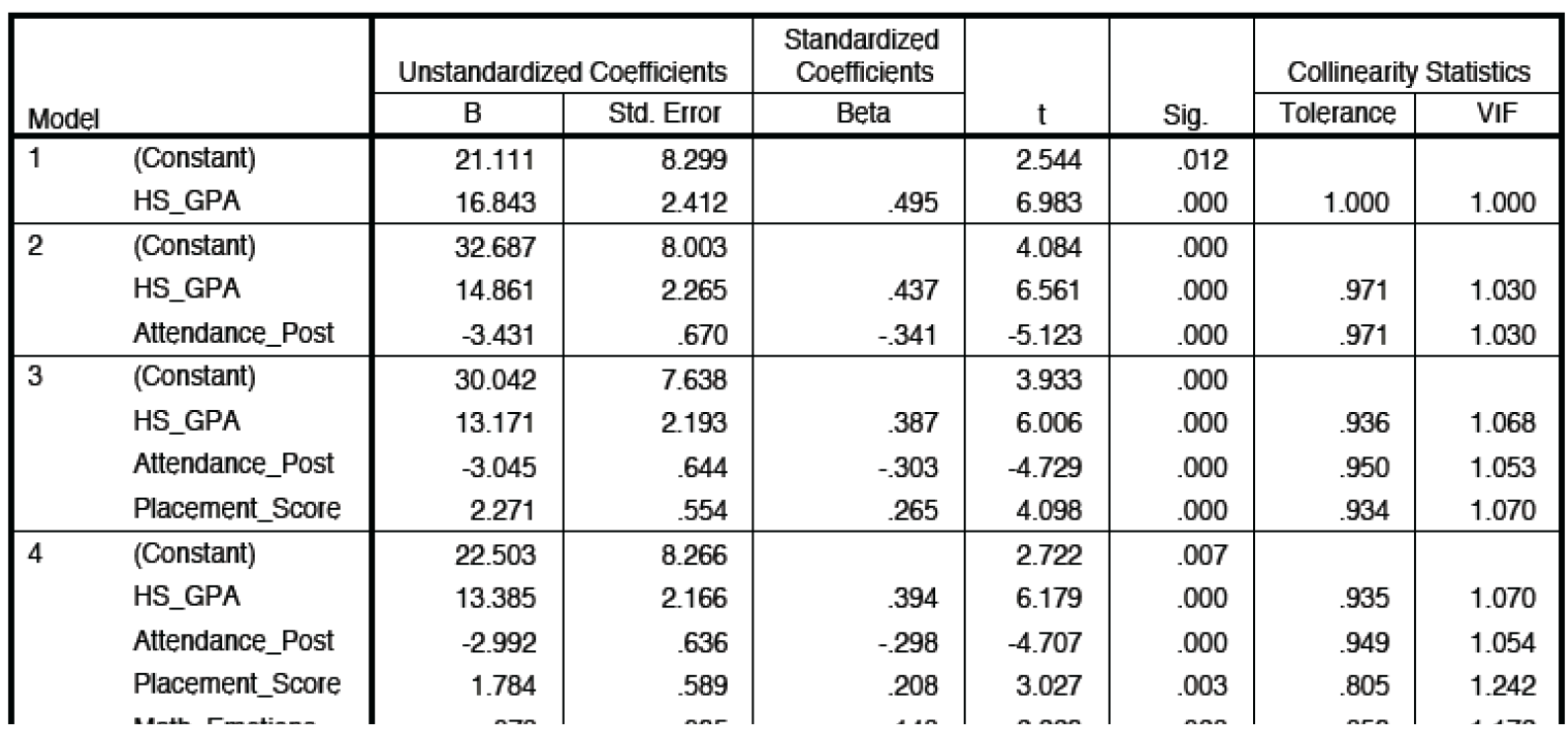


Table 21. SPSS Coefficients Table for Step-Wise MR Results with Math Emotions

From this output, I was able to build and analyze the regression equation if only these four independent variables were used, with attitudes and anxiety combined as emotions. I defined these variables as described in the previous section. The multiple regression equation for the step-wise model is given as:

With this model, we see that all of the variables chosen are statistically significant at the $\alpha=0.05$ level, and the multicollinearity restrictions are easily satisfied for each, with all tolerance statistics above 0.8 and all VIF scores below 1.25 with an average VIF of only about 1.13, which are considered very good (Kutner et al., 2003; Myers, 1990). Thus, this is likely a better model to use than not only the first step-wise model, but also both enter-all models, as it is more efficient, has higher statistical significance, and is still able to explain $44.2 \%$ of the variability in final BUS 111 course grade.

The unstandardized coefficients (B) in this regression model indicate that we would expect a 0.078 point increase in final grade for each additional point in mathematical emotions. Additionally, we would expect students to earn an additional 13.385 points in their final course grade for each additional point on their high school GPA and 1.784 more points for each higher level they placed into on the placement exam. Finally, we could expect a drop of 2.992 points in BUS 111 course average for each class a student missed over the semester, indicating that after about three absences, we would anticipate a student's final average to drop by a letter grade.

Again, this step-wise model, combining attitudes towards mathematics and mathematical anxiety as one independent variable (termed "mathematical emotions"), is likely the best model to use when predicting students' overall course average in BUS 111 
at URI. This model uses only four of the independent variables, yet it still explains nearly half of the variability in final course grade and easily satisfies collinearity statistics.

\section{Block-Wise/Hierarchical Results}

Once these step-wise regression results were analyzed, variables were entered into the model in a block-wise method to investigate whether the new, less-researched, affective variables were significant on their own in student success. The hierarchical results were of particular interest in this case because they helped address concerns of multicollinearity by grouping similar "blocks" of variables together and inserting them into the model one block at a time (using enter-all/simultaneous entry in each block).

Similar to the other methods, the null hypothesis and alternative hypothesis for this analysis were as follows:

$\mathrm{H}_{0}$ : The regression model is not significant for making predictions about overall BUS 111 average; none of the variance in BUS 111 average can be explained by the variables selected in a block-wise fashion because all of the coefficients in the model are zero.

$\mathrm{H}_{\mathrm{A}}$ : The regression model is significant for making predictions about overall BUS 111 grade; some of the variance in BUS 111 average can be explained by the variables selected in a block-wise fashion because at least one of the coefficients in the model is not equal to zero.

This regression model hypothesis was tested using ANOVA analysis and the results are shown below. As can be seen in Table 22, the F-statistic in the final step (Model 3, including all blocks) was $F(8,135)=14.023$ with $p=0.000$, so the null hypothesis was rejected and I could conclude that the model, using all of the independent variables, but organized in the block-wise analysis, was significant. These are, of course, the same final statistics as were observed in the first enter-all analysis, as all of the independent variables were still being used. The difference here is that, with this hierarchical 
analysis, I was able to conclude that each block of variables was significant in the model. The first block entered included variables that have already been researched and included non-affective measures (placement score, gender, high school GPA, and mathematics SAT score). I will refer to this block as the "Non-Affective Block". The second block entered included how much time students devoted to mathematics: the hours they spent outside of class working on the material and the number of classes they missed. I will refer to this block as the "Time Block". Finally, the third block consisted of the least quantitatively researched variables: attitudes towards mathematics (ATMI scores) and mathematical anxiety (MAS scores). I will refer to this final block as the "Mathematical Emotions Block". We can see from the ANOVA analysis that, even after the NonAffective Block was entered, adding in the Time and Mathematical Emotions Blocks contributed a statistically significant amount to the dependent variable, as both $p$-values were 0.000 .

Variables Entered/Removed ${ }^{a}$

\begin{tabular}{|c|c|c|c|c|}
\hline Model & $\begin{array}{l}\text { Variables } \\
\text { Entered }\end{array}$ & $\begin{array}{l}\text { Variables } \\
\text { Removed }\end{array}$ & Method & \\
\hline 1 & $\begin{array}{l}\text { Placement_S } \\
\text { core, Gender, } \\
\text { HS_GPA, } \\
\text { SAT_Scoreb }\end{array}$ & - & Enter & Non-Affective Block \\
\hline 2 & $\begin{array}{l}\text { Attendance_P } \\
\text { ost, } \\
\text { Time_Spent_ } \\
\text { Post }^{5}\end{array}$ & - & Enter & $\zeta$ Time Block \\
\hline 3 & $\begin{array}{l}\text { Math_Attitude } \\
\text { Pre, } \\
\text { Math_Anxiety } \\
\text { _Pre }\end{array}$ & - & Enter & $\zeta$ Mathematical Emotions Block \\
\hline
\end{tabular}

a. Dependent Variable: BUS111_Average

b. All requested variables entered.

\begin{tabular}{|ll|r|r|r|r|r|}
\hline \multicolumn{2}{|l|}{} & \multicolumn{1}{c|}{$\begin{array}{c}\text { Sum of } \\
\text { Squares }\end{array}$} & \multicolumn{1}{c|}{ df } & Mean Square & \multicolumn{1}{c|}{$\mathrm{F}$} & Sig. \\
\hline 1 & Regression & 9962.054 & 4 & 2490.514 & 21.996 & $.000^{\mathrm{b}}$ \\
& Residual & 15738.644 & 139 & 113.228 & & \\
& Total & 25700.699 & 143 & & & \\
\hline 2 & Regression & 11376.872 & 6 & 1896.145 & 18.136 & $.000^{\mathrm{c}}$ \\
& Residual & 14323.827 & 137 & 104.553 & & \\
& Total & 25700.699 & 143 & & & \\
\hline 3 & Regression & 11664.229 & 8 & 1458.029 & 14.023 & $.000^{\mathrm{d}}$ \\
& Residual & 14036.470 & 135 & 103.974 & & \\
& Total & 25700.699 & 143 & & & \\
\hline
\end{tabular}




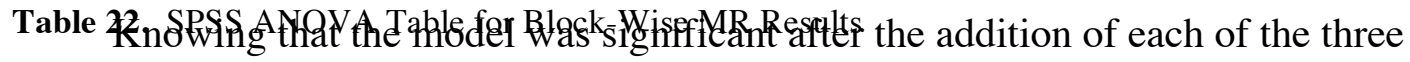
blocks, I examined the regression coefficient as well as the $\mathrm{R}^{2}$ value for this block-wise analysis. As shown in Table 23 below, using only the Non-Affective Block produced an $\mathrm{R}^{2}=0.388$, indicating that only $38.8 \%$ of the variance in BUS 111 course grade could be explained by these non-affective variables alone (Huck, 2012; Weiss 2008). It is important to note, however, that an additional $6.6 \%$ of the variance was explained by the addition of the Time Block and the Mathematical Emotions Block, so the affective and cognitive variables were also statistically significant in explaining course average. Additionally, the standard error of the estimate in the final model was still about 10.2, indicating that the observed BUS 111 averages differed from the values that would be predicted using this model by about 10.2 points (so within one letter grade).

\begin{tabular}{|l|c|r|r|r|}
\multicolumn{6}{c|}{ Model Summary } \\
\hline Model & $\mathrm{R}$ & R Square & $\begin{array}{c}\text { Adjusted R } \\
\text { Square }\end{array}$ & $\begin{array}{c}\text { Std. Error of the } \\
\text { Estimate }\end{array}$ \\
\hline 1 & $.623^{\mathrm{a}}$ & .388 & .370 & 10.64085 \\
2 & $.665^{\mathrm{b}}$ & .443 & .418 & 10.22514 \\
3 & $.674^{\mathrm{c}}$ & .454 & .421 & 10.19676 \\
\hline
\end{tabular}

a. Predictors: (Constant), Placement_Score, Gender, HS_GPA, SAT_Score

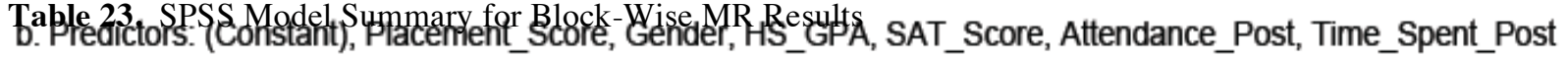

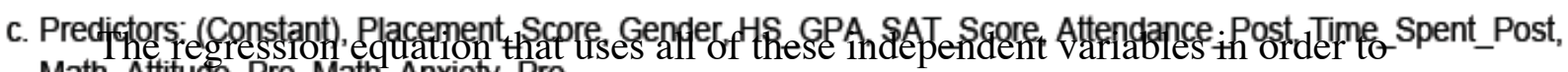
Math_Attitưe_Pre, Math_Anxiety_Pre make predictions about students' final course average in BUS 111 is shown below. It should be noted that these final results, including all three blocks, are the same as they were in the initial enter-all model. The collinearity statistics with just the Non-Affective 
Block and Time Block are easily satisfied, with tolerance levels all above 0.74 and VIF scores all below 1.36 with an average VIF score of approximately 1.2. Using these two blocks alone explained $44.3 \%$ of the variance in overall BUS 111 course average. VIF scores only go above 1.36 when the third block, mathematical emotions, is added into the model, because those two variables were strongly correlated with each other. Since they were considered significant as a block, however (seen together), they are still significant in the overall model.

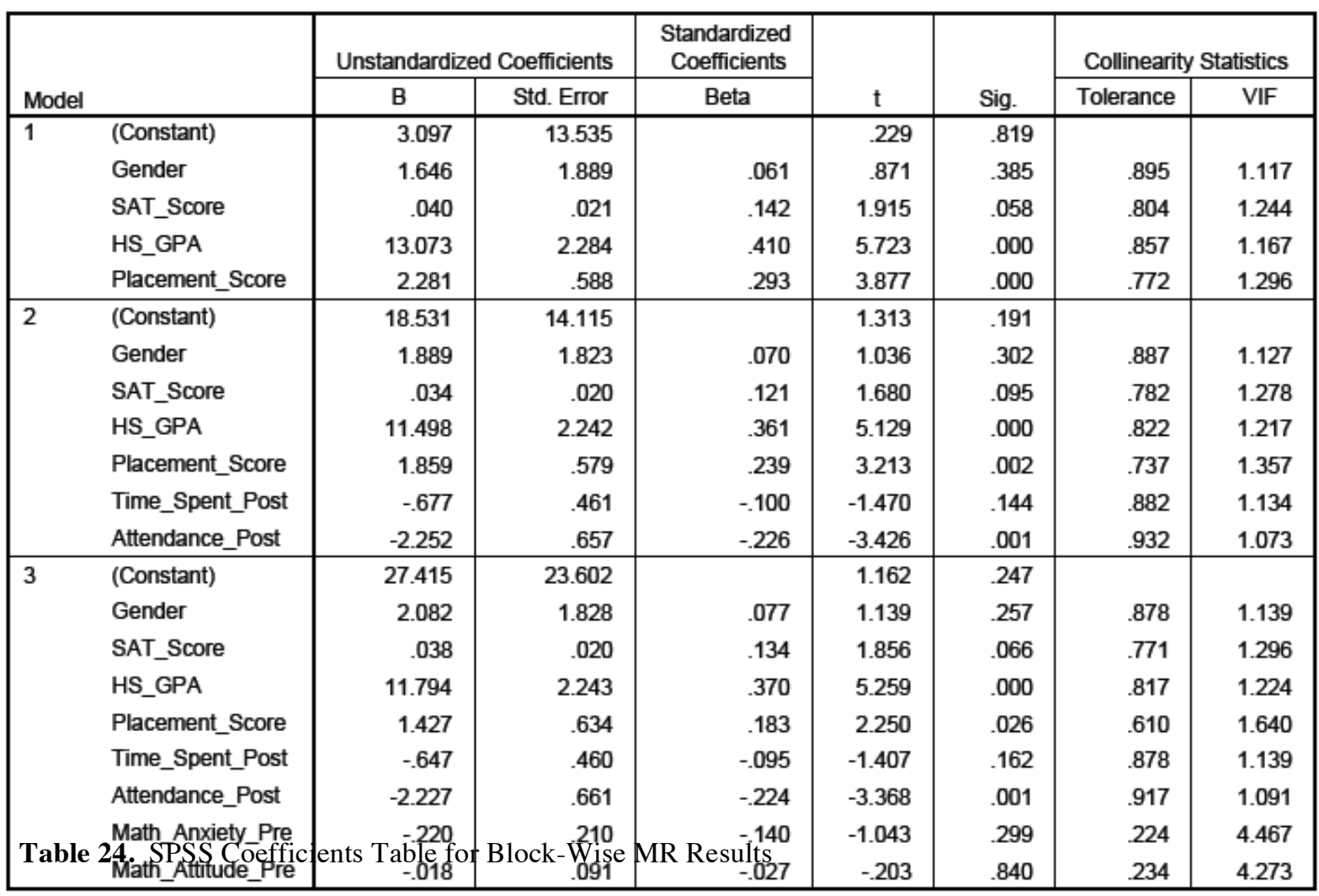

Na Dependent Variable: BuS111 Average

As described in the review of literature (chapter three), I was very interested in examining the usefulness and predictability of non-affective variables (such as test scores) versus affective variables (such as attitudes and time devoted to the subject) when it came to success in a business mathematics course. Therefore, in addition to the hierarchical model, I also ran two separate multiple regression analyses based on predictors. First, I examined the relationship between course average and non-affective 
variables: gender, SAT score, high school GPA, and placement score by entering these predictors into SPSS. I then examined the relationship between BUS 111 grade and the affective, cognitive variables: number of absences, hours spent on mathematics outside of class per week, ATMI score, and MAS score by entering these predictors into SPSS to examine whether each model as a whole was significant in making predictions. The null hypothesis and alternative hypothesis for these two sets of analyses were as follows:

$\mathrm{H}_{01}$ : The regression model with non-affective variables is not significant for making predictions about overall BUS 111 average; none of the variance in BUS 111 average can be explained by these non-affective variables because the coefficients are all equal to zero.

$\mathrm{H}_{\mathrm{A} 1}$ : The regression model with non-affective variables is significant for making predictions about overall BUS 111 grade; some of the variance in BUS 111 average can be explained by these non-affective variables because at least one of the coefficients is not equal to zero.

$\mathrm{H}_{02}$ : The regression model with affective and cognitive variables is not significant for making predictions about overall BUS 111 average; none of the variance in BUS 111 average can be explained by these affective and cognitive variables because the coefficients are all equal to zero.

$\mathrm{H}_{\mathrm{A} 2}$ : The regression model with affective and cognitive variables is significant for making predictions about overall BUS 111 grade; some of the variance in BUS 111 average can be explained by these affective and cognitive variables because at least one of the coefficients is not equal to zero.

I focused on the non-affective variables first. The overarching hypothesis $\mathrm{H}_{01}$ was tested using ANOVA, the results of which are shown below. As shown, the $F$-statistic was $F(4,175)=21.14$ with $p=0.000$, so the null hypothesis was rejected and I could conclude that the model, using all of the non-affective independent variables, was significant.

\begin{tabular}{|c|c|c|c|c|c|c|}
\hline \multicolumn{7}{|c|}{ ANOVA $^{a}$} \\
\hline Model & & $\begin{array}{l}\text { Sum of } \\
\text { Squares }\end{array}$ & df & Mean Square & $F$ & Sig. \\
\hline 1 & Regression & 14595.814 & 4 & 3648.953 & 21.140 & $.000^{b}$ \\
\hline & Residual & 30206.619 & 175 & 172.609 & & \\
\hline
\end{tabular}


Table 25. SPSS ANOVA Table for Non-Affective Measures in MR Results

Knowing that the model was significant, I examined the $\mathrm{R}^{2}$ value for this enter-all analysis using high school GPA, placement score, mathematics SAT score, and gender. As shown below, using each of the non-affective independent variables produced an $\mathrm{R}^{2}=$ 0.326 , indicating that $32.6 \%$ of the variance in BUS 111 course grade could be explained by this regression model (Huck, 2012; Weiss 2008). This is a significant amount of Model Summary variabilit ind

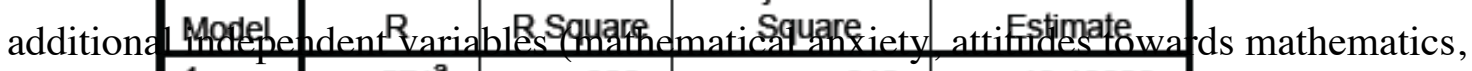
\begin{tabular}{|l|r|r|r|r|}
\hline 1 & $.571^{\mathrm{a}}$ & .326 & .310 & 13.13808 \\
\hline
\end{tabular}

time devoted to the subject,and nHmber of classes missed) were added in (which corresponded to $\mathrm{R}^{2}=0.454$ in the enter-all analysis, or an additional $12.8 \%$ of the variability in final course average explained). Additionally, the standard error of the estimate in the final model was about 13.14, indicating that the observed BUS 111 averages differ from the values that would be predicted using this model by about 13.14 points, which is higher than when affective variables were also considered. This indicates that using a combination of these affective and non-affective variables is preferable to using non-affective measures alone.

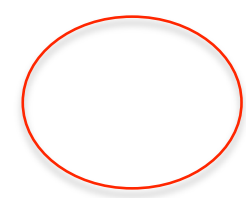

Table 26. SPSS Model Summary for Non-Affective Measures in MR Results

The next piece of output to be analyzed in SPSS was the model itself, that is, the regression equation that uses these non-affective independent variables to make 
predictions about students' final course average in BUS 111. Those results are printed below, in Table 27:

Table 27. SPSS Coefficients Table for Non-Affective Measures in MR Results

From this output, I was able to build and analyze the regression equation if all of the non-affective independent variables were used. I will define these variables as I did before. Then the regression equation is given as:

$$
\hat{y}=7.465+2.956 x_{3}+0.017 x_{4}+14.322 x_{5}+2.835 x_{6}
$$

The unstandardized coefficients (B) indicate that we would expect students to earn an additional 0.017 points in the course for each additional point earned on the SAT. Again, since the SAT is scaled in tens, it might be easier to think of this as a 1.7 point increase in course grade for each 100 point increase on the SAT. We would also expect to see an increase of 14.322 points in BUS 111 average for each additional point earned on high school GPA and 2.835 points higher on final grade for each point on the placement exam. Recalling that gender was dummy coded with male $=$ " 0 " and female $=$ "1", and since the unstandardized coefficient for gender is positive, being a female tends to have a positive effect on BUS 111 course average while holding everything else constant. Specifically, females can expect to earn about 2.956 points more than their male counterparts in this model. This is interesting since fewer females tend to stick with the business major than males, as explained in more detail in chapter three. I was also able to note that high school GPA and placement score were more significant than gender and SAT score, according to this model. 
I then turned the focus to the less-researched, affective variables examined. The overarching null hypothesis, $\mathrm{H}_{02}$, was tested using ANOVA analysis and the results of that analysis are shown below. As can be seen in Table 28 , the F-statistic was $F(4,174)=$ 16.039 with $p=0.000$, so the null hypothesis was rejected and I was able to conclude that the model, using all of the affective, cognitive independent variables, was also significant in making predictions about final course average in BUS 111.

\begin{tabular}{|c|c|c|c|c|c|c|}
\hline \multicolumn{7}{|c|}{ ANOVA $^{\mathrm{a}}$} \\
\hline & & $\begin{array}{l}\text { Sum of } \\
\text { Squares }\end{array}$ & df & Mean Square & $\mathrm{F}$ & Sig. \\
\hline \multirow[t]{3}{*}{1} & Regression & 9963.176 & 4 & 2490.794 & 16.039 & $.000^{6}$ \\
\hline & Residual & 27020.706 & 174 & 155.291 & & \\
\hline & Total & 36983.882 & 178 & & & \\
\hline
\end{tabular}

the course of the semester, time devoted to mathematics outside of class, attitudes towards mathematics, and mathematical anxiety. As shown in Table 29, using each of these independent variables produced an $\mathrm{R}^{2}=0.269$, indicating that $26.9 \%$ of the variance in BUS 111 course grade could be explained by this regression model alone (Huck, 2012; Weiss 2008). Thus, without knowing any of the student's previous test scores or gender, I would still be able to explain over a quarter of the variance in their BUS 111 average. This is a significant amount of variability in course grade, but again, allows us to explain less of the variability than when the additional non-affective variables were added in (which corresponded to $\mathrm{R}^{2}=0.454$, or an additional $18.5 \%$ of the variability in course average explained). Here, the standard error of the estimate in the final model was about 12.46, indicating that the observed BUS 111 averages may differ from the values that would be predicted using this model by about 12.46 points, which is a smaller difference than when considering only non-affective measures, but still a greater difference than when considering a combination of these variables. 


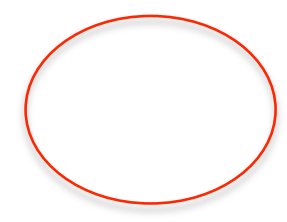

Table 29. SPSS Model Summary for Affective and Cognitive Measures in MR Results

I then analyzed the regression equation that used these affective, cognitive independent variables to make predictions about students' final course average in BUS 111. Those results are printed below, in Table 30:

Coefficients $^{\mathbf{a}}$

\begin{tabular}{|c|c|c|c|c|c|c|c|c|}
\hline \multirow[b]{2}{*}{ Mod } & & \multicolumn{2}{|c|}{ Unstandardized Coefficients } & \multirow{2}{*}{$\begin{array}{c}\begin{array}{c}\text { Standardized } \\
\text { Coefficients }\end{array} \\
\text { Beta }\end{array}$} & \multirow[b]{2}{*}{$t$} & \multirow[b]{2}{*}{ Sig. } & \multicolumn{2}{|c|}{ Collinearity Statistics } \\
\hline & & B & Std. Error & & & & Tolerance & VIF \\
\hline \multirow[t]{5}{*}{1} & (Constant) & 101.359 & 22.195 & & 4.567 & .000 & & \\
\hline & Math_Anxiety_Pre & -.364 & .231 & -.210 & -1.576 & .117 & .237 & 4.226 \\
\hline & Math_Attitude_Pre & .010 & 100 & .013 & .101 & .920 & .239 & 4.192 \\
\hline & Time_Spent_Post & -1.797 & .476 & -.246 & -3.775 & .000 & .989 & 1.012 \\
\hline & Attendance_Post & -3.565 & .628 & -.370 & -5.675 & .000 & .988 & 1.012 \\
\hline
\end{tabular}

Täbfepopdent5sachoeffus111 Average or Affective and Cognitive Measures in MR Results

From this output, I could build and analyze the regression equation if all of the affective and cognitive variables were used. I note first, however, that the tolerance statistics and VIF scores are relatively close to their limits. It still seems that combining mathematical anxiety and attitudes towards mathematics, as I did in the step-wise model, may help increase confidence in the model, which I will examine next. I will define the variables again as they were defined before. Then the regression equation is given as:

$$
\hat{y}=101.359-0.364 x_{1}+0.010 x_{2}-1.797 x_{7}-3.565 x_{8}
$$

The standardized coefficients (Beta) in this multiple regression model indicate that the order of significance in this model, starting with the most significant, is: number of absences, time devoted to mathematics outside of class (which are both statistically significant predictors on their own, while holding everything else constant), followed by mathematical anxiety and attitude towards mathematics. 
The unstandardized coefficients (B) here indicate that we would expect a 0.364 point drop in BUS 111 grade for each point scored on the MAS and a 0.010 point increase in grade for each additional point scored on the ATMI. Thus, we would expect higher final averages for students with lower mathematical anxiety and more favorable attitudes towards mathematics. We would also expect to see a 1.797 point drop in course average for each extra hour spent on the course. Again, this may indicate that students who struggled with the material felt compelled to spend more time working on the course outside of class. Finally, we could expect a drop of 3.565 points in course average for each class the student missed over the course of the semester.

Since the VIF scores were close to their limits here, however, indicating potential multicollinearity concerns, I also examined the affective, cognitive independent variables after combining mathematical anxiety and attitudes towards mathematics as a single predictor: mathematical emotions. Here, the F-statistic was $F(3,198)=30.199$ with $p=$ 0.000 , so I was able to conclude that this model was also significant in making predictions about final course average in BUS 111.

After verifying that the model was significant, I examined the $\mathrm{R}^{2}$ value for this analysis using number of classes missed over the course of the semester, time devoted to mathematics outside of class, and mathematical emotions. As shown in Table 31 below, using each of these independent variables produced an $\mathrm{R}^{2}=0.314$, indicating that $31.4 \%$ of the variance in BUS 111 course grade could be explained by this regression model (Huck, 2012; Weiss 2008).

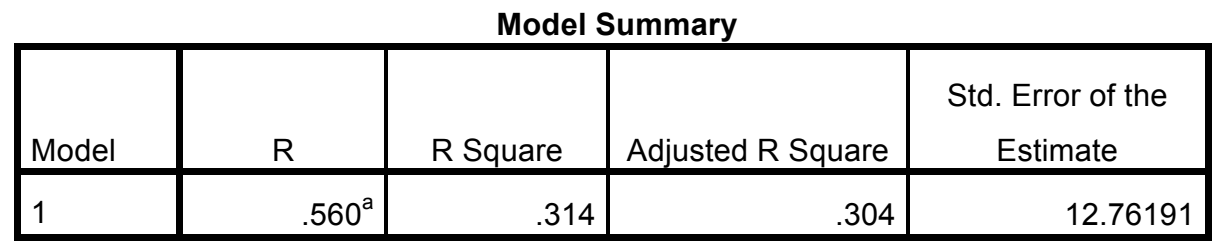

a. Predictors: (Constant), Math_Emotions, Attendance_Post, Time_Spent_Post

Table 31. SPSS ANOVA Table for Affective and Cognitive Measures in MR Results with Math Emotions 
I then analyzed the regression equation, which used these affective, cognitive independent variables to make predictions about students' final course average in BUS 111. From this output, I was able to build and analyze the regression equation if these independent variables were used. Defining the variables again as they were defined before, the regression equation is given as:

$$
\hat{y}=74.101+0.138 x_{1,2}-1.508 x_{7}-4.163 x_{8}
$$

\section{Individual Exams}

As previously mentioned, each of the BUS 111 instructors gave students three different exams over the course of the semester leading up to an optional final exam. Together, these three exams accounted for between $70 \%$ and $75 \%$ of the students' final

course grades. Because this course is so exam-heavy, I also analyzed the results of each of the three exams to determine which, if any, of the independent variables were significant in predicting each exam grade, and whether those variables differed from exam to exam.

\section{Exam One}

Using the enter-all multiple regression analysis in SPSS, including all of the independent variables, I was able to account for $19.4 \%$ of the variance in exam one scores, which was a significant model overall $(F(8,135)=4.050 ; p=0.000)$. However, using step-wise multiple regression, SPSS revealed that the most efficient model would include only two variables: placement score and high school GPA. These predictors alone were able to explain $15.4 \%$ of the variance in exam one scores, and the change in $\mathrm{R}^{2}$ after the addition of each new variable was not significant enough to include in the step-wise model. Additionally, each tolerance statistic was above 0.94 and each VIF score was below 1.06, with an average VIF of 1.054, which were all very good. The standard error of the estimate was about 12.9, indicating that the observed exam one scores differed from the values predicted using this model by about 12.9 points. Though we would like to see this value lower, being able to predict a student's exam one score 
within 13 points is still noteworthy. Since this step-wise model is more efficient, the regression equation that could be used to predict student scores on exam one (using the same independent variables as identified earlier) would be:

$$
\hat{y}_{\text {Exam } 1}=52.432++5.694 x_{5}+2.564 x_{6}
$$

This equation indicates that we could expect a 5.694\% higher exam one grade for each additional point earned in high school GPA and a $2.564 \%$ higher exam one grade for each level increase on the placement exam. Specifically, using this regression equation would indicate that a student in BUS 111 who earned a 3.2 GPA in high school and earned a 4 (group B/C) on the placement exam, would earn a predicted grade on exam one in BUS 111 of about a:

$$
\begin{aligned}
\hat{y}_{\text {Exam } 1} & =52.432+5.694(3.2)+2.564(4) \\
& =80.9088 \quad( \pm 12.9) \quad(\text { Thus, a letter grade of B-) }
\end{aligned}
$$

Therefore, by examining a student's university-developed mathematics placement score and high school GPA, we could predict her BUS 111 exam one grade to a moderate degree (within about a letter grade).

This first exam is administered, graded, and handed back to students before the university "drop date", indicating that students who drop a course before this date are not penalized and their transcripts do not reflect that they were ever in the course. Therefore, I wanted to further investigate the relationship between students' exam one grades and their final course averages. I found that these two scores were strongly, positively correlated with each other $(r=0.65 ; p=0.000)$. Furthermore, even though exam one was only worth $23-25 \%$ of the students' final grades in BUS $111,42.2 \%$ of the variability in their final averages was able to be explained using exam one grades alone $(F(1,242)=$ $176.9 ; p=0.000)$. Of the students who failed exam one during the Fall 2015 semester, only $35 \%$ ended up passing BUS 111 with a successful grade ( $\mathrm{C}$ or better). Exam Two 
Using the enter-all multiple regression analysis in SPSS, including all of the independent variables, I was able to account for $33 \%$ of the variance in exam two scores, which was a significant model overall $(F(8,135)=8.324 ; p=0.000)$ and it allowed me to explain much more of the variability in exam two grades than I was able to explain with exam one grades using these predictors. Then, using step-wise multiple regression, SPSS outputs revealed that the most efficient model for predicting exam two scores would include three variables: high school GPA, the number of classes a student missed during the semester, and their mathematical anxiety. Of course, number of classes missed in total would still be uncertain after exam two. However, students could still be made aware of these relationships to encourage future attendance. These predictors were able to explain $30.6 \%$ of the variance, and the change in $\mathrm{R}^{2}$ after the addition of each variable was not significant enough to include in the step-wise model. Furthermore, each tolerance statistic was above 0.96 and each VIF score was below 1.04, with an average VIF of 1.026. The standard error of the estimate was about 16.5, indicating that the observed exam two scores differed from the values predicted using this model by about 16.5 points. Again, we would like to have closer estimates, but being able to predict a student's exam two score within 16.5 points is still noteworthy. Because the step-wise model was more efficient, the regression equation that could be used to predict exam two scores (using the same independent variables as identified earlier) would be:

$$
\hat{y}_{\text {Exam } 2}=49.085-0.549 x_{1}+15.369 x_{5}-4.357 x_{8}
$$

This equation indicates that, for each additional point on the MAS, we would expect a $0.549 \%$ decrease in exam two grade (so the more anxious a student is about mathematics, the lower we would expect his exam grade to be). Further, we could expect a $15.369 \%$ higher exam two grade for each additional point earned in high school GPA, which indicates that someone who earned a 3.8 GPA in high school could expect to earn about 15.369 percentage points higher on exam two than a peer who earned a 2.8 GPA in high school. Finally, for each class missed over the course of the semester, we would 
expect a decrease of $4.357 \%$ in that student's exam two score. Unfortunately, this score cannot be predicted within a letter grade. Specifically, using this regression equation would indicate that a student in BUS 111 who scored an anxiety level of 30 on the MAS, who earned a 3.2 GPA in high school, and who missed two classes over the course of the semester, would earn a predicted grade on exam two in BUS 111 of about a:

$$
\begin{aligned}
\hat{y}_{\text {Exam2 }} & =49.085-0.549(30)+15.369(3.2)-4.357(2) \\
& =73.0819 \quad( \pm 16.5) \quad \text { (Thus, a letter grade of C) }
\end{aligned}
$$

Therefore, by examining a student's high school GPA, mathematical anxiety/MAS results, and attendance, we could predict his BUS 111 exam two grade to some reasonable degree of accuracy. This may help encourage class attendance in BUS 111.

This second exam is generally (though not always) administered, graded, and handed back to students before the university's final drop deadline, indicating that students can still drop a course before this date, but their transcripts will reflect that they were in the course with a "W" grade for "withdrew". Since students are still usually eligible to drop courses after exam two, I wanted to further investigate the relationship between students' first two exam grades and their final course averages. Over $55 \%$ of the students who failed exam one also failed exam two, and none of students who failed both exam one and exam two ended up successfully completing the course with a grade of $\mathrm{C}$ or better. Looking at exam two grades alone, I discovered that less than $15 \%$ of the students who failed exam two ended up successfully completing BUS 111. Even though the first two exams together were only worth $46-50 \%$ of the students' final grades in BUS $111,79 \%$ of the variability in their final averages was able to be explained using exam one and exam two scores alone. Additionally, the standard error of estimate here was only 8.2 points. This was a significant model and, as shown in the printouts below, students' final averages could be predicted within about 8 points using the equation:

$$
\widehat{y}=7.238+0.379(\text { Exam } 1 \text { Score })+0.525(\text { Exam } 2 \text { Score })
$$

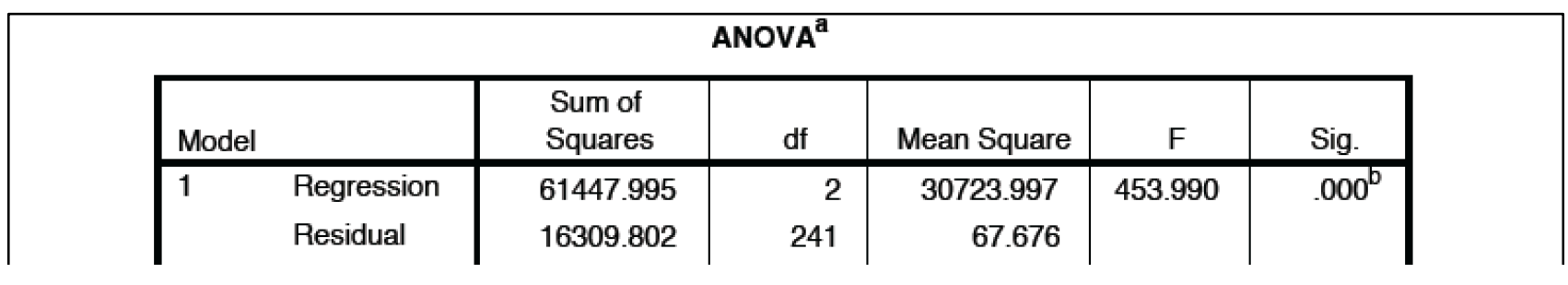


Model Summary

\begin{tabular}{|l|c|r|r|c|}
\hline Model & $\mathrm{R}$ & R Square & $\begin{array}{c}\text { Adjusted R } \\
\text { Square }\end{array}$ & $\begin{array}{c}\text { Std. Error of the } \\
\text { Estimate }\end{array}$ \\
\hline 1 & $.889^{\mathrm{a}}$ & .790 & .789 & 8.22651 \\
\hline
\end{tabular}

a. Predictors: (Constant), Exam_2, Exam_1

Coefflclents $^{\mathrm{a}}$

\begin{tabular}{|c|c|c|c|c|c|c|c|c|}
\hline \multirow[b]{2}{*}{ Mode } & & \multicolumn{2}{|c|}{ Unstandardized Coefficients } & \multirow{2}{*}{$\begin{array}{c}\begin{array}{c}\text { Standardized } \\
\text { Coefficients }\end{array} \\
\text { Beta } \\
\end{array}$} & \multirow[b]{2}{*}{$t$} & \multirow[b]{2}{*}{ Sig. } & \multicolumn{2}{|c|}{ Collinearity Statistics } \\
\hline & & B & Std. Error & & & & Tolerance & VIF \\
\hline 1 & (Constant) & 7.238 & 2.685 & & 2.695 & .008 & & \\
\hline & Exam_1 & 379 & .037 & .338 & 10.180 & .000 & .791 & 1.265 \\
\hline & Exam_2 & .525 & .026 & .682 & 20.561 & .000 & .791 & 1.265 \\
\hline
\end{tabular}

a. Dependent Variable: BUS111_Average

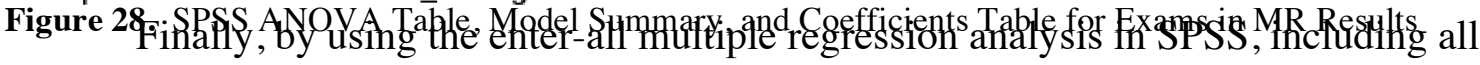

of the independent variables, I was able to account for $39.6 \%$ of the variance in exam three scores, which was a significant model overall $(F(8,135)=11.047 ; p=0.000)$ and produced the highest explainable variability of the three exams. However, using stepwise multiple regression, SPSS outputs revealed that the most efficient model for predicting exam three grades would include only four of the examined variables: mathematical anxiety, the number of classes the student missed (which would be known to a fairly exact amount by this time), their placement score, and their high school GPA. These predictors were able to explain $36.5 \%$ of the variance, and the change in $\mathrm{R}^{2}$ after the addition of each new variable was not significant enough to include in the step-wise model. Additionally, each tolerance statistic was above 0.75 and each VIF score was below 1.33, with an average VIF of 1.176, which are considered very good. The standard error of the estimate was about 16.1, indicating that, similar to exam two, the observed exam three scores differed from the values predicted using this model by about 16.1 
points. Since this step-wise model is more efficient, the regression equation that could be used (using the same independent variables as identified earlier) would be:

$$
\hat{y}_{\text {Exam } 3}=22.354-0.413 x_{1}+17.476 x_{5}+2.720 x_{6}-2.326 x_{8}
$$

This equation indicates that, for each additional point on the MAS, we would expect to see a $0.413 \%$ decrease in exam three grade (so, similar to exam two, the more anxious a student is about mathematics, the lower we would expect her exam grade to be). Further, we could expect an additional 17.476 percentage points to be earned on exam three for each additional point earned in high school GPA and an additional 2.72 percentage points on exam three for each level increase (out of seven levels) on URI's mathematics placement exam. Finally, for each class missed over the course of the semester, we would expect a decrease of $2.326 \%$ in that student's exam three score. This score also can only be predicted within about one and one half letter grades. Specifically, using this regression equation would indicate that a student in BUS 111 who scored a 30 on the MAS measuring anxiety, who earned a 3.2 GPA in high school, who placed in group 4 (group B/C) on the placement exam, and who missed two classes over the course of the semester, would earn a predicted grade on exam three of about a:

$$
\begin{aligned}
\hat{y}_{\text {Exam } 3} & =22.354-0.413(30)+17.476(3.2)+2.720(4)-2.326(2) \\
& =72.1152 \quad( \pm 16.1) \quad \text { (Thus, a letter grade of C-) }
\end{aligned}
$$

Therefore, by examining a student's high school GPA, mathematical anxiety/MAS results, placement score, and attendance, we would be able to predict her BUS 111 exam three grade to some moderate degree of accuracy.

\section{Gender-Specific Results}

Research Question Addressed: Are the predictive factors examined in BUS 111 different for male and female students?

Because there were significant differences discovered in final course grades between male and female students in BUS 111, and because $t$-tests revealed significant 
differences in some of the predictor variables based on gender (as explained above), I also ran multiple regression analyses on each gender separately (Smith \& Schumacher, 2005). First, I used simultaneous (enter-all) multiple regression on male participants only. Using all of the independent variables except gender, I was able to explain $51.3 \%$ of the variance in males' BUS 111 final average $(F(7,73)=10.968 ; p=0.000)$. Though collinearity statistics were satisfied, with all tolerance levels above 0.3 and all VIF scores below 3.31, a more parsimonious model was desirable, especially if a new model allowed these tolerance statistics to increase, thus reducing the risk of multicollinearity.

Therefore, I again combined attitudes towards mathematics and mathematical anxiety into one variable: mathematical emotions. Here, I was able to explain $52.3 \%$ of the variability in males' BUS 111 final average $(F(6,80)=14.632 ; p=0.000)$. With the combination of these scores, tolerance levels were all above 0.74 and all VIF statistics were all below 1.35 , indicating this was likely a better model. However, even in this model, as shown in Table 32 below, not all of the predictor variables were significant on their own, while holding everything else constant. Mathematical emotions, number of classes missed, and high school GPA appeared to be the most significant in this model.

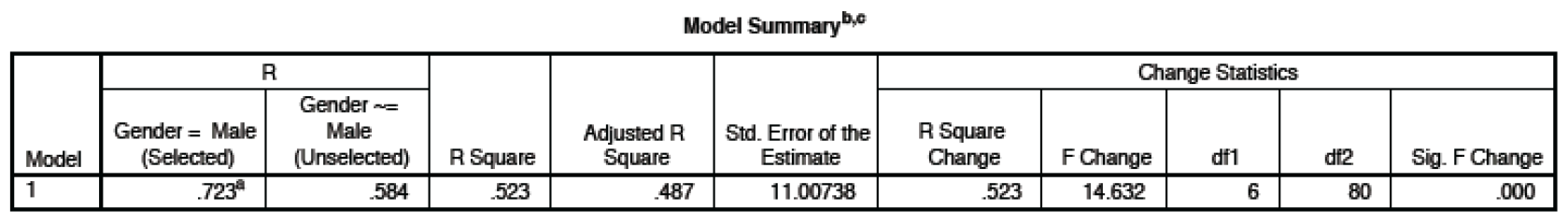

a. Predictors: (Constant), Math_Emotions, HS_GPA, SAT_Score, Attendance_Post, Time_Spent_Post, Placement_Score

b. Unless noted otherwise, statistics are based only on cases for which Gender = Male. c. Dependent Variable: BUS111_Average

\begin{tabular}{|c|c|c|c|c|c|c|c|c|}
\hline & & $\mathrm{B}$ & Std. Error & Beta & $\mathrm{t}$ & Sig. & Tolęrance & VIF \\
\hline \multirow[t]{7}{*}{1} & (Constant) & -4.645 & 20.613 & & -.225 & .822 & & \\
\hline & SAT_Score & .038 & .027 & .125 & 1.404 & .164 & .748 & 1.337 \\
\hline & HS_GPA & 15.100 & 3.058 & .389 & 4.937 & .000 & .962 & 1.039 \\
\hline & Placement_Score & 1.202 & .858 & .125 & 1.401 & .165 & .743 & 1.346 \\
\hline & Time_Spent_Post & -.276 & .622 & -.036 & -.443 & .659 & .889 & 1.125 \\
\hline & Attendance_Post & -4.117 & .750 & -.433 & -5.487 & .000 & .956 & 1.046 \\
\hline & Math_Emotions & .107 & .052 & .168 & 2.069 & .042 & .900 & 1.111 \\
\hline
\end{tabular}

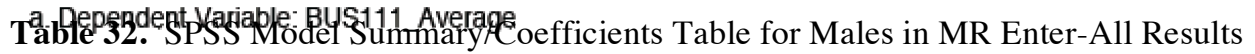
b. Selecting only cases for which Gender = Male 
Therefore, I followed by using step-wise multiple regression, where SPSS

revealed that the most efficient model would include only three predictor variables for males: the number of classes they missed over the course of the semester, their placement score, and their high school GPAs $(F(3,83)=26.077 ; p=0.000)$. These predictors alone were able to explain $48.5 \%$ of the variance, as shown below, and the change in $\mathrm{R}^{2}$ after the addition of each variable was not significant enough to include in the step-wise model. Further, in this regression model, all tolerance statistics were above 0.966 and all VIF scores were below 1.035 with an average VIF of about 1.029 , which are considered very strong. Additionally, the standard error of the estimate was about 11.2, indicating that the observed BUS 111 averages of male students differed from the values predicted using this model by about 11.2 points. This indicates that male's final averages would be predictable within about a letter grade.

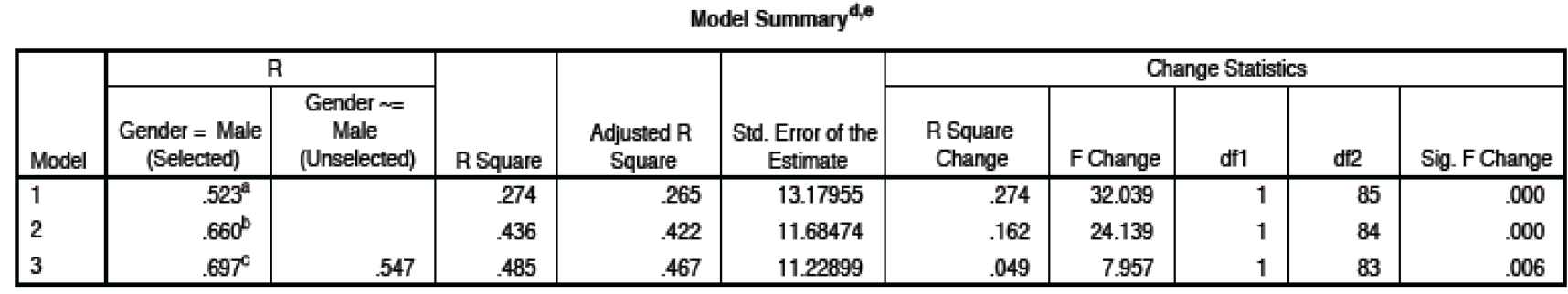

a. Predictors: (Constant), Attendance_Post

b. Predictors: (Constant), Attendance_Post, HS_GPA

c. Predictors: (Constant), Attendance_Post, HS_GPA, Placement_Score

d. Unless noted otherwise, statistics are based only on cases for which Gender $=$ Male.

e. Dependent Variable: BUS111_Average

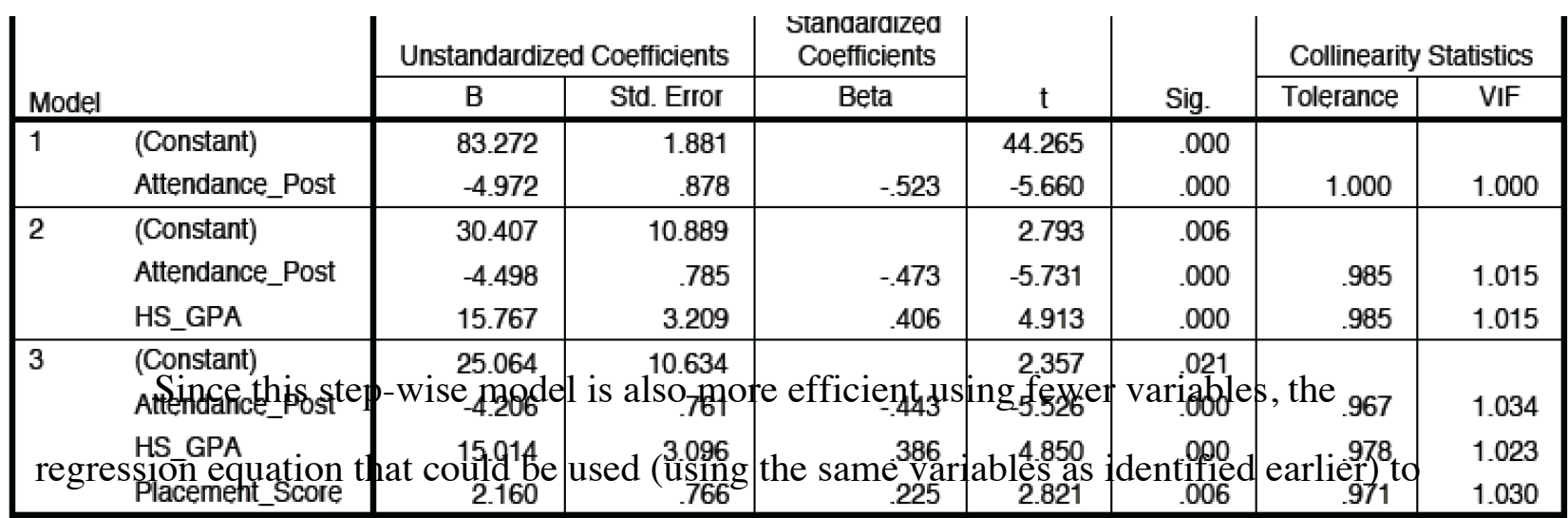

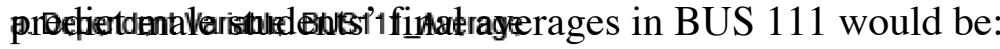

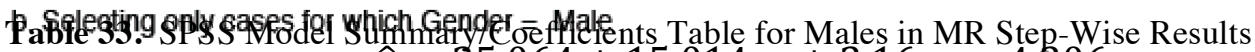

$$
\hat{y}=25.064+15.014 x_{5}+2.16 x_{6}-4.206 x_{8}
$$


This equation indicates that we could expect male students to earn 15.014 points higher in BUS 111 for each additional point earned in high school GPA and an additional 2.16 points in final course average for each level increase of the placement exam.

Finally, for each class the student missed, we would anticipate a 4.206 point decrease in his BUS 111 final average. Specifically, for example, using this regression equation would indicate that a male student in BUS 111 who earned a 2.9 GPA in high school, who placed in group 4 (group B/C) on the placement exam, and who missed one class over the course of the semester, would earn a predicted final course grade in BUS 111 of about a:

$$
\begin{aligned}
\hat{y} & =25.064+15.014(2.9)+2.16(4)-4.206(1) \\
& =73.0386 \quad( \pm 11.2) \quad(\text { Thus, a letter grade of } \mathrm{C})
\end{aligned}
$$

Therefore, by examining a male student's attendance, mathematics placement score, and high school GPA, we could predict his BUS 111 course grade to a reasonable degree of accuracy.

After this analysis, I used simultaneous (enter-all) multiple regression on female participants only. Using all of other the independent variables, I was able to explain $41.9 \%$ of the variance in females' BUS 111 final average $(F(7,55)=5.678 ; p=0.000)$. Again, however, tolerances were all above 0.147 and VIF scores were all below 6.81 , which are acceptable, but could warrant further investigation to address multicollinearity concerns. Since all VIF scores were below 2 except for ATMI and MAS results, a different model or combination of variables was desired.

Thus, I again combined attitudes towards mathematics and mathematical anxiety into one variable: mathematical emotions. Here, I was able to explain $42.1 \%$ of the variability in females' BUS 111 final average $(F(6,58)=7.031 ; p=0.000)$. With the combination of these scores, tolerance levels were all above 0.71 and all VIF statistics were all below 2.05 , indicating this was likely a better model. However, even in this model, as shown in the printout (Table 34) below, only a few of the predictor variables 
were found to be significant on their own, while holding everything else in the model constant, so further investigation was appropriate. Mathematical emotions, placement score, and high school GPA appeared to be the most significant in this model.

\section{Coefticients $^{\mathrm{a}, \mathrm{b}}$}

\begin{tabular}{|c|c|c|c|c|c|c|c|c|}
\hline \multirow[b]{2}{*}{ Mod } & & \multicolumn{2}{|c|}{ Unstandardized Coefficients } & \multirow{2}{*}{$\begin{array}{c}\begin{array}{c}\text { Standardized } \\
\text { Coefficients }\end{array} \\
\text { Beta }\end{array}$} & \multirow[b]{2}{*}{$\mathrm{t}$} & \multirow[b]{2}{*}{ Sig. } & \multicolumn{2}{|c|}{ Collinearity Statistics } \\
\hline & & $\mathrm{B}$ & Std. Error & & & & Tolęrance & VIF \\
\hline \multirow[t]{7}{*}{1} & (Constant) & 36.839 & 20.713 & & 1.779 & .081 & & \\
\hline & SAT_Score & -.010 & .032 & -.037 & -.325 & .746 & .759 & 1.318 \\
\hline & HS_GPA & 10.344 & 3.207 & .352 & 3.225 & .002 & .838 & 1.193 \\
\hline & Placement_Score & 1.944 & .996 & .279 & 1.951 & .056 & .488 & 2.049 \\
\hline & Time_Spent_Post & -.670 & .714 & -.104 & -.937 & .353 & .813 & 1.230 \\
\hline & Attendance_Post & .216 & 1.167 & .020 & .185 & .854 & .851 & 1.176 \\
\hline & Math_Emotions & .087 & .047 & 216 & 1.828 & .073 & .717 & 1.394 \\
\hline
\end{tabular}

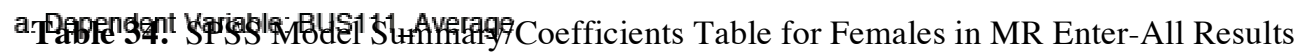
b. Selecting only cases for which Gender $=$ Female

Similar to male students, using step-wise multiple regression, SPSS revealed that

the most efficient model would include only two predictor variables for females: their placement scores and their high school GPAs $(F(2,62)=19.302 ; p=0.000)$. These predictors alone were able to explain $38.4 \%$ of the variance, as shown below, and the change in $\mathrm{R}^{2}$ after the addition of each variable was not significant enough to include in the step-wise model. Further, all tolerance statistics were then above 0.88 and all VIF scores were below 1.14 with an average VIF of 1.134, which are again considered much better than they were in the enter-all model. Additionally, the standard error of the estimate was about 9.9, indicating that the observed BUS 111 averages of female students differed from the values predicted using this model by about 9.9 points. This indicates that female's final averages would be predictable within a letter grade as well.

\begin{tabular}{|c|c|c|c|c|c|c|c|c|c|c|}
\hline \multicolumn{11}{|c|}{ Model Summary ${ }^{\mathrm{e}, \mathrm{d}}$} \\
\hline \multirow[b]{2}{*}{ Model } & \multicolumn{2}{|c|}{$\mathrm{R}$} & \multirow[b]{2}{*}{ R Square } & \multirow[b]{2}{*}{$\begin{array}{l}\text { Adjusted R } \\
\text { Square }\end{array}$} & \multirow[b]{2}{*}{$\begin{array}{l}\text { Std. Error of the } \\
\text { Estimate }\end{array}$} & \multicolumn{5}{|c|}{ Change Statistics } \\
\hline & $\begin{array}{l}\text { Gender = } \\
\text { Female } \\
\text { (Selected) }\end{array}$ & $\begin{array}{c}\text { Gender } \approx= \\
\text { Female } \\
\text { (Unselected) }\end{array}$ & & & & $\begin{array}{c}\text { R Square } \\
\text { Change }\end{array}$ & F Change & df1 & $\mathrm{df} 2$ & Sig. F Change \\
\hline 1 & $.527^{a}$ & & .278 & .266 & 10.66034 & .278 & 24.238 & 1 & 63 & .000 \\
\hline 2 & $.619^{b}$ & .662 & 384 & 364 & 9.92694 & .106 & 10.653 & 1 & 62 & .002 \\
\hline
\end{tabular}

a. Predictors: (Constant), Placement_Score

b. Predictors: (Constant), Placement_Score, HS_GPA

c. Unless noted otherwise, statistics are based only on cases for which Gender = Female. 


\section{Coefficlents $^{\mathrm{a}, \mathrm{b}}$}

\begin{tabular}{|c|c|c|c|c|c|c|c|c|}
\hline \multirow{2}{*}{\multicolumn{2}{|c|}{ Model }} & \multicolumn{2}{|c|}{ Unstandardized Coefficients } & \multirow{2}{*}{$\begin{array}{c}\begin{array}{c}\text { Standardized } \\
\text { Coefficients }\end{array} \\
\text { Beta }\end{array}$} & \multirow[b]{2}{*}{$\mathrm{t}$} & \multirow[b]{2}{*}{ Sig. } & \multicolumn{2}{|c|}{ Collinearity Statistics } \\
\hline & & $\mathrm{B}$ & Std. Error & & & & Tolerance & VIF \\
\hline \multirow[t]{2}{*}{1} & (Constant) & 68.925 & 2.932 & & 23.511 & .000 & & \\
\hline & Placement_Score & 3.672 & .746 & .527 & 4.923 & .000 & 1.000 & 1.000 \\
\hline \multirow[t]{3}{*}{2} & (Constant) & 35.651 & 10.554 & & 3.378 & .001 & & \\
\hline & Placement_Score & 2.844 & .740 & .408 & 3.845 & .000 & .882 & 1.134 \\
\hline & HS_GPA & 10.180 & 3.119 & .346 & 3.264 & .002 & .882 & 1.134 \\
\hline
\end{tabular}

a. Dependent Variable: BUS111_Average

Table 35 . SPSS Model Summary and Ceefficients Table for Females in MR Step-Wise Results

Since this step-wise model is also more efficient, using fewer predictors, the regression equation that could be used (using the same independent variables as identified earlier) to predict female students' final averages in BUS 111 would be:

$$
\hat{y}=35.651+10.18 x_{5}+2.844 x_{6}
$$

This equation indicates that we could expect female students to earn an additional 10.18 points in BUS 111 course grade for each additional point earned in high school GPA and an additional 2.844 points in course average for each level increase of the placement exam. Specifically, using this regression equation would indicate that a female student in BUS 111 who earned a 2.9 GPA in high school and who placed in group 4 (group B/C) on the placement exam would earn a predicted final grade in BUS 111 of about a:

$$
\begin{aligned}
\hat{y} & =35.651+10.18(2.9)+2.844(4) \\
& =76.549 \quad( \pm 9.9) \quad \text { (Thus, a letter grade of } \mathrm{C})
\end{aligned}
$$

Therefore, by examining only a female student's university mathematics placement score and high school GPA, we could predict her BUS 111 course grade to a relatively accurate degree. 
These results indicate that it may be easier to predict BUS 111 final course grades for male students than for female students, at least using this set of independent variables, and that mathematical emotions may play a more significant role in males' business mathematics final grades than in females' final course grades. Since the male to female ratio in BUS 111 is generally around 3:2, this is definitely a practically significant discovery for the College of Business. For male students, over half of the variability in their final course grade in BUS 111 could be explained by the predictors used here: SAT score, high school GPA, university placement score, attitude towards mathematics, mathematical anxiety, hours spent working on mathematics outside of class, and number of classes missed.

\section{Instructor-Specific Results}

Because there were some significant differences revealed by the ANOVA analyses among the three different instructors, I thought it might be prudent to analyze each instructor separately to see if the variables that were significant for students in one instructor's class may be different than those from another instructor's class. The results of these individual analyses are shown below. It is important to note first that these results may be misleading for Instructor 3's class, as she only had 29 students participating in this research, and therefore the multiple regression analyses may not be appropriate for this number of predictors and this small of a sample. However, for Instructor 1 and Instructor 2, the sample sizes are appropriate.

\section{Instructor 1}

First, I used simultaneous (enter-all) multiple regression on Instructor 1's participants only. Using all of the independent variables, I was able to explain $51 \%$ of the variance in Instructor 1's students' BUS 111 final course averages $(F(8,70)=9.105 ; p$ $=0.000)$. Though collinearity statistics were satisfied, the lowest tolerance levels were only just above 0.18 and the VIF scores were sometimes as high as 5.513. Thus, a more 
effective model was desirable, especially if a new model allowed these tolerance statistics to increase, thus reducing the risk of multicollinearity.

Therefore, I again combined attitudes towards mathematics and mathematical anxiety into one variable: mathematical emotions. At that point, I was able to explain $55.7 \%$ of the variability in the BUS 111 final averages of students in Instructor 1's class $(F(7,75)=13.491 ; p=0.000)$, which is a very significant amount of variance explained.

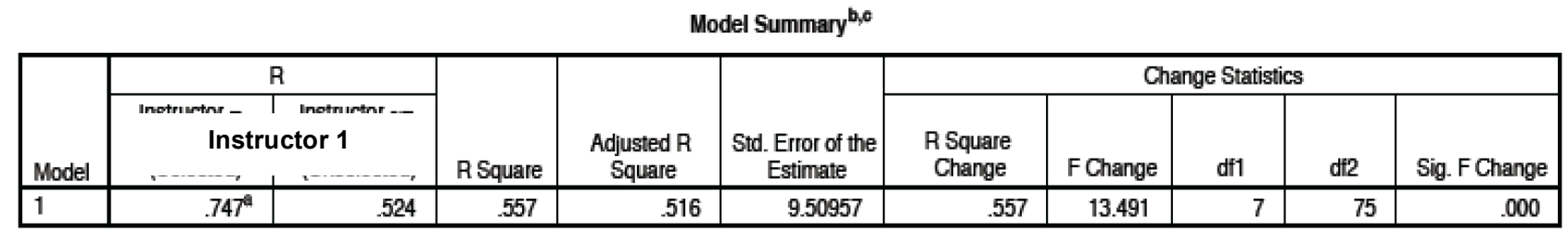

a. Predictors: (Constant), Gender, Time_Spent_Post, Math_Emotions, Attendance_Post, SAT_Score, HS_GPA, Placement_Score

b. Unless noted otherwise, statistics are based only on cases for which Instructor = Instructor 1

c. Dependent Variable: BUS111_Average

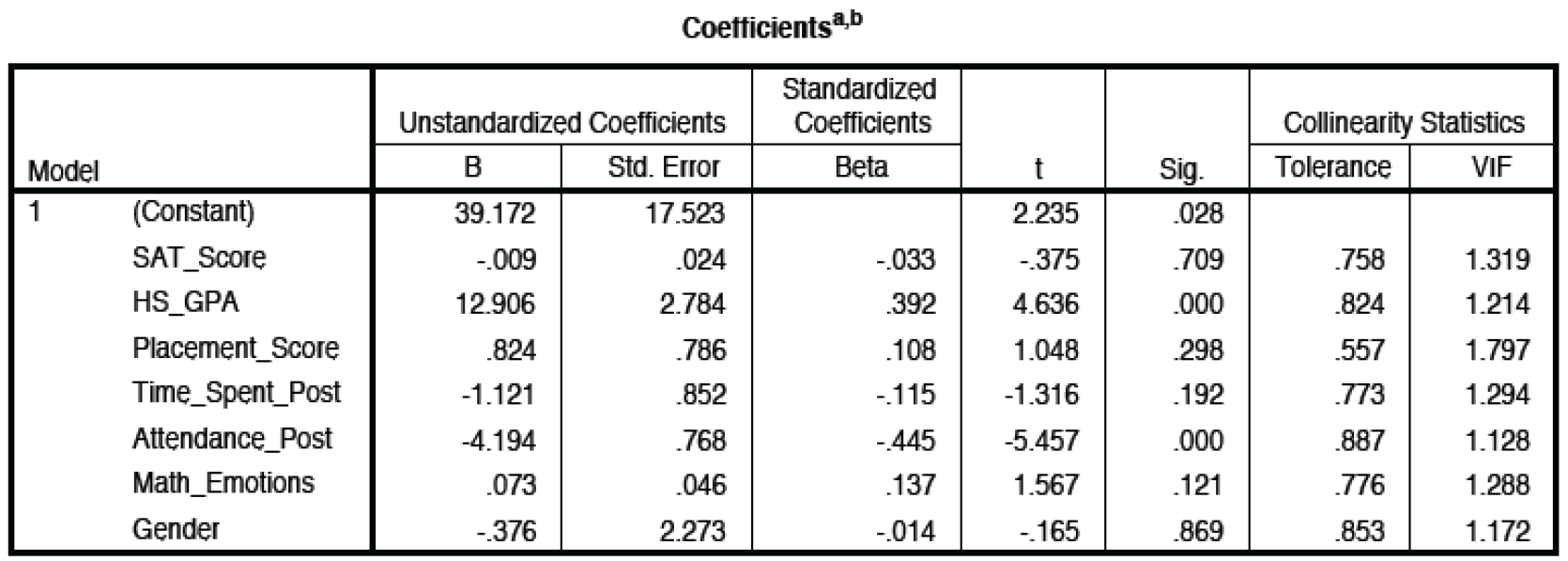

a. Dependent Variable: BUS111_Average

b. Selecting only cases for which Instructor $=$ Instructor 1

With the combination

of these scores, tolerance

levels were all above 0.55 and all VIF statistics were below 1.8 , indicating this was likely a better model. However, even in this model, as shown in Table 36 below, only some of the predictor variables were significant on their own, while holding everything else constant. Number of classes missed over the semester and high school GPA appeared to be the most significant. 
Therefore, I then used step-wise multiple regression, where SPSS revealed that the most efficient model would include only three predictor variables for Instructor 1's students' final course averages: the number of classes they missed over the course of the semester, their placement score, and their high school GPAs $(F(3,79)=30.126 ; p=$ 0.000). These predictors alone were able to explain $53.4 \%$ of the variance, as shown in Table 37 below, and the change in $\mathrm{R}^{2}$ after the addition of each variable was not significant enough to include in the step-wise model. Further, in this regression model,

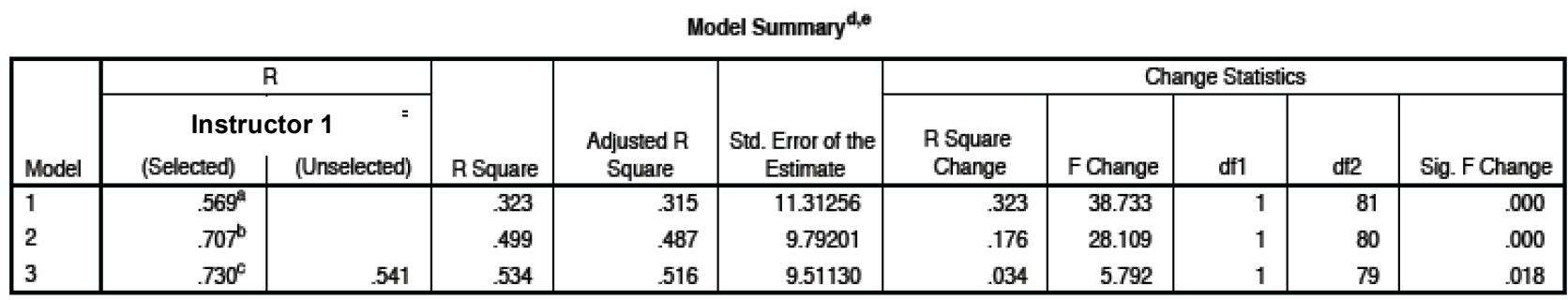

a. Predictors: (Constant), Attendance_Post

b. Predictors: (Constant), Attendance_Post, HS_GPA

c. Predictors: (Constant), Attendance_Post, HS_GPA, Placement_Score

d. Unless noted otherwise, statistics are based only on cases for which Instructor = Instructor 1

e. Dependent Variable: BUS111_Average

all tolerance statistics were above 0.89 and all VIF scores were below 1.12 with an average VIF of about 1.08 , which are considered very strong. Additionally, the standard error of the estimate was about 9.5, indicating that the observed BUS 111 averages of students in Instructor 1's class differed from the values predicted using this model by about 9.5 points. Similar to males and females, this indicates that the final averages of students in Instructor 1's class were predictable within about a letter grade. 


\begin{tabular}{|c|c|c|c|c|c|c|c|c|}
\hline \multicolumn{9}{|c|}{ Coefficlents $^{a, b}$} \\
\hline \multirow[b]{2}{*}{ Mode } & & \multicolumn{2}{|c|}{ Unstandardized Coefficients } & \multirow{2}{*}{$\begin{array}{c}\begin{array}{c}\text { Standardized } \\
\text { Coefficięnts }\end{array} \\
\text { Beta }\end{array}$} & \multirow[b]{2}{*}{$\mathrm{t}$} & \multirow[b]{2}{*}{ Sig. } & \multicolumn{2}{|c|}{ Collinearity Statistics } \\
\hline & & $\mathrm{B}$ & Std. Error & & & & Tolerance & VIF \\
\hline \multirow[t]{2}{*}{1} & (Constant) & 88.464 & 1.773 & & 49.899 & .000 & & \\
\hline & Attendance_Post & -5.358 & .861 & -.569 & -6.224 & .000 & 1.000 & 1.000 \\
\hline \multirow[t]{3}{*}{2} & (Constant) & 38.563 & 9.536 & & 4.044 & .000 & & \\
\hline & Attendance_Post & -4.492 & .763 & -.477 & -5.888 & .000 & .954 & 1.048 \\
\hline & HS_GPA & 14.122 & 2.664 & .429 & 5.302 & .000 & .954 & 1.048 \\
\hline \multirow[t]{4}{*}{3} & (Constant) & 38.688 & 9.263 & & 4.177 & .000 & & \\
\hline & Attendance_Post & -4.358 & .743 & -.463 & -5.865 & .000 & .949 & 1.054 \\
\hline & HS_GPA & 12.527 & 2.671 & .381 & 4.690 & .000 & .895 & 1.117 \\
\hline & Placement_Score & 1.470 & .611 & .192 & 2.407 & .018 & .923 & 1.083 \\
\hline
\end{tabular}

a. Dependent Variable: BUS111_Average

b. Selecting only cases for which Instructor = Instructor 1

This step-wise model is also more efficient, because it uses fewer variables, so the regression equation that would be recommended for use (using the same variables as identified earlier) to predict students' final averages in BUS 111, if taken with Instructor 1, would be:

$$
\hat{y}=38.688+12.527 x_{5}+1.47 x_{6}-4.358 x_{8}
$$

This equation indicates that we could expect students in Instructor 1's class to earn 12.527 more points in BUS 111 for each additional point earned in high school GPA and an additional 1.47 points in final course average for each level increase of the

Table 37. SPSS Model Summary/Coefficients Table for Instructor 1 in MR Step-Wise Results placement exam. Finally, for each of Instructor 1's classes the student missed, we would anticipate a 4.358 point decrease in their BUS 111 final average. Specifically, for example, using this regression equation would indicate that a student in Instructor 1's section of BUS 111 who earned a 2.9 GPA in high school, who placed in group 4 (group $\mathrm{B} / \mathrm{C}$ ) on the placement exam, and who missed one class over the course of the semester, would earn a predicted final course grade in BUS 111 of about a:

$$
\hat{y}=38.688+12.527(2.9)+1.47(4)-4.358(1)
$$




$$
=76.5383( \pm 9.5) \quad \text { (Thus, a letter grade of } \mathrm{C})
$$

Therefore, by examining a student's attendance, mathematics placement score, and high school GPA in Instructor 1's class, we could predict her BUS 111 course grade to a reasonable degree of accuracy (within one letter grade).

\section{Instructor 2}

Similar to Instructor 1's students, I started by using simultaneous (enter-all) multiple regression on Instructor 2's student participants only. Using all of the independent variables, I was able to explain 53.2\% of the variance in Instructor 2's students' BUS 111 final course averages $(F(8,48)=6.812 ; p=0.000)$. Though collinearity statistics were satisfied, the lowest tolerance levels were only just above 0.26 and the VIF scores were only below 3.5. Thus, again, a more effective model was desirable, especially if a new model allowed these tolerance statistics to increase, thus reducing the risk of multicollinearity.

Therefore, I again combined attitudes towards mathematics and mathematical anxiety into the mathematical emotions variable. Here, I was able to explain less of the variability in the BUS 111 final averages of students in Instructor 2's class, 48.9\% $(F(7,53)=7.255 ; p=0.000)$, but still a significant amount of variance could be explained. With the combination of these scores, tolerance levels were all above 0.6 and all VIF statistics were below 1.65, indicating this was likely a better model. However, even in this model, as shown in Table 38 below, only some of the predictors were significant on their own, while holding everything else constant. Here, high school GPA, mathematics SAT score, placement score, and gender appeared to be the most significant.

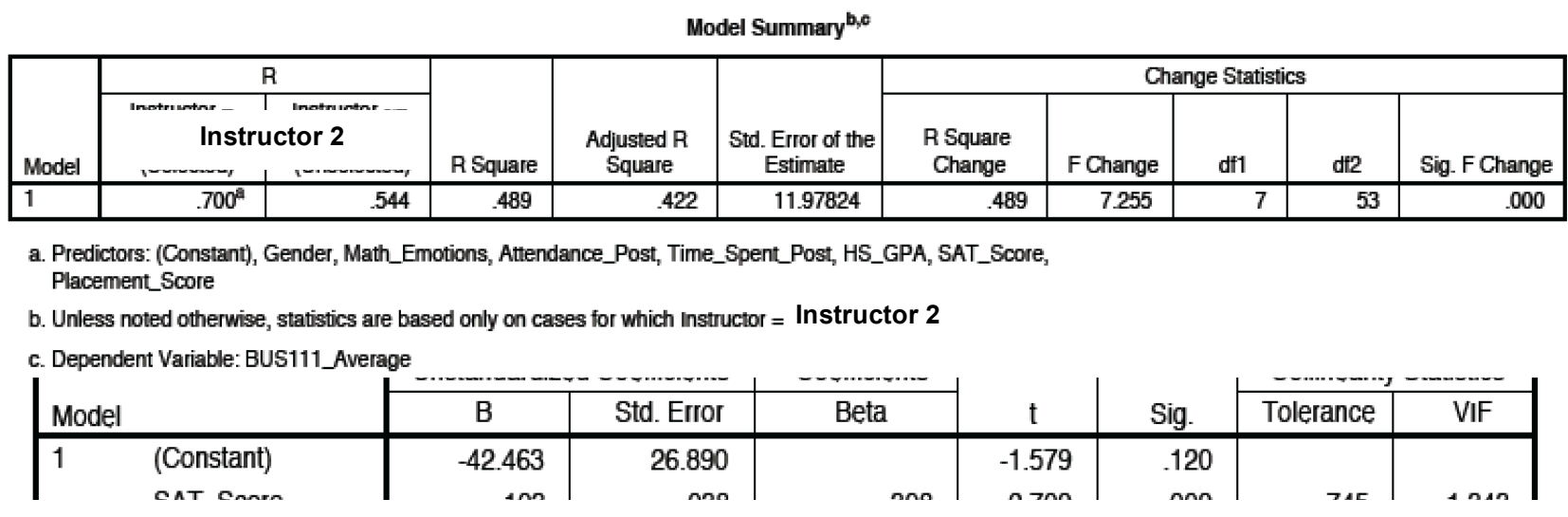


Thus, I then implemented a step-wise multiple regression, and SPSS revealed that the most efficient model would include only three predictor variables for Instructor 2's students' final course averages: their placement score, their high school GPAs, and now, instead of absences, mathematics SAT scores were a better predictor for Instructor 2's

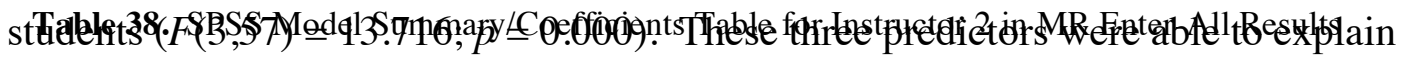
$41.9 \%$ of the variance, as shown below, and the change in $\mathrm{R}^{2}$ after the addition of each variable was not significant enough to include in the step-wise model. In this regression model, all tolerance statistics were above 0.75 and all VIF scores were below 1.33 with

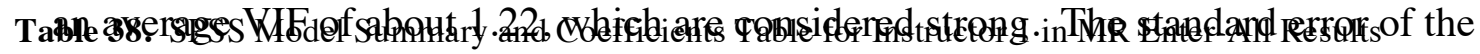
estimate was about 12.3, indicating that the observed BUS 111 averages of students in Instructor 2's class differed from the values predicted using this model by about 12.3 points, so again, about one letter grade.

Table 39. SPSS Model Summary for Instructor 2 in MR Step-Wise Results

In the following table (Table 40), the coefficients corresponding to this model are

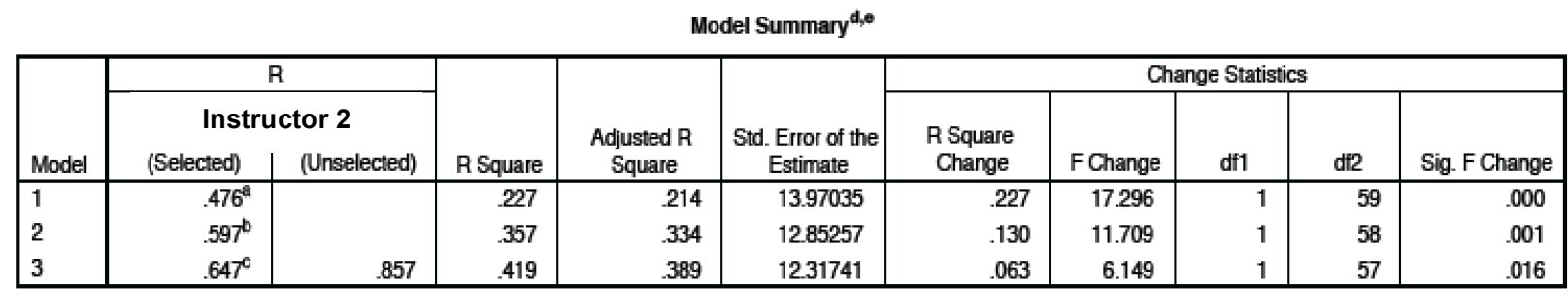

a. Predictors: (Constant), Placement_Score

b. Predictors: (Constant), Placement_Score, HS_GPA

c. Predictors: (Constant), Placement_Score, HS_GPA, SAT_Score

d. Unless noted otherwise, statistics are based only on cases for which Instructor =

Instructor 2

e. Dependent Variable: BUS111_Average

provided. Because this step-wise model is also more efficient, as it uses fewer variables, the regression equation that would be recommended for use (using the same variables as identified earlier) to predict students' final averages in BUS 111 taken with Instructor 2 is given below the coefficients table. 


\begin{tabular}{|c|c|c|c|c|c|c|c|c|}
\hline \multicolumn{9}{|c|}{ Coefficlents $^{a, b}$} \\
\hline \multirow{2}{*}{\multicolumn{2}{|c|}{ Model }} & \multicolumn{2}{|c|}{ Unstandardized Coefficients } & \multirow{2}{*}{$\begin{array}{c}\begin{array}{c}\text { Standardized } \\
\text { Coefficients }\end{array} \\
\text { Betta }\end{array}$} & \multirow[b]{2}{*}{$\mathrm{t}$} & \multirow[b]{2}{*}{ Sig. } & \multicolumn{2}{|c|}{ Collinearity Statistics } \\
\hline & & $\mathrm{B}$ & Std. Error & & & & Toleerance & VIF \\
\hline \multirow[t]{2}{*}{1} & (Constant) & 59.596 & 4.281 & & 13.920 & .000 & & \\
\hline & Placement_Score & 4.767 & 1.146 & .476 & 4.159 & .000 & 1.000 & 1.000 \\
\hline \multirow[t]{3}{*}{2} & (Constant) & 17.129 & 13.021 & & 1.316 & .194 & & \\
\hline & Placement_Score & 4.063 & 1.074 & .406 & 3.782 & .000 & .963 & 1.038 \\
\hline & HS_GPA & 13.406 & 3.918 & .367 & 3.422 & .001 & .963 & 1.038 \\
\hline \multirow[t]{4}{*}{3} & (Constant) & -37.323 & 25.256 & & -1.478 & .145 & & \\
\hline & Placement_Score & 2.726 & 1.162 & .272 & 2.346 & .022 & .756 & 1.323 \\
\hline & HS_GPA & 14.943 & 3.805 & .409 & 3.927 & .000 & .938 & 1.066 \\
\hline & SAT_Score & .094 & .038 & .283 & 2.480 & .016 & .782 & 1.279 \\
\hline
\end{tabular}

a. Dependent Variable: BUS111_Average

b. Selecting only cases for which Instructor = Instructor 2

Table 40. SPSS Coefficients Table for Instructor 2 in MR Step-Wise Results

$$
\hat{y}=-37.323+0.094 x_{4}+14.943 x_{5}+2.726 x_{6}
$$

This equation indicates that we could expect students in Instructor 2's class to earn 14.943 points higher in BUS 111 for each additional point earned in high school GPA, an additional 2.726 points in final course average for each level increase of the placement exam, and an additional 0.094 points in their BUS 111 final average for each additional point earned on the mathematics portion of the SAT (or about 9.4 additional points for each 100 point increase in SAT score). Specifically, for example, using this regression equation would indicate that a student in Instructor 2's section of BUS 111 who earned a 2.9 GPA in high school, who placed in group 4 (group B/C) on the placement exam, and who earned a 580 on the mathematics SAT, would earn a predicted final course grade in BUS 111 of about a:

$$
\begin{aligned}
\hat{y} & =-37.323+0.094(580)+14.943(2.9)+2.726(4) \\
& =71.4357 \quad( \pm 12.3) \quad \text { (Thus, a letter grade of } \mathrm{C}-)
\end{aligned}
$$


Therefore, by examining a student's mathematics SAT score, mathematics placement score, and high school GPA in Instructor 2's class, we could also predict his BUS 111 course grade to a reasonable degree of accuracy (varying by about one letter grade).

\section{Instructor 3}

Finally, I examined Instructor 3's student participants only. With a sample size of only 29 , I was unable to run an enter-all (simultaneous) multiple regression analysis, as there were too many predictor variables for the small sample. Therefore, I again combined attitudes towards mathematics and mathematical anxiety into the mathematical emotions variable. I then used step-wise multiple regression, and SPSS revealed that the most efficient model would include only one predictor variable for Instructor 3's final course averages: gender $(F=9.163 ; p=0.023)$. The gender predictor alone was able to explain $60.4 \%$ of the variance in Instructor 3's final class averages, as shown below, and the change in $\mathrm{R}^{2}$ after the addition of each variable was not significant enough to include in the step-wise model. Further, in this regression model, the tolerance statistic and the VIF score were 1.000 (as would be expected, since only one independent variable was included in the model). The standard error of the estimate for this step-wise model was only about 4.8, indicating that the observed BUS 111 final averages of students in Instructor 3's class differed from the values predicted using this model by less than five points (within half of a letter grade).

In the following table, the coefficient corresponding to this model is provided.

The regression equation that could be used (using the same variable $x_{3}=$ gender as

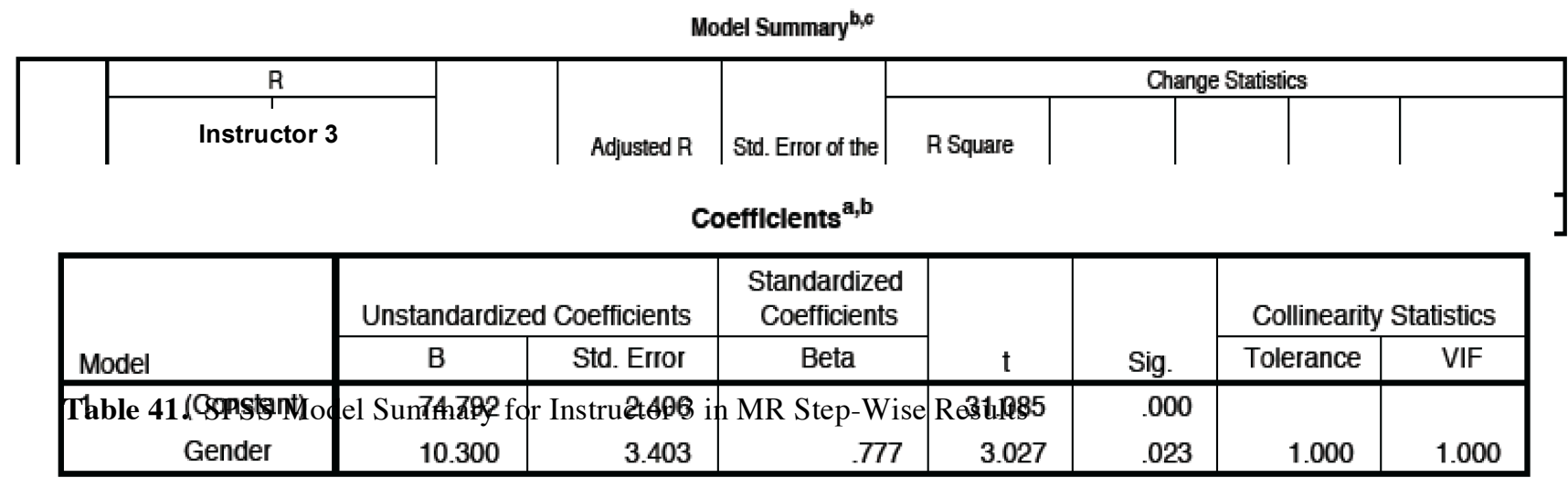

\footnotetext{
a. Dependent Variable: BUS111_Average

b. Selecting only cases for which Instructor $=$ Instructor 3
} 
identified earlier) to predict students' final averages in BUS 111 taken with Instructor 3 is given below the coefficients table.

$$
\hat{y}=74.792+10.3 x_{3}
$$

This equation indicates that we could expect female students in Instructor 3's class to earn 10.3 points higher in final BUS 111 grade than their male counterparts. Specifically, for example, using this regression equation would indicate that a female

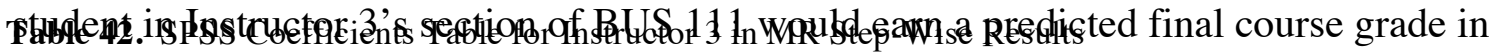
BUS 111 of about a:

$$
\begin{aligned}
\hat{y} & =74.792+10.3(1) \\
& =85.092 \quad( \pm 4.8) \quad(\text { Thus, a letter grade of } B)
\end{aligned}
$$

Similarly, we would expect that a male student in Instructor 3's section of BUS 111 would earn a predicted final course grade in BUS 111 of about a:

$$
\begin{aligned}
\hat{y} & =74.792+10.3(0) \\
& =74.792 \quad( \pm 4.8) \quad \text { (Thus, a letter grade of } C)
\end{aligned}
$$

Therefore, by examining a student's gender alone in Instructor 3's class during the Fall 2015 semester, we could also predict their BUS 111 course grade. Again, it should be stressed that Instructor 3 only had 29 students participating in this research, so the sample size is too small to make generalized conclusions and further investigation would need to be carried out to make more confident predictions about final BUS 111 course grades for this specific instructor.

\section{Other Noteworthy Results}

Other regression models were run in SPSS to investigate various relationships between certain variables. One model I was particularly interested in examining was what variables (other than a student's final course grade) might predict a student's attitude towards mathematics and their level of mathematical anxiety at the end of the 
BUS 111 course. Step-wise multiple regression analyses revealed that $31.9 \%(p=0.000)$ of the variance in a student's attitude towards mathematics and $29.9 \%(p=0.000)$ of the variance in a student's mathematical anxiety could be explained by the combination of only two predictor variables: their mathematics placement score and their final perceived effectiveness of their BUS 111 instructor. This suggests that how students are initially placed in college mathematics (their labeled ability) and how well they believe their course instructor can deliver the material may play a large role in their attitudes and anxiety in mathematics.

\section{Correlational Results}

Research Question Addressed: What is the relationship between perceived instructional quality and success in the BUS 111 course at URI?

\section{Perceived Instructor Effectiveness and ATMI}

I initially hypothesized that students' attitudes towards mathematics (as measured by the ATMI) may correlate with how effective they perceived their instructor to be. The role of the instructor is momentous in how students approach mathematical processes and how they value the subject (Blaszczynski, 2001; Hiebert \& Grouws, 2007). The results of the pre-surveys revealed a statistically significant, positive (though relatively weak) correlation between perceived instructor effectiveness and students' pre-survey ATMI results $(r=0.296, p=0.000)$. This indicates that students with more favorable attitudes towards mathematics were also slightly more likely to initially believe that their instructors were capable of effectively delivering the BUS 111 course material. Similarly, the results of the post-surveys revealed a statistically significant, positive correlation (which was stronger than the relationship from the pre-surveys) between perceived instructor effectiveness and ATMI results $(r=0.312 p=0.000)$. Therefore, students who ended the course with more favorable attitudes towards mathematics were also more likely to believe that their BUS 111 instructor had effectively delivered the course material. 


\section{Perceived Instructor Effectiveness and MAS}

I also hypothesized that students' mathematical anxiety may correlate with how effective they perceived their instructor to be, as instructors may impact how anxious students feel about mathematics, or anxiety may impact how effective students perceive their instructors. The results of the pre-surveys revealed a statistically significant, negative (though fairly weak) correlation between perceived effectiveness and students' MAS results $(r=-0.222 ; p=0.001)$. This indicates that students with higher levels of mathematical anxiety coming into the BUS 111 course also believed their instructors were less likely to be capable of effectively delivering course material. Similarly, the results of the post-surveys revealed a statistically significant, negative correlation between perceived effectiveness and MAS results, which was stronger than the correlation with the results from the pre-surveys $(r=-0.320 p=0.000)$. Thus, students

who ended the course with high mathematical anxiety were also less likely to report that their instructor was effective at delivering the course material.

\section{Perceived Instructor Effectiveness and Time Spent}

One unanticipated result from this research was the statistically significant correlation that existed between the amount of time students reported spending on mathematics outside of class per week and how effective they perceived their instructor to be. There was a statistically significant, negative correlation between these two variables $(r=-0.284 ; p=0.000)$, indicating that students who spent less time working on BUS 111 outside of class also tended to perceive their instructors as more effective at delivering the course material. There was no correlation, however, between how many classes a student missed over the course of the semester and how effective they perceived their instructor to be. Thus, perceived effectiveness seems to be related to how many hours students spent outside of class working on mathematics, but unrelated to the amount of time they spent in class.

\section{Perceived Instructor Effectiveness and Course Average}


Students often make decisions about the effectiveness of their instructor early in the semester. Once students begin to receive grades and determine their likelihood of being successful in a course, however, their perceptions of their instructors sometimes change. On the pre-surveys, a statistically significant, positive correlation was found between perceived effectiveness of the instructor and students' overall BUS 111 course averages $(r=0.173 ; p=0.010)$. Similarly, on the post-surveys, a stronger (though still relatively weak), statistically significant, positive correlation existed between perceived instructor effectiveness and course averages $(r=0.293 ; p=0.000)$. This relationship may indicate that students who were successful in the course were willing to attribute some of their success to their instructor's effectiveness. Alternatively, students may have perceived their instructor to be more effective at teaching the material due to the fact that they were able to earn a successful grade in the course. Causation cannot be assumed.

\section{Concluding Remarks}

With the results from each of these analyses in mind, some overall conclusions can be drawn about the relationship between these variables and their influence on student success. First, students' attitudes towards mathematics appear to be very closely related to their mathematical anxiety. Specifically, students with higher levels of mathematical anxiety tend to hold less favorable attitudes towards mathematics. Because of this strong, negative relationship, in the multiple regression analyses presented in this chapter, it was often better to consider a student's overall "mathematical emotions" by combining these two measures, rather than looking at them separately. An average of the two scores could be used, or we could measure the overall emotion variable as the MAS score subtracted from the ATMI score (as was done here), or we could use only one of these two measures in future analyses on success in business mathematics courses. Since mathematical anxiety had a slightly stronger correlation with final BUS 111 course average than attitudes towards mathematics ( $r=-0.452$ and $r=0.436$, respectively) and the instrument to measure anxiety is shorter in length than the instrument measuring 
attitudes towards mathematics (14 questions versus 40 questions), I might suggest using only MAS scores for analysis, for example.

Another important conclusion is that, in general, some combination of affective, cognitive measures and non-affective measures, such as test scores, is best to use in order to predict overall course grade in a business mathematics class. While using only test scores and other measures such as gender, high school GPA, mathematics SAT score, and the university placement grouping might help explain some of the variability in BUS 111 average, adding in predictors such as mathematical anxiety/attitudes towards mathematics, time devoted to the subject outside of class, and number of absences over the course of the semester will allow us to explain more of the variability in final course grade. Therefore, it is important for admissions teams, advisors, and instructors to gather information that focuses on the whole student, not just a student's previous measures of achievement. The implications of these findings are discussed in more detail in chapter six.

Of all of the models presented here, keeping sample size and overall usability in mind, likely the best model, which I would recommend for use, would be the step-wise regression model combining students' mathematical anxiety and attitudes towards mathematics as the single predictor variable: mathematical emotions. Again, this model was:

$\hat{y}=22.503+0.078($ MathEmotions $)+13.385($ HSGPA $)+1.784$ (Placement) -2.992 (Absences)

This model was able to explain $44.2 \%$ of the overall variability in final BUS 111 course grades for all BUS 111 students. To further verify the accuracy of this model, I used SPSS to randomly split my sample in half. I then used one of those halves to re-run the step-wise multiple regression analysis and make sure it was similar to the original model. Though the new $\mathrm{R}^{2}$ value was slightly higher at $47.3 \%$, no significant differences existed between this test group and the original model (which included all student 
participants). With the other random half of the sample selected, I tested the regression model as written above against students' actual final averages (M. Shim, personal communication, September 2014). Finally, I ran a paired samples $t$-test analysis to investigate whether differences between these predicted averages and the actual BUS 111 final course averages existed at a statistically significant level. Thus, the null and alternative hypotheses for this statistical test were as follows:

$\mathrm{H}_{0}$ : The mean of the predicted averages $\left(\mu_{P}\right)$ is equal to the mean of the observed averages $\left(\mu_{A}\right)$. In other words: $\mu_{P}=\mu_{A}$

$\mathrm{H}_{\mathrm{A}}$ : The mean of the predicted averages $\left(\mu_{P}\right)$ is not equal to the mean of the observed averages $\left(\mu_{A}\right)$. In other words: $\mu_{P} \neq \mu_{A}$

As shown in the SPSS output below, $p=0.158$, so I failed to reject the null hypothesis and thus was able to conclude that no statistically significant differences existed between the predicted averages, as given in the model, and students' actual final averages in BUS 111.

Paired Samples Statistics

\begin{tabular}{|ll|c|c|c|r|}
\hline & & & & \\
& & Mean & N & Std. Deviation & Std. Error Mean \\
\hline Pair 1 & BUS111_Average & 74.6729 & 120 & 18.87555 & 1.72309 \\
& Predicted_Overall & 72.1084 & 120 & 15.65180 & 1.42881 \\
\hline
\end{tabular}

Paired Samples Test

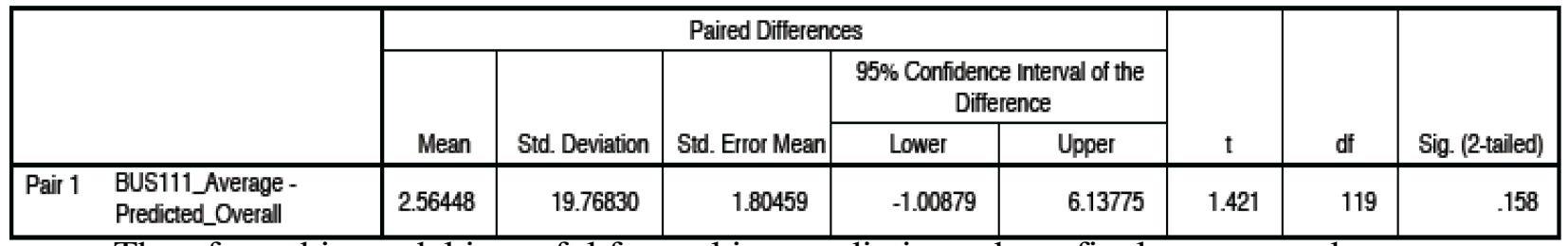

Table Thy.

Because this model uses only four predictor variables (mathematical emotions, high school GPA, placement exam score, and number of absences over the course of the semester), it is also practically significant for the business advisors to use as they talk to 
prospective business majors about BUS 111. However, this model and the included variables also have significant implications for business mathematics courses in general, which are discussed in detail in the following chapter. 


\section{CHAPTER SIX: IMPLICATIONS AND DISCUSSION}

In this study, I investigated which factors were significant predictors of college student business mathematics achievement through a quantitative multiple regression analysis using the results from a survey coupled with pre-existing data. Specifically, I examined students' attitudes towards mathematics, students' varying levels of mathematical anxiety, the number of business mathematics classes each student missed, the time each student devoted to mathematics outside of class each week, mathematics SAT scores, gender, scores earned on the university's mathematics placement exam, and high school GPAs. The findings described in the previous chapter can be used to inform future practice, policy decisions, and research initiatives in the College of Business Administration as well as the Mathematics Department at URI and other colleges and universities, as this sample was similar to the national representation of schools of business. The predictive relationships discovered from the multiple regression equations, in addition to the correlational relationships described, could be used to inform future decisions for the business mathematics curriculum and could also help inform potential instructional design techniques employed in the College of Business and elsewhere.

In the remainder of this chapter, I begin by discussing five main policy implications that have arisen from my research: (1) a necessary shift in focus from college-readiness to student-readiness, (2) a call for personalization of the instructional environment, (3) necessary curricular and instructional changes, (4) the implementation of more formal instructor evaluation procedures, and (5) suggested changes to the current university mathematics placement exam procedure for business majors. After this, I examine some of the current reform efforts being implemented in institutions of higher education in an attempt to promote student-readiness and college-readiness in mathematics-based courses. I discuss the strengths and weaknesses of these programs and examine their potential for implementation and success at URI. Finally, I provide suggestions and questions for future research that have arisen from this study. 


\section{Policy Recommendations}

\section{Change in Focus: From College-Readiness to Student-Readiness}

In chapter three, I described the difference between college-readiness and studentreadiness. College-readiness is frequently written about and discussed by teachers, professors, students, parents, and college advisors (Bilsky, 2011; Blanchard, 2008; Conley, 2007; Corbishley \& Truxaw, 2010; Doubleday, 2013; Frost et al., 2009; Long et al., 2009; Thiel et al., 2008; Zelkowski, 2011). The idea of a student being college-ready implies that she has developed and made changes as necessary in an attempt to become prepared for a successful academic life in college. She has learned about what it means to be "college material" and is prepared to fit the mold that colleges have created for her. I believe that a major shift in focus needs to occur to move the responsibility from the students to instead a shared responsibility among teachers, college staff, and students. In other words, student-readiness must also enter the discussion if we want to enhance the learning experiences and opportunities for students in higher education.

Student-readiness would involve college instructors and university staff members working with K-12 educators to prepare coursework and make necessary adjustments to suit the interests and needs of their incoming students. Institutions of higher education are essentially businesses, which rely on their students' loyalty (as customers) in order to stay in business. Without the students and their tuition dollars, a university would cease to exist. Companies do not expect their customers to change their demands to fit the current supply, and similarly, universities should not expect their students to change their needs to fit what the university is currently offering. If a university cannot fit the needs and satisfy the interests of a student, that student will choose to take their business elsewhere. And they should. University faculty members and administrators must take the time to investigate the needs and desires of their incoming students each year to ensure they are offering these customers a quality education that is both meaningful and supportive of their interests. What must be recognized is that, especially after years of 
studying mathematics or business, instructors develop a certain appreciation for the content and they value its importance in their work. After 15 weeks in a course, instructors cannot expect students to simply mimic or create this deep connection; instead, instructors should allow students to develop and evaluate their own relationships with mathematics. By talking to students on a regular basis and communicating with secondary educators, colleges can personalize the learning environment, perform a needs assessment for their academic programs, and make adjustments as necessary (Frost et al., 2009; Travis, Hursh, Lankewicz, \& Tang, 1996). Working towards student-readiness would involve the implementation of support systems designed to foster student relationships with their instructors as well as student relationships with mathematics.

The remaining policy recommendations, described in detail below, focus on helping colleges become more student-ready. Many universities rely on students' high school GPAs and SAT scores to determine whether that student is prepared for the current state of the university. Given that the results of this research (described in detail in chapter five) revealed the importance of students' attitudes towards mathematics, students' mathematical anxiety, and time devoted to mathematics when it comes to success in a course, colleges can make changes to better prepare for the needs of the students attending.

\section{Personalizing Instructional Environments (Reduction in Class Size)}

Currently, class sizes in college mathematics courses and business mathematics courses vary greatly across the nation. However, these courses tend to be medium or large lectures, holding at least 40-50 students, and accommodating as many as 200-300 students (Frost et al., 2009; Guder et al., 2011; Zelkowski, 2011). Due to a recent combination of a greater number of high school graduates and a greater demand for business majors, many universities (especially business schools) have witnessed an increasing number of students (and therefore an increase in class size) over the last decade (Guder et al., 2011). At the University of Rhode Island, the most frequently taken 
freshmen-level mathematics courses (MTH 101: College Algebra, MTH 107: Finite Mathematics, and MTH 111: Pre-Calculus) have class sizes of between 44 and 180 students. The business mathematics courses at URI (MTH 110: Mathematical Foundations for Business Analysis and BUS 111: Introduction to Business Analysis and Applications) typically have class sizes of 40-60 students. However, students who are deemed unprepared for these business mathematics courses are strongly encouraged to start in MTH 101, which currently accommodates 120-150 students.

When asked why they fail to use informal assessments, promote inquiry, or implement project-based, personalized learning strategies in their classrooms, many instructors claim that they have too many students to teach and too much curriculum to cover (DeBerard et al., 2004; J. Baglama, personal communication, January 23, 2015). Many educators could appreciate that, with over 40 students in a class and multiple classes to teach, it would become rather challenging to know each student and understand their individual mathematical needs, struggles, and interests. Even though business mathematics (such as BUS 111) class sizes are small in comparison to other gateway freshmen mathematics courses at URI and other universities, the lecturers in charge of developing and teaching BUS 111 teach four sections of the course each semester. Therefore, although each individual class seats 40-60 students, the instructor still sees and teaches 160-240 students three times per week. Though I was unable to include class size as a variable in my research (each BUS 111 class examined had approximately the same number of students, varying only from 44-52 students), I still believe it is extremely important to consider when examining student-readiness and student success in college mathematics.

Research on the impact of class size over the past few decades has yielded mixed results (Borden \& Burton, 1999; Chapman \& Ludlow, 2010; Cuseo, 2007; De Paola, Ponzo, \& Scoppa, 2013; Feldman, 1984; Gibbs \& And, 1994; Gilbert, 1995; Gleason, 2012; Guder et al., 2011). While some research indicates class size does not significantly 
effect student achievement, the majority of this research involving class size has focused on elementary and secondary schools, not post-secondary classrooms. In mathematics courses especially, it seems that class size does play a significant role in student performance (Chapman \& Ludlow, 2010; Gleason, 2012; Guder et al., 2011). Even if class size does not directly impact skill acquisition, it "may affect motivational, attitudinal, and higher-level cognitive processes" (Borden \& Burton, 1999, p. 3), which are significant predictors of overall course grade in business mathematics. Further, class sizes are likely associated with retention and student enjoyment in college (Gleason, 2012).

Some research strongly supports a negative relationship between class size and student performance in college courses (Chapman \& Ludlow, 2010; Cuseo, 2007; De Paola et al., 2013; Gibbs \& And, 1994; Guder et al., 2011). In other words, as class size increases, student performance tends to decrease. One study in higher education found that, in business classes specifically, students' GPAs were on average 0.1 points higher in small classes (with less than 40 students) than they were in large classes (Guder et al., 2011). Another study showed that earning an A grade was less than half as likely in a class with over 50 students enrolled (Lindsay \& Paton-Saltzberg, 1987). Mirroring these results, a team of researchers revealed that $42.2 \%$ of students enrolled in classes with fewer than 20 students earned As or Bs, but only 33.6\% of students enrolled in classes with over 70 students were able to earn those grades (Gibbs \& And, 1994). More recently, researchers discovered that adding eight more students to a mathematics class led to an average exam grade decrease of 3\% (De Paola et al., 2013) and that each additional student in a class corresponded to a $1 \%$ decrease in the number of students who "[agreed] that they attained the skills associated with learning in that class" (Chapman \& Ludlow, 2010, p. 112).

Larger class sizes have not only been shown to correlate with lower student performance in the course, as described above, but also correlate to lower student 
performance in subsequent courses (Borden \& Burton, 1999; Cuseo, 2007; Gibbs \& And, 1994). Educational researchers Victor Borden and Kathy Burton (1999) cautioned university educators that introductory courses, especially those taken during a student's freshman year, are critical in helping the student decide on both academic and career goals. The researchers discovered that, while class size was not a factor in all discipline areas, class size significantly affected student grades in mathematics courses (Borden \& Burton, 1999). Specifically, students who were placed in introductory mathematics courses according to their major with a class size of less than 30 were more likely to earn a higher grade in the course and persist in their major. This is perhaps due to the fact that research dating back to the early 1920s has revealed (and more recent studies continue to confirm) that students in smaller classes show "statistically significant differences in problem solving, student attitudes to teaching, and knowledge retention" (Gilbert, 1995, p. 322).

Studies also indicate that lower class sizes are strongly correlated with higher instructor evaluation scores (Chapman \& Ludlow, 2010; Feldman, 1984; Guder et al., 2011; Perrine \& And, 1995). "Student involvement and personal contact between the professor and the students make a significant difference in learning outcomes" (Gilbert, 1995, p. 320). However, relationships are more difficult to maintain with larger class sizes. Students in large classes often report feeling uncomfortable asking their instructors for help and report worrying that their instructors are unlikely to be able to help them because of the number of students in the course (Perrine \& And, 1995). Students in larger college classes tend to exert unfavorable attitudes about learning as well (De Paola et al., 2013). They feel they have fewer opportunities to talk to their instructors or ask questions during class, which often leads them to generate negative attitudes towards their instructors or towards college in general. Research also suggests that students in larger classes feel anonymous and less engaged with the class, and therefore are more likely to not attend the course (Gleason, 2012; Perrine \& And, 1995). Since both course 
attendance and students' anxiety levels/attitudes towards mathematics were found to be significant predictors of success in business mathematics in this research, reducing class sizes might help promote more successful behaviors.

In 2007, educational researcher Joe Cuseo analyzed class size and its effect on students, faculty, learning, and teaching. He found seven core problems with increasing class size when it came to student learning:

1. Professors of larger classes were more likely to use lecture as their sole method of instruction.

2. There was "less active student involvement in the learning process" (Cuseo, 2007, p. 6).

3. Less feedback from professors as well as less student-professor interactions both within and outside of the classroom occurred in larger classes.

4. Students were engaging in more lower-level thinking processes rather than higher-level thinking.

5. Larger classes had "reduced breadth and depth of course objectives, course assignments, and course-related learning strategies used by students outside the classroom" (Cuseo, 2007, p. 6).

6. Lower student grades and lower academic advancement/learning occurred in larger sections.

7. Students in larger classes reported lower course satisfaction ratings as well as lower ratings of their instructors (Cuseo, 2007).

Because student emotions towards mathematics (especially their mathematical confidence and anxiety levels in mathematics) help predict success in business mathematics courses according to the results of this research, more personalized learning environments would allow instructors and advisors to more easily and effectively address these issues. First, advisors could discuss the importance of attitudes towards 
mathematics and mathematical anxiety with students and suggest meeting more frequently with their instructors (which would be possible with smaller class sizes) to help them gain confidence and lower their anxiety levels. Similarly, since course attendance predicts success, smaller class sizes would make it easier for an instructor to get to know all of her students and therefore be able to recognize and reach out when a student is missing. This would arguably allow each student to feel noticed and missed, and therefore may discourage future absences. Research supports the fact that "students who become adequately integrated into the social and academic systems of their college are most likely to develop and maintain a strong commitment to attaining a college degree. Part of the integration process is developing relationships with college faculty" (Perrine \& And, 1995, p. 42). Thus, in order to personalize learning and maximize opportunities for success, it would be ideal to start by lowering class sizes in college mathematics courses, specifically those for business majors.

This policy change may initially be expensive to implement, as smaller classes require more instructors and a greater number of available classrooms. However, the choice must be to pay now (financially) in order to increase student learning and thus avoid paying later (socially and culturally) with a society of math-phobic leaders and citizens (Chapman \& Ludlow, 2010). Once class sizes are lowered, instructors may be able to approach new student-centric teaching strategies with a more open mind through a variety of resources and professional development opportunities (McDuffie \& Graeber, 2003).

Research reveals that instructional practices and curricular choices in college business and mathematics courses often have an even greater impact on student learning than class size, and thus, these practices must also be considered (Gilbert, 1995). Not surprisingly, what seems to matter even more than the size of the class is what is happening during the class.

\section{Instruction and Curriculum Practices in College Business Mathematics}


Based on the results of this study, coupled with the existing literature available, it seems that both the college business mathematics curriculum and the corresponding curriculum delivery procedures are currently inadequate. Many researchers are quick to blame college instructors (Anderson, 1967). Their general lack of pedagogical expertise was discussed in detail in chapter three. However, college instructors cannot be the only ones to blame. Many want to be better educators, but most do not know how to improve. Without policies to encourage good teaching practices, many professors do not even realize the flaws in their current instructional methods (McDuffie \& Graeber, 2003). Few receive pedagogical support and the promotional, tenure focus remains on research publications and conference presentations. College instructors are full-time professionals and "if we assume that the essence of professionalism is professional action, then teaching actions should be based on the best available knowledge and should be in the best interests of clients" (Munby et al., 2001, p. 899). In the case of college mathematics and business education, the clients are the students and they are best served when they are placed in the center of their educational experiences in a safe, encouraging environment that is adaptable based on their needs and interests (Dewey, 1938). However, "the foundation of systemic change is individual change" (Gess-Newsome et al., 2003, p. 763). Therefore, in implementing policy changes in higher education, one must focus on helping college business mathematics instructors recognize and reflect on the problems in the current curriculum and delivery methods and introduce a more student-centered, constructivist framework.

"Decision to change within an organization is influenced by (a) cues from the organizational environment, and (b) individual beliefs, attitudes, goals, and knowledge acquired from experience" (Richardson, 1990, p. 11). Therefore, in order for meaningful change to take place in higher education, instructors must first develop a concern regarding their current student learning outcomes and feel supported by their institution to be reflective practitioners and change their teaching practices (Gess-Newsome et al., 
2003; McDuffie \& Graeber, 2003; Richardson, 1990; Schön, 1983). Instructors must recognize that what is currently happening in many college business mathematics classrooms is not working for the majority of students, and therefore significant change is necessary. A failure rate of over 17\%, as was found this semester in BUS 111, is too high and leaves too many students behind. Over 35\% of the students taking BUS 111 over the Fall 2015 semester failed to reach the minimum "C" letter grade for successful completion of the course and will likely need to retake the class or may choose to switch their major. If instructors fail to see the problems with the current business mathematics curriculum or instructional methods, then, "they [will] have little motivation to engage in reform and [will] have little investment in making reform work" (Gess-Newsome et al., 2003, p. 738). Therefore, an important first step in implementing change at the institutional level must be to help instructors identify the current problems in both the curriculum and their teaching practices, and then show them that positive change is possible and necessary. This could be accomplished through an initial presentation to faculty revealing the overall lack of student learning and success in mathematics and providing information on low student retention in STEM and business fields. Additionally, change could be initiated by presenting multiple regression and correlational models related to student success, such as those revealed in chapter five, coupled with ongoing professional development, departmental support, and institutional recognition of effective instructional practices.

College instructors can no longer use a "one-size-fits-all" approach to mathematics instruction and ignore whether the course they are teaching is intended for mathematics majors or business majors or students with diverse interests. Instead, students' prior knowledge, experiences, and future career goals must guide the curriculum, assignments, and instructional practices. The new curriculum in business mathematics courses must be flexibly designed so that as each semester moves forward, changes can be made based on the specific needs, attitudes, interests, anxiety levels, and 
experiences of the incoming group of students (Bransford, 2000; Hiebert \& Grouws, 2007). Classrooms should provide opportunities for continuous dialogue, questioning, and frequent reflection to potentially decrease mathematical anxiety and develop more favorable attitudes towards mathematics. Mathematics educators James Hiebert and Douglas Grouws suggest the following practices in teaching high school students mathematical concepts:

... [discuss] the mathematical meaning underlying procedures, [ask] questions about how different solution strategies are similar to and different from each other, [and consider] the ways in which mathematical problems build on each other or are special (or general) cases of each other attending to the relationships among mathematical ideas. (Hiebert \& Grouws, 2007, p. 383)

Strategies like these, which have already been found to be successful for high school students, should be incorporated into college classrooms as well and evaluated for success.

In addition to adapting successful strategies such as those presented above, business mathematics instructors should be encouraged to reflect on, discuss, and revise their teaching practices as they move forward (Schön, 1983). To promote this professional reflection, instructors should also have clear objectives for students to achieve. They must help students develop and achieve their personal goals, which can focus on problem solving and critical thinking, rather than just presenting students with a general list of content or skills on a syllabus that they hope to cover over the semester. Educators should not "want to cover a subject; [they should] want to uncover it" by letting their students construct their own meaning and develop a deep, personal understanding about mathematics (Hawkins, 2000, p. 79 as cited in Duckworth, 2006, p. 7). Some of these new, broadly stated course objectives might align better with the Common Core State Standards on Mathematical Practice (Common Core State Standards Initiative, 2015) and could include things such as: 
- Students will be able to solve authentic business-based problems using a variety of mathematical strategies.

- Students will develop and be able to apply their own problem solving techniques to business situations.

- Students will construct and critique mathematical arguments (Common Core State Standards Initiative, 2015).

- Students will be able to approach new problems with confidence in their mathematical abilities and mathematical literacy and will persevere in solving these problems (Common Core State Standards Initiative, 2015).

- Students will develop number sense and be able to use various estimation strategies in business scenarios.

- Students will understand the value and relevance of mathematics in the business world as they investigate the mathematics that exists in their future careers.

Other course objectives should be created with student involvement during the first week of the course to ensure that student goals, not just the instructor's goals, are being addressed. These goals could be personalized for each student, and may include things such as:

- I will approach mathematics problems in business with more confidence and less fear. My instructor can help me reach this goal by understanding my current mathematical anxiety and providing practice problems and modeling strategies during class.

- I will collaborate with my classmates each week to master new material. My instructor can help me reach this goal by assigning group projects or allowing collaboration during class.

- I will study small chunks of information over a longer period of time to help 
better understand the material.

- I will visit my professor when I have questions. My instructor can help me reach this goal by holding regular office hours and welcoming questions regardless of the skill level.

- I will relate the course material to personal experiences in my life. My instructor can help me reach this goal by modeling this technique and encouraging reflection through class assignments.

These collaborative objectives could help alleviate mathematical anxiety and increase student interest and engagement in the course, encouraging students to attend class regularly. Additionally, it allows the instructor to understand students' current relationships with the subject matter.

In order to reach these personalized goals, college business mathematics instructors might introduce constructivist, problem-based, student-centered classrooms, like those described in chapter three's review of the literature (Cobb, 2005; Fosnot \& Perry, 2005; Von Glasersfeld, 2005; Vygotsky, 1978). Even when instructors have the best intentions to implement a lesson and transmit knowledge into their students' minds, it is "the learners' generation of meaning from the teaching that influences achievement" (Wittrock, 1986, p. 311). Thus, students must be provided with opportunities to reflect on their experiences and construct their own knowledge. Instructors must strongly diminish the current focus on lecture and teacher-centered practices and instead encourage student collaboration and discourse. Together with students, they must consistently evaluate their initial goals to reflect on possible classroom changes.

By building a classroom community that revolves around dialogue/discourse, understanding, and support, college educators can widen the learning possibilities for all students (Fosnot \& Perry, 2005; Vygotsky, 1978). In designing and implementing a new curriculum and learning environment, college mathematics instructors must encourage student communication and serve as facilitators to student learning; rather than all- 
knowing providers of decontextualized information. Researcher Ann Brown (1987) argues that the role of the instructor is to "tailor the information to the [student's] existing level of understanding... activate relevant background knowledge," and help students monitor their growing knowledge base through support and recognition (p. 102). Learning often occurs with, and is facilitated by, the support of others (Cobb, 2005; Fosnot \& Perry, 2005; Vygotsky, 1978). Thus, "social settings, where the [student] interacts with experts in a problem solving domain, are settings where a great deal of learning occurs" (Brown, 1987, p. 100). Business mathematics instructors can therefore enhance learning and increase students' desire to attend class by providing opportunities for students to work collaboratively with their peers and discuss strategies for approaching and solving new problems.

To accomplish this collaborative goal and provide more authentic learning situations, college instructors should help students realize that problem solving is not unique to business mathematics classes: it is important to be an efficient problem solver in future careers and within students' personal lives. Limiting the importance of mathematics to the classroom can immediately reinforce students' attitudes of believing that mathematics is not applicable to their lives (Cobb, 2005; McDuffie \& Graeber, 2003). In order to ensure a widening frame about problem solving, instructors need to work to increase the comfort level with which their students approach new problems and their persistence in solving these problems, as well as increasing their confidence to be able to apply their problem solving skills to diverse contexts. One way this could successfully be accomplished would be by offering students more open-ended projects based on realistic problems that arise in business settings (Kesici \& Erdogan, 2009). These projects could have a wide variety of "correct" solutions and could foster mathematical dialogue and applicability. Constructive, problem-based activities encourage students to take as many routes as possible when they are solving any given problem without fear of penalty, so that they may utilize each of their ideas, discover 
where each route may lead them, and remember those attempts in future situations and learn which solution paths are more efficient in a given context (Cobb, 2005; Von Glasersfeld, 2005).

Dr. Carol Blaszczynski (2001), a business mathematics educator at California State University, suggests that business students need their instructors to serve as role models in learning mathematics. She emphasizes that instructors need to show students that they themselves are excited about understanding the mathematical applications in real dilemmas, are enthusiastic about approaching new problems, and can persevere in solving them. Specifically, she suggests that business mathematics instructors should exhibit modeling behaviors including "estimating answers before solving a problem, reading a problem several times before attempting to solve it, drawing diagrams or charts to make a problem more understandable, and making errors and correcting them" (Blaszczynski, 2001, p. 4). Each of these instructional behaviors can help lead students to value the importance of mathematics, recognize that genuine problem-solving takes time and sometimes struggle, and approach new problems without the anxiety or fear of making a mistake.

Business mathematics instructors should also help their students build personal connections between what they are experiencing in class and what they are experiencing in their daily lives. Communicating about mathematics in business courses can help students appreciate its importance. Further, communication allows students to recognize that getting the right answer is only half as important as being able to discuss what that answer means (Blaszczynski, 2001). I have many students who are able to calculate the correct mathematical solutions but struggle to articulate what they can do with that knowledge in a business context. Similarly, some of my students can clearly convey how to approach a business scenario but struggle to perform the necessary mathematics. These students could learn a great deal from each other and excel as a team: building on each others' strengths, teaching each other new skills, and devoting time to understanding 
and discussing the business mathematics concepts. "Engaging in writing, reading, listening, or speaking about math reinforces vocabulary, concepts, and procedures and empowers students with the necessary associations to make the math meaningful" (Blaszczynski, 2001, p. 3).

By placing students at the center of learning experiences, college instructors can encourage students to construct a deeper understanding of and appreciation for mathematics. When incorporating these ideas, a new vision for a college business mathematics course comes into view: one in which students use problem-solving strategies to collaboratively tackle realistic, business-based dilemmas, persevere in solving these problems, and develop an understanding of the applicability and usefulness of mathematics. Through project-based learning, constructivism, and an appreciation for student attitudes and perceptions, college business mathematics educators could show students the importance of problem solving and diminish the current negative view and anxiety that many students hold about mathematics.

Many of the reform efforts in education often involve elementary and secondary levels, but these reforms must not ignore the pedagogical issues that exist in higher education. New policies must be put in place to strongly diminish, or at least discourage, the lecture-based, teacher-centered models currently being used in college mathematics and business mathematics courses. In most cases, college is the final formal schooling experience a person encounters before entering their career. Thus, faculty members in institutions of higher education must change the existing teaching and learning practices to ensure adults are entering the community prepared to approach and address the use of mathematics in practical and authentic situations that they may encounter. Specifically, because of the results discovered in chapter five, instructors should work to help students: (1) realize the importance of devoting time to mathematics, (2) decrease their mathematical anxiety, and (3) promote confidence and more favorable attitudes towards mathematics, as described in further detail below. 


\section{Increasing Time Devoted to Mathematics}

In my multiple regression analysis, it was discovered that the number of classes a student missed over the semester as well as the number of hours a student spent on mathematics outside of class each week were useful predictors of student achievement in a business mathematics course. Thus, further departmental actions could be taken in order to help promote student success. For example, in addition to considering the implementation of some of the recommendations above, instructors might consider taking attendance in the course to encourage students to attend, while letting students know that those who come to class regularly tend to earn higher grades, as supported by my findings. Instructors could also start requiring more thought-provoking assignments, explaining that solving problems takes time, and encouraging independent practice and collaborative thinking both inside and outside of the classroom (Barnes et al., 2004).

Most importantly, business mathematics instructors should ensure class time is motivating and meaningful to students so that students will want to attend, regardless of external incentives. By offering interesting and stimulating course material that encourages peer interaction and personal exploration, as described above, students will more likely be willing to devote time and effort to the course both during and outside of class (Kesici \& Erdogan, 2009). The tasks that instructors assign should be meaningful and spark student interest and curiosity about problem solving (Rittenhouse, 1998). This way, students will likely be more inspired to devote time to the assignments, connect the information to personal experiences, and construct their own knowledge based on the tasks provided.

\section{Decreasing Anxiety and Promoting Favorable Attitudes Towards Mathematics}

Because high levels of mathematical anxiety tend to predict lower course grades and more favorable attitudes towards mathematics tend to predict higher course grades, instructors and advisors can make students aware of these connections and provide strategies to help them address stress, increase interest, and lower anxiety in business 
mathematics. Furthermore, in a student-centered classroom, instructors could strongly diminish the lecturing model and introduce student voice and peer interactions to support learning and lower anxiety (Davis \& Shih, 2007; Kesici \& Erdogan, 2004). By focusing on teaching students rather than just teaching mathematics, instructors could help students see the relevance of mathematics in their lives and feel confident approaching new problems in business scenarios. With a new goal of increasing confidence and getting students interested in mathematics, instructors may consider options such as activating prior knowledge in the classroom or displaying the value of mathematics in the world through inquiry learning and exploration (Levy \& Petrulis, 2012; Ormrod, 2011). Both of these student-centric strategies were described in detail in chapter three's review of the literature. College instructors must be held at least partially accountable for the success of their students. In the following section, I describe a policy recommendation that could help further promote these positive behaviors amongst instructors.

\section{Implementing Instructor Evaluations}

In elementary and secondary education, there are various sets of standards (such as the Common Core State Standards) that educators are expected to follow as they teach (Darling-Hammond, 2010). However, in higher education, instructors have great freedom in both what and how they decide to teach. Perceived instructor effectiveness (one of the variables investigated in this research) was significantly correlated with student anxiety $(r=-0.320 ; p=0.000)$, attitudes towards mathematics $(r=0.312 ; p=$ $0.000)$, and overall student achievement in BUS $111(r=0.293 ; p=0.000)$. Under the current system, college mathematics and business instructors have very little accountability when it comes to student achievement in their courses (Davis \& Shih, 2007). At the same time, their teaching effectiveness is likely to impact student success and learning opportunities. In this research, for example, significant differences existed in student grades based on their assigned instructor. Different instructors had different success rates and different variables that were significant in predicting their students' 
final grades and confidence levels in BUS 111. When students trust their instructor's ability to effectually present course material, they tend to feel more capable of being successful in the course (Bahr, 2012; Corbishley \& Truxaw, 2010; Hiebert \& Grouws, 2007). Therefore, college instructors should be evaluated and held accountable for the results of their teaching practices, not just their research publications.

Even with autonomy in instructional decisions and curriculum design, many mathematics and business mathematics instructors admit to teaching courses the same way they have been taught for years (McDuffie \& Graeber, 2003). Instructors believe that they must cover certain content because it is listed in the course catalog or because they assume students will need it in subsequent courses. However, in general, many students view mathematics courses as extremely repetitive and claim they often find themselves being re-taught material they are already familiar with (Hall \& Ponton, 2005). In business classes at URI, for example, students report learning time value of money computations and procedures in multiple classes. Why do college instructors feel so rushed to cover content that students will likely be exposed to again in subsequent mathematics or business mathematics courses? New policies must be executed to expose these overlaps and enhance course content and design. Unfortunately, professors are very independent educators and rarely discuss course content with their colleagues (Ballard \& Johnson, 2007). College instructors need to spend time discussing the various courses offered by the department to understand what topics are actually being addressed and what prerequisite skills students are expected to have before entering each of those courses. To address courses with no specific subsequent course, designed to meet general education requirements, business mathematics instructors should also be given opportunities to communicate with faculty from other specialty fields (Marketing, Management, Finance, Accounting, Supply Chain Management, etc.) in order to determine how to best prepare students for each specialty (Ballard \& Johnson, 2007).

Unlike K-12 educators, college professors are rarely formally evaluated based on 
their teaching practices or student success rates. Currently at the University of Rhode Island, similar to other universities across the nation, students are asked to evaluate their professors at the end of the semester (Barnes et al., 2004; Feldman, 1984; Guder et al., 2011; Reisel et al., 2012). This summative feedback is collected through an anonymous survey and results are compiled into averages. Professors receive the results of this data one or two semesters after the surveys have been submitted. Receiving feedback about a class long after that class has ended is not sufficient. I propose a new policy be implemented, which involves instructors asking students for constructive feedback at least three times during the course of the semester - either formally or informally. As the course progresses, students can anonymously let the instructor know what they are enjoying, what they need, what they already know, and what could be improved. Instructors can make changes as they move forward, rather than waiting until the course is over to decide whether to make changes for a new group of students, who will likely have different needs and learning styles than those who completed the evaluation surveys the previous year.

In addition, teaching should become a more significant responsibility for college mathematics and business mathematics instructors in terms of career advancement and job stability. I believe that department members who are considered to be leaders in pedagogy should be encouraged to help evaluate peer instructors at least once every 1-2 years on their teaching practices. Faculty members who are known for their effective teaching can offer suggestions and share best practices and new ideas with their colleagues. Instructors can also reflect and set goals for improving their teaching methods and can evaluate themselves after each semester passes with the support of another faculty member or the department chairperson (Schön, 1983). Past students and business major alumni could discuss what most benefitted them in future classes and occupations and what they wished would have been explored more deeply. When tenure meetings come up, department members should spend a great amount of time considering 
these teaching evaluations (both from students and from fellow faculty members) when making promotional decisions (McDuffie \& Graeber, 2003). Instructors should spend time reflecting on their instruction and delivery and searching for ways to improve their practice as professional educators (Schön, 1983). These evaluations will demonstrate to professors that their teaching, not just their research and publications, is an extremely important and influential component of their careers.

Effective teaching practices should also be recognized at the university level. Often, successful teachers at the university are recognized during an annual meeting or through a newsletter, but greater recognition may influence greater change (Bolman \& Deal, 2008; McDuffie \& Graeber, 2003; Richardson, 1990). For example, perhaps the top five pedagogues each year could be rewarded with reduced research requirements to devote more time to teaching, mentoring, and inspiring other faculty to improve instructional practices. Furthermore, conducting research on teaching business mathematics courses in college should be recognized as equally rigorous and appropriate when considering promotions and publications. Journals that include articles on teaching and college curricular designs should be included on the list of acceptable research journals for college instructors, which is not currently the case at many institutions (McDuffie \& Graeber, 2003). If we want to increase students' mathematical abilities and confidence in business mathematics while simultaneously increasing the teaching effectiveness of instructors, then I believe the university culture, as a whole, must shift. We must move from only an appreciation of being able to perform new mathematical or business-based research to an appreciation of being able to implement, discuss, and analyze successful teaching practices in college classrooms. By enforcing new policies that assess and promote instructor effectiveness at the college level, I believe such a cultural shift can start to occur.

\section{Recognizing Potential Obstacles/Weaknesses in Instructor Evaluations}

Instructor independence is strongly valued by instructors in higher education 
(Johnson, 2007; McDuffie \& Graeber, 2003). Many instructors enjoy the freedom and autonomy that they have grown accustomed to in their careers and they have an existing understanding of what is expected of them in terms of instruction. Since the current system seems to place more value on innovative research and frequent publications than on successful teaching strategies, instructors often focus their attention on research over teaching as well. Therefore, by evaluating instructors on their teaching practices, universities run the risk of initially meeting great resistance. To help with this necessary transition, professional development opportunities that focus on pedagogical strategies and classroom resources would be necessary.

Further, in implementing this change, instructors may initially feel as though their autonomy is at risk by being told they may be subjected to more frequent and formal evaluation procedures in their classrooms. As they consider themselves to be expert mathematicians or business/financial gurus, they may feel devalued or belittled when being observed by their department chair or fellow faculty members (Bransford, 2000). Part of my current contract highlights my professional freedom in my teaching decisions. However, if no changes are implemented, the risk of students failing to learn, caused by having instructors who are not $100 \%$ committed to or capable of teaching, is far worse. Thus, instructors must understand that student learning is the primary objective. Classroom observations and teaching evaluations will help ensure this goal is being addressed and will also help the department understand what resources need to be provided to faculty members to help them achieve this goal.

\section{Changing Placement Exam Procedures}

This multiple regression model also included a variety of student test scores, many of which other universities have found to be correlated with student achievement (Reisel, et al., 2012; Smith \& Schumacher, 2005). For example, the current placement test designed and implemented by the University of Rhode Island's Mathematics Department was used as an independent variable in my model. Since I found that this 
test was a strong predictor of student mathematics achievement in a business mathematics course, perhaps a new process needs to be designed and implemented to better inform and prepare students for this test so that a higher percentage of students take the placement exam and consider the corresponding recommendations made. Additionally, I found that the current placement test and high school GPA were strong predictors of BUS 111 success, and explained a significant amount of the variance in student achievement, but adding in mathematics SAT score generally did not explain significantly more of the variance. Thus, perhaps a modified, required version of the placement test and high school GPAs are sufficient in accepting students into the program and SAT scores are not a necessary component to examine for admission or placement. The College of Business at URI may want to reconsider their specific admissions requirements to better align with these indicators, once a more appropriate version of the placement procedure is implemented.

Many recent studies have investigated the use of placement tests, SAT scores, and high school GPAs for college mathematics courses, as described in the review of literature in chapter three (Bisk et al., 2013; Doubleday, 2013; Foley-Peres \& Poirier, 2008; Reisel et al., 2012; Smith \& Schumacher, 2005). Most research has found that using a proctored, enforced placement test helps accurately place students into the mathematics course for which they are best prepared and in which they are most likely to be successful (Bisk et al., 2013; Foley-Peres \& Poirier, 2008; Reisel et al., 2012; Smith \& Schumacher, 2005). URI's placement exam must accurately reflect the expectations of the prerequisite skills a student is expected to need in each mathematics course, including BUS 111. Therefore, as courses change, so should the placement test (Bisk et al., 2013). Students should be made aware of these expectations and understand the purpose of the placement exam as well as the implications of the results. A policy needs to be implemented to explain the following information to incoming students: what they are expected to know and be able to do in college business mathematics courses at URI, why 
the placement exam is used and enforced, and how strongly the results typically correlate with mathematics-based course achievement. Currently, the business department is not involved in the development or implementation of the mathematics placement exam. The current placement procedures, while seemingly effective according to the mathematics department, are designed for mathematics courses, which differ slightly from business mathematics courses, where students are expected to have more problem solving and mathematical literacy skills.

As of the Summer of 2015, URI mathematics department claimed that they would require all incoming freshmen to take a proctored placement exam during their summer orientation in order to determine which mathematics course would suit them best. However, in the College of Business Administration, advisors sat down with each student and reevaluated the student's placement based on their high school coursework and which course the student wanted/needed to take (J. Baglama \& K. Conlon, personal communication, October 7, 2015). The placement score was examined, but students often admitted to not taking the placement exam seriously or just needing a quick refresher on some material, and thus chose more advanced courses despite their scores. Students may also take the placement exam multiple times and only their highest score will be recorded and sent to the university. Not surprisingly, not a single student in BUS 111 retook the placement exam to try to earn a higher score, likely because they knew they did not have to in order to register for the course they wanted (T. Bella, personal communication, October 13, 2015). Further, similar to other universities, without a policy in place that thoroughly describes the details of this exam and its results to new students, students often end up choosing a business mathematics course other than the one into which they were placed according to the exam (Bisk et al., 2013; Jacobson, 2006; Reisel et al., 2012).

For the Fall 2015 semester, less than 12\% of all of the students enrolled in BUS 111 (including all students enrolled in the course, not just the participants of this study) actually placed into the BUS 111 course according to the current procedures; $65 \%$ placed in a 
lower-level course, and $23 \%$ of the students never took the placement exam. Those who did not take the placement exam instead worked with a business advisor to choose their courses based on their previous experiences and test scores. However, even though placement scores were significant predictors of BUS 111 course grade and there was a significant correlation between students' placement scores and their final course averages $(r=0.386 ; p=0.000)$, it is important to note that placing into group D (the highest group, which is currently the placement requirement for BUS 111) is likely not necessary for this course. Perhaps placing into group B/C is sufficient for this course, as the average grade for students placing into this group or a higher group was above an $82 \%$, which corresponds to a successful completion grade of a B- in BUS 111.

Under the current procedures, upon finishing the mathematics placement exam for the University of Rhode Island, a recommendation is made as to which mathematics course the student should take. This recommendation is based on course expectations and previous student success in that course. However, again, the student is currently under no obligation to follow this recommendation for business mathematics courses. If the student is placed into a course that is lower than what they feel is appropriate, for example, they can choose to take a more challenging course and are often not successful. Rather than taking an extra semester to enroll in an introductory course, many times students take and fail the higher-level course. This causes those students to fall behind in their programs of study while they either retake the course they failed or take the originally recommended preliminary course, and then retake the higher-level course at a later time. Falling behind in their program leads students to abandon the business field, or, in some cases, leave the university entirely (Bisk et al., 2013; P. Boyd, personal communication, October 16, 2015; Reisel et al., 2012). Without changing this current placement exam policy, I do not believe URI can anticipate higher success rates in business mathematics courses over the next few years.

Therefore, I would propose that all incoming business students at URI be required 
to take a proctored version of the mathematics placement exam during their two-day summer orientation. The mathematics department has tested their current exam, consulted students and mathematics faculty members, and used past student results to create what they believe to be a valid measure of future student achievement. However, because business mathematics classes have different curriculum goals, collaboration on new questions specifically designed for business students needs to occur. To help ensure students enroll in a business mathematics course that is best suited for their needs, in order to subsequently help them find success in business mathematics at URI, it is my opinion that a business version of this placement exam needs to be created and tested, and then corresponding placement decisions need to be enforced.

Additionally, BUS 111 instructors and/or advisors should meet with students individually after each of the course exams to discuss their grades and learning goals and make possible suggestions for moving forward. For example, as discussed in chapter five, only $35 \%$ of students who failed the first exam ended up passing the course. Less than $15 \%$ of students who failed exam two completed the course successfully, and no students (at least during the Fall 2015 semester) were able to successfully complete the course after failing both of the first two exams. Currently, no support systems or additional instructional methods are in place for these students. Students need to be made aware of these statistics so that they can make informed decisions about their future in business mathematics courses. They need to know that they may have to significantly change their current study habits, discuss their struggles with their instructor, or see how the instructor may be able to help better address their learning goals. Alternatively, they may decide that it will be better for them to drop the course for the semester and enroll in a more foundational course, such as MTH 110, to begin.

Currently, much time and energy is being devoted to "teaching to the middle" in freshmen business mathematics classes at URI (A. Armstrong and a small group of graduate teaching assistants, personal communication, September, 2014). Because students 
enter the courses at such varying skill levels (some appropriately placed, others taking the course as an "easy A", and still others taking the course despite being placed into a lowerlevel course), the range of student abilities is widespread. Even the most expert educators with experience evaluating student needs and differentiating instruction might struggle with such a heterogeneous group of students (McDuffie \& Graeber, 2003; Rittenhouse, 1998). College mathematics instructors are typically far from expert educators and thus often do not know how to handle this situation effectively to help all students (McDuffie \& Graeber, 2003). Therefore, many instructors generally end up failing a high percentage of students who either could not keep up with the material or were bored with the material presented in their course.

Under the current policies in the department, neither the instructors nor the students seem to be satisfied with the placement procedures at URI. Many freshmen who fail their first business mathematics class complain to the department about not enforcing and better explaining their placement exam score. Once all students are taking an exam best suited for their career goals under similar conditions (with accommodations available as needed), the mathematics and business departments can concentrate on ensuring the exam is placing students into the right courses. Prerequisites can be reevaluated and students can be made aware of the purpose and significance of the exam. Further, and more importantly, the department can then focus their energy on redesigning the curriculum of these courses based on student needs, which is where their attention should be in order to maximize the learning opportunities for all students.

One fear at some universities, including URI, is that students might resent being forced into a certain mathematics course from the results of a single placement exam and thus choose to attend a different university (Jacobson, 2006). Many university staff members believe orientation should be a time to get students excited about joining the university, rather than scaring students away with an exam. While I agree that orientation should be fun, we are not doing students any favors by enrolling them in a mathematics 
course that they will struggle in or fail due to their lack of prerequisite knowledge. The short (generally 45 minutes or less) placement exam does not take a great amount of time away from the other activities of orientation, and part of introducing students to the university should be introducing them to the academic requirements and procedures in place designed to help them self-assess and succeed (Bisk et al., 2013; Reisel et al., 2012). URI should be sending students the message that they want each of their students to be successful and get their freshmen year off to a good start by taking mathematics courses for which they are prepared. Examining the results and questions missed on this enforced placement exam would give instructors an opportunity to enhance their student-readiness as they gain a better understanding of the overall abilities and struggles of the students in their course.

In order to increase opportunities for student learning and success in college mathematics courses, I believe significant policy changes are necessary. First, a general shift in both language and focus needs to occur to equally distribute the responsibility of readiness for college: it is not only the new college student who needs to prepare for the university, but also the university that must prepare for the incoming students. Second, by enforcing a valid, reliable placement test, students can be confident that they are placed into the business mathematics course for which they are prepared and in which they can be successful. This will ensure instructors have more opportunities to appropriately challenge their students and enhance learning activities. It will also allow instructors to focus on the curriculum and instruction without the excuse of having inappropriately placed students. Further, by lowering class size, changing the curriculum to a more personalized, engaging, student-centered approach, and implementing formal teaching evaluations of instructors, teaching and learning can become the top priority at the university. While instructors' research and publications are important, student learning should be the number one goal. 
There are some universities working to enhance student success, especially in mathematics-based courses. With the increasing number of students in need of remedial education especially, reform efforts to prepare these students have been implemented across the nation. In the next section, I examine some of these trends and their purpose and success in helping students.

\section{Current Reform Efforts Implemented to Promote Readiness}

Approximately one in every three college freshmen is found to be in need of a remedial/developmental mathematics course, which often does not count for college credit, as described in chapter three (Davis \& Shih, 2007; Jacobson, 2006). In the business department at URI, students in need of remedial help (about $50 \%$ of incoming freshmen) are encouraged to start their coursework in either MTH 101 (Introduction to College Algebra) or MTH 110 (Mathematical Foundations for Business Analysis), rather than BUS 111. However, BUS 111 is the foundational mathematics course required for continuation in a College of Business degree program at URI.

Nearly all colleges and universities today face issues regarding college-readiness to some degree (Belfield \& Crosta, 2012; Bisk et al., 2013; Reisel et al., 2012; Zelkowski, 2011). As readiness has historically been a challenge for universities, rather than search for reform efforts to eliminate remedial education or use remedial courses to "weed out" unprepared students, university administrators and policy makers in higher education should focus their attention on building new reforms to embrace this challenge and offer support for students at all readiness levels, which many have started to do. "From a public policy standpoint, it makes little sense to promote greater college access if students are failing once they get there. Figuring out how to boost college completion is the challenge" (Brock, 2010, p. 115). Many universities have implemented new policies and programs to increase students' opportunities for success, especially those students considered unprepared for college-level work. Below, I summarize and analyze some of the best improvement programs intended for this purpose: (1) an attempt to 
bridge the gap between high school and college; (2) providing students with on-campus review prior to enrollment; and (3) offering development mathematics courses at an alternate pace.

\section{Bridging the Gap Between High School and College}

A key problem that arises when discussing college readiness tends to be the vast differences that exist between a student's K-12 experience and their experiences in higher education. Unlike other transitions throughout a student's life, the transition from high school to college requires them to undergo many of the most challenging changes they may ever face, all within an extremely short period of time, as highlighted in chapter three. For decades, high school teachers and college professors have blamed each other for students' lack of academic readiness, or worse: they start to blame the individual students. Instructors at different levels often struggle to agree on the true purpose of mathematics education and what it means to be ready for college. Thus, bridging the gap between high school and college expectations may help better prepare students for college and better prepare colleges for students. To address the specific problem of college-readiness, some university officials have realized that communication between secondary educators and college instructors needs to occur more regularly (Bilsky, 2011; Frost et al., 2009).

Specifically, after identifying key competencies required for success in their higher education programs, some states have developed preparatory programs and entrance exams for college, which all students are strongly encouraged to take prior to graduating from high school (Bilsky, 2011). In 2010, Florida created a statewide policy to determine the readiness of students who were considering entering any college program in the state. College instructors, secondary educators, and the State Board of Education worked together to develop an assessment closely aligned to the Common Core College and Career Readiness Standards, entitled the Postsecondary Education Readiness Test (PERT) (Bilsky, 2011). Upon taking this exam and quickly receiving 
their scores, students were given a detailed description about which areas of mathematics need development and they were given opportunities after school to improve those skills before entering college. Unfortunately, this, like many reform efforts, focuses on helping students prepare for college, while neglecting the necessary aid faculty members require in order to properly prepare for students.

The initial purpose of this PERT program in Florida was to more personally inform students of their readiness and allow them to more purposefully prepare for college while still in high school (Bilsky, 2011). Research on programs such as this one reveals that implementing a state-wide readiness procedure could also more accurately inform: curricular and instructional needs of students, prerequisite expectations of college faculty, and professional development needs of instructors (Bilsky, 2011). The impact of the program thus far has been an overall increase in retention among freshmen in addition to a greater number of faculty members reporting college-readiness for advanced mathematics courses (Bilsky, 2011). Further, the program has the potential to inform high school practitioners of the competencies desired in higher education and foster communication between K-12 educators and instructors in higher education (Bilsky, 2011; Frost et al., 2009).

However, a major limitation of this reform effort is that it is specific to colleges and universities in Florida (or in whatever other specific state may choose to run such a program). Students residing in Florida during high school who have no interest in attending college in-state may find this test unnecessary, as the concepts addressed may not be aligned with other universities across the nation. Further, this assessment does little to explain the expectations in college-level courses other than some of the specific mathematical competencies required. The PERT assessment does not explain to students what a college syllabus looks like, how much time they will be expected to devote to coursework outside of class, or how to cope with anxiety or low self-efficacy in college. I believe these factors are also necessary in helping ensure a student is college-ready, but 
these are ignored in this program. The idea of student-readiness, in general, also seems to be ignored here.

\section{On-Campus Review and Support Prior to Enrollment}

At Worcester State University in Massachusetts, a different readiness program has been implemented for the past decade that has fostered powerful, positive change. Worcester State administrators and faculty members require their students to take a practice version of the college's placement exam and receive a passing score before registering for orientation (Bisk et al., 2013). If students are unable to receive a passing score before orientation (receiving only a few chances to do so), they are required to attend at least one two-hour review session on campus in order to receive additional help with the mathematics. Worcester State bases their model on three key principles developed by the mathematics department: (1) students have greater chances of earning high grades and feeling successful when they are placed in an appropriate course; (2) students appreciate "clear, consistent standards" and; (3) students need a supportive environment where professors are willing to help them find success (Bisk et al., 2013, p. 1). Therefore, the purpose of this program was to provide students with additional instruction before enrolling in college courses to help them better prepare for these courses and feel ready to proceed (thus, college-readiness enhancement). The program also gave students an opportunity to meet other freshmen, meet some mathematics instructors, and learn about college teaching methods and expectations (Bisk et al., 2013). Further, it allowed faculty members to identify what their incoming students may need, thus also enhancing student-readiness.

Since implementing this program, the university has seen a drastic improvement in mathematical readiness and student achievement in mathematics. Specifically, the number of students recommended to enroll in non-credit bearing, remedial courses has dropped by $50 \%$ and the success rate in entry-level mathematics courses has increased from $31 \%$ to $80 \%$ (Bisk et al., 2013). Further, the university is retaining more students 
from freshman to sophomore year. Allowing students to preview the material on a mandatory placement exam while simultaneously offering additional, supportive resources on campus to ensure student achievement has proven to be a successful endeavor at this university.

Similar to Worcester State University's program, the University of WisconsinMilwaukee created a summer bridge program to help incoming freshmen improve their mathematical skills before entering the university (Reisel et al., 2012). “The primary purpose of this program has been to improve the mathematics course placement for incoming students" (Reisel et al., 2012, p. 421). Since low placement scores tend to steer students away from both business and STEM-based majors, the original goal of this initiative was to offer students additional instruction and describe the benefits of STEMrelated career paths. On a deeper level, the overall intended purpose of the program was to enhance college-readiness, and the involved faculty members tried to prepare students and introduce them to college expectations (Reisel et al., 2012). In this program, similar to Worcester State's program, students took an initial placement exam and were given feedback on which areas required additional practice or development. Instructors were then made available on campus to assist students through an adaptive, online teaching program known as ALEKS (Reisel et al., 2012; Taylor, 2008). ALEKS helps students move through mathematical material at their own pace after creating an individualized plan based on their pre-test performance. Students' correct or incorrect responses to new questions determine the difficulty level of future questions. While this system has not been deemed successful on its own or as a replacement to teaching (Belfield \& Crosta, 2012), the mathematics department at the University of Wisconsin-Milwaukee has found it to be very useful when supplemented with additional instruction and faculty support on campus.

Of the 107 students who participated in the program with on-campus instruction, $74 \%$ successfully placed into a higher mathematics course upon completion (Reisel et al., 
2012). Research shows that students who are not required to take remedial mathematics courses are more likely to pursue mathematics-related majors (Bahr, 2012; Bilsky, 2011; Calcagno \& Long, 2008; Hagedorn et al, 1999; Hammerman \& Goldberg, 2005; Taylor, 2008). Further, as discussed in chapter three, in four-year institutions nationwide, $78 \%$ of students who do not need remedial coursework during college end up graduating within 8.5 years, but only $52 \%$ of students who do require remedial courses graduate in that time (Brock, 2010). Therefore, providing students with personalized support and instruction before entering college could help improve their overall readiness in mathematics, which could also increase their confidence and their corresponding chances of majoring in a business or STEM-based field.

Furthermore, and again mirroring the program at Worchester State, students in this program at the University of Wisconsin-Milwaukee are given an opportunity to meet their instructors and navigate the campus before entering college. This could lower their initial anxiety and foster relationships between students and college instructors (Kesici \& Erdogan, 2009; Perrine \& And, 1995). Though the problem of college-readiness is often framed in terms of academic ability (Bisk et al., 2013; Conley, 2007; Davis \& Shih, 2007; Long et al., 2009), I believe many students struggle equally with feeling a sense of belonging on the campus and feeling confident in their ability to be successful in college. In my professional experience working with freshmen, these issues often overshadow academic concerns. The summer programs described here address these issues of readiness as well as academic issues by allowing students to spend time on campus, meet new people, and work through mathematics problems with other new students and faculty members to validate and enhance their abilities in mathematics. Thus, I believe the impact of these programs could be significant in enhancing student-readiness, collegereadiness, self-efficacy, and success.

Both of these summer programs have limitations, however. One limitation, which some members of the URI mathematics department use to justify why they will not enact 
such a program, is that students coming to the university from out-of-state may not be able to travel to campus over the summer, limiting their ability to participate. Further, students who do travel to participate in such a program would be required to find and pay for their own housing, as on-campus housing is generally not provided to students over the summer. Both of these programs also focus heavily on the use of placement exams to ensure students are prepared for college and are taking the appropriate courses. While placement exams have generally been found to increase overall student retention and GPA (Bisk et al., 2013; Foley-Peres \& Poirier, 2008; Reisel et al., 2012; Smith \& Schumacher, 2005), there are also limitations to using and relying on the results of an exam, which are recognized earlier in chapter three (the review of related literature), as many educators are against enforcing placement. However, if programs such as the one at the University of Wisconsin-Milwaukee can help students increase their placement score, enhance their readiness for college, and thus allow them to begin in a more advanced course during their freshmen year, these students may be more likely to seek STEM or business degrees.

\section{Change in Pace}

An additional approach to helping students find success and enhance collegereadiness has been to allow students to move through remedial courses at a faster pace than standard courses (Brock, 2010). This change of pace has been especially popular in mathematics courses. Since students who take remedial courses are less likely to graduate (Calcagno \& Long, 2008), several colleges have started to offer courses over the summer months or during winter break to help students learn remedial material at an accelerated pace, or a more high-intensity course that is held over a shorter period of time. At some universities, "students who test just below college level may be assigned to a short-term review class rather than a full-semester course... [or] basic skills 'immersion' courses that are shorter in duration but require more hours of attendance each week" (Brock, 2010, p. 118). These programs were designed to enhance student 
skills in mathematics and thus improve their college-readiness. The corresponding impact of these programs has varied from student to student: some students were able to excel within a few weeks and felt prepared to advance to other courses; others were frustrated that their peers were advancing quickly while they struggled to keep up, which caused some to stop attending.

Offering competency-based courses, which students can attend until they feel more prepared for advanced courses, may help students graduate sooner while still receiving the supplemental instruction or support they need, which was the original purpose of implementing alternatively-paced programs (Brock, 2010). Rather than assuming all students who score below a certain level on a placement exam are not college-ready and require semester-long remediation, these programs recognize that students have varying needs and require diverse levels of instruction. A potential limitation to these review courses, when offered during the regular academic semester, may be that students are often allowed to take them while also taking a more advanced mathematics course, and thus may not have time to fully grasp the foundational concepts before being expected to use them in their other course. Similar to other programs, however, if these courses are offered over the breaks rather than during the regularly scheduled semester, out-of-state students may not be able to attend, thus potentially limiting participation to in-state students.

Universities implementing programs similar to those described here have noted that: "faculty members generally agree that developing... [new programs] brought the department together to discuss how the curriculum would appear" (Felder, Finney, \& Kirst, 2007, p. 11). Therefore, communicating about the content and results of these new reform efforts could bring the mathematics department together with the College of Business and other departments, and force them to examine the current curriculum on a more regular basis so that they may work on their own definition of what it means to be "college-ready" in mathematics. Personalizing the readiness enhancement procedures 
and rationale to fit the specific needs of a university's students and faculty members would be a necessary first step in implementing any reform effort or policy changes (Gess-Newsome et al., 2003). Thanks to this research, the College of Business at URI has plans in place to begin the implementation of some alternatively-paced business mathematics courses with "just in time" simultaneous review next Fall (D. Rosen, personal communication, November 6, 2015).

\section{Professional Experiences and Connections to My Research}

The business mathematics course I investigated in this research, BUS 111 at URI, consisted of nearly all college freshmen. Thus, college-readiness is frequently a concern for these students, their instructors, and the administration. Student-readiness should also be a concern as universities adapt curricular and instructional methods to accommodate new students. Many students in this BUS 111 course report feeling anxious and unsure of how to be successful in business mathematics. I believe some of the recent reform efforts described above, aimed at increasing readiness for mathematics in higher education, could benefit students enrolling in BUS 111. Specifically, offering a summer program such as the one at Worcester State or the bridge program at the University of Wisconsin-Milwaukee could significantly enhance student success in this gateway business mathematics course. Explaining college expectations and introducing students to a syllabus and sample mathematics problems or projects during the summer could lower their anxiety, boost their confidence, and make them more aware of what to expect in the Fall semester.

From my professional experience as an instructor for the College of Business at URI, I have found summer immersion programs to be very beneficial to enhancing both college-readiness and student-readiness. I would love to implement summer preparation programs for all interested students in the future. For the past few years, I have taught summer courses at URI for the Talent Development (TD) program, which offers financial scholarships to first-generation college students who are from racially diverse or 
underprivileged backgrounds. These students are required to complete a summer program prior to their admittance to the university to demonstrate that they are college-ready. They take three courses, attend daily tutorials, and participate in workshops on study skills and computer literacy. They are provided free on-campus housing throughout the six-week program.

During the Summer of 2014, I created a new TD course specifically intended for students who were business majors, to help them assess and advance their mathematical skills prior to taking either MTH 110 or BUS 111. Students who took this new, transitional course and then proceeded to take MTH 110 or BUS 111 in the Fall tended to perform better than many of their peers who were not in the TD program, even though those non-TD students usually earned higher SAT scores and high school GPAs. Therefore, I strongly believe that college-readiness may not be solely due to academic ability or performance on exams. Student exposure to this summer program, which showed them how to self-assess their mathematical abilities, introduced them to university life and faculty expectations, enhanced their mathematical skills through hands-on, business-based projects, and allowed them get to know faculty members and other students, had a positive impact on their corresponding grades in a college-level business mathematics course. Further, the course allowed me to better prepare myself as an instructor for the students arriving in the Fall once I understood the group's needs, challenges, and strengths. Thus, offering summer programs to help more students at URI prepare for college could have a significantly positive impact on college-readiness, student-readiness, and student success in business mathematics.

Remedial education and supportive introductory programs have been, and will likely continue to be, necessary components for some students entering higher education who may not be deemed "college-ready" from the start, especially in mathematics. Students in need of such programs should still be granted the opportunity to earn a college degree, and therefore universities must be prepared to meet these students' needs 
and offer them support. Mathematics is one of the key areas where support is needed, especially in the business field (Ballard \& Johnson, 2007; Smith \& Schumacher, 2005). Implementing a program that increases communication across K-16 educational levels and/or allows students to improve their current readiness level by advancing or brushing up on skills essential for college success could create a more welcoming environment and could provide students with greater opportunities to maximize their potential for success in college.

\section{Suggestions for Future Research}

As described in detail in the limitations section of chapter four (the research design and methodology), this research was limited in the conclusions I was able to draw. While the multiple regression analysis I used in this dissertation was quantitative in nature to investigate which variables (attitudes towards mathematics, mathematical anxiety, time devoted to mathematics outside of class, number of absences, gender, placement score, high school GPA, and mathematics SAT score) were significant predictors of student achievement in BUS 111, the results from this study can be used to inform future research.

On a personal level, for example, after performing this research, I now want to examine students' specific learning experiences when they are preparing for exams versus when they are working on projects, since both assessment procedures are frequently employed in the College of Business. I personally utilize both evaluation techniques in the courses I teach (including MTH 110 and BUS 111) and recently have been wondering how students experience each assessment, especially considering that the results of this research indicate that student attitudes and anxiety in mathematics, as well as the time they devote to the subject both in and outside of class, likely influence their overall grades in the course.

Through personal communication, many students have reported feeling as though they are able to earn higher grades when they have the opportunity to display their 
knowledge through a project that they can usually work on with others and spend more time on, as opposed to a typical 50-minute or 90-minute exam. Other students, however, have expressed that they feel more comfortable preparing for and taking exams since they require less total time and are generally completed on an individual basis where they can let their personal learning shine. Therefore, I would be interested in leading an investigation that would lend itself to a mixed-methods research design, as I could observe student behaviors in each setting, interview students about their learning experiences in each case, compare their scores on each assessment, and administer a survey regarding time devoted to studying for exams versus working on projects, for example. This explanatory sequential design would allow me to collect quantitative data first and then explore the potential reasoning behind that data using qualitative analysis of student voice and experience (Creswell, 2014).

Furthermore, the research performed in this dissertation addresses many factors that lead to (or serve as obstacles to) student success in college business mathematics courses. Each affective and cognitive factor is associated with future research interests. Since student attitude towards mathematics is a predictor of student achievement in a business mathematics class, for instance, some follow-up questions for further research and deeper investigation include:

1. How do students' attitudes towards mathematics initially develop?

2. How do students' attitudes towards mathematics (specifically confidence levels in mathematics) change over time?

3. What factors influence the way students think about mathematics in business courses?

4. Who influences the way students think about mathematics in business?

5. How do college freshmen perceive the value of mathematics in business? 
Similarly, since mathematical anxiety was found to be a predictor of achievement in this college business mathematics course, follow-up research studies should address questions such as:

1. What experiences may lead college students to feel anxious in business mathematics classes?

2. How prepared do business students feel in making the transition from high school to college-level mathematics?

3. How do students experience anxiety in business mathematics?

4. How do student experiences in high school mathematics differ from experiences in college mathematics, and what impact does this have on students?

These questions are much more exploratory in nature and would require a more inductive approach to research. Therefore, to address these questions, qualitative research designs, including interviews and observations, would likely be the appropriate methodology (Creswell, 2014; Fraenkel et al., 2011). Holding in-depth, open-ended interviews with students would help the researcher better understand student experiences with business mathematics in college. Students would be able to explain in greater detail how they feel about mathematics and how those feelings may have developed over time. The researcher could listen and then ask them follow-up questions to truly gain a deeper understanding (Patton, 2002). Observing students in class would allow the researcher to witness some of the perceived expectations of the instructor as well as the climate of the classroom. There would be an opportunity to see how much time the instructor spends lecturing, what students tend to be doing during the class, as well as the layout of the classroom. These observations could be discussed and analyzed with students during interviews or focus groups. Further, the instructors could be interviewed about their expectations of students and their general pedagogical views. 
Finally, this research was limited to one course during one semester at one university. Similar research should be carried out at other universities to confirm (or contest) the results presented here. The same study should be replicated to confirm that these results were not unique to this specific sample of students. Further, other predictor variables, such as method of instruction, time of day class meets, and class size could be included. I look forward to expanding my knowledge of this topic by performing more research in the future.

\section{Concluding Remarks on Implications for Practice}

College instructors cannot be assured that all students who come to them will be ready for college-level work as it is currently presented, but they should offer opportunities for dialogue, peer interaction, and reflection that encourage learners to relate new knowledge to past experiences, which may help them better understand new material (Dewey, 1938; Vygotsky, 1978). Instructors may find that, with the curricular and instructional changes described earlier in this chapter, students are more ready for college than originally assumed. College-readiness cannot be determined by the results of standardized test scores, university placement exams, or high school GPAs alone. Nor can students be expected to become college-ready after taking a remedial lecture with few opportunities for dialogue or reflection. In addition to academic advancement opportunities, students must engage in conversations about mathematics during, after, and prior to their freshman year to help them mentally and emotionally prepare for college courses and life after college.

Most importantly, all instructors should work to prepare themselves for their incoming students, with the support of the institution. In my experiences with students, I believe that what is currently considered a lack of college-readiness or maturity in freshmen courses may actually be, in part, a lack of student interest and motivation in mathematics or high mathematical anxiety. It may be a lack of student-readiness on the part of the university. If students do not believe that what they are learning is important, 
they are unlikely to spend much time on the course, which may appear to be a lack of ability to perform the task as assigned. By offering interesting and stimulating course material that encourages peer interaction and personal exploration, students will likely be more willing to devote time and effort to the course (Kesici \& Erdogan, 2009; Vygotsky, 1978). Regardless of the specific policies implemented to address college-readiness and student-readiness, in order to enhance student success in college courses, students in business mathematics courses must be engaged in learning practices that foster their development and prepare them to become self-directed learners who will thus feel empowered to become leaders in their field. 
Appendices 
Appendix A

THE

Beginning of the Semester: Survey Consent Form and Additional Questions

UNIVERSITY

OF RHODE ISLAND

COLLEGE OF BUSINESS

ADMINISTRATION

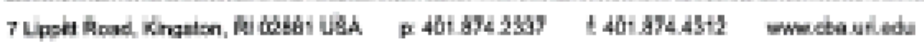

The University of Rhode Island; Brooke D'Aloisio, BrookeElise@uri.edu

Department of the College of Business Administration, 7 Lippitt Road, Kingston, RI 02881

Investigating Predictors of Academic Success in a Foundational Business Mathematics Course

\section{CONSENT FORM FOR RESEARCH}

You have been invited to take part in a research project described below. The researcher will explain the project to you in detail. You should feel free to ask questions. If you have more questions later, Comelis de Groot (faculty supervisor: degrootc@uriedu, (401)874-4149) or Brooke D'Aloisio (student researcher.

BrookeElise@uriedu, (401)874-4992), the people mainly responsible for this study, will discuss them with you. You must be at least 18 years old to participate in this research project.

\section{Exclusionary criteria}

If you are under the age of 18 , you may not participate in this study.

Description of the project:

During the Fall 2015 semester, all students enrolled in BUS 111 are invited to participate in a research study designed to investigate the factors that predict success in business mathematics courses at the University of Rhode Island. Findings from this research may used to support future students in BUS 111 and similar courses toward success. If you decide to take part in this study, you will complete one survey on the second day of the semester and another during the last full week of the semester. Each survey will take you approximately 20 minutes, so no more than one total hour of time will be required.

\section{What will be done:}

If you decide to take part in this study here is what will happen: You will complete two surveys - one today and one during the last week of class. Your student ID number will be used as an initial identifier to match your pre- and post-survey results with other indicators from eCampus and the mathematics department. Specifically, if you agree to participate, your gender, math SAT scores, and high school GPA will be obtained through URT's PeopleSoft/eCampus system. Further, your placement exam score will be obtained from the mathematics department at URI. Finally, your final course average in BUS 111 will be obtained at the end of the semester from SAKAI. This data will be stored in a locked filing cabinet in the researcher's private, locked office in Ballentine Hall. However, once these matches have been made, your ID number will be eliminated from the data to protect your identity (this de-identification process will happen before April 2016). Your name will not be identified in anv wav in the oresentation of the research and all of vour responses will be held in confidence. Risks or discomfort:

Your student ID number and private information from PeopleSoft/eCampus will be used throughout this study during the data collection (see details above). However, this information will be de-identified before data 
analysis begins. Your name will not be identified in any way in the presentation of the research and all of your responses will be held in confidence. It is not anticipated that you will experience any negative effects as a result of this study and it will not affect your grade in this course or your academic standing in any way.

Benefits of this study:

As a result of your participation in this study, you may have a better understanding of your own feelings and attitudes about mathematics. Further, the researcher may learn more about the factors that help predict success in BUS 111 at URI. Findings from this research may used to support future students in BUS 111 and similar courses toward success.

Confidentiality:

Your part in this study is confidential. None of the information will identify you by name and all of your responses will be held in confidence. All records will be kept in a locked filing cabinet in the researcher's locked office in Ballentine Hall. Electronic files containing data will be kept in a password-protected file on a password-protected computer in the researcher's locked office. Your ID number will be deleted from this file immediately upon making matches (before April 2016) to protect your identity.

Decision to quit at any time:

The decision to take part in this study is up to you. You do not have to participate. If you decide to talke part in the study, you may quit at any time. Whatever you decide will in no way affect vour grade in this course or you academic standing. If you wish to quit, simply inform Comelis de Groot, (401)874-4149, or Brooke D'Aloisio, (401)874-4992, of your decision.

Rights and Complaints:

If you are not satisfied with the way this study is performed, you may discuss your complaints with Comelis de Groot, (401)874-4149 or with Brooke D'Aloisio, (401)874-4992, anonymously, if you choose. In addition, if you have questions about your rights as a research participant, you may contact the office of the Vice President for Research and Economic Development, 70 Lower College Road, Suite 2, University of Rhode Island, Kingston, Rhode Island, telephone: (401) 874-4328.

You have read the Consent Form. Your questions have been answered. Your signature on this form means that you understand the information and you agree to participate in this study.

Signature of Participant

Typed/printed Name

Date

Participant ID Number
Signature of Researcher

Typed/printed name

Date

Please sign both consent forms, keeping one copv for vourself. 
Student ID number:

Please check the appropriate blank:

I am 18 years of age or older.

I am under 18 years of age.

Is this your first time taking BUS 111? Please circle one: $\quad$ Yes / No

1. On average, how many hours per week do you anticipate you will spend working on mathematics (BUS 111) this semester (outside of class time)?
a. Less than 1 hour per week
b. Approximately 1-3 hours per week
c. Approximately 3-5 hours per week
d. Approximately 5-7 hours per week
e. More than 7 hours per week

2. Approximately how many BUS 111 classes do you anticipate you will miss this semester?
a. I will never miss a class this semester
b. I will miss 1-3 classes this semester
c. I will miss 4-6 classes this semester
d. I will miss 7-9 classes this semester
e. I will miss 10 or more classes this semester

3. To what extent do you agree with the statement: I believe my instructor will effectively deliver the content required for this course.
a. I strongly agree with this statement
b. I agree with this statement
c. I neither agree nor disagree with this statement
d. I disagree with this statement
e. I strongly disagree with this statement 
Appendix B

End of the Semester: Survey Consent Form and Additional Questions

THE

\section{UNIVERSITY}

OF RHODE ISLAND

OOLLEE OF BUSINESS

ADMINISTRATION

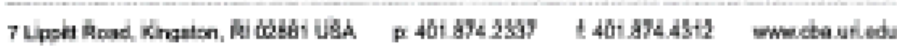

The University of Rhode Island; Brooke D'Aloisio, BrookeElise@uriedu

Department of the College of Business Administration, 7 Lippitt Road, Kingston, RI 02881

Investigating Predictors of Academic Success in a Foundational Business Mathematics Course

\section{CONSENT FORM FOR RESEARCH}

You have been invited to take part in a research project described below. The researcher will explain the project to you in detail. You should feel free to ask questions. If you have more questions later, Comelis de Groot (faculty supervisor: degrootc@uriedu, (401)874-4149) or Brooke D'Aloisio (student researcher-

BrookeElise @uriedu, (401)874-4992), the people mainly responsible for this study, will discuss them with you. You must be at least 18 years old to participate in this research project.

\section{Exclusionary criteria}

If you are under the age of 18 , you may not participate in this study.

Description of the project:

During the Fall 2015 semester, all students enrolled in BUS 111 are invited to participate in a research study designed to investigate the factors that predict success in business mathematics courses at the University of Rhode Island. Findings from this research may used to support future students in BUS 111 and similar courses toward success. If you decide to take part in this study, you will complete one survey on the second day of the semester and another during the last full week of the semester. Each survey will take you approximately 20 minutes, so no more than one total hour of time will be required.

\section{What will be done:}

If you decide to take part in this study here is what will happen: You will complete two surveys - one today and one during the last week of class. Your student ID number will be used as an initial identifier to match your pre- and post-survey results with other indicators from eCampus and the mathematics department. Specifically, if you agree to participate, your gender, math SAT scores, and high school GPA will be obtained through URT's PeopleSoft/eCampus system. Further, your placement exam score will be obtained from the mathematics department at URI. Finally, your final course average in BUS 111 will be obtained at the end of the semester from SAKAI. This data will be stored in a locked filing cabinet in the researcher's private, locked office in Ballentine Hall. However, once these matches have been made, your ID number will be eliminated from the data to protect your identity (this de-identification process will happen before April 2016). Your name will not be identified in any way in the presentation of the research and all of your responses will be held in confidence. Risks or discomfort:

Your student ID number and private information from PeopleSoft/eCampus will be used throughout this study during the data collection (see details above). However, this information will be de-identified before data 
analysis begins. Your name will not be identified in any way in the presentation of the research and all of your responses will be held in confidence. It is not anticipated that you will experience any negative effects as a result of this study and it will not affect your grade in this course or your academic standing in any way.

Benefits of this study:

As a result of your participation in this study, you may have a better understanding of your own feelings and attitudes about mathematics. Further, the researcher may leam more about the factors that help prectict success in BUS 111 at URI. Findings from this research may used to support future students in BUS 111 and similar courses toward success.

\section{Confidentiality:}

Your part in this study is confidential. None of the information will identify you by name and all of your responses will be held in confidence. All records will be kept in a locked filing cabinet in the researcher's locked office in Ballentine Hall. Electronic files containing data will be kept in a password-protected file on a password-protected computer in the researcher's locked office. Your ID number will be deleted from this file immediately upon making matches (before April 2016) to protect your identity.

Decision to quit at any time:

The decision to take part in this study is up to you. You do not have to participate. If you decide to take part in the study, you may quit at any time. Whatever you decide will in no way affect your grade in this course or your academic standing. If you wish to quit, simply inform Comelis de Groot, (401)874-4149, or Brooke D'Aloisio, (401)874-4992, of your decision.

Rights and Complaints:

If you are not satisfied with the way this study is performed, you may discuss your complaints with Comelis de Groot, (401)874-4149 or with Brooke D'Aloisio, (401)874-4992, anonymously, if you choose. In addition, if you have questions about your rights as a research participant, you may contact the office of the Vice President for Research and Economic Development, 70 Lower College Road, Suite 2, University of Rhode Island, Kingston, Rhode Island, telephone: (401) 874-4328.

You have read the Consent Form. Your questions have been answered. Your signature on this form means that you understand the information and you agree to participate in this study.

Signature of Participant

Typed/printed Name

Date
Signature of Researcher

Typed/printed name

Date

Participant ID Number

Please sign both consent forms, keeping one copv for vourself.

Student ID number: 
Please check the appropriate blank:

I am 18 years of age or older.

I am under 18 years of age.

Was this your first semester taking BUS 111? Please circle one: $\quad$ Yes $\quad / \quad$ No

1. On average, how many hours per week did you spend working on mathematics (BUS

111) over the past three weeks (outside of class time)?
a. Less than 1 hour per week
b. Approximately 1-3 hours per week
c. Approximately 3-5 hours per week
d. Approximately 5-7 hours per week
e. More than 7 hours per week

2. Approximately how many BUS 111 classes did you miss this semester?
a. I never missed a class this semester
b. I missed 1-3 classes this semester
c. I missed 4-6 classes this semester
d. I missed 7-9 classes this semester
e. I missed 10 or more classes this semester

3. To what extent do you agree with the statement: I believe my instructor effectively delivered the content required for this course.
a. I strongly agree with this statement
b. I agree with this statement
c. I neither agree nor disagree with this statement
d. I disagree with this statement
e. I strongly disagree with this statement 


\section{Appendix C}

Attitudes Towards Mathematics Inventory (ATMI)

Directions: This inventory consists of statements about your attitude toward mathematics. There are no correct or incorrect responses. Read each item carefully. Please think about how you feel about each item. Circle the response that most closely corresponds to how each statement best describes your feelings. Please answer every question.

Student ID number:

1. Mathematics is a worthwhile and necessary subject.

Strongly Agree Agree Neutral Disagree Strongly Disagree

2. I want to develop my mathematical skills.

Strongly Agree Agree Neutral Disagree Strongly Disagree

3. I get a great deal of satisfaction out of solving a mathematics problem.

Strongly Agree Agree Neutral Disagree Strongly Disagree

4. Mathematics helps develop the mind and teaches a person to think.

Strongly Agree Agree Neutral Disagree Strongly Disagree

5. Mathematics is important in everyday life.

Strongly Agree Agree Neutral Disagree Strongly Disagree

6. Mathematics is one of the most important subjects for people to study.

Strongly Agree Agree Neutral Disagree Strongly Disagree

7. College math courses would be very helpful no matter what I decide to study.

Strongly Agree Agree Neutral Disagree Strongly Disagree

8. I can think of many ways that use math outside of school. 
Strongly Agree Agree Neutral Disagree Strongly Disagree

9. Mathematics is one of my most dreaded subjects.

Strongly Agree Agree Neutral Disagree Strongly Disagree

10. My mind goes blank and I am unable to think clearly when working with math.

Strongly Agree Agree Neutral Disagree Strongly Disagree

11. Studying mathematics makes me feel nervous.

Strongly Agree Agree Neutral Disagree Strongly Disagree

12. Mathematics makes me feel uncomfortable.

Strongly Agree Agree Neutral Disagree Strongly Disagree

13. I am always under a terrible strain in math class.

Strongly Agree Agree Neutral Disagree Strongly Disagree

14. When I hear the word mathematics, I have a feeling of dislike.

Strongly Agree Agree Neutral Disagree Strongly Disagree

15. It makes me nervous to even think about having to do a mathematics problem.

Strongly Agree Agree Neutral Disagree Strongly Disagree

16. Mathematics does not scare me at all.

Strongly Agree Agree Neutral Disagree Strongly Disagree

17. I have a lot of self-confidence when it comes to mathematics.

Strongly Agree Agree Neutral Disagree Strongly Disagree

18. I am able to solve mathematics problems without too much difficulty.

Strongly Agree Agree Neutral Disagree Strongly Disagree

19. I expect to do fairly well in any math class I take.

Strongly Agree Agree Neutral Disagree Strongly Disagree 
20. I am always confused in my mathematics class.

Strongly Agree Agree Neutral Disagree Strongly Disagree

21. I feel a sense of insecurity when attempting mathematics.

Strongly Agree Agree Neutral Disagree Strongly Disagree

22. I learn mathematics easily.

Strongly Agree Agree Neutral Disagree Strongly Disagree

23. I am confident that I could learn advanced mathematics.

Strongly Agree Agree Neutral Disagree Strongly Disagree

24. I have usually enjoyed studying mathematics in school.

Strongly Agree Agree Neutral Disagree Strongly Disagree

25. Mathematics is dull and boring.

Strongly Agree Agree Neutral Disagree Strongly Disagree

26. I like to solve new problems in mathematics.

Strongly Agree Agree Neutral Disagree Strongly Disagree

27. I would prefer to do an assignment in math than to write an essay.

Strongly Agree Agree Neutral Disagree Strongly Disagree

28. I would like to avoid using mathematics in college.

Strongly Agree Agree Neutral Disagree Strongly Disagree

29. I really like mathematics.

Strongly Agree Agree Neutral Disagree Strongly Disagree

30. I am happier in a math class than in any other class.

Strongly Agree Agree Neutral Disagree Strongly Disagree

31. Mathematics is a very interesting subject. 
Strongly Agree

Agree

Neutral

Disagree

Strongly Disagree

32. I am willing to take more than the required amount of mathematics.

Strongly Agree

Agree

Neutral

Disagree

Strongly Disagree

33. I plan to take as much mathematics as I can during my education.

Strongly Agree

Agree

Neutral

Disagree

Strongly Disagree

34. The challenge of math appeals to me.

Strongly Agree

Agree

Neutral

Disagree

Strongly Disagree

35. I think studying advanced mathematics is useful.

Strongly Agree

Agree

Neutral

Disagree

Strongly Disagree

36. I believe studying math helps me with problem solving in other areas.

Strongly Agree

Agree

Neutral

Disagree

Strongly Disagree

37. I am comfortable expressing my own ideas on how to look for solutions to a difficult problem in math.

Strongly Agree Agree Neutral Disagree Strongly Disagree

38. I am comfortable answering questions in math class.

Strongly Agree Agree Neutral Disagree Strongly Disagree

39. A strong math background could help me in my professional life.

Strongly Agree Agree Neutral Disagree Strongly Disagree

40. I believe I am good at solving math problems.

Strongly Agree Agree Neutral Disagree Strongly Disagree 
(C) Martha Tapia 1996 


\section{Appendix D \\ Mathematics Anxiety Scale (MAS)}

Directions: The following are statements about which your opinions are sought. For each statement, please circle the response that most closely indicates your extent of agreement or disagreement with the statement.

Student ID number:

1. Math makes me feel uncomfortable and nervous.

Strongly Agree Agree Neutral Disagree Strongly Disagree

2. Math is the most dreaded subject for me.

Strongly Agree Agree Neutral Disagree Strongly Disagree

3. I find math interesting.

Strongly Agree Agree Neutral Disagree Strongly Disagree

4. I feel worried before entering a math class.

Strongly Agree Agree Neutral Disagree Strongly Disagree

5. Math is one of my favorite subjects.

Strongly Agree Agree Neutral Disagree Strongly Disagree

6. I am not afraid of math exams.

Strongly Agree Agree Neutral Disagree Strongly Disagree

7. Solving math problems is pleasant for me.

Strongly Agree Agree Neutral Disagree Strongly Disagree

8. I feel nervous when I am about to do math homework. 
9. I feel happy and excited in a math class as compared to any other class.

Strongly Agree Agree Neutral Disagree Strongly Disagree

10. I would prefer math as one of my subjects in higher studies.

Strongly Agree Agree Neutral Disagree Strongly Disagree

11. Math is a headache for me.

Strongly Agree Agree Neutral Disagree Strongly Disagree

12. I am afraid to ask questions in math class.

Strongly Agree Agree Neutral Disagree Strongly Disagree

13. Math doesn't scare me at all.

Strongly Agree Agree Neutral Disagree Strongly Disagree

14. My mind goes blank when the teacher asks math questions.

Strongly Agree Agree Neutral Disagree Strongly Disagree

\section{Appendix E}

\section{E-Mail Sent to Students Prior to Fall 2015 Semester}

The following email was sent to all students who were enrolled in BUS 111 during the Fall 2015 semester. The email list was obtained from the course instructors via URI's eCampus system. The email was sent one week prior to the start of classes.

To:

BCC:

BrookeElise@uri.edu

Subject:

\{Email addresses of all students enrolled in BUS 111 during Fall 2015\}

BUS 111 Fall 2015 Research Survey 
Good morning,

You are receiving this email because of your current enrollment in BUS 111 for the Fall 2015 semester at the University of Rhode Island. If you are not in BUS 111, please disregard this email.

During the Fall 2015 semester, all students enrolled in BUS 111 will be invited to participate in a research study designed to investigate the factors that predict success in business mathematics courses at URI. The researcher, Brooke D'Aloisio, will explain the project to you in detail during the first week of classes and more information is provided below. You should feel free to ask questions.

If you decide to take part in this study, you will complete one survey on the second day of the semester and another during the last full week of the semester. Each survey will take you approximately 20 minutes. Your student ID number will be used as an initial identifier to match your pre- and post-survey results with other indicators (your gender, course grade for BUS 111, SAT scores, and placement score), but will then be recoded randomly to protect your identity. Your name will NEVER be identified in the research and all of your responses will be held in confidence.

As a result of your participation in this study, you may have a better understanding of your own feelings and attitudes about mathematics. Further, the researcher may learn more about the factors that help predict success in the BUS 111 course at URI. Findings from this research may used to support future students in BUS 111 and similar courses toward success. It is not anticipated that you will experience any negative effects as a result of this study and it will not affect your academic standing or your grade in BUS 111, or any other courses, in any way.

Participation is completely voluntary and refusal to participate will not result in any penalty. You do not have to participate. If you decide to participate, you may choose to stop participating at any time during the study. You may withdraw your consent at any time by simply informing me of your decision.

If you have any questions regarding the study, please contact me, Brooke D'Aloisio, in Ballentine Hall, Room 202 at BrookeElise@uri.edu or (401)874-4992.

Best wishes with the start of the new semester!

Brooke D'Aloisio 


\section{APPENDIX F}

\section{Sample Questions from URI's Mathematics Placement Exam: Tier A}

Instructions. This is a sample placement exam to show you the type of questions that will appear on the actual placement exam. To get the most out of the placement exam, you should try these practice problems without any outside help, such as calculators, books, notes, or friends or relatives. Also, on the actual placement exam, all fractions must be fully reduced to be marked correct. Good luck!!

\section{Placement Exam Part 1}

1. Compute $31-(-11)-(6-9)$.

2. Find the numerical value of $11-3(21-16)$.

3. Evaluate $|-24+17|$.

4. Compute $\left(\frac{3}{5}\right)^{3}$ in lowest terms.

5. Add the following fractions and express your answer as a fully reduced fraction:

$$
\frac{2}{3}+\frac{5}{11}
$$

6. Divide the following fractions and express your answer as a fully reduced fraction:

$$
\frac{13}{5} \div \frac{10}{3}
$$

7. Simplify:

$$
\frac{1}{2} \cdot \frac{-4}{5}+\frac{-1}{3} \cdot \frac{3}{4}
$$

8. Simplify the expression

$$
4(3 x+1)-(2 x-6)
$$

to one of the form

$$
a x+b .
$$

9. Simplify the expression

$$
\left(3 x^{2}+2 x-3\right)-\left(4 x^{2}-2 x-6\right)
$$

to one of the form

$$
a x^{2}+b x+c .
$$

10. Solve for $x$ :

$$
5 x+2=-3 x+4
$$


Sample Questions from URI's Mathematics Placement Exam: Tier B

\section{Placement Exam Part 2}

1. Find the two roots $x_{1}$ and $x_{2}$ of the quadratic equation

$$
x^{2}-8 x+12=0 \text {. }
$$

Enter the smaller answer first.

2. Solve for $x$ :

$$
3 x+2=1-5 x .
$$

3. Solve for $x$ :

$$
2(x-3)=1-4(2 x+5)
$$

4. Simplify $2(-3 x+1)-(-3 x+1)-5 x+2$ to the form $a x+b$.

5. Solve for $x$ :

$$
|4 x+1|+3=6
$$

Enter the smaller (or more negative) answer first.

6. Solve for $x$ :

$$
x^{2}-11 x=-28
$$

Enter the smaller (or more negative) answer first.

7. Simplify

$$
20 x^{3} y^{4} \div 2 x^{6} y^{3}
$$

Enter $a, b$, and $c$, where the answer is $a x^{b} y^{c}$.

8. Calculate the slope of the line going through the points $(-5,6)$ and $(2,3)$.

9. Solve for $x$ :

$$
\frac{2}{x}-\frac{1}{4}=\frac{1}{7}
$$

10. Evaluate $x^{2}-2 x+6$ for $x=-1$. 


\section{Placement Exam Part 3}

1. If $f(x)=-3 x+7$, calculate and simplify

$$
\frac{f(4+h)-f(4)}{h} .
$$

Enter the values of $a$ and $b$, where your answer is in the form $a h+b$.

2. Solve for $\mathrm{x}$ by factoring:

$$
x^{2}+-9 x+14=0 \text {. }
$$

Enter the smaller (or more negative) answer first.

3. The graph of $y=\frac{1}{x+2}+9$ is the graph of $y=\frac{1}{x}$ with what transformations?
(a) shifted left 9 units and down 2 units
(b) shifted left 2 units and up 9 units
(c) shifted left 2 units and down 9 units
(d) shifted right 2 units and up 9 units
(e) shifted left 9 units and up 2 units

4. Write the exponential equation $2^{x}=7$ in an equivalent logarithm equation. Enter $a, b$, and $c$ where your answer is $\log _{b} a=c$.

5. A right triangle has sides $\mathrm{A}, \mathrm{B}$, and $\mathrm{C}$, where $\mathrm{C}$ is the hypotenuse. Side $\mathrm{A}$ has length 18 , side $\mathrm{B}$ has length 24 , and side $\mathrm{C}$ has length 30 . If $\theta$ is the angle between sides $\mathrm{A}$ and $\mathrm{C}$, what is the value of $\sin \theta$ ? Enter your answer as a fully simplified fraction.

6. Which of the following is the inverse of $f(x)=(x-10)^{3}$ ?
(a) $f^{-1}(x)=(x-10)^{1 / 3}$
(b) $f^{-1}(x)=(x+10)^{1 / 3}+10$
(c) $f^{-1}(x)=x^{1 / 3}-10$
(d) $f^{-1}(x)=x^{1 / 3}+10$
(e) $f^{-1}(x)=x^{3}+10$

7. Solve for $x$ :

$$
7^{x+6}=2 .
$$

Enter $a, b$, and $c$, where your answer is $x=\log _{a} b+c$.

8. Evaluate $\ln e^{43}$ without using a calculator.

9. Find the equation of the curve formed by vertically stretching the graph of $y=\sin x$ by 2 and then shifting it right by 7 units. Enter $a, b, c$, and $d$, where your answer is $y=a \sin (b x+c)+d$.

10. Use the method of completing the square to write $x^{2}+6 x-2$ in the form $(x+a)^{2}+b$. 


\title{
APPENDIX G
}

\author{
Sample BUS 111 Syllabus
}

\section{BUS 111 Syllabus}

Introduction to Business Analysis and Applications

University of Rhode Island, Fall 20xx

\section{Instructor Contact Information}

Name:

Office:

Office Hours:

E-mail:
$* * * * * * * * * * * *$

Ballentine Hall, Room ***

MWF 9:00AM-9:50AM; MWF 11:00AM-11:50AM; by appointment $* * * * * * * * * * @$ uri.edu

\section{Course Materials}

- Optional: Applied Mathematics for Business, Economics and the Social Sciences by Frank S. Budnick, McGraw-Hill Book Company (ISBN: 0-390-23153-3)

- Required: Scientific calculator, frequent use of SAKAI, access to Microsoft Excel

\section{BUS 111 Description}

BUS 111 presents selected mathematical tools and techniques for analysis of business and economic problems. Topics include finite and modern mathematics, the mathematics of finance and applied calculus. Note: In order to become mathematically literate, it is important to link the concepts of mathematics to applications. Thus, applications (word problems) will be emphasized throughout the course.

\section{General Education}

BUS 111 counts as a general education course for Mathematical or Quantitative Reasoning (MQ).

\section{Overview of Goals}

The goals of BUS 111 are to help you develop a deeper mathematical knowledge and competency required for your career and to prepare you for problem solving in future courses and daily life.

\section{Course Expectations}

Because this is a large class, certain "house rules" are needed, and they will be strictly enforced:

1. Attend each class. Come prepared and be punctual. If you must be absent, as a professional courtesy, contact me prior to your absence and explain to me why you will miss class. There will be many quizzes in class and they will be given at the very beginning of the class, so make sure you have made the necessary arrangements to be on time.

2. I expect that you will give this course 6-7 hours per week, in addition to class time. This is an approximate figure, but don't assume that you can spend less time and still earn a grade that you will like. 
3. Doing well in this course requires effort on your part: come to class, be ready to learn, review your notes regularly, and ask questions. We will devote some class time each day to addressing any problems or concerns you might have.

4. Be respectful of yourself and your classmates. No electronic devices of any kind are permitted. This means:

- No active cell phones. Turn your cell phones off or on silent prior to coming to class.

- No calculators may be used unless specifically instructed to use one. CELL PHONES MAY NOT BE USED AS CALCULATORS DURING QUIZZES OR EXAMS.

5. The University of Rhode Island strongly promotes academic integrity. All submitted work must be your own. If you consult other sources (class readings, articles or books from the library, articles available through internet databases, or websites) these MUST be properly documented, or you will be charged with plagiarism and will receive an $\mathrm{F}$ for the paper. In some cases, this may result in a failure of the course as well. In addition, the charge of academic dishonesty will go on your record in the Office of Student Life. If you have any doubt about what constitutes plagiarism, visit the website: http://gervaseprograms.georgetown.edu/hc/plagiarism.html, the URI Student Handbook, and UNIVERSITY MANUAL sections on Plagiarism and Cheating at http://www.uri.edu/facsen/8.20-8.27.html - cheating. Any good writer's handbook as well as reputable online resources will offer help on matters of plagiarism and instruct you on how to acknowledge source material. If you need more help understanding when to cite something or how to indicate your references, PLEASE ASK.

\section{Grading Policy}

Your grade will be based accumulating points based on exams in class, a comprehensive, optional final exam, attendance, projects, homework, and quizzes (some announced, some unannounced).

$\begin{array}{lllll}\text { Online Homework } & 10 \% & & \text { Online Homework } & 10 \% \\ \text { Quizzes/Attendance } & 10 \% & & \text { Quizzes/Attendance } & 10 \% \\ \text { Projects } & 10 \% & \text { OR } & \text { Projects } & 10 \% \\ \text { Exams (3 total) } & 50 \% & & \text { Exams (3 total) } & 70 \% \\ \text { Final Exam } & 20 \% & & & \end{array}$

\section{Grading Scale}

A class-wide scale will not be used in this course. Grades are not negotiable and no extra credit is offered on an individual basis. Letter grades will be assigned using the following scale:

\begin{tabular}{|c|c|}
\hline Numeric Average & Letter Grade \\
\hline 92.5 and above & A \\
\hline $90.0-92.4$ & A- \\
\hline $87.5-89.9$ & B+ \\
\hline $82.5-87.4$ & B \\
\hline $80.0-82.4$ & B- \\
\hline $77.5-79.9$ & C + \\
\hline $72.5-77.4$ & C \\
\hline $70.0-72.4$ & C- \\
\hline $67.5-69.9$ & D + \\
\hline $60.0-67.4$ & D \\
\hline Below 60.0 & F \\
\hline
\end{tabular}




\section{Attendance}

Attendance is mandatory. Students who attend this course regularly have been found to be much more successful. If you are unable to attend class, you will receive a zero on any assignments or quizzes given during class that day.

\section{BUS 111 Exams}

NOTE: EXAMS WILL BE HELD DURING THE EVENING:

$\begin{array}{lllll}\text { Exam 1 } & \text { DAY } & \text { DATE } & \text { TIME } & \text { LOCATION } \\ \text { Exam 2 } & \text { DAY } & \text { DATE } & \text { TIME } & \text { LOCATION } \\ \text { Exam 3 } & \text { DAY } & \text { DATE } & \text { TIME } & \text { LOCATION }\end{array}$

\section{Homework Expectations}

Homework is an integral component to help you do well in this course. Each homework assignment is expected to reflect your best work. Weekly homework assignments will be posted on Sakai. They can be found under the 'Online HW' tab in Sakai and will be due every Sunday. You will be allowed more than one submission for each assignment and your best grade will be recorded. Start the assignments early to ensure you give yourself adequate time to complete it. NO LATE WORK WILL BE ACCEPTED.

\section{Projects}

Further into the semester, you will receive information about each project requirements in detail.

1. Projects will not be accepted beyond the stated due date.

2. Unless otherwise stated, projects are not to be handwritten. They must be typed in 12point font with 1-inch margins.

3. For some projects, you will have the option of working with a partner. If you work with a partner, one copy of the project is to be submitted with both names indicated.

\section{SAKAI}

It is your responsibility to check SAKAI on a daily basis. Important announcements will be posted to SAKAI regularly and you will be held responsible for the information posted there. SAKAI will contain:

- A comprehensive, updated grade book to allow you to keep track of your grades.

- A list of helpful resources including examples, problem sets for each chapter, video resources to help you get a handle on some of the concepts covered in the course, study guides for exams, etc.

- Access to the online homework.

\section{Make-Up Policy}

- Exam dates throughout the semester are indicated above. Start planning now. If you are unable to take the exam at the announced time/day, you must notify me by email or in person prior to the date of the exam. Any conflicts need to be worked out with your instructor at least one week in advance of the exam. Make-up exams will be administered for documented/excused conflicts only. Failure to take an exam at the announced day/time without prior notification will result in the revocation of the privilege of a make-up exam.

- There are NO MAKE-UPS for on-line homework or in-class quizzes.

- Your attendance in class, therefore, is critical to your success in this course. 


\section{AN IMPORTANT NOTE ABOUT THE IMPORTANCE OF ALGEBRA RECALL}

The one prerequisite for this course is a recall of your high school algebra/MTH 110 material. Without this recall, you may be setting yourself up for failure. If you have a weak algebra background, it may appear that you are doing okay during the first half of the course. However, when we get to the differential calculus, the need for recall will become VERY important. If your background is weak, you are likely to perform very poorly in this portion of the course.

If you have a weak algebra background, you may not be adequately prepared to be successful in this class. If you have a good background, you might need to go back and brush up on some areas of algebra that you have not used recently. On the course website, there is a practice algebra pretest. This short and self-correcting exercise will allow you to assess where you stand in the recall of the algebra skills that are required in this course. If the material seems familiar, but you have forgotten some of the algebra principles, you should go back and review these areas or see your instructor for additional resources.

\section{University of Rhode Island's civility policy}

The University of Rhode Island is committed to developing and actively protecting a class environment in which respect must be shown to everyone in order to facilitate the expression, testing, understanding, and creation of a variety of ideas and opinions. Rude, sarcastic, obscene or disrespectful speech and disruptive behavior have a negative impact on everyone's learning and are considered unacceptable. I will not tolerate that behavior in my classroom. Therefore, if you feel someone is harassing you during my class, please reach out to me immediately. I will have disruptive persons removed from the class if necessary.

\section{Accommodations}

Section 504 of the Rehabilitation act of 1973 and the Americans with Disabilities Act of 1990 require the University of Rhode Island to provide academic adjustments or the accommodations for students with documented disabilities. The student with a disability shall be responsible for self-identification to the Disability Services for Students in the Office of Student Life, providing appropriate documentation of disability, requesting accommodation in a timely manner, and follow-through regarding accommodations requested.

It is the student's responsibility to make arrangements for any special needs and the instructor's responsibility to accommodate them with the assistance of the Office of Disability Services for Students. Any student with a documented disability is welcome to contact me as early in the semester as possible so that we may arrange reasonable accommodations. As part of this process, please be in touch with Disability Services for Students Office at 330 Memorial Union, 401-8742098.

\section{Standards of Behavior}

Students are responsible for being familiar with and adhering to the published "Community

Standards of Behavior: University Policies and Regulations which can be accessed in the University Student Handbook. If you must come in late, please do not disrupt the class. Please turn off all cell phones, pagers, or any electronic devices. 


\section{Religious Holidays}

It is the policy of the University of Rhode Island to accord students, on an individual basis, the opportunity to observe their traditional religious holidays. Students desiring to observe a holiday of special importance must provide written notification to each instructor. I request that you provide this notification as early as possible.

\section{Free Tutoring}

Free tutoring is available for BUS 111 students. Students who attend tutoring regularly tend to earn higher grades than students who do not take advantage of these services. The tutor for BUS111 will introduce him/herself during the first week of class. The graduate assistant will tutor in Ballentine 211 throughout the semester. Their schedule will be posted on our class SAKAI page as soon as it becomes available. Going to see the TA as frequently as possible will help you in this course.

\section{The Academic Enhancement Center}

The work in this course is complex and intensive. To do the best you can, it's a good idea to visit the Academic Enhancement Center (AEC) in Roosevelt Hall. The AEC offers a comfortable environment in which to study alone or together, with or without a tutor. AEC tutors can answer questions, clarify concepts, check understanding, and help you to study. You can make an appointment or walk during office hours -- Monday through Thursday from 9 am. to $9 \mathrm{pm}$ and Friday from 9 am to $1 \mathrm{pm}$. For a complete schedule For a complete schedule including when tutors are available specifically for this class - go to www.uri.edu/aec, call (401) 874-2367, or stop by the fourth floor in Roosevelt Hall. A schedule for the Math Walk-In Center can be found on SAKAI.

\section{The Writing Center}

Projects in this course will be written in professional documents. The Writing Center is for all writers, all disciplines, at all levels, and all stages of writing. If an instructor suggests that you go to the Writing Center, it is not a punishment, and does mean that you are a terrible writer. It means the instructor wants you to receive more individualized attention to your writing than $\mathrm{s} /$ he is able to provide, given the constraints of the class. It will only improve your grade. If possible, call ahead for an appointment (874-4690). Drop-in tutorials are often available, but I suggest making an appointment first. You may make repeat appointments, requesting the same tutor each time if you wish. See their Web Page: http://www.uri.edu/artsci/writing/center/index.shtml for tips on how to make the best of your Writing Center visit.

\section{Course Content}

This is a working list of what topics can be expected to be covered in class this semester. Topics and dates listed below may change. 


\begin{tabular}{|c|c|c|}
\hline Week & Chapter & Topic(s) Discussed \\
\hline Week 1 & 8 & $\begin{array}{l}\text { Introduction to BUS 111, Competency Exam } \\
\text { Mathematics of Finance }\end{array}$ \\
\hline Week 2 & 8 & Mathematics of Finance \\
\hline Week 3 & $\begin{array}{c}8 \\
10\end{array}$ & $\begin{array}{l}\text { Mathematics of Finance } \\
\text { Linear Programming }\end{array}$ \\
\hline Week 4 & 10 & Linear Programming \\
\hline Week 5 & $\begin{array}{c}10 \\
5\end{array}$ & $\begin{array}{l}\text { Linear Programming } \\
\text { Linear Functions/Break-Even Analysis }\end{array}$ \\
\hline Week 6 & 6 & $\begin{array}{l}\text { Quadratic Functions } \\
\text { EXAM ONE }\end{array}$ \\
\hline Week 7 & $\begin{array}{l}6 \\
7\end{array}$ & $\begin{array}{l}\text { Quadratic Functions } \\
\text { Exponential Functions }\end{array}$ \\
\hline Week 8 & $\begin{array}{c}7 \\
15\end{array}$ & Differentiation \\
\hline Week 9 & \multicolumn{2}{|c|}{ SPRING BREAK - CLASSES DO NOT MEET } \\
\hline Week 10 & 15 & $\begin{array}{l}\text { Differentiation } \\
\text { EXAM TWO }\end{array}$ \\
\hline Week 11 & 16 & Optimization \\
\hline Week 12 & $\begin{array}{l}16 \\
17\end{array}$ & $\begin{array}{l}\text { Optimization } \\
\text { Applications of Optimization }\end{array}$ \\
\hline Week 13 & 17 & Applications of Optimization \\
\hline Week 14 & 17 & $\begin{array}{l}\text { Applications of Optimization } \\
\text { EXAM THREE }\end{array}$ \\
\hline Week 15 & $\begin{array}{c}5,6,7,8,10 \\
15,16,17\end{array}$ & Review for the Final Exam \\
\hline
\end{tabular}

*The final exam will take place during one of the common exam time slots. Information regarding time/place will be forwarded when it becomes available. 


\section{APPENDIX H}

Approval Letter to Reproduce and Use ATMI

Tapia, Martha

May 8,2015 at 2:48 PM

To: Brooke D'Aloisio

Re: Requesting Permission to use ATMI

Dear Brooke,

You have permission to use the Attitudes Toward Mathematics Inventory (ATMI) in your dissertation. If you have any question, please do not hesitate to ask me.

Please let me know of the findings in your study.

Sincerely,

Martha Tapia

Martha Tapia, Ph.D.

Associate Professor

Department of Mathematics and Computer Science

Berry College

P.O. Box 495014

Mount. Berry, Georgia 30149-5014 


\section{APPENDIX I}

\section{Approval Letter to Reproduce and Use MAS}

\section{Sadia Qaiyum}

To: Brooke D'Aloisio

Re: Mathematics Anxiety Scale

Dear Brooke,

Hello!

I am happy to hear that you want to use my scale on Mathematics Anxiety for your upcoming Doctoral Research Programme. I grant you permission for the use of my MAS-Mathematics Anxiety Scale, provided that you mention my details in reference to the MAS in your thesis.

I will be glad receiving a copy of your results. Feel free to contact me if you need any other assistance.

Good Luck!

Regards

Dr. Sadia Mahmood

Assistant Professor

Aligarh Muslim University-Aligarh

India

\section{Tahira Khatoon}

To: Brooke D'Aloisio

Re: Mathematics Anxiety Scale

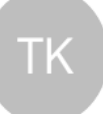

Dear brooke

I have no objection,you can use math anxiety scale in your research study,if possible send your result also. 


\title{
APPENDIX J
}

\author{
Verbal Scripts Read to Participants
}

\section{$\underline{\text { Second Day of Classes Verbal Script }}$}

Hello everyone! My name is Brooke D'Aloisio and I am interested in examining the factors that can be used to predict success in BUS 111. Therefore, I would like to invite each of you to participate in a research study to help me investigate this issue. You should have received an e-mail from me last week explaining this study. Still, I will explain the project to you in detail. More information will be provided on the consent form that I will hand you shortly. You should feel free to ask questions as I explain.

First, you must be at least 18 years old to participate in this research. If you decide to take part in this study, you will be asked to complete one survey today and another during the last full week of the semester. Each survey will take you approximately 20 minutes, so no more than 1 hour total time will be required. Since you will be taking two surveys, your student ID number will be used as an initial identifier to match your pre- and post-survey results with other indicators such as the grade you receive in this course, your gender, your SAT scores, and your high school GPA, which I will obtain from eCampus, along with your mathematics placement score, which I will obtain from the math department, with your permission. As soon as those matches are made, your ID number will be deleted to protect your identity. Your name and any other identifying information will NEVER be used throughout this research and all of your responses will be held in strict confidence.

If you choose to participate in this study, because of the nature of the questions, you may end up having a better understanding of your own feelings and attitudes about math. I am also hoping I will learn more about the factors that help predict success in BUS 111, so the findings from this research may used to support future students who take BUS 111 and similar courses.

I do not anticipate that you will experience any negative effects as a result of this study and please note that it will not affect your grade in this course or your academic standing in any way. Your participation is completely voluntary. If you decide not to participate, there will be no penalty. Your course instructor will not be told of your decision to participate, nor will he/she have access to your survey results. If you decide you want to participate, but later change your mind, that is okay as well; you may choose to stop participating at any time during the study. To withdraw your consent at any point - now or later on in the semester - just let me know. My contact information is on the board and I will also e-mail you all of my contact information again. The principal investigator and faculty supervisor for this study is Cornelis de Groot. I will also provide his contact information, should you have any questions or concerns.

Are there any questions? I will hand a copy of the survey and consent form to each of you so that you can read this information yourself before making your decision. If you choose not to participate, you are welcome to stay in the room with your classmates.

Thank you all for your time. 


\section{Last Week of Classes Verbal Script}

Hello everyone! My name is Brooke D'Aloisio. You may remember me from the beginning of the semester: I am interested in examining the factors that can be used to predict success in BUS 111. I would like to invite each of you to participate in a research study to help me investigate this issue. I will explain the project to you in detail and more information will be provided on the consent form that I will hand you shortly. This is the same consent form you received in the beginning of the semester. You should feel free to ask questions as I explain.

First, you must be at least 18 years old to participate in this research. If you decide to take part in this study, you will be asked to complete a survey today. This survey will take you approximately 20 minutes. Since you will be taking two surveys, your student ID number will be used as an initial identifier to match your pre- and postsurvey results with other indicators such as the grade you receive in this course, your gender, your SAT scores, and your high school GPA, which I will obtain from eCampus, along with your mathematics placement score, which I will obtain from the math department, with your permission. As soon as those matches are made, your ID number will be deleted to protect your identity. Your name and any other identifying information will NEVER be used throughout this research and all of your responses will be held in strict confidence.

If you choose to participate in this study, because of the nature of the questions, you may end up having a better understanding of your own feelings and attitudes about math. I am also hoping I will learn more about the factors that help predict success in BUS 111, so the findings from this research may used to support future students who take BUS 111 and similar courses.

I do not anticipate that you will experience any negative effects as a result of this study and please note that it will not affect your grade in this course or your academic standing in any way. Your participation is completely voluntary. If you decide not to participate, there will be no penalty. Your course instructor will not be told of your decision to participate, nor will he/she have access to your survey results. If you decide you want to participate, but later change your mind, that is okay as well; you may choose to stop participating at any time. To withdraw your consent at any point - now or later on in the week - just let me know. My contact information is on the board and I will also e-mail you all of my contact information again. The principal investigator and faculty supervisor for this study is Cornelis de Groot. I will also provide his contact information, should you have any questions or concerns.

Are there any questions?

I will hand a copy of the survey and consent form to each of you so that you can read this information yourself before making your decision. If you choose not to participate, you are welcome to stay in the room with your classmates.

Thank you all for your time. 


\section{BIBLIOGRAPHY}

Alexander, M.W., Mundrake, G.A., \& Brown, B.J. (2009). Pre-business college freshman perception of classroom behavior: An analysis among and between genders. The Delta Pi Epsilon Journal, L1(2), 99-116.

American Association of Collegiate Schools of Business (2015). Eligibility procedures and standards for business accreditation [PDF file]. Tampa, FL: Author. Retrieved January 21, 2016 from: http://www.aacsb.edu/ /media/AACSB/Docs/ Accreditation/Standards/2013-bus-standards-update-jan2015.ashx

Anderson, R.D. (1967). Qualifications for a college faculty in mathematics. Presented at Mathematics Association of America Committee on the Undergraduate Program in Mathematics. Berkeley, CA: January 1967.

Bahr, P.R. (2012). The aftermath of remedial math: Investigating the low rate of certificate completion among remedial math students. Research in Higher Education, 54(2), 171-200.

Ballard, C.L., \& Johnson, M.F. (2004). Basic math skills and performance in an introductory economics class. Journal of Economic Education, Winter 2004, 323.

Bandura, A. (1986). Social foundations of thought and action: A social cognitive theory. Englewood. Cliffs, NJ: Prentice-Hall.

Bandura, A. (1997). Self-efficacy: The exercise of control. New York, NY: Freeman.

Barnes, G., Cerrito, P., \& Levi, I. (2004). An assessment of general education mathematics courses via examination of student expectations and performance. The Journal of General Education, 53(1), 20-36.

Barth, M.M., Liu, J, \& Wells, W.H. (2009). A comparative analysis of grading practices by discipline within a college of business. Academy of Educational Leadership Journal, 13(4), 93-107.

Belenky, M.F., Clinchy, B.M., Goldberger, N.R., \& Tarule, J.M. (1986). Women's ways 
of knowing: The development of self, voice, and mind. New York, NY: Basic Books.

Belfield, C., \& Crosta, P. (2012). Predicting success in college: The importance of placement tests and high school transcripts. CCRC Working Paper No. 42. New York, NY: Community College Research Center.

Berliner, D.C. (2004). Expert teachers: Their characteristics, development and accomplishments. A: De la teoria ... a l'aula. Bellaterra: UAB.

Berube, C., \& Glanz, J. (2008). Equal opportunity: Reframing gender differences in science and math. Principal Leadership, 8(9), 28-33.

Betz, N. E. (1978). Prevalence, distribution, and correlates of math anxiety in college students. Journal of Counseling Psychology, 25(5), 441-448.

Bilsky, J. (2011). Crossing boundaries: Postsecondary readiness assessment in Florida. Change: The Magazine of Higher Learning, July-August 2011, 20-25.

Bisk, R., Fowler, M., \& Perez, E.B. (2013). Successful developmental math: "ReviewPretest-Retest" model helps students move forward. The New England Journal of Higher Education. Retrieved February 19, 2015 from: http://www.nebhe.org/thejournal/successful-developmental-math-review-pretestretest-model-helps-students-move-forward-in-math/

Blanchard, J. (2008, February 28). Freshmen's weak math skills worry UW faculty. Retrieved June 30, 2013 from: http://www.seattlepi.com/local/article/Freshmen-sweak-math-skills-worry-UW-faculty-1265873.php

Blaszczynski, C. (2001). Stamping out business mathematics illiteracy. The Delta Pi Epsilon Journal, 43(1), 1-5.

Bolman, L.G., \& Deal, T.E. (2008). Reframing organizations: Artistry, choice, and leadership (4th ed.). San Fransisco, CA: Jossey-Bass.

Borden, V.M.H., \& Burton, K.L. (1999). The impact of class size on student performance in introductory courses. Paper presented at the 39th Annual Forum 
of the Association for Institutional Research. Seattle, WA: May 30-June 3, 1999. Bransford, J. (2000). How experts differ from novices. In J. Bransford, A.L. Brown, and R.R. Cocking (Eds.), How people learn: Brain, mind, experience, and school (pp. 29-50). Washington D.C.: National Academy Press.

Bridgeman, B., Pollack, J., \& Burton, N. (2008). Predicting grades in college courses: A comparison of multiple regression and percent succeeding approaches. Journal of College Admission, 199(1), 19-25.

Britton, S., Daners, D., \& Stewart, M. (2007). A self-assessment test for incoming students. International Journal of Mathematical Education, 38(7), 861-868.

Brock, T. (2010). Young adults and higher education: Barriers and breakthroughs to success. The Future of Children, 20(1), 109-132.

Brown, A. (1987). Metacognition, executive control, self-regulation, and other more mysterious mechanisms. In F.E. Weinert and R.H. Kluwe (Eds.), Metacognition, motivation, and understanding (pp. 65-116). Hillsdale, NJ: Erlbaum.

Calcagno, J.C., \& Long, B.T. (2008). The impact of postsecondary remediation using a regression discontinuity approach: Addressing endogenous sorting and noncompliance. New York, NY: National Center for Postsecondary Research.

Center for Post-Secondary and Economic Success. (2011, June 29). Yesterday's nontraditional student is today's traditional student [PDF file]. Retrieved June 3, 2013 from: http://www .clasp.org/admin/site/publications/files/NontraditionalStudents-Facts-2011.pdf

Chen, X., Ender, P.B., Mitchell, M., \& Wells, C. (2003). Regression with STATA. Received January 4, 2016 from: http://www.ats.ucla.edu/stat/stata/webbooks/reg.

Cobb, P. (2005). Where is the mind? A coordination of sociocultural and cognitive constructivist perspectives. In C.T. Fosnot (Ed.), Constructivism: Theory, perspectives, and practice (pp. 39-61). New York, NY: Teachers College Press.

Common Core State Standards Initiative. (2015) Mathematics Standards. Retrieved 
October 19, 2015 from: http://www.corestandards.org/Math/

Conley, D. T. (2007). Redefining college readiness. Eugene, OR: Educational Policy Improvement Center.

Corbishley, J., \& Truxaw, M. (2010). Mathematical readiness of entering college freshmen: An exploration of perceptions of mathematics faculty. School Science and Mathematics, 110(2), 71-85.

Creswell, J. W. (2014). Research design: Qualitative, quantitative, and mixed methods approaches (4th ed.). Thousand Oaks, CA: Sage.

Cuseo, J. (2007). The empirical case against large class size: Adverse effects on the teaching, learning, and retention of first-year students. Journal of Faculty Development, 21(1), 5-21.

Darling-Hammond, L. (2010). New standards and old inequalities: How testing narrows and expands the opportunity gap. In L. Darling-Hammond (Ed.), The flat world and education: How America's commitment to equity will determine our future (pp. 66-98). New York, NY: Teachers College Press.

Davis, J., \& Shih, J. (2007). Secondary options and post-secondary expectations: Standards-based mathematics programs and student achievement on college mathematics placement exams. School Science and Mathematics, 107(8), 336346.

Deberard, S., Spielman, G. I., \& Julka, D. L. (2004). Predictors of academic achievement and retention among college freshmen: A longitudinal study. College Student Journal, 38(1), 66-80.

De Paola, M., Ponzo, M., \& Scoppa, V . (2013). Class size effects on student achievement: Heterogeneity across abilities and fields. Education Economics, 21(2), 135-153.

Dewey, J. (1938). Experience and education. New York, NY: Touchstone Books. Doubleday, J. (2013). Most students are not ready for college, SAT report says. 
Chronicle of Higher Education, 60(5), A17.

Duckworth, E. (2006). The having of wonderful ideas. In E. Duckworth (Ed.), “The having of wonderful ideas" and other essays of teaching and learning (pp. 1-74). New York, NY: Teachers College Press.

Epstein, J.P. (2009). Behind the SAT-optional movement: Context and controversy. Journal of College Admission, 1(204), 8-19.

Felder, J. E., Finney, J. E., \& Kirst, M. W. (2007). "Informed self-placement” at American River College: A case study. National Center Report \#07-2. San Jose, CA: National Center for Public Policy and Higher Education.

Feldman, K.A. (1984). Class size and college students' evaluations of teachers and courses: A closer look. Research in Higher Education, 21(1), 45-116.

Ferry, N.M., \& Ross-Gordon, J.M. (1998). An inquiry into Schön's epistemology of practice: Exploring links between experience and reflective practice. Adult Education Quarterly, 48(2), 98-112.

Foley-Peres, K., \& Poirier, D. (2008). College math assessment: SAT scores vs. college math placement scores. Educational Research Quarterly, 32(2), 41-48.

Fosnot, C.T. (1996). Constructivism: Theory, perspectives, and practice. New York, NY: Teachers' College Press.

Fosnot, C.T., \& Perry, R.S. (2005). Constructivism: A psychological theory of learning. In C.T. Fosnot (Ed.), Constructivism: Theory, perspectives, and practice (pp. 833). New York, NY: Teachers' College Press.

Fraenkel, J.R., Wallen, N.E., \& Hyun, H.H. (2011). How to design and evaluate research in education (8th ed.). New York, NY: McGraw-Hill.

Frankenstein, M. (1997). Multicultural and gender equity in the mathematics classroom: The gift of diversity. Reston, VA: National Council of Teachers of Mathematics.

Frost, J., Coomes, J., \& Lindebald, K. (2009). Collaborating to improve students' transitions from high school mathematics to college: Characteristics and outcomes 
of a cross-sector professional development project. National Association of Secondary School Principals Bulletin, 93(4), 227-240.

Gehring, J. (2001). SAT said to be reliable predictor of college success. Education Week: May 9, 2001, 20(34), 3.

George, D., \& Mallery, M. (2010). SPSS for Windows step by step: A simple guide and reference, 17.0 update (10a ed.). Boston: Pearson.

Gess-Newsome, J., Southerland, S., Johnston, A., \& Woodbury, S. (2003). Educational reform, personal practical theories, and dissatisfaction: The anatomy of change in college science teaching. American Educational Research Journal, 40(3), 731767.

Gibbs, G., \& And, O. (1996). Class size and student performance: 1984-1994. Studies in Higher Education, 21(3), 261-273.

Gilbert, S. (1995). Quality education: Does class size matter? Canadian Society for the Study of Higher Education, 14, 320-350.

Guder, F., Malliaris, M., \& Jalilvand, A. (2011). Changing the culture of a school: The effect of larger class size on instructor and student performance. American Journal of Business Education, 2(9), 83-90.

Guido, F.M., Chávez, A.F., \& Lincoln, Y.S. (2010). Underlying paradigms in student affairs research and practice. Journal of Student Affairs Research and Practice, 47(1), 1-22.

Hagedorn, L., Siadat, M., Fogel, S., Nora, A., \& Pascarella, E. (1999). Success in college mathematics: Comparisons between remedial and nonremedial first-year college students. Research in Higher Education, 40(3), 261-284.

Hair, J.F., Anderson, R.E., Tatham, R.L., \& Black, W.C. (1998). Multivariate data analysis (5th ed.). Upper Saddle River, NJ: Prentice Hall.

Hall, J., \& Ponton, M. (2005). Mathematics self-efficacy of college freshman. Journal of Developmental Education, 28(3), 26-33. 
Hammerman, N., \& Goldberg, R. (2003). Strategies for developmental mathematics at the college level. Mathematics and Computer Education, 37(1), 79-95.

Hiebert, J., \& Grouws, D.A. (2007). The effects of classroom mathematics teaching on students' learning. In F.K. Lester (Ed.), Second handbook of research on mathematics teaching and learning (pp. 371-404). Charlotte, NC: Information Age.

Hofer, B., \& Pintrich, P. (1997). The development of epistemological theories: Beliefs about knowledge and knowing and their relation to learning. Review of Educational Research, 67(1), 88-140.

Huck, S.W. (2012). Reading statistics and research (6th ed.). Boston, MA: Pearson Education.

Imm, K.L., Fosnot, C.T., Dolk, M., Jacob, B., \& Stylianou, D. (2012). Learning to support young mathematicians at work: An early algebra resource for professional development. Portsmouth, NH: Heinemann.

Ironsmith, M., Marva, J., Harju, B., \& Eppler, M. A. (2003). Motivation and performance of college students enrolled in self-paced versus lecture-format remedial mathematics courses. Journal of Instructional Psychology, 30 (1), 276284.

Jacobson, E. (2006). Higher placement standards increase course success but reduce program completions. Journal of General Education, 55(2), 138-159.

Jaeger, E.L. (2013). Teacher reflection: Supports, barriers, and results. Issues in Teacher Education, 22(1), 89-104.

Johnson, P. (2007). What are we developing? A case study of a college mathematics program. School Science and Mathematics, 107(7), 279-292.

Kesici, S., \& Erdogan, A. (2009). Predicting college students' mathematics anxiety by motivational beliefs and self-regulated learning strategies. College Student Journal, 43(2), 631-642. 
King, P.M., \& Kitchener, K.S. (1981). Reflective judgement: Concepts of justification and their relationship to age and education. Journal of Applied Developmental Psychology, 2(2), 89-116.

King, P.M., \& Kitchener, K.S. (1993). The development of reflective thinking in the college years: The mixed results. In C. Schneider \& W. S. Green (Eds.), Strengthening the college major, New Directions for Higher Education, No. 84 (pp. 25-42). San Francisco: Jossey-Bass.

King, P.M., \& Kitchener, K.S. (2004). Reflective judgement: Theory and research on the development of epistemic assumptions through adulthood. Educational Psychologist, 39(1), 5-18.

Kobrin, J.L., \& Patterson, B.F. (2011). Contextual factors associated with the validity of SAT scores and high school GPA for predicting first-year college grades. Educational Assessment, 16(1), 207-226.

Kohlberg, L., \& Mayer, R. (1972). Development as the aim of education. Harvard Educational Review, 42(1), 449-496.

Korthagen, F.A.J. (2001). Linking practice and theory: The pedagogy of realistic teacher education. Mahwah, NJ: Lawrence Erlbaum Associates, Inc.

Kozulin, A. (1994). The cognitive revolution in learning: Piaget and Vygotsky. In J. Mangier and C. Collins Block (Eds.), Creating powerful thinking in teachers and students: Diverse perspectives (pp. 269-287). Fort Worth, TX: Harcourt Brace College Publishers.

Knowles, M.S. (1988). The modern practice of adult education: From pedagogy to andragogy (Revised and updated edition). New York, NY: Cambridge Book Company.

Kutner, M.H., Nachtsheim, C.J., \& Neter, J. (2003). Applied Linear Regression Models (4th ed.). New York, NY: McGraw-Hill Higher Education. 
Lang, D.M. (2007). Class rank, GPA, and valedictorians: How high schools rank students. American Secondary Education, 35(2), 36-48.

Leaper, C., Farkas, T., \& Brown, C.S. (2012). Adolescent girls' experiences and gender-related beliefs in relation to their motivation in math/science and English. Journal of Youth \& Adolescence, 41(1), 268-282.

Levy, P., \& Petrulis, R. (2012). How do first-year university students experience inquiry and research, and what are the implications for the practice of inquiry-based learning. Studies in Higher Education, 37(1), 85-101.

Lindsay, R., \& Paton-Saltzberg, R. (1987). Resource changes and academic performance at an English polytechnic. Studies in Higher Education, 12(1), 213227.

Long, M., Iatarola, P., \& Conger, D. (2009). Explaining gaps in readiness for collegelevel math: The role of high school courses. American Education Finance Association, 4(1), 1-33.

Mahmood, S., \& Khatoon, T. (2011). Development and validation of the mathematics anxiety scale for secondary and senior secondary school students. British Journal of Arts and Social Sciences, 2(2), 169-179.

Mathematical Association of America. (2012). A joint position statement of the Mathematical Association of America and the National Council of Teachers of Mathematics on teaching calculus [PDF file]. Retrieved October 19, 2015 from: http://www.nctm.org/uploadedFiles/About_NCTM/Position_Statements/Calculus\% 20MAA\%20NCTM\%20Joint\%20Statement.pdf

Marcus, R., Fukawa-Connelly, T., Conklin, M., \& Fey, J. (2008). New thinking about college mathematics: Implications for high school teaching. Mathematics Teacher, $101(5), 354-358$.

Marsh, C.M., Vandehey, M.A., \& Diekhoff, G.M. (2008). A comparison of an introductory course to SAT/ACT scores in predicting student performance. The 
Journal of General Education, 57(4), 245-255.

Martin-Connell, S.J. (2014). Recovering the social dimension of reflection. Journal of Catholic Education, 17(2), 5-24.

Marzano, R.J., Gaddy, B.B., \& Dean, C. (2000). What works in classroom instruction. Aurora, CO: Mid-Continent Research for Education and Learning.

McCluskey, H. (2007). Education: Background. In S. Merriam, R. Caffarella, \& L. Baumgartner (Eds.), Learning in adulthood: A comprehensive guide (3rd ed.) (pp. 79-104). San Francisco, CA: Jossey-Bass.

McDuffie, A., \& Graeber, A. (2003). Institutional norms and policies that influence college mathematics professors in the process of changing to reform-based practices. School Science and Mathematics, 103(7), 331-344.

McGowen, M.A. (2006). Who are the students who take precalculus? In N.B. Hastings (Ed.), A fresh start for collegiate mathematics: Rethinking the courses below calculus (pp. 15-27). Washington, DC: Mathematical Association of America.

McRaney, D. (2011). The misinformation effect. In D. McRaney (Ed.), You are not so smart (pp. 175-182). New York, NY: Datton.

Merriam, S.B., \& Brockett, R.G. (2007). The profession and practice of adult education. San Francisco, CA: Jossey-Bass.

Merriam, S.B., Caffarella, R., \& Baumgartner, L. (2007). Learning in adulthood: A comprehensive guide (3rd ed.). San Francisco, CA: Jossey-Bass.

Mesa, V. (2012). Achievement goal orientations of community college mathematics students and the misalignment of instructor perceptions. Community College Review, 40(1), 46-74.

Munby, H., Russell, T., \& Martin, A.K. (2001). Teachers' knowledge and how it develops. In V. Richardson (Ed.), Handbook of research on teaching (pp. 877904). Washington, DC: American Educational Research Association.

Myers, R.H. (1990). Classical and modern regression application (2nd ed.). Boston, 
MA: Duxbury Press.

Nathan, M.J., Koedinger, K.R., \& Alibali, M.W. (2001). Expert blind spot: When content knowledge eclipses pedagogical content knowledge. In L. Chen (Ed.), Proceedings of the Third International Conference on Cognitive Science (pp. 644648). Beijing, China: University of Science and Technology of China Press.

Nathan, M.J., \& Petrosino, A. (2003). Expert blind spot among preservice teachers. American Educational Research Journal, 40(4), 905-928.

National Business Education Association (1995). National standards for business education: What America's students should know and be able to do in business. Reston, VA: Author.

Okoro, J. (2014). Assessment of resources for training prospective teachers in business education at the colleges of education. Education, 140(2), 562-578.

Ormrod, J.E. (2011). Educational psychology: Developing learners (7th ed.). Boston, MA: Pearson.

Osborne, J., \& Waters, E. (2002). Four assumptions of multiple regression that researchers should always test. Practical Assessment, Research \& Evaluation, 8(2). Retrieved January 9, 2016 from: http://PAREonline.net/getvn.asp?v=8\&n=2

PARCC college- and career-ready determination policy in English language arts/literacy and mathematics and policy-level performance level descriptors [PDF file] (Adopted October 2012; Updated March 2013). Retrieved April 2, 2015 from http://parcconline.org/files/79/College\%20and\%20Career\%20Ready/92/PARCCC CRDPolicyandPLDsFINAL.pdf

Paris, L.D., \& Decker, D.L. (2012). Sex role stereotypes: Does business education make a difference? Gender in Management: An International Journal, 27(1), 36-50.

Parker, M. (2005). Placement, retention, and success: A longitudinal study of mathematics and retention. The Journal of General Education, 54(1), 22-40.

Patton, M. Q. (2002). Qualitative research and evaluation methods (3rd ed.). Thousand 
Oaks, CA: SAGE Publications.

Perini, M., Silver, H., Strong, R., \& Thomas, E. (2004). Improving achievement in mathematics and science. Educational Leadership Journal, 61(5), 73-78.

Perls, F.S., Hefferline, R., \& Goodman, P. (1951). Gestalt therapy: Excitement and growth in the human personality. Gouldsboro, ME: The Gestalt Journal Press, Inc.

Perrine, R.M., \& And, O. (1995). Effects of a syllabus offer of help, student age, and class size on college students' willingness to seek support from faculty. Journal of Experimental Education, 64(1), 41-52.

Perry, W. (1970). Forms of intellectual and ethical development in the college years. New York, NT: Holt, Rinehart, \& Winston.

Piaget, J. (1964). Development and learning. In R.E. Ripple \& V.N. Rockcastle (Eds.), Piaget rediscovered (pp. 7-20). Ithaca, NY: Cornell University.

Pritchard, R.E., Saccucci, M.S., \& Potter, G.C. (2010). Evaluating a program designed to demonstrate continuous improvement in teaching at an AACSB-accredited College of Business at a regional university: A case study. Journal of Education for Business, 85(1), 280-283.

Pugh, C.M., \& Lowther, S. (2004). College math performance and last high school math course. Presented at the Annual Conference of the Southern Association for Institutional Research. Biloxi, MS [PDF file]. Retrieved from: http://oira.auburn.edu/about/publications/SAIRPaper2004.pdf

Reisel, J.R., Jablonski, M., Hosseini, H., \& Munson, E. (2012). Assessment of factors impacting success for incoming college engineering students in a summer bridge program. International Journal of Mathematical Education in Science and Technology, 43(4), 421-433.

Richardson, V. (1990). Significant and worthwhile change in teaching practice. Educational Researcher, 19(7), 10-18. 
Rittenhouse, P.S. (1998). The teacher's role in mathematical conversations: Stepping in and stepping out. In M. Lampert and M.L. Blunk (Eds.), Talking mathematics in school: Studies of teaching and learning (pp. 163-189). New York, NY: Cambridge University Press.

Samad, A.B., Tuah, N.B., \& Haron, A.R. (2009). Research on factors affecting students' achievement in business mathematics: A case study. Universiti Teknologi MARA, $1-13$

Sanders, J., \& Peterson, K. (1999). Close the gap for girls in math-related careers. The Education Digest, 65(4), 47-49.

Sawyer, R. (2013). Beyond correlations: Usefulness of high school GPA and test scores in making college admission decisions. Applied Measurement in Education, 26(1), 89-112.

Schön, D.A. (1983). The reflective practitioner: How professionals think in action. New York, NY: Basic Books, Inc.

Siebens, J., \& Ryan, C.L. (2012). Field of Bachelor's degree in the United States: 2009, American community survey reports. U.S. Census Bureau [PDF file]. Retrieved May 3, 2015 from: https://www.census.gov/prod/2012pubs/acs-18.pdf Sjøberg, S. (2010). Constructivism and learning. In E. Baker, B. McGaw, \& P. Peterson (Eds). International Encyclopedia of Education 3rd Edition (pp. 485-490). Oxford, UK: Elsevier.

Soper, D.S. (2006). Statistics calculator: A-priori sample size calculator for multiple regression. Retrieved January 12, 2014 from: http://www.danielsoper.com/statcalc3/category.aspx?id=19

Smith, R. M., \& Schumacher, P. A. (2005). Predicting success for actuarial students in undergraduate mathematics courses. College Student Journal, 39(1), 165-177.

Snyder, T. (1993). 120 Years of American education: A statistical portrait. Washington, D.C.: National Center for Education Statistics. 
Tapia, M. (1996). The attitudes towards mathematics instrument (ATMI). Paper presented at the Annual Meeting of the Mid-South Educational Research Association. Tuscaloosa, AL: November 6-8, 1996.

Tapia, M., \& Marsh, G. E. (2004). An instrument to measure mathematics attitudes. Academic Exchange Quarterly, 8(2), 16-21.

Taylor, J. (2008). The effects of a computerized-algebra program on mathematics achievement of college and university freshmen enrolled in a developmental mathematics course. Journal of College Reading \& Learning, 39(1), 35-53.

Thiel, T., Perman, S., \& Brown, M. (2008). Addressing the crisis in college mathematics. Change: The Magazine of Higher Learning, 40(4), 44-49.

Travis, J. E., Hursh, D., Lankewicz, G., \& Tang, L. (1996). Monitoring the pulse of the faculty: Needs assessment in faculty development programs. In L. Richlin (Ed.), To Improve the Academy (pp. 95-113). Stillwater, OK: New Forums Press and the Professional and Organizational Development Network in Higher Education.

Tobias, S. (1987). Succeed with math: Every student's guide to conquering math anxiety. New York, NY: College Board Publications.

Tobias, S., \& Weissbrod, C. (1980). Anxiety and mathematics: An update. Harvard Educational Review, 50(1), 63-70.

Truell, A.D., \& Woosley, S. (2008). Admission criteria and other variables as predictors of business student graduation. College Student Journal, 42(2), 348-356.

U.S. Department of Education. (November 2009) . Race to the Top program: Executive summary [PDF file]. Retrieved May 3, 2015 from: http://www2.ed.gov/programs/racetothetop/executive-summary.pdf

U.S. Department of Education, National Center for Education Statistics. (2015). Digest of education statistics, 2013 (NCES 2015-011). Retrieved May 3, 2015 from: https://nces.ed.gov/fastfacts/display.asp?id=37

U.S. Department of Education. The National Commission on Excellence in Education. 
(April 1983). A nation at risk: The imperative for educational reform,

Washington, D.C.: The Commission [Print].

University of Rhode Island Office of Admission information for freshmen applicants:

General admission requirements and the evaluation process (2015). Retrieved

January 8, 2016 from: http://www.uri.edu/admission/freshmanrequirements.html

University of Rhode Island Department of Mathematics. (2014). Department of

mathematics course placement: Sample placement exam [PDF file]. Retrieved

September 29, 2015 from:

http://math.uri.edu/placement/urimath_sampleplacementexam_2014.pdf

Von Glasersfeld, E. (2005). Introduction: Aspects of constructivism. In C.T. Fosnot

(Ed.), Constructivism: Theory, perspectives, and practice (pp. 3-7). New York, NY: Teachers College Press.

Vygotsky, L.S. (1978). Mind in society: The development of higher psychological processes. Cambridge, MA: Harvard University Press.

Waycaster, P. (2004). The best predictors of success in developmental mathematics courses. Inquiry, 9(1), 1-8.

Weiss, N. A. (2008). Introductory statistics (8th ed.). Boston, MA: Pearson Education.

Whitworth, J.E., Price, B.A., \& Randall, C.H. (2002). Factors that affect college of business student opinion of teaching and learning. Journal of Education for Business, 77(5), 282-289.

Wittrock, M. (1986). Students' thought processes. In M. Wittrock (Ed.), Handbook of research on teaching (3rd ed., pp. 297-314). New York, NY: MacMillian.

Zelkowski, J. (2011). Defining the intensity of high school mathematics: Distinguishing the difference between college-ready and college-eligible students. American Secondary Education, 39(2), 27-54. 